\title{
Cost-effective monitoring of dioxins in agri-production chains
}

Víctor Hugo Lascano Alcóser 


\section{Thesis committee}

\section{Promotor}

Prof. Dr A.G.J.M. Oude Lansink

Professor of Business Economics

Wageningen University \& Research

\section{Co-promotors}

Dr M.C.M. Mourits

Associate professor, Business Economics Group

Wageningen University \& Research

Dr H.J. van der Fels-Klerx

Associate professor, Business Economics Group

Senior Scientist, RIKILT

Wageningen University \& Research

\section{Other members}

Prof. Dr J.M. Bloemhof-Ruwaard, Wageningen University \& Research

Dr M. Bouwknegt, VION Food Group, Boxtel, The Netherlands

Dr C.P.A. van Wagenberg, Wageningen University \& Research

Dr H.A. van der Schee, Dutch Food and Consumer Products Safety Authority, Utrecht

This research was conducted under the auspices of the Wageningen School of Social Sciences (WASS). 


\section{Cost-effective monitoring of dioxins in agri-production chains}

\section{Víctor Hugo Lascano Alcóser}

\section{Thesis}

submitted in fulfilment of the requirements for the degree of doctor at Wageningen University

by the authority of the Rector Magnificus,

Prof. Dr A.P.J. Mol,

in the presence of the

Thesis Committee appointed by the Academic Board

to be defended in public

on Wednesday14 November 2018

at 1:30 p.m. in the Aula. 
Víctor Hugo Lascano Alcóser

Cost-effective monitoring of dioxins in agri-production chains, 214 pages.

$\mathrm{PhD}$ thesis, Wageningen University, Wageningen, the Netherlands (2018)

With references, with summary in English

ISBN: 978-94-6343-360-0

DOI: https://doi.org/10.18174/460751 


\section{Abstract}

Feed ingredients and additives used in compound feed for livestock production have been a main cause of various food dioxin incidents in recent decades. Monitoring dioxins in feed and food products is deemed crucial to prevent and diminish the financial impacts of dioxin incidents in agribusiness along the food chain. However, economic aspects embedded in the practical assessment and implementation of dioxin monitoring schemes along the food chain have not yet been analyzed in the scientific literature. Hence this dissertation aims to analyze the costeffectiveness of schemes for monitoring dioxins along the food chain by 1) assessing the financial impact of a dioxin incident in the food chain, 2) determining the cost-effectiveness of monitoring dioxins at a single control point along the food chain 3) determining the cost-effective allocation of resources for monitoring dioxins at different stages of the food chain, and 4) determining the cost-effective allocation of resources at one stage of the food chain considering incoming ingredients and final products. This thesis depicts deterministic and stochastic simulation models to assess the effect of monitoring on the flow of dioxin contaminations in the evaluated food chains (dairy, pork and poultry). Linear programming is the core methodology used in this dissertation to assess the cost-effectiveness of schemes for monitoring dioxins. The main findings indicate that establishing effective monitoring plans requires elevated financial resources. However, the size of the direct financial losses of a dioxin incident suggests that there is substantial financial room for monitoring dioxins along the food chain. Testing dioxins levels in aggregate samples rather than in individual samples is a valid strategy for reducing monitoring costs. However, pooling strategies must take into account the target dioxin concentration in individual samples, in order to avoid dilution of dioxin levels and to ensure the proper detection of a dioxin contamination. Monitoring dioxins in an integrated chain approach rather than in an independent chain actor approach has large economic benefits for the whole chain. For all evaluated contamination scenarios, monitoring dioxins at the feed mill stage contributes, on average, $90 \%$ to the total effectiveness of the optimal monitoring schemes. 


\section{Acknowledgements}

During my doctoral study, Wageningen University did not only give me the opportunity to enhance my professional career acquiring new knowledge and skills through inspiring and encouraging teachers and colleagues. Studying at Wageningen University also gave me the chance of meeting new friends from all over the world and to share many sorts of life experiences that enriched my personal life. The development and completion of this $\mathrm{PhD}$ thesis is the result of the contribution, help and support of all of them, to whom in the following lines, I would like to express my deep gratitude.

I would gratefully acknowledge Annet Velthuis and Ine van der Fels-Klerx who opened the possibility of starting my $\mathrm{PhD}$ journey. Without their guidance and support, the story of this $\mathrm{PhD}$ had not happened. Annet, thank you for trusting in my work, encouraging me to continue in adverse times and allowing me to explore my own ideas. Ine, I am grateful for your clear and pragmatic suggestions to carry on the research and your commitment to my work. I would like to express my gratitude to Monique Mourits who, from the moment she started to be part of my supervising board, invited me to think out of the box. I very much appreciate the sharpness of your detailed suggestions to my scientific articles. I am deeply thankful to my promotor Alfons Oude Lansink who gave me the possibility of pursuing my doctoral study in the Business Economics Group at Wageningen University. His positive and constructive feedback enabled me to find solutions regarding my research considering different perspectives. I would like to thank Ron Hoogenboom from RIKILT whose expertise on dioxins enhanced the scientific articles in my thesis that have already been published. I would also like to express my gratitude to Lourens Heres who contributed to the fourth chapter of this thesis. Thank you for your wise guidance on the structure of the research considering the perspective of the pork industry. Thank you to all of you for sharing your knowledge with me, improving my expertise on interdisciplinary research and enhancing my capabilities as independent researcher 
I would like to express my gratitude to all my colleagues of Business Economics and RIKILT. Anne, thank you for your support and for your always positive and proactive attitude, willing to solve any administrative issue. Ilona and Jeannette thank you very much for your help to solve practical issues at the office, I always appreciate your friendly and happy spirit. Simon, Hugo, Robert, Tsion, Christina, Yani, Argyris, Tamara, Farahnaz, Koenraad, Solomie, Hurria, Xuezhen, Adane, Ewaldus, Erika, thank you for creating a nice working environment and sharing good times while enjoying together cappuccinos at coffee break times.

Special thanks go to my singing teacher Ellen van Velthoven. Ellen, thank you for teaching me the way of connecting my voice with my soul, this was very much helpful at times to overcome the many challenges I faced during my studies. I would like to offer my special thanks to Rob, Arie, Daniel and Jose, for sharing your musical expertise with me at the end of the $\mathrm{PhD}$ journey. I will never forget our performances and blooming energy while showing our art loudly to the world.

I would like to offer my special thanks to a good Brazilian friend. Carla thanks for our philosophical talks about life, introducing me your nice taste for country music and your always positive and deep advices. Stylouni, "Stellita" thank you for sharing with me your fantastic Greek dinners, your beautiful voice and offering me a home in Utrecht and Thessaloniki. Monica, "parcerita", thank you for introducing me to the climbing world in the moment that I needed it the most. To the climbers Balaji, Rita, Sacha, Suvi and Erik, thank you for sharing your happiness at always challenging adventures in front of the climbing wall.

I would like to express my very great appreciation to the Ecuadorian community of students in Wageningen. Thanks Xavier, Luis, Horacio, Alejandra, Mel, Sol, Roberto, Andres, Ximena and all "Wageningenos" for keeping the hospitality and culture of our homeland while we were abroad. 
I would like to offer my special thanks to friends from all over the world. Thanks Ignacio, Daniela, Bijo, Patrizia, Sofia, Antonio, Roselia, Matthijs, Andrea, Paola, Diana, Cheron, Myluska, Ivan, Alejandra, Gabriela, Alvaro, Claudia for sharing your culture by sharing your meals with me and giving me the chance of being part of your life.

To my paranymphs Carlos Mogrovejo and Ioanna Stampelou. Carlos thank you very much for sharing your life experiences, the trips to do mountain biking in the surrounding hilly areas of Wageningen and our fruitful talks while sharing a Weinestephan. Ioanna thank you for your support and sincere friendship since 2007 that we met during my first trip to Belgium. Thank you for hospitality in Athens, showing me the beauty of your city and our authentic journey in the Greek islands.

I am particularly grateful to Kim Baudewijns for all the meaningful moments we lived together during the last four years. Thank you for standing by me in the good and challenging times. My life wears your smile as a divine gift of resilience and love. In particular, let me express my deep gratitude to you for all the support and encouragement you gave me to finish this thesis. My profound appreciation to your family: Johan, Marga, Maron and Bas for your hospitality in Lommel and for your cheering messages.

I would like to express my gratitude to my family, my father Victor Hugo, my mother Guadalupe and my brother Diego for giving me your unconditional love and confidence in my capabilities to accomplish this goal. Thanks to Maita, Negra, Boli, Alejandro, Ana María for your unconditional support. I would like to offer my gratitude to Paco, Mary, Eduardo and Zenayda for your hospitality in Houston. 


\section{Table of Contents}

$\begin{array}{lr}\text { Abstract } & 5\end{array}$

$\begin{array}{ll}\text { Acknowledgements } & 7\end{array}$

Chapter 1 General introduction 13

Chapter 2 Financial impact of a dioxin incident in the Dutch dairy chain

Chapter 3 Optimizing bulk milk dioxin monitoring based on costs and effectiveness

Chapter 4 Cost-effective allocation of resources for monitoring dioxins along the pork production chain

Chapter 5 Cost-effective strategies for monitoring dioxins at the feed mill

Chapter 6 General discussion

Summary

About the Author

Completed Training and Supervision Plan 


\section{Chapter 1}

\section{General introduction}


General introduction

\subsection{Background}

The term Dioxins encompasses a group of chemically related compounds, including polychlorinated dibenzo-p-dioxins (PCDDs) and polychlorinated dibenzofurans (PCDFs) (Hoogenboom, 2009, WHO, 2016). As part of the Persistent Organic Pollutants (POPs), dioxins occupy a predominant position due to their high toxicity to human health at very low concentrations (UNEP, 2009 ). Exposure of humans to dioxins has been proven to result into health disorders, such as cancer and reproductive and immune disruptions (Hoogenboom, 2009, SCF, 2001). Due to their lipophilic nature, dioxins accumulate in animal fatty tissues (WHO, 2016) and bioaccumulate along the food chain (Huwe, 2002). Dietary intake of dioxins via food consumption is the main route, entailing for more than $90 \%$ of human exposure to dioxins (Büchert et al., 2001, Malisch, 2017, Parzefall, 2002). Specifically, for the European population, animal derived products are the main source of human exposure to dioxins (EFSA, 2012), where animal feed is the predominant contributor of such pollutants in livestock farming (Malisch and Kotz, 2014). A major dioxin incident in the food chain was first reported in the US in 1957, resulting from the use of dioxin-contaminated-fat obtained from cow hides cured with chlorophenols in poultry feed production (Firestone, 1973, Hoogenboom et al., 2015). As a consequence, millions of broilers died after developing symptoms of a so-called chicken edema disease (Firestone, 1973). In Europe, in that period, food dioxin contaminations were primarily related to dioxins deployed from the atmosphere (Quaß et al., 2000). In Western Europe from the 1970s to 1990s, combustion processes at municipal solid waste incinerators (MSWI) were pointed as the main source of dioxin emissions into the environment (Pacyna et al., 2003, Quaß et al., 2004). Elevated levels of dioxins were detected in food products produced in the surrounding areas of such waste treatment facilities (Domingo et al., 2002, Liem et al., 1991). Abatement measures implemented in the 1990s in these dioxin-releasing facilities achieved a salient reduction of 
environmental emissions along with a decrease in the human exposure to dioxins (Quaß et al., 2004). At the end of the 1990s, however, two food-dioxin contaminations enlightened other (until that time) unknown entry points of dioxins into the European food chain. In 1998, citrus pulp produced in Brazil consisting of dioxin-contaminated lime and used as animal feed for dairy cows in Germany triggered a sharp rise of dioxin levels in milk (Malisch, 2000). One year later, outstanding high levels of dioxins were identified in several Belgian livestock supply chains. Similar to the US contamination pathway described earlier, compound feed produced from recycled animal fat mixed with mineral oil containing PCBs (intended for industrial purposes) was the origin of the contamination (Bernard et al., 2002). Both cases showed the vulnerability of European food chains towards dioxin contamination sources and the complexity of the global food chain regarding the extent of contaminations. Specifically, the Belgian dioxin crisis raised the awareness of the catastrophic impact of feed-and-fooddioxin contamination on the health of the European population (Bernard et al., 1999; van Larebeke et al., 2001) and on the economic status of worldwide food and feed industries (Bernard et al., 1999, Buzby and Chandran, 2003, van Larebeke et al., 2001).

The Belgian dioxin crisis promoted the establishment of a European Union (EU) wide legislation, enacted by the European Commission (EC) (EC, 2000, SCF, 2001), defining an entire Dioxin strategy aimed at reducing human dioxin exposure with time (EC, 2001a). This strategy included the setting of maximum levels (ML), action levels (AL) and target levels of dioxins in food and feed products with the idea of a future reduction of these levels (EC, 2001c, d, 2002, 2006, 2012b, d). As part of the Dioxin Strategy, permanent monitoring programs for dioxin concentrations in feed and food across the entire EU were deemed crucial when pursuing to diminish dioxin exposure levels to the EU inhabitants (EC, 2001b, 2006, EFSA, 2010). As a result of public and private routine monitoring programs, introduced with the European Dioxin Strategy, new dioxin-food safety incidents were discovered and traced 
General introduction

back to the use of contaminated feed or feed ingredients such as the choline chloride (Llerena et al., 2003) in Germany, dried bakery waste (Hoogenboom et al., 2004, Heres et al., 2010) in Germany (2003) and Ireland (2008), recycled fat in gelatin production (Hoogenboom et al., 2007) in Belgium and The Netherlands, kaolinic clay in potato peels (Hoogenboom et al., 2010) in The Netherlands and, recently, technical fats (Fürst, 2011, Rieger et al., 2016) in Germany.

\subsection{Problem Statement}

Dioxins have been the focus of a vast scientific literature, particularly in terms of their impact on human health (Hoogenboom, 2009). As part of monitoring, the detection and sources of food-dioxin contaminations have received special attention together with the development of analytical methods aimed at improving the quantification of these pollutants in a variety of matrices (Hoogenboom et al., 2007, Hoogenboom, 2002, Hoogenboom et al., 2004, Hoogenboom et al., 2010, Hoogenboom et al., 2016). The EC have issued (and reviewed with time) directives and regulations regarding sampling and analytical methods and procedures for official control of dioxins in food and feed in the EU (EC, 2009, 2012a, c, 2014). However, economic aspects embedded in the practical assessment and implementation of dioxin monitoring schemes along the food chain have not yet been analyzed in the scientific literature.

One of the practical difficulties for establishing a targeted monitoring scheme is the relatively large number of possible sources of dioxin contaminations (Heres et al., 2010). Moreover, the total number of samples that can be collected and analyzed is limited by the costs and time required when using the currently available dioxin analytical methods (Huwe, 2002). As simpler cleaning methods are required for testing dioxins in samples of feed ingredients, it is less expensive to monitor dioxins in these products than in food products 
(Huwe, 2002). However, the number of feed ingredients and their suppliers are enormous and larger than the variety of animal food products to monitor. Therefore, according to Huwe (2002), it is more logical to monitor dioxins in food products rather than feed products or their ingredients. Monitoring dioxins in food products implies, nevertheless, detecting dioxin contaminations at later stages of the food chain, with potentially much larger economic consequences of contaminations. Moreover, when feed or food dioxin incidents occur, the economic losses can be enormous. Estimates of the Belgian crisis showed that direct losses on the Belgian agricultural sector were estimated at $€ 1$ billion, while indirect losses summed up to $€ 3$ billion (Malisch, 2017). Major losses were estimated for livestock farms and food processors, while feed mills -which were the cause of the contamination- faced relatively smaller financial impact (Buzby and Chandran, 2003). These huge losses suggest an economic rationale for allocating more resources to the control and prevention of dioxin incidents, such as monitoring schemes. These statements are not underpinned by scientific, published studies, since research on cost-effectiveness for monitoring food safety threats is limited (Focker et al., 2018). In order to optimize the use of available monitoring resources for feed and food industry and food safety authorities, the cost-effectiveness of schemes for monitoring dioxins have to be analyzed. This could be done by bio-economic modelling. This method has been applied in previous studies -in related areas- to determine the optimal surveillance strategy when maximizing the efficacy of import phytosanitary inspection (Surkov et al., 2009, Surkov et al., 2008), or improving food safety at the Dutch dairy chain (Valeeva and Huirne, 2008). 
General introduction

\subsection{The objective of the thesis}

The overall objective of this thesis was to analyze the cost-effectiveness of schemes for monitoring dioxins along the food chain. This overall objective was broken down in four specific objectives:

1. Asses the financial impact of a dioxin incident in the food chain;

2. Determine the cost-effectiveness of monitoring dioxins at a single control point along the food chain;

3. Determine the cost-effective allocation of resources for monitoring dioxins at different stages of the food chain;

4. Determine the cost-effective allocation of resources at one stage of the food chain considering incoming ingredients and final products.

The framework developed in this thesis uses data and information of three Dutch agrifood industries that have faced food safety incidents in the past, being Dairy, Pork and Poultry chains. Each of these industries is relevant to the Dutch society from a nutritional and economic point of view.

\subsection{Outline of the thesis}

The thesis consists of six Chapters, including this General Introduction and the General Discussion chapter. Chapters 2-5 address each of the four specific objectives as outlined in section 1.3. Figure 1.1 presents an overview of how the thesis is structured, with arrows indicating the data flows and their directions between the chapters. 


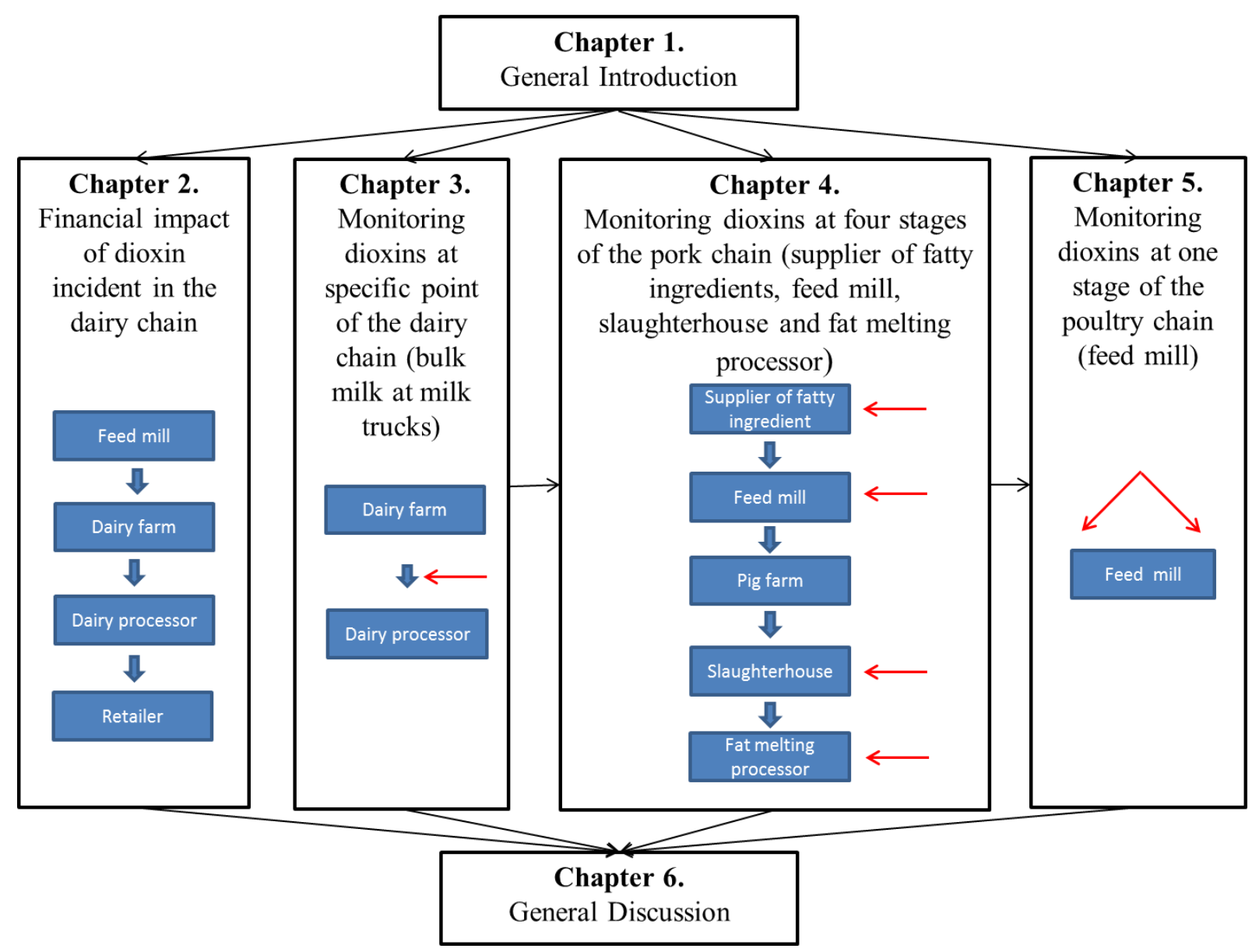

Figure 1.1. Outline of the thesis

In Chapter 2, the direct financial losses due to a crisis of dioxins in the Dutch dairy chain are estimated.

In Chapter 3, monitoring of dioxins was directed to bulk milk collected by milk trucks in the Dutch dairy chain. This chapter addresses the questions of: 1) how many incremental samples should be collected, 2) how many samples should be pooled, and 3) which analytical method should be used for dioxin analyzes, in order to achieve a cost-effective monitoring.

In Chapter 4, cost and effectiveness at four monitoring points at different stages of the Dutch pork chain are assessed, including: 1) supplier of fatty ingredients, 2) feed mill, 3) pig farm 4) slaughterhouse, and 5) fat melting processor, in order to optimize the allocation of monitoring resources along the pork chain. In this chapter, the number of samples that should be collected and analyzed in each stage is determined. 
General introduction

In Chapter 5, the focus is on the feed mill stage of the poultry chain, with incoming feed ingredients that are processed into compound feed. This chapter describes the costeffectiveness of monitoring dioxins in feed ingredients and compound feed simulating the feed production of one year.

In Chapter 6 a synthesis of the results obtained in the previous chapters is provided and discussed with respect to existing literature. This chapter also presents a critical discussion of methodological issues regarding data availability and modelling approaches used to analyze the data. This is followed by a discussion about the implications of the findings for policy makers as well as for food safety managers in agri-food business. To finalize topics for further research that go in line with this dissertation are proposed, together with the main conclusions of this dissertation. 


\section{References}

Bernard, A., C. Hermans, F. Broeckaert, G. De Poorter, A. De Cock, and G. Houins. 1999. Food contamination by PCBs and dioxins. Nature 401(6750):231-232.

Bernard, A., F. Broeckaert, G. De Poorter, A. De Cock, C. Hermans, C. Saegerman, and G. Houins. 2002. The Belgian PCB/dioxin incident: Analysis of the food chain contamination and health risk evaluation. Environ. Res. 88(1):1-18.

Büchert, A., T. Cederberg, P. Dyke, H. Fiedler, P. Fürst, A. Hanberg, J. Hosseinpour, O. Hutzinger, J. G. Kuenen, R. Malisch, L. L. Needham, K. Olie, O. Papke, J. Rivera Aranda, G. Thanner, G. Umlauf, T. Vartiainen, and C. van Holst. 2001. Dioxin contamination in food. Bayreuth, Germany, from September 28 to October 1, 2000. Environ. Sci. Poll. Res. 8(2):84-88.

Buzby, J. C., and R. Chandran. 2003. The Belgian Dioxin Crisis and its effects on Agricultural Production and Exports, p125-139. In J.C. Buzby (ed.), International Trade and Food Safety: Economic Theory and Case Studies. Agricultural Economic Report No. 828. Economic Research Service. USDA.

Domingo, J. L., M. Schuhmacher, M. C. Agramunt, J. M. Llobet, J. Rivera, and L. Muller. 2002. PCDD/F levels in the neighbourhood of a municipal solid waste incinerator after introduction of technical improvements in the facility. Environ. Int. 28(1-2):19-27.

European Commission (EC). 2000. Report of experts participating in Task 3.2.5 "Assessment of dietary intake of dioxins and related PCBs by the population of EU Member States". In Reports on Tasks for Scientific Cooperation. European Commission, Health and Consumer Protection Directorate-General, Brussels. 


\section{General introduction}

European Commission (EC). 2001a. The Commission adopts strategy to reduce dioxins and PCBs in environment, feed and food. Brussels, 25 October 2001. IP/01/1492 www.europa.eu/rapid/pressrelease_IP-01-1492_en.pdf.

European Commission (EC). 2001b. Communication from the Commission to the Council, the European Parliament and the Economic and Social Committe. Community Strategy for Dioxins, Furans and Polychlorinated Biphenyls. COM(2001) 593 final. Off. J. Eur. Comm. C322:2-18.

European Commission (EC). 2001c. Council Directive 2001/102/EC of 27 November 2001 amending Directive 1999/29/EC on the undesirable substances and products in animal nutrition. Off. J. Eur. Comm. L6:45-49.

European Commission (EC). 2001d. Council Regulation (EC) No 2375/2001 of 29 November 2001 amending Commission Regulation (EC) No 466/2001 setting maximum levels for certain contaminants in foodstuffs. Off. J. Eur. Comm. L321:1-5.

European Commission (EC). 2002. Directive 2002/32/EC of the European parliament and of the council of 7 May 2002 on undesirable substances in animal feed. Off. J. Eur. Comm. L140:10-22.

European Commission (EC). 2006. Commission Recommendation 2006/88/EC of 6 February 2006 on the reduction of the presence of dioxins, furans and PCBs in feedingstuffs and foodstuffs. Off. J. Eur. Comm. L42:26-28.

European Commission (EC). 2009. Commission Regulation (EC) No 152/2009 of 27 January 2009 laying down the methods of sampling and analysis for the official control of feed. Off. J. Eur. Comm. L54:1-129. 
European Commission (EC). 2012a. Commission Regulation (EU) No 252/2012 of 21 March 2012 laying down methods of sampling and analysis for the official control of levels of dioxins, dioxin-like PCBs and non-dioxin-like PCBs in certain foodstuffs and repealing Regulation (EC) No 1883/2006. Off. J. Eur. Comm. L84:1-22.

European Commission (EC). 2012b. Commission Regulation (EU) No 277/2012 of 28 March 2012 amending Annexes I and II to Directive 2002/32/EC of the European Parliament and of the Council as regards maximum levels and action thresholds for dioxins and polychlorinated biphenyls. Off. J. Eu. Comm. L91:1-7.

European Commission (EC). 2012c. Commission Regulation (EU) No 278/2012 of 28 March 2012 amending Regulation (EC) No 152/2009 as regards the determination of the levels of dioxins and polychlorinated biphenyls. Off. J. Eur. Comm. L91:8-22.

European Commission (EC). 2012d. Commission Regulation (EU) No 744/2012 of 16 August 2012 amending Annexes I and II to Directive 2002/32/EC of the European Parliament and of the Council as regards maximum levels for arsenic, fluorine, lead, mercury, endosulfan, dioxins, Ambrosia spp., diclazuril and lasalocid A sodium and action thresholds for dioxins. Off. J. Eur. Comm. L219:5-12.

European Commission (EC). 2014. Commission Regulation (EU) No 589/2014 of 2 June 2014 laying down methods of sampling and analysis for the control of levels of dioxins, dioxin-like PCBs and nondioxin-like PCBs in certain foodstuffs and repealing Regulation (EU) No 252/2012. Off. J. Eur. Comm. L164:18-40.

European Food Safety Authority (EFSA). 2010. Results of the monitoring of dioxin level in food and feed. EFSA J. 8(3):1385. 


\section{General introduction}

European Food Safety Authority (EFSA). 2012. Update of the monitoring of levels of dioxins and PCBs in food and feed. EFSA J. 10(7):2832.

Firestone, D. 1973. Etiology of chick edema disease. Environ. Health Perspect. 5:59-66.

Focker, M., H. J. van der Fels-Klerx, and A. G. J. M. Oude Lansink. 2018. Systematic Review of Methods to Determine the Cost-Effectiveness of Monitoring Plans for Chemical and Biological Hazards in the Life Sciences. Compr. Rev. Food Sci. Food Saf. 17(3):633-645.

Fürst, P. 2011. Dioxins in feed and food again - real or perceived risk? Eur. J. Lipid Sci. Technol. 113(4):401-402.

Heres, L., R. Hoogenboom, R. Herbes, W. Traag, and B. Urlings. 2010. Tracing and analytical results of the dioxin contamination incident in 2008 originating from the Republic of Ireland. Food Addit. Contam. Part A-Chem. 27(12):1733-1744.

Hoogenboom, R. 2002. The combined use of the CALUX bioassay and the HRGC/HRMS method for the detection of novel dioxin sources and new dioxin-like compounds. Environ. Sci. Pollut. Res. Int. 9(5):304-306

Hoogenboom, R., T. Bovee, L. Portier, G. Bor, G. Van Der Weg, C. Onstenk, and W. Traag. 2004. The German bakery waste incident; Use of a combined approach of screening and confirmation for dioxins in feed and food. Talanta. 63(5):1249-1253.

Hoogenboom, L. A. P., J. C. H. Van Eijkeren, M. J. Zeilmaker, M. J. B. Mengelers, R. Herbes, J. Immerzeel, and W. A. Traag. 2007. A novel source for dioxins present in recycled fat from gelatin production. Chemosphere. 68(5):814-823. 
Hoogenboom, L. A. P. 2009. Dioxins, polychlorinated biphenyls and brominated flame retardants. p. 383-405. In I. Shaw (ed.), Endocrine disrupting chemicals in food. Woodhead Publishing Ltd. Oxford.

Hoogenboom, R., M. Zeilmaker, J. van Eijkeren, K. Kan, M. Mengelers, D. Luykx, and W. Traag. 2010. Kaolinic clay derived PCDD/Fs in the feed chain from a sorting process for potatoes. Chemosphere. 78(2):99-105.

Hoogenboom, R., W. Traag, A. Fernandes, and M. Rose. 2015. European developments following incidents with dioxins and PCBs in the food and feed chain. Food Control. 50:670-683.

Hoogenboom, R. L. A. P., G. ten Dam, M. van Bruggen, S. M. F. Jeurissen, S. P. J. van Leeuwen, R. M. C. Theelen, and M. J. Zeilmaker. 2016. Polychlorinated dibenzo-p-dioxins and dibenzofurans (PCDD/Fs) and biphenyls (PCBs) in home-produced eggs. Chemosphere. 150:311-319.

Huwe, J. K. 2002. Dioxins in food: A modern agricultural perspective. J. Agric. Food Chem. 50(7):1739-1750.

Liem, A. K. D., R. Hoogerbrugge, P. R. Kootstra, E. G. van der Velde, and A. P. J. M. de Jong. 1991. Occurrence of dioxins in cow's milk in the vicinity of municipal waste incinerators and a metal reclamation plant in the Netherlands. Chemosphere. 23(11-12):1675-1684.

Llerena, J. J., E. Abad, J. Caixach, and J. Rivera. 2003. An episode of dioxin contamination in feedingstuff: the choline chloride case. Chemosphere. 53(6):679-683.

Malisch, R. 2000. Increase of the PCDD/F-contamination of milk, butter and meat samples by use of contaminated citrus pulp. Chemosphere. 40(9-11):1041-1053. 


\section{General introduction}

Malisch, R. and A. Kotz. 2014. Dioxins and PCBs in feed and food - Review from European perspective. Sci. Total Environ. 491-492(0):2-10.

Malisch, R. 2017. Incidents with Dioxins and PCBs in Food and Feed-Investigative Work, Risk Management and Economic Consequences. J. Environ. Prot. 8:06:42.

Pacyna, J. M., K. Breivik, J. Münch, and J. Fudala. 2003. European atmospheric emissions of selected persistent organic pollutants, 1970-1995. Atmos. Environ. 37:119-131.

Parzefall, W. 2002. Risk assessment of dioxin contamination in human food. Food Chem. Toxicol. 40(8):1185-1189.

Quaß, U., M. W. Fermann, and G. Bröker. 2000. Steps towards a European dioxin emission inventory. Chemosphere. 40(9):1125-1129.

Quaß, U., M. Fermann, and G. Bröker. 2004. The European Dioxin Air Emission Inventory ProjectFinal Results. Chemosphere. 54(9):1319-1327.

Rieger, J., C. Kuhlgatz, and S. Anders. 2016. Food scandals, media attention and habit persistence among desensitised meat consumers. Food Policy. 64:82-92.

Surkov, I. V., A. G. J. M. Oude Lansink, O. van Kooten, and W. van der Werf. 2008. A model of optimal import phytosanitary inspection under capacity constraint. Agric. Econ. 38(3):363-373.

Surkov, I. V., A. G. J. M. Oude Lansink, and W. van der Werf. 2009. The optimal amount and allocation of sampling effort for plant health inspection. Eur. Rev. Agric. Econ. 36(3):295-320. 
Scientific Committee on Food (SCF). 2001. Opinion of the Scientific Committee on Food on the risk assessment of dioxins and dioxin-like PCBs in food. Scientific Committee on Food report CS/CNTM/DIOXIN/20 final. Accessed Apri. 2012. http://ec.europa.eu/food/fs/sc/scf/out90_en.pdf.

United Nations Environment Program (UNEP). 2009. Stockholm Convention on persisten organic pollutants (POPs), as amedded in 2009. Text and Anexes. United Nations Environment Program. Accessed June 2012. http://chm.pops.int/Convention/ConventionText/tabid/2232/Default.aspx.

Valeeva, N. I. and R. B. M. Huirne. 2008. Strategies to improve food safety in the dairy chain: A casestudy from The Netherlands. Opportunities and Challenges for Smallholder Ruminant Systems in Latin America. Universidad Autonoma Estado Mexico, Toluca, Mexico.

van Larebeke, N., L. Hens, P. Schepens, A. Covaci, J. Baeyens, K. Everaert, J. L. Bernheim, R. Vlietinck, and G. De Poorter. 2001. The Belgian PCB and dioxin incident of January-June 1999: Exposure data and potential impact on health. Environ. Health Perspect. 109(3):265-273.

World Health Organization (WHO). 2016. Dioxins and their effects on human health. Fact sheets. World Health Organization, Geneva, Switzerland. Accessed July 2018. http://www.who.int/newsroom/fact-sheets/detail/dioxins-and-their-effects-on-human-health. 


\title{
Chapter 2
}

\section{Financial impact of a dioxin incident in the Dutch dairy chain}

\author{
V. H. Lascano Alcoser, A. G. J. Velthuis,
} L. A. P. Hoogenboom, H. J. van der Fels-Klerx

Published in Journal of Food Protection, 74(6): 967-979

DOI 10.4315/0362-028X.JFP-10-350 
Financial impact of a dioxin incident

\section{Abstract}

The aim of this study was to quantify the financial consequences of a milk-dioxin crisis on the stages of the dairy chain involved. The milk dioxin contamination impact model was designed for this purpose and also was used to estimate the net costs of control measures limiting the impact. Results obtained based on the assumption of the worst-case scenario in which the entire daily production of each business unit from feed supplier to milk processor is contaminated suggested that the financial impact of one dioxin incident would be $€ 141.2$ million. Another assumption was that the dioxin contamination started at one feed supplier processing plant and was detected 2 weeks after initial contamination (called high-risk period), which would result in the involvement of 714 dairy farms, 26 milk processors and 2,664 retailers. The stages of the chain that contributed most to the total net costs were the milk processor $(76.9 \%)$ and the dairy farm (20.5\%). If the high-risk period were shorter, i.e. 3 days, the estimated total financial impact decreases to $€ 10.9$ million. Thus, early detection of the contamination is crucial for decreasing the number of food businesses involved and lowering the total financial impact value. The most influential inputs of the model were the sale price of milk at the processing stage, the daily amount of milk processed per processing plant, the farm-blocking period, and the daily amount of milk produced per farm. However, the effect of these inputs on the total financial impact was less than $10.0 \%$. These results can be used to establish priorities in the application of control measures to limit the financial and public health impact of a possible food safety incident. 


\subsection{Introduction}

Dioxins are environmental pollutants produced by natural and industrial processes and are important causes of food contamination. Polychlorinated dibenzo-p-dioxins and polychlorinated dibenzofurans and dioxin-like compounds such as certain polychlorinated biphenyls can affect human health and therefore are of great concern. Health risks are associated with two aspects of these compounds: i) their persistence and accumulation in the human body and ii) their extreme toxicity and the fine line between toxic and safe human intake levels (Hoogenboom et al., 2004; WHO, 2007).

Dioxins and dioxin-like compounds have distinct toxic effects on human and animal health (WHO, 2007). They act as endocrine disruptors of sexual development and thyroid function (Hoogenboom, 2009) and may cause immunotoxicity, neurological disorders, and cloracne and may cause teratogenic and carcinogenic effects (De Meulenaer, 2006). In 1997, the International Agency for Research on Cancer (IARC) reclassified the 2,3,7,8tetrachlorodibenzo-p-dioxin into group 1 of human carcinogenic compounds (Hayward et al., 1999). Laboratory animals exposed to tetrachlorodibenzo-p-dioxin develop liver tumors, and immunological and reproductive alterations occur at lower levels of exposure (Hayward et al., 1999). Humans accidentally exposed to these compounds have a major risk of developing diabetes and cancer (Hayward et al., 1999). Although the individual effects of these compounds on human health are known, the effects on humans of exposure to a mixture of dioxins and dioxin-like polychlorinated biphenyls are unknown, which makes the actual toxics effects of these compounds difficult to determine (Hayward et al., 1999).

During the past five decades, a number of dioxin-related incidents have occurred in the feed and food chains (Behnisch, 2005); the main source of these compounds has been contaminated feed ingredients (Huwe and Smith, 2005). In 1996, the US Environmental Protection Agency determined that ball clay used as feed for poultry and catfish was the 
Financial impact of a dioxin incident

source of dioxin contamination in fish and chicken products (Hayward et al., 1999; Hoogenboom et al., 2004). After, this investigation, the U.S. Food and Drug Administration prohibited the use of ball clay in feed production (Hayward et al., 1999). Two years later (1998), an important incident occurred in The Netherlands and Germany in which milk samples had higher than usual dioxin levels. In this case, the source was contaminated citrus pulp (imported from Brazil) used as ingredient for ruminant feed (Hoogenboom et al., 2004; Malisch, 2000). One of the most important dioxin crises occurred in Belgium in 1999, where increased levels of dioxins and polychlorinated biphenyls were found in eggs, poultry and pork products. The cause of this crisis was the use of animal feed contaminated with about 200 to $300 \mathrm{~kg}$ of polychlorinated biphenyl oil (Bernard et al., 1999, 2002; Buzby and Chandran, 2003; Huwe and Smith, 2005; Lok and Powel, 2000). This incident raised the awareness of these kinds of contaminants in the food chain and resulted in strict regulations within the European Union, including contaminant limits in feed and food and increased monitoring. As a result of better monitoring, several other incidents were detected. In 2004 in The Netherlands, high levels of dioxins were found in milk from a dairy farm during routine testing by the dairy industry. The source of this contamination was traced to the use of potato peels, an industry by-product, as animal feed. The peels were contaminated with dioxincontaining kaolinic clay used for sorting potatoes (Hoogenboom et al., 2010). Although only a small number of farms actually were affected, the incident led to the precautionary restrictions (blocks) on a large number of farms and feed commodities. The main food products that contribute to human exposure worldwide are milk and other dairy products, fish, meat and meat products (WHO, 2007). The impact of these contributors may differ during food incidents because of higher levels of dioxins found in specific products (EC, 2000).

Dioxin incidents are a threat to both human health and the economy of a country, specifically the agri-food chains involved. Control measures taken during an incident like, 
such as temporary blocking of production facilities (Valeeva et al., 2006) or recall of products from the market, results in direct costs and losses for companies (Velthuis et al., 2009). These measures also affect both internal and external business relationships. For example, the crisis in Belgium in 1999, caused a temporary disruption of commercial relations with more than 30 countries worldwide (Buzby and Chandran, 2003). Similar disruptions occurred during two incidents in 2008, one with pork in Chile (Kim et al., 2009) and one with pork and beef in Ireland (Tlustos, 2009a; Tlustos 2009b). Previous research has been conducted to assess the impact of a feed crisis at different stages of the food chain (Meuwissen et al., 2008, 2009) and to estimate the direct recall cost in the Dutch milk chain (Velthuis et al., 2009). However, the financial consequences of a dioxin incident for the various members of the agri-food chain have not yet been evaluated.

The aim of this study was to estimate the financial consequences of a dioxin incident in the dairy chain relative to the time of incident detection. We used the dioxin incident of 2004 in the Dutch dairy chain (Hoogenboom et al., 2010) as a model and considered feed, primary production, processing and retail stages of this chain. Because of the high amount of milk produced and consumed in The Netherlands and because milk is common source of dioxin contamination, milk for consumption was the focus of this study (Baars et al., 2004; De Mul et al., 2008).

\subsection{Materials and Methods}

Dutch feed industry and dairy sector. In 2008, the Dutch compound feed industry consisted of 120 production facilities producing 14,507 million tons of compound feed, including 3,168 million tons of compound feed for dairy cattle (FEFAC, 2008). In the same year, the Dutch dairy sector consisted of 20 milk processor companies with 52 processing plants (PZ, 2008). In total, more than 11.3 million tons of milk were processed in 2008 
Financial impact of a dioxin incident

coming from 18,470 dairy farms (only considering farms with a heard of more than 16 dairy cows) with, on average, 76.6 dairy cows per farm (LEI, 2009). At that time, there were 5,790 dairy retailers in The Netherlands (CBS, 2010).

Milk dioxin contamination impact model. A deterministic model was developed in Microsoft Office Excel 2003 (Microsoft, Redmond, WA) to calculate the financial impact of a dioxin contamination incident on a dairy chain. This model, the milk dioxin contamination impact model (MiDCIM), includes four chain stages: feed supplier, dairy farm, milk processor and retailer. We assumed that a single feed supplier production facility $\left(f_{s}\right)$ is the starting point of the contamination by producing and supplying dioxin-contaminated compound feed for dairy cows. From this stage, the contamination is spread through the dairy farms ( $d f$ ), where contaminated feed is offered to dairy cows and contaminated milk is collected, the milk processors $(m p)$, where contaminated milk is processed into milk for consumption, and the retailers ( $r t)$, where milk for consumption is sold to the consumers. In this study, the worst-case scenario was assumed: i) all produced milk was converted into milk for consumption and not into other dairy products, ii) the contamination was continuous over time, and iii) the entire daily production of each business unit from feed supplier to milk processor stage was contaminated.

Number of feed and food businesses contaminated in each stage of the chain. Based on statistics of the Dutch feed and dairy industry mentioned above, the following assumptions were made. Given the total amount of compounded feed for dairy cattle produced in 2008 (FEFAC, 2008), it was assumed that 26 of 120 Dutch feed mills produce this kind of feed, with an average production of 334,000 kg/day (FEFAC, 2008; LEI, 2009). Considering the total number of dairy farms in 2008 (LEI, 2009) and assuming that each farm receives new feed every 14 days (most common situation), it was estimated that each feed producing site distributed feed to 51 different dairy farms per day. Once feed was received by the dairy 
farms, it was immediately offered to the dairy cows, and this feed batch was assumed to be used for 2 weeks. Milk produced by these cows was collected and stored at each farm for a maximum of 3 days before being delivered to a milk processing plant. Given the lack of information regarding the path that milk followed from each farm to each specific milk processing site, it was assumed that each group of 51 farms delivered milk to two milk processing plants from one milk company beginning on the first day of having received new feed. This assumption leads to the prediction that in 14 days, contaminated milk would be spread across a maximum 26 of the 52 milk processing sites in the Netherlands (PZ, 2008). At the processing plant, milk is processed and packed as milk for consumption, which is delivered to the supermarket (the retailer) 1 day after being processed. An average milk processing plant distributes milk for consumption to 111 retailers per day, assuming the total number of retailers at the national level $(5,790)$ is supplied by 52 milk processing plants (CBS, 2008). Consequently, each subsequent day, 51 new farms, two new milk processors from one milk company, and 111 new retailers of 7 retailer companies will be contaminated, assuming that the contaminated ingredient is used for feed production for a longer period of time.

High-risk period. In the MiDCIM model, the financial impact of a dioxin incident can be calculated for scenarios that differ in the time between the start of the contamination and the moment of detection (the high-risk period; HRP). For each scenario the consequential cost related to this incident is taken into account. The HRP can range from 1 to 14 days. The maximum of 14 days was chosen based on the assumption that each farm received new compounded feed every 2 weeks. If detected on day 14, the maximum number of dairy farms, milk processing plants, and retailers contaminated from a single feed production site is reached. Therefore, although the contamination could continue after day 14 (i.e. given a new 
Financial impact of a dioxin incident

delivery of contaminated compounded feed), the level of damage would not increase further after day 14.

Partial Budgeting. The calculation of the financial impact of a dioxin incident is based on a partial budgeting approach, which is the comparison between a basic situation without the incident and one with the incident. With this method, the negative effects of a dioxin incident, which are extra costs and loss of revenue, and the positive effects, which are additional returns and reduced costs, are considered. The net cost is the sum of the positive effects minus the negative effects (Dijkhuizen and Morris, 1997; Velthuis et al., 2009).

Model description. The total financial impact of a dioxin contamination event (TIDC) on a dairy chain is given by:

$T I D C=T C+T I_{r a}$

Where $T C$ is the total financial impact of different control measures applied in a specific stage of the chain for all farms and firms (production site of a feed or food business) involved in the dioxin incident and $T I_{r a}$ is the impact based on the extra costs of carrying out a risk analysis $(r a)$.

$T C$ is given by the summation of multiplying the net impact $\left(N I_{i, c}\right)$ of all control measures $(c)$ applied for a single business unit in each stage $(i)$ and the number of business units $\left(n b_{i}\right)$ in each $i$ that are involved in the incident:

$T C=\sum_{i}\left(\left(\sum_{c} N I_{i, c}\right) \cdot n b_{i}\right)$

$N I_{i, c}$ is the set of values representing the net impact of each $c$ for a single business unit in each $i$. The control measures $(c)$ included in the model are tracking and tracing of the contamination ( $T T$ ), sampling and testing of suspected products $(S T)$, identification and registration of contaminated products $(I R)$, blocking of farms and firms containing suspected 
and contaminated products and livestock $(B L)$, recalling contaminated products $(R C)$, replacing recalled products $(R P)$ and destruction of contaminated products $(D T)$. The general structure of the model by type of cost is depicted in figure 1 . The net impact for each $c$ is described in the following paragraphs.

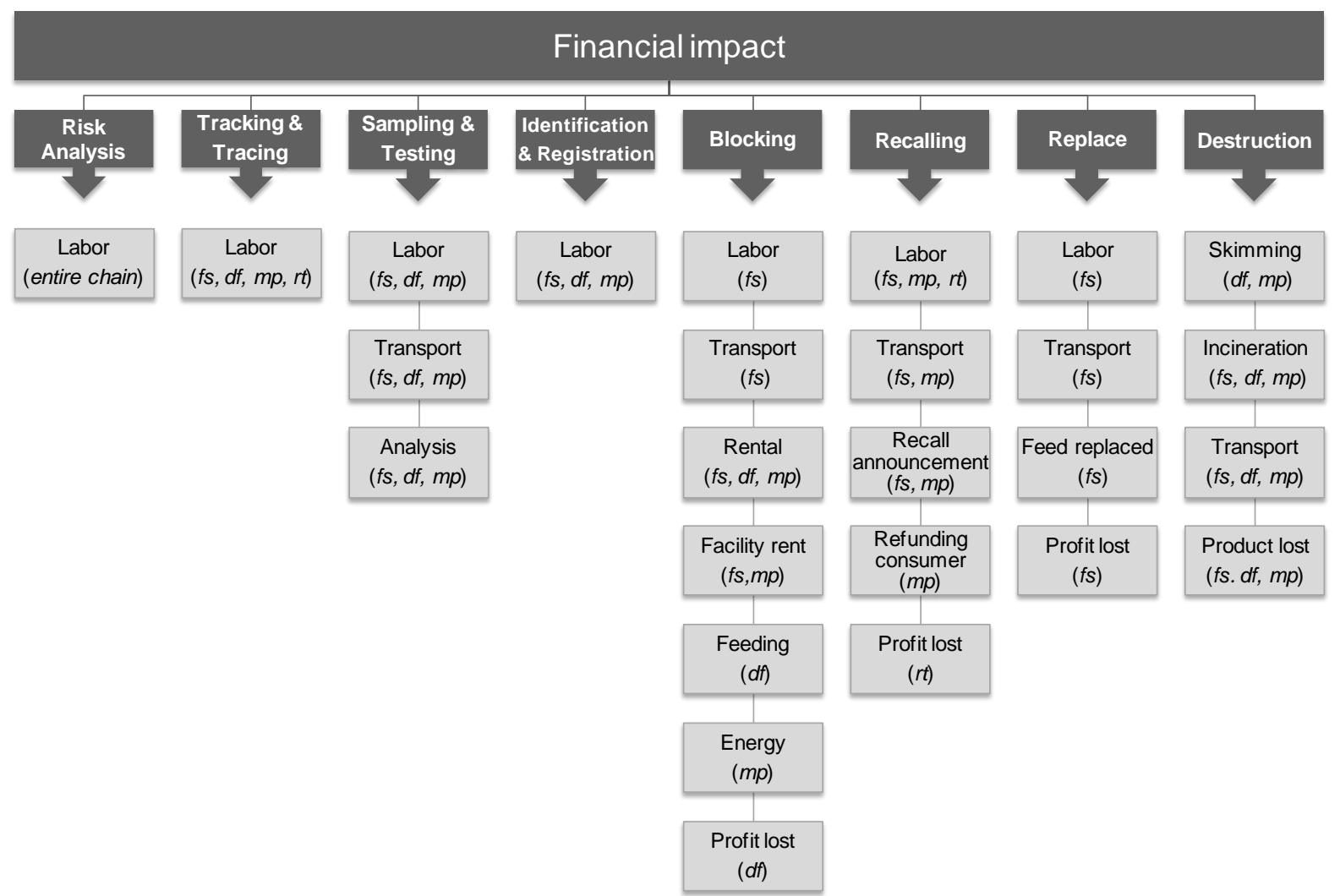

Figure 1. General structure of the model by type of cost: $f s$ : feed supplier; $d f$ : dairy farm; $m p$ : milk processor; $r t$ : retailer.

Tracking and tracing. Because tracking and tracing involves only extra labor (i.e. computer data analysis of all the information required to identify the source and extent of the contamination), the net impact of $T T$ is

$$
N I_{i, T T}=L_{i, T T, a}
$$

where $L_{i, T T, a}$ is the general formula for labor cost in which $T T$ is the control measure for $c$ :

$$
L_{i, c, a}=\sum_{i, c, a}\left(l c_{a} \cdot l t_{i, c, a}\right)
$$


Financial impact of a dioxin incident

The general formula of labor cost $L_{i, c, a}$ includes six possible wages tariffs $a$. They are divided into three categories (high, medium and low) depending on the education level and skill required to carry out specific activities and depending on the source of the labor, which can be currently part of the business (internal) or temporarily hired for a specific task required (external). The $l c_{a}$ represents the labor costs at $a$ and $l t_{i, c, a}$ is the number of hours required to accomplish activity $c$ in stage $i$ at $a$. The inputs are given in Table 1 . 
Table 1. Labor and transport variables used for calculation of the financial impact of a dioxin incident on the Dutch dairy chain

\begin{tabular}{|c|c|c|c|c|c|c|c|}
\hline \multirow[b]{2}{*}{ Variable } & \multirow[b]{2}{*}{ Description } & \multirow[b]{2}{*}{ General value } & \multicolumn{4}{|c|}{ Value per stage $(i)^{\mathrm{a}}$} & \multirow[b]{2}{*}{ Source or remark } \\
\hline & & & $f_{s}$ & $d f$ & $m p$ & $r t$ & \\
\hline$l c_{e x t, h i g h}$ & External labor cost, high tariff $(€ / \mathrm{h})$ & 125.0 & & & & & Tariffs Dutch Gov., LNV, $2009^{b}$ \\
\hline$l c_{e x t, \text { medium }}$ & External labor cost, medium tariff $(€ / \mathrm{h})$ & 112.0 & & & & & Tariffs Dutch Gov., LNV, 2009 \\
\hline$l c_{e x t, l o w}$ & External labor cost, low tariff $(€ / \mathrm{h})$ & 65.0 & & & & & Tariffs Dutch Gov., LNV, 2009 \\
\hline$l c_{\text {int, } h i g h}$ & Internal labor cost, high tariff $(€ / \mathrm{h})$ & 63.0 & & & & & Tariffs Dutch Gov., LNV, 2009 \\
\hline$l c_{\mathrm{int}, \text { medium }}$ & Internal labor cost, medium tariff $(€ / \mathrm{h})$ & 49.0 & & & & & Tariffs Dutch Gov., LNV, 2009 \\
\hline$l c_{\text {int }, l o w}$ & Internal labor cost, low tariff $(€ / \mathrm{h})$ & 31.0 & & & & & Tariffs Dutch Gov., LNV, 2009 \\
\hline$l t_{r a}$ & No. hours to carry out the risk analysis & 20.0 & & & & & Opinion by risk analysis expert \\
\hline$l t_{i, T T}$ & No. hours for tracking and tracing & & 4.0 & 4.0 & 4.0 & 4.0 & EC178/2002 (EC, 2002) with Dutch implementation \\
\hline$l t_{i, S T}$ & No. hours for sampling and testing & & 21.0 & 14.0 & 4.0 & & $\begin{array}{l}\text { Values relative to the proportion of the possible sources of } \\
\text { contamination }\end{array}$ \\
\hline$l t_{i, I R}$ & No. hours for identification and registration & & 4.0 & 4.0 & 4.0 & & EC178/2002 (EC, 2002) with Dutch implementation \\
\hline$l t_{i, c h d}$ & No. hours for consumer help desk & & & & 80.0 & 80.0 & 2 wk of five working days ( $8 \mathrm{~h}$ ) for $1 \mathrm{FTE} /$ company \\
\hline$l t_{i, R C}$ & No. hours for recalling activities & & & & & 2.0 & Time estimated to withdraw milk from shelves per retailer \\
\hline$t t_{\text {truck }}$ & $\begin{array}{l}\text { Avg travel time for moving feed or milk } \\
\text { (h/truck) }\end{array}$ & 4.0 & & & & & Opinion by feed production expert \\
\hline$q_{\text {truck }}$ & Truck capacity for feed and milk (tons) & 25.0 & & & & & Opinion by feed production expert Velthuis et al. (2009) \\
\hline$d t f_{f s}$ & $\begin{array}{l}\text { No. hours for delivering or withdrawing feed } \\
\text { to or from dairy farm (h/farm) }\end{array}$ & & 4.0 & & & & Opinion by feed production expert \\
\hline tcs $_{\text {feed }}$ & Transport cost of feed samples ( $€ /$ batch) & 10.0 & & & & & TNT post mail (TNT, 2010) \\
\hline tcs $s_{\text {milk }}$ & Transport cost of milk samples ( $€ /$ batch) & 10.0 & & & & & TNT post mail (TNT, 2010) \\
\hline$t c f$ & Transport cost of feed $(€ / \mathrm{kg})$ & 0.01 & & & & & Estimated as five times less than transport cost of milk \\
\hline tcm & Transport cost of milk $(€ / \mathrm{kg})$ & 0.05 & & & & & Velthuis et al. (2009) \\
\hline
\end{tabular}

${ }^{\mathrm{a}} \mathrm{fs}$, feed supplier; df, dairy farm; mp, milk processor; rt, retailer.

${ }^{\mathrm{b}}$ Tariffs, Dutch Government, LNV, 2009 information is available from the authors on request. 
Sampling and testing. The net impact of sampling and testing $\left(N I_{i, S T}\right)$ includes labor ( $L_{i, c, a}$ ) (i.e. computer work to determine the sampling plan and field work to collect the samples for delivery to the laboratory), transport costs of samples and analysis costs:

$$
\begin{aligned}
& N I_{i, S T}=L_{i, S T, a}+\sum_{i}\left(t c s_{\text {milk }} \cdot \frac{n s_{i, \text { milk }}}{n s_{\text {batch }}}+t c s_{\text {feed }} \cdot \frac{n s_{i, \text { feed }}}{n s_{\text {batch }}}\right)+ \\
& \sum_{i}\left(a c_{\text {screening }} \cdot\left(n s_{i, \text { milk }}+n s_{i, \text { feed }}\right)+a c_{\text {confirmation }} \cdot p r_{\text {pos }} \cdot\left(n s_{i, \text { milk }}+n s_{i, \text { feed }}\right)\right)
\end{aligned}
$$

where tcs is the transport cost per batch of feed or milk samples, $n s_{\text {batch }}$ is the number of samples per batch, and $n s_{i}$ is the number of samples of feed and milk transported from stage $i$. The analysis costs include costs for screening and confirmation, where $a c_{\text {screening }}$ is the cost for performing one screening test and $a c_{\text {confirmation }}$ is the cost for performing one confirmation test. Hence, only the proportion of samples tested positive in the screening test $\left(p r_{p o s}\right)$ are tested again in the confirmation test. It is assumed that all samples of milk and feed are sent by postal mail to the laboratory, where the transport cost equals $€ 10$ per batch of samples weighing 0.5 to $2.0 \mathrm{~kg}$. It is assumed that 10 samples of milk or feed (weighed 0.5 to $2.0 \mathrm{~kg}$ ) make up a batch. The cost of shipping 1 sample is the same as the cost of shipping 10 samples of feed or milk, which is assumed to be $€ 10$ euro minimum. Consequently, because the transport cost is fixed per batch of samples, the relationship between the number of samples and the transport cost is not linear. Additionally, it is assumed that each feed, farm, or food business always ships the complete number of samples in each batch.

Given the diversity of ingredients and their sources, it is assumed that five times more samples are needed at each feed supplier production plant $\left(n s_{i}\right)$ than at farms or food business. The inputs are given in Tables 2 and 3 . 
Table 2. Variables associated with number of samples, blocking times and number of feed and food companies used for calculation of the financial impact of a dioxin incident on the Dutch dairy chain

\begin{tabular}{|c|c|c|c|}
\hline Variable & Description & Value & Source or remark \\
\hline$n s_{f s, \text { feed }}$ & No. of feed samples at feed supplier & 50.0 & $\begin{array}{l}\text { Because of the possible no. of sources of } \\
\text { contamination, the no. of samples is five } \\
\text { times higher than at other stages. }\end{array}$ \\
\hline$n s_{d f, \text { feed }}$ & No. of feed samples at dairy farm & 10.0 & $\begin{array}{l}\text { Value relative to the proportion of the } \\
\text { possible sources of contamination }\end{array}$ \\
\hline$n s_{d f, \text { milk }}$ & No. of milk samples at dairy farm & 10.0 & $\begin{array}{l}\text { Value relative to the proportion of the } \\
\text { possible sources of contamination }\end{array}$ \\
\hline$n s_{m p, m i l k}$ & No. of milk samples at milk processor & 10.0 & $\begin{array}{l}\text { Value relative to the proportion of the } \\
\text { possible sources of contamination }\end{array}$ \\
\hline$n s_{\text {batch }}$ & No. of samples per batch & 10.0 & $\begin{array}{l}\text { Value relative to the proportion of the } \\
\text { possible sources of contamination }\end{array}$ \\
\hline$p r_{p o s}$ & $\begin{array}{l}\text { Proportion of samples with positive result } \\
\text { at screening test (\%) }\end{array}$ & 20 & Value assumed \\
\hline$b t_{f s}$ & Blocking time at feed supplier (day) & 7.0 & Opinion by food safety expert \\
\hline$b t_{d f}$ & Blocking time at dairy farm (day) & 30.0 & $\begin{array}{l}\text { Avg time period: Traag et al., } 1999 \text { and } \\
\text { Hoogenboom et al., } 2010\end{array}$ \\
\hline$b t_{m p}$ & Blocking time at milk processor (day) & 7.0 & Opinion by food safety expert \\
\hline$t m_{\text {no-stock }}$ & Time that no milk in stock at retailer (day) & 5.0 & Value assumed \\
\hline$H R P_{\text {days }}$ & $\begin{array}{l}\text { Detection in days after initial contamination } \\
\text { (day) }\end{array}$ & $1.0-14.0$ & Value estimated and explained in the text \\
\hline$n b_{f s}$ & No. of contaminated feed processing plants & 1.0 & Value estimated and explained in the text \\
\hline$n b_{d f}$ & No. of farms receiving feed per day & 51.0 & Value estimated and explained in the text \\
\hline$n b_{m p}$ & $\begin{array}{l}\text { No. of milk processing plants receiving } \\
\text { milk per day }\end{array}$ & 2.0 & Value estimated and explained in the text \\
\hline$n b_{r t}$ & $\begin{array}{l}\text { No. of retailers receiving milk per day per } \\
\text { milk processor }\end{array}$ & 111 & Value estimated and explained in the text \\
\hline$n c_{m p, R C}$ & $\begin{array}{l}\text { No. of processor companies involved in the } \\
\text { recall }\end{array}$ & 4.0 & Value estimated and explained in the text \\
\hline$n c_{r t, R C}$ & $\begin{array}{l}\text { No. of retailer companies involved in the } \\
\text { recall }\end{array}$ & 7.0 & Value estimated and explained in the text \\
\hline
\end{tabular}


Financial impact of a dioxin incident

Table 3. Service and related costs variables used for calculation of the financial impact of a dioxin incident on the Dutch dairy chain

\begin{tabular}{|c|c|c|c|}
\hline Variable & Description & Value & Remark or source \\
\hline$a c_{\text {screening }}$ & Screening test cost $(€ /$ sample $)$ & 250.0 & Hoogenboom, 2009 \\
\hline$a c_{\text {confirmation }}$ & Confirmation test cost $(€ /$ sample $)$ & 900.0 & Hoogenboom, 2009 \\
\hline$r c_{f s}$ & Renting cost at feed supplier ( $€ /$ month) & $12,000.0$ & $\begin{array}{l}\text { Assuming a cost of } € 30 / \mathrm{m}^{2} \text { and a } \\
\text { storage area of } 400 \mathrm{~m}^{2}\end{array}$ \\
\hline$r c_{m p}$ & Renting cost at milk processor ( $€ /$ month) & $24,000.0$ & $\begin{array}{l}\text { Assuming a cost of } € 60 / \mathrm{m}^{2} \text { and a } \\
\text { storage area of } 400 \mathrm{~m}^{2}\end{array}$ \\
\hline$e c$ & Energy cost (€/kg/day) & 0.01 & Value assumed \\
\hline$i r$ & Interest rate $(\%)$ & 0.05 & CBS, 2010 \\
\hline$i c_{l o w}$ & Incineration cost as low-risk material $(€ / \mathrm{kg})$ & 0.09 & Opinion by waste management expert \\
\hline$i c_{h i g h}$ & Incineration cost as high-risk material $(€ / \mathrm{kg})$ & 0.33 & Opinion by waste management expert \\
\hline$s k c$ & Skimming cost of milk $(€ / \mathrm{kg})$ & 0.08 & Velthuis et al. (2009) \\
\hline$a d_{p r}$ & $\begin{array}{l}\text { Press release cost and web page publication } \\
\text { (€/announcement) }\end{array}$ & $1,000.0$ & Velthuis et al. (2009) \\
\hline$a d_{p c}$ & $\begin{array}{l}\text { Cost of publishing recall announcement in a } \\
\text { newspaper ( } € / \text { announcement) }\end{array}$ & $6,000.0$ & Velthuis et al. (2009) \\
\hline nad & Number of newspapers brands & 2.0 & Velthuis et al. (2009) \\
\hline$a d_{c d}$ & Advertisement design cost ( $€ /$ advertisement) & $1,000.0$ & Velthuis et al. (2009) \\
\hline pstc & Postal cost for sending barcodes of milk ( $€ /$ unit) & 0.44 & TNT post mail (TNT, 2010) \\
\hline$r r$ & Proportion of customer asking for refund (\%) & 0.13 & Velthuis et al. (2010) \\
\hline
\end{tabular}

Identification and registration. The net impact of identification and registration $\left(N I_{i, I R}\right)$ of contaminated products at stage $i$ is given only by the labor cost required for this activity, $L_{i, I R, a}$, as given in equation 4. Labor activities of IR includes labeling and registering all contaminated products that has been identified by TT.

$N I_{i, I R}=L_{i, I R, a}$

Blocking. Once contamination is detected, the farms or firms are blocked until the source and extent of contamination is defined. The net impact of blocking businesses $\left(N I_{i, B L}\right)$ differs per stage $i$. The net impact of blocking a feed production plant, $N I_{f s, B L}$, includes labor costs ( $L_{f s, B L, a}$ ) (i.e. organizing the movement of all suspected or contaminated products [not recalled 
products] to temporal storage place), transport costs $\left(T f_{B L}\right)$ to move suspected and/or contaminated feed to a storage facility, rental costs for feed in storage, and costs for renting a storage facility:

$$
N I_{f s, B L}=L_{f s, B L, a}+T f_{B L}+\left(c p f_{f s, c o w} \cdot n f_{B L} \cdot \frac{i r}{365} \cdot b t_{f s}\right)+\left(r c_{f s} \cdot b t_{f s}\right)
$$

It is assumed that the amount of feed stored $\left(n f_{B L}\right)$ is that produced in 1 day, and it is stored until test results are available. It is assumed that if the test results are positive, the stored feed is destroyed. In this research, it was assumed that stored feed is contaminated. Labor costs are given by the sum of labor cost (equation 4). However, the amount of time required to move the feed to storage place ( $\left.l t_{f s, B L}\right)$ is given by the amount of stored feed $\left(n f_{B L}\right)$, the average truck capacity $\left(q_{\text {truck }}\right)$ and the average travel time per truck $\left(t t_{\text {truck }}\right)$ :

$$
l t_{f s, B L}=\frac{n f_{B L}}{q_{\text {truck }}} \cdot t t_{\text {truck }}
$$

If the result of $n f_{B L} / q_{\text {truck }}$ is not a whole number, the fraction is round up before multiplication by $t t_{\text {truck }}$.

Transport costs are given by the general equation for transport cost for feed $T f_{c}$ :

$$
T f_{c}=\sum_{c}\left(t c f \cdot n f_{c}\right)
$$

Transport costs include the costs to transport $1 \mathrm{~kg}$ of feed (tcf) and the amount of feed transported $\left(n f_{c}\right)$ for each measure $c$. The inputs are given in Tables 1 and 4 . The rental costs of feed products in storage are opportunity costs. These include the value of the feed in storage, which is calculated from the cost price $\left(c p f_{f s, c o w}\right)$, the amount of feed stored $\left(n f_{B L}\right)$, the annual interest rate (ir ) and the blocking time $\left(b t_{f s}\right)$ (Tables 3 and 4$)$. The cost for renting an extra storage facility is given by the monthly renting cost per facility $\left(r c_{f_{s}}\right)$ and the 
blocking time in stage $f_{s}\left(b t_{f s}\right)$. The renting cost is assumed in monthly periods because storage areas are rented for a minimum of 1 month. The inputs are given in Tables 2 and 3.

The net impact of blocking dairy farms $\left(N I_{d f, B L}\right)$ is given by the sum of all extra costs and lost revenue for $B L$ at $d f$ :

$$
\begin{aligned}
& N I_{d f, B L}=\left(\sum_{d}\left(s p l_{d} \cdot n l_{B L, d} \cdot \frac{i r}{365} \cdot b t_{d f}\right)+\sum_{d}\left(s p f_{f s, d} \cdot d f i_{d} \cdot n l_{B L, d} \cdot b t_{d f}\right)\right)+ \\
& \left(\left(s p l_{\text {calf }}-s p l_{\text {calf }>10 \text { days }}\right) \cdot n l_{B L, \text { calf }}\right)
\end{aligned}
$$

The extra costs are obtained by the sum of rental and extra feeding cost, whereas the loss of revenue is determined by the lost profit margin when older calves are sold to the veal industry (suboptimal age). It is assumed that all cows and calves of the farm can be contaminated with dioxin. However, only the portion of replacement cows (at a rate of 30\%) and calves not sold to the slaughterhouse and veal industry are considered in the cost calculations. Given the average number of cows per farm, it is estimated that two cows and six calves per month are confined at the farm (not trade) until the levels of dioxin have decreased below maximum levels. The total rental cost (for holding suspected or contaminated livestock confined at farm) is the sum of rental costs for each type of livestock ( $d$; dairy cow or calf), where $s p l_{d}$ denotes the value of the livestock. For dairy cows, this value is the average market price of a dairy cow, whereas for calves, the calf's fattening industry sale price is considered. The number of livestock not commercialized for each $d$ is represented by $n l_{B L, d}$, ir is the annual interest rate, and $b t_{d f}$ is the time during which the farm is blocked. The inputs are given in Tables 2 through 4 . The extra cost of feeding livestock is calculated using the feed sale price at feed supplier, $s p f_{f s, d}$, for each $d$ and the daily feed intake, $d f i$, per each unit of $d$. The inputs are given in Table 4. The loss of revenue is calculated using the calf's standard sale 
price (at 10 days old) $\left(s p l_{\text {calf }}\right)$, the sale price for a calf older than 10 days $\left(s p l_{\text {calf }>10 d a y s}\right)$, and the number of calves not sold at the optimal age $\left(n l_{B L, \text { calf }}\right)$. See Table 4 for the inputs.

The net impact of blocking milk processing companies $\left(N I_{m p, B L}\right)$ is estimated by the sum of extra costs such as the rental cost of holding suspected or contaminated milk intended for consumption, the cost of renting an extra storage facility, and the cooling cost for keeping the milk in storage:

$$
N I_{m p, B L}=\left(c p m_{m p, c o n s} \cdot n m_{B L, c o n s} \cdot \frac{i r}{365} \cdot b t_{m p}\right)+\left(r c_{m p} \cdot b t_{m p}\right)+\left(e c \cdot n m_{B L, c o n s} \cdot b t_{m p}\right)
$$

The rental cost is given by the value of milk for consumption that is being stored ( $\left.c p m_{m p, c o n s}\right)$, the amount of milk for consumption that is being stored $\left(n m_{B L, c o n s}\right)$, and the processor blocking time $\left(b t_{m p}\right)$. The inputs are given in Tables 2 and 4 . When the dioxin contamination is detected, it is assumed that the contaminated milk is stored at the stage of the chain where the contamination was before the milk was destroyed. According to Velthuis et al., 2009, the size of a processing batch of milk for consumption equals the capacity of a silo of 150.0 tons. Thus, it is assumed that 150 tons of contaminated milk will be stored. The cost of renting an extra storage site includes the monthly rental cost $\left(r c_{m p}\right)$ and $b t_{m p}$. The cooling cost is determined by the energy cost of keeping $1 \mathrm{~kg}$ of milk cool $(e c)$, the amount of milk for consumption that is being stored $\left(n m_{\text {cons }}\right)$ and $b t_{m p}$. 
Table 4. Feed, milk and livestock variables used for calculation of the financial impact of a dioxin incident on the Dutch dairy chain

\begin{tabular}{|c|c|c|c|c|c|}
\hline \multirow[b]{2}{*}{ Variable } & \multirow[b]{2}{*}{ Description } & \multirow[b]{2}{*}{ General value } & \multicolumn{2}{|c|}{ Livestock value } & \multirow[b]{2}{*}{ Remark or Source } \\
\hline & & & Cow & Calf & \\
\hline$n f_{B L}$ & Amt of feed storage (tons) & 334.0 & & & $\begin{array}{l}\text { Assumed at least } 1 \text { day of } \\
\text { production per facility }\end{array}$ \\
\hline$n f_{R C}$ & Amt of feed recalled (tons) & $310.0-2,171.0$ & & & Value varies depending on the HRP \\
\hline$n f_{R P}$ & Amt of feed replaced (tons) & $310.0-2,171.0$ & & & Value varies depending on the HRP \\
\hline$c p f_{f s}$ & $\begin{array}{l}\text { Value of feed stored at feed } \\
\text { supplier }(€ / \mathrm{kg})\end{array}$ & & 0.18 & & Assumed to be $70 \%$ of market price \\
\hline$s p f_{f s, d}$ & $\begin{array}{l}\text { Sale price of feed at supplier } \\
(€ / \mathrm{kg})\end{array}$ & & 0.26 & 1.30 & $\begin{array}{l}\text { LEI BINternet (LEI, 2010); KWIN, } \\
\text { (ASG, 2008) }\end{array}$ \\
\hline$p r_{f a t}$ & Proportion of fat in milk (\%) & 3.7 & & & $\begin{array}{l}\text { LEI and Central Bureau voor de } \\
\text { Statistiek (LEI, 2009) }\end{array}$ \\
\hline$n m_{d f, \text { raw }}$ & $\begin{array}{l}\text { Amt of raw milk produced at } \\
\text { dairy farm }(\mathrm{kg} / \text { farm/day })\end{array}$ & $1,674.0$ & & & LEI BINternet (LEI, 2010) \\
\hline$n m_{m p, r a w}$ & $\begin{array}{l}\text { Amt of raw milk destroyed at } \\
\text { milk processor (tons) }\end{array}$ & 150.0 & & & $\begin{array}{l}\text { Assuming at least one milk silo is } \\
\text { contaminated }\end{array}$ \\
\hline$n m_{B L, \text { cons }}$ & $\begin{array}{l}\text { Amt of milk for consumption } \\
\text { stored at milk processor (tons) }\end{array}$ & 695.6 & & & LEI BINternet (LEI, 2010) \\
\hline$n m_{R C, \text { cons }}$ & $\begin{array}{l}\text { Amt of milk for consumption } \\
\text { recalled at milk processor (tons) }\end{array}$ & $0-5,153.7$ & & & Value varies depending on the HRP \\
\hline$n m s_{r t, c o n s, t o t a l}$ & $\begin{array}{l}\text { Amt of milk for consumption } \\
\text { sold to consumers (tons) }\end{array}$ & $0-3,193.4$ & & & Value varies depending on the HRP \\
\hline$n m s_{r t, c o n s, d a i l y}$ & $\begin{array}{l}\text { Amt of milk for consumption } \\
\text { sold daily }(\mathrm{kg})\end{array}$ & $1,335.0$ & & & $\begin{array}{l}\text { LEI BINternet (LEI, 2010; CBS, } \\
\text { 2010) }\end{array}$ \\
\hline$s p m_{d f, \text { raw }}$ & $\begin{array}{l}\text { Sale price of raw milk at dairy } \\
\text { farm }(€ / \mathrm{kg})\end{array}$ & 0.32 & & & Velthuis et al. (2009) \\
\hline$c p m_{m p, c o n s}$ & $\begin{array}{l}\text { Value of milk for consumption } \\
\text { stored at milk processor }(€ / \mathrm{kg})\end{array}$ & 0.61 & & & Velthuis et al. (2009) \\
\hline$s p m_{m p, c o n s}$ & $\begin{array}{l}\text { Sale price of milk for } \\
\text { consumption at milk processor } \\
(€ / \mathrm{kg})\end{array}$ & 0.66 & & & Velthuis et al. (2009) \\
\hline$c p m_{r t, c o n s}$ & $\begin{array}{l}\text { Value of milk for consumption } \\
\text { stored at retailer }(€ / \mathrm{kg})\end{array}$ & 0.69 & & & Velthuis et al. (2009) \\
\hline$s p m_{r t, c o n s}$ & $\begin{array}{l}\text { Sale price of milk for } \\
\text { consumption at retailer }(€ / \mathrm{kg})\end{array}$ & 0.72 & & & Velthuis et al. (2009) \\
\hline$d f i_{d}$ & Livestock feed intake ( $\mathrm{kg} /$ day $)$ & & 6.0 & 1.83 & KWIN, (ASG, 2008) \\
\hline$n l_{B L, d}$ & $\begin{array}{l}\text { No. of livestock confined } \\
\text { (animal/mo) }\end{array}$ & & 2.0 & 6.0 & KWIN, (ASG, 2008) \\
\hline$s p l_{d}$ & $\begin{array}{l}\text { Livestock market price } \\
(€ / \text { animal) }\end{array}$ & & 570.0 & 127.0 & LEI BINternet (LEI, 2010) \\
\hline$S p_{\text {calf }>10 \text { days }}$ & $\begin{array}{l}\text { Sale price for calves }>10 \text { days } \\
\text { old }(€ / \text { calf })\end{array}$ & & & 114.3 & $\begin{array}{l}\text { Assumed } 10 \% \text { discount on market } \\
\text { price }\end{array}$ \\
\hline
\end{tabular}

Recalling. Based on the assumption that all daily production of each business unit at each stage of the chain is contaminated, it is also assumed that a total recall of all products in the market and in the supply chain takes place. Feed producer and milk processor companies are responsible for the recall procedure and related costs of their respective products. 
The net impact of recall activities at the feed supplier stage is given by labor costs $\left(L_{f s, R C, a}\right.$ ) (i.e., organization of the movement of all contaminated feed from the market and further stages of supply chain to the storage place at feed supplier facility), transport $\left(T f_{R C}\right)$ and the costs of a press release $\left(a d_{p r}\right)$ :

$$
N I_{f s, R C}=L_{f s, R C, a}+T f_{R C}+a d_{p r}
$$

The labor cost $\left(L_{f s, R C, a}\right)$ is given by equation 4 . However, the amount of labor time required to recall feed from the farms ( $\left.l t_{f s, R C}\right)$ is calculated by the amount of time required to withdraw feed from each farm $\left(d t f_{f s}\right)$, the number of farms receiving feed per day $\left(n b_{d f}\right)$, and the day when the contamination is detected $\left(H R P_{\text {days }}\right)$. The inputs are given in Tables 1 and 2.

$$
l t_{f s, R C}=d t f_{f s} \cdot n b_{d f} \cdot H R P_{d a y s}
$$

Transport cost $\left(T f_{R C}\right)$ is given by equation 9 . The $a d_{p r}$ includes costs for publishing the recall announcement on the feed supplier's web page and informing each dairy farm involved in the recall. The amount of feed recalled equals the daily production multiplied by the highrisk period minus the amount of feed that has already been consumed by the cattle. The inputs are given in Tables 1 and 4.

The net impact of recalling products at milk processor stage $\left(N I_{m p, R C}\right)$ is accounted by the sum of labor costs (i.e., organization of the movement of all contaminated milk from the market and further stages of supply chain to the storage place at milk processor facilities), transport costs, media costs for the recall announcement, and costs of refunds to consumers:

$$
N I_{m p, R C}=L_{m p, R C, a}+\left(t c m \cdot n m_{R C, \text { cons }}\right)+\left(\left(s p m_{r t, c o n s}+p s t c\right) \cdot r r \cdot n m s_{r t, c o n s, t o t a l}\right)
$$

Labor cost ( $\left.L_{m p, R C, a}\right)$ includes the labor required to bring back milk from retailer, as given by equation 4 , but the labor time to recall the milk $\left(l_{m p, R C}\right)$ is set by the amount of milk for 
Financial impact of a dioxin incident

consumption that is being recalled $\left(n m_{R C, \text { cons }}\right)$, the capacity of the truck $\left(q_{\text {truck }}\right)$, and the travel time per truck $\left(t t_{\text {truck }}\right)$ :

$l t_{m p, R C}=\frac{n m_{R C, \text { cons }}}{q_{\text {truck }}} \cdot t t_{\text {truck }}$

If the result of $n m_{R C \text {,cons }} / q_{\text {truck }}$ is not a whole number, the fraction is round up before multiplication by $t t_{\text {truck }}$.

Transport cost is calculated based on the cost of transporting $1 \mathrm{~kg}$ of milk for consumption ( $t c m)$ and the amount of milk for consumption that is being recalled $\left(n m_{R C, c o n s}\right)$. The inputs are given in Tables 1 and 4 . The amount of milk recalled equals the daily milk processed multiplied by the high-risk period minus the amount of milk already consumed. The cost of refunding the cost of milk to consumers is determined by the sale price of the milk at the retailer $\left(s p m_{r t, c o n s}\right)$, the postal cost $(p s t c)$ of sending the bar codes of milk packages to milk processor, the number of consumers asking for refunds ( $r r$ ), and the amount of milk sold to consumers $\left(n m s_{r t, c o n s, t o t a l}\right)$. The inputs are given in Tables 3 and 4.

The net impact of a milk recall at the retailer stage is calculated by the sum of the extra cost and loss revenue:

$$
N I_{r t, R C}=L_{r t, R C, a}+\left(\left(\operatorname{spm}_{r t, c o n s}-c p m_{r t, c o n s}\right) \cdot n m s_{r t, c o n s, d a i l y} \cdot t m_{n o-s t o c k}\right)
$$

where $L_{r t, R C, a}$ is the extra labor cost given by equation 4 and includes the labor for withdrawing milk from the shelves. The inputs are given in Table 1 . The lost revenue is accounted for by the retailer losses because of no milk in stock, where $s p m_{r t, c o n s}$ is the sale price of milk for consumption at the retailer, $c p m_{r t, c o n s}$ is the value of milk for consumption stored at the retailer, $n m s_{r t, c o n s, \text { daily }}$ is the amount of daily sales of milk for consumption at the retailer, and $t m_{n o-s o t c k}$ is the time during which milk is not in stock at the retailer. The inputs 
are given in Tables 2 and 4. The calculation of the amount of milk processed and consumed is based on values from the average milk processing plant, which is adjusted on each day of the crisis to the number of milk processing plants contaminated that day.

The total impact of recalling contaminated products $\left(T I_{i, R C}\right)$ is accounted for based on the number of feed or food companies involved in the recall $\left(n c_{i, R C}\right)$ at stage $i$, the cost of the media recall announcement $\left(R C_{\text {announ }}\right)$, and the costs associated with the consumer help desk ( $\left.L_{i, c h d, a}\right):$

$T I_{i, R C}=\sum_{i, R C}\left(N I_{i, R C} \cdot n b_{i}\right)+\left(n c_{i, R C} \cdot\left(R C_{\text {announ }}+L_{i, c h d, a}\right)\right)$

The costs of the media recall announcement $\left(R C_{\text {announ }}\right)$ include costs of publishing the recall announcement in newspapers $\left(a d_{p c}\right)$, the number of newspaper brands that publish the announcement ( $\mathrm{nad}$ ), the cost of designing the announcement $\left(a d_{d c}\right)$, and the press release cost $\left(a d_{p r}\right)$ (see Table 3 for the inputs):

$$
R C_{\text {announ }}=\left(\left(a d_{p c} \cdot n a d\right)+a d_{d c}+a d_{p r}\right)
$$

The costs of the consumer help desk ( $\left.L_{i, c h d, a}\right)$ reflect the extra labor for guiding and attending to customers and consumer complaints and is calculated with a general formula for labor costs (equation 4) in which the consumer help desk ( chd) is the control measure $c$. Inputs are given in Table 1.

A feed or food company has one or more feed or food production or processing sites. At the milk processor and the retailer stages, additional costs associated with the recall announcement and the extra labor at the consumer help desk are added to obtain $T I_{i, R C}$. These costs are based on the number of milk processing firms and retailer organizations involved in the crisis instead of the number of processing plants or supermarkets. 
Financial impact of a dioxin incident

Replace. The replacing activities at feed supplier stage $\left(N I_{f s, R P}\right)$ are the result of the sum of extra cost and lost revenue. The extra costs are the sum of labor costs (i.e., organizing the movement of new uncontaminated compounded feed to the dairy farms), transport costs and feed replacement costs, whereas the lost revenue is given by the profit lost because of need for replacement feed:

$$
N I_{f s, R P}=\left(L_{f s, R P, a}+T f_{R P}+\left(c p f_{f s, c o w} \cdot n f_{R P}\right)\right)+\left(\left(s p f_{f s, \text { cow }}-c p f_{f s, c o w}\right) \cdot n f_{R P}\right)
$$

where labor cost $\left(L_{f s, R P, a}\right)$ is given by equation 4 , assuming that all feed recalled is replaced, and delivering new feed takes the same labor time as recalling the contaminated feed (Table 1). Transport cost $\left(T f_{R P}\right)$ is given by equation $9, c p f_{f s, c o w}$ is the value of the feed, which is assumed to be the cost price, and $n f_{R P}$ is the amount of feed replaced. It is assumed that the total amount of feed recalled is replaced. The inputs are given in Table 4.

Destruction. The net impact of destruction measures in the feed supplier stage $\left.N I_{f s, D T}\right)$ is given by the extra cost of incineration and the transport costs for contaminated feed, and the lost revenue regarding the loss of the feed destroyed:

$$
N I_{f s, D T}=\left(\left(i c_{l o w} \cdot\left(n f_{B L}+n f_{R C}\right)\right)+T f_{D T}\right)+\left(s p f_{f s, c o w} \cdot\left(n f_{B L}+n f_{R C}\right)\right)
$$

where $i c_{\text {low }}$ represents the cost to incinerate $1 \mathrm{~kg}$ of feed at low-risk material tariff, $T f_{D T}$ is the transport cost of feed for incineration given by the equation 9, and $\operatorname{spf} f_{f s, \text { cow }}$ is the end value of feed at $f$ s (Table 1, 3 and 4). The amount of feed for incineration equals the contaminated feed stored $\left(n f_{B L}\right)$ plus the feed recalled $\left(n f_{R C}\right)$ (see Table 4 for the inputs).

The net impact of destruction activities at dairy farm stage $\left(N I_{d f, D T}\right)$ is given by the net impact of contaminated milk destroyed. The $N I_{d f, D T}$ includes extra cost for the skimming (i.e., separating cream and milk which are incinerated by different methods), incineration costs and milk transport costs, and lost revenue is losses incurred because the milk is not sold: 
$N I_{d f, D T}=\left(s k c \cdot n m_{d f, r a w} \cdot b t_{d f}\right)+\left(i c_{l o w} \cdot n m_{d f, r a w} \cdot\left(1-p r_{f a t}\right) \cdot b t_{d f}\right)+$

$\left(i c_{\text {high }} \cdot n m_{d f, \text { raw }} \cdot p r_{\text {fat }} \cdot b t_{d f}\right)+\left(t c m \cdot n m_{d f, \text { raw }} \cdot b t_{d f}\right)+$

$\left(t c m \cdot n m_{d f, r a w} \cdot\left(1-p r_{f a t}\right) \cdot b t_{d f}\right)+\left(t c m \cdot n m_{d f, r a w} \cdot p r_{f a t} \cdot b t_{d f}\right)+$

$\left(\operatorname{spm}_{d f, \text { raw }} \cdot n m_{d f, \text { raw }} \cdot b t_{d f}\right)$

where $s k c$ is the skimming cost, ic the incineration cost, which is different for high-risk materials $\left(i c_{h i g h}\right)$ or low-risk materials $\left(i c_{l o w}\right), n m_{d f, r a w}$ is the amount of contaminated raw milk to be destroyed at the dairy farm, $p r_{f a t}$ is the proportion of fat in the milk, and $b t_{d f}$ is the farm blocking period. The inputs are given in Tables 2 through 4 . The transport costs represent the transport of raw milk from farm to skimming plant to incineration plant, where tcm is the cost of transporting $1 \mathrm{~kg}$ of raw milk or cream (Table 1). The losses for milk destroyed are based on the sale price of raw milk at the dairy farm $\left(s p m_{d f, \text { raw }}\right)$ (see Table 4 for the inputs). At dairy farm stage, daily milk production is estimated at $1,674 \mathrm{~kg}$ given by an average farm of 76 dairy cows per farm in production and a milk yield of 22 liters per cow. It is assumed that the total amount of milk produced per farm in the blocking period is destroyed.

The net impact for destruction activities at milk processor stage $\left(N I_{m p, D T}\right)$ includes extra cost and lost revenue. The extra cost are defined by the skimming, incineration and transport costs of raw milk and milk for consumption, and the lost revenue is losses incurred because of the destruction of milk for consumption:

$$
\begin{aligned}
& N I_{m p, D T}=\left(s k c \cdot n m_{m p, r a w}\right)+\left(i c_{l o w} \cdot n m_{m p, r a w} \cdot\left(1-p r_{f a t}\right)\right)+ \\
& \left(i c_{h i g h} \cdot n m_{m p, r a w} \cdot p r_{f a t}\right)+\left(i c_{h i g h} \cdot\left(n m_{B L, \text { cons }}+n m_{R C, \text { cons }}\right)\right)+ \\
& \left(t c m \cdot n m_{m p, \text { raw }}\right)+\left(t c m \cdot n m_{m p, \text { raw }} \cdot\left(1-p r_{f a t}\right)\right)+ \\
& \left(t c m \cdot n m_{m p, \text { raw }} \cdot p r_{f a t}\right)+\left(t c m \cdot\left(n m_{B L, \text { cons }}+n m_{R C, \text { cons }}\right)\right)+ \\
& \left(\left(\mathrm{spm}_{m p, \text { cons }}-s p m_{d f, \text { raw }}\right) \cdot\left(n m_{B L, \text { cons }}+n m_{R C, \text { cons }}\right)\right)
\end{aligned}
$$

where $s k c$ is the cost of skimming $1 \mathrm{~kg}$ of raw milk and ic is the incineration cost for $1 \mathrm{~kg}$ of high- or low-risk material (Table 3). The amount of milk to be destroyed is given by the type of milk, i.e., raw $\left(n m_{m p, r a w}\right)$ and milk for consumption $\left(n m_{B L, c o n s}\right)$, and the amount of 
Financial impact of a dioxin incident

contaminated milk for consumption that is to be stored $\left(n m_{B L, c o n s}\right)$ and recall $\left(n m_{R C, c o n s}\right)$ by milk processor. The inputs are given in Table 4. It is assumed that transport costs $(\mathrm{tcm})$ are the same for all type of milk products (raw milk, cream and milk for consumption) at stages $d f$ and $m p$. The inputs are given in Table 1 . The losses for destroying milk for consumption are given by the total value of milk destroyed, where $s p m_{m p, c o n s}$ is the sale price of $1 \mathrm{~kg}$ of milk for consumption at the milk processor, and $s p m_{d f, \text { raw }}$ is the sale price of $1 \mathrm{~kg}$ of raw milk at the dairy farm (see Table 4 for inputs).

In The Netherlands, incineration of dioxin-contaminated products is carried out for strict control of the possible emission of pollutants. Consequently, the possible environmental costs of destroying contaminated products are assumed to be included in the incineration cost.

The total impact of the risk analysis $\left(T I_{r a}\right)$ carried out for the dairy chain as a whole equals the sum of the labor costs $\left(L_{r a, a}\right)$ for all $a$, which is given by the general equation of labor costs (equation 4).

Sensitivity analysis. The sensitivity analysis was carried out to determine the effect of each input on the total financial impact obtained by the MiDCIM, based on a univariate analysis. This analysis was done by increasing and decreasing each input value one at a time by $10 \%$ and recording the change in the total impact value calculated as a percentage. This analysis was carried out with Microsoft Office Excel 2003 using the add-in program TopRank 5.5 for Excel from Palisade Decision Tools (PC, 2010).

\subsection{Results}

Total financial impact and stages of the chain. Based on the food chain previously defined, the results of the total financial impact are presented by stage of the chain, by the control measures applied during an incident, and by the most influential inputs of the model. 
The model predicted that the total financial impact of a dioxin incident would grow from $€ 2.5$ million for an HRP of 1 to $€ 141.2$ million for an HRP of 14 days. On day 1, only the feed supplier and the dairy farm stages are involved in the incident. On day 2, the milk processor also is involved, and on consecutive days the retailer begins to become involved. The milk processor stage is the main contributor to the total financial impact, which increases from $€ 0.9$ million on day 1 to $€ 108.5$ million on day 14 . The dairy farm stage is the most influential stage, whose contribution increases from $€ 2.1$ million to $€ 29.0$ million from day 1 to day 14 (Fig 2A). Although the daily increase in the number of contaminated milk processors is less than that of the dairy farms or retailers, the financial impact at the milk processor stage during the HRP is on average 2.1 and 39.9 times higher than the average impact at the dairy farm or the retailer stages, respectively, because the contribution of each milk processing plant is larger than the contribution of any single retailer or dairy farm.

The contribution of the milk processor stage to the total financial impact value increases with time, from $16.7 \%$ on day 2 to $76.9 \%$ on day 14 . This increase is even higher at earlier days of the HRP than at later days. Looking at the contribution of each stage of the chain, Figure 2 shows that the relative contribution of the dairy farm stage decreases from $85.0 \%$ to $20.5 \%$ with an increasing HRP. This decrease is higher at lower values of the HRP. Although the contribution of the dairy farm decreases with time, this contribution is higher than that of the milk processor stage until day 4, whereas after this day, the relation is inverted. The relative contribution of the feed supplier stage decreases from $15.0 \%$ at an HRP of 1 day to $1.2 \%$ at an HRP of 14 days. Again, larger changes are seen in the early days of the HRP. Figure 2 also shows the relative contribution of the retailer stage, which starts on day 3 and remains constant during the rest of the 11 days of the HRP (i.e., an average contribution of $1.6 \%)$ 
Financial impact of a dioxin incident
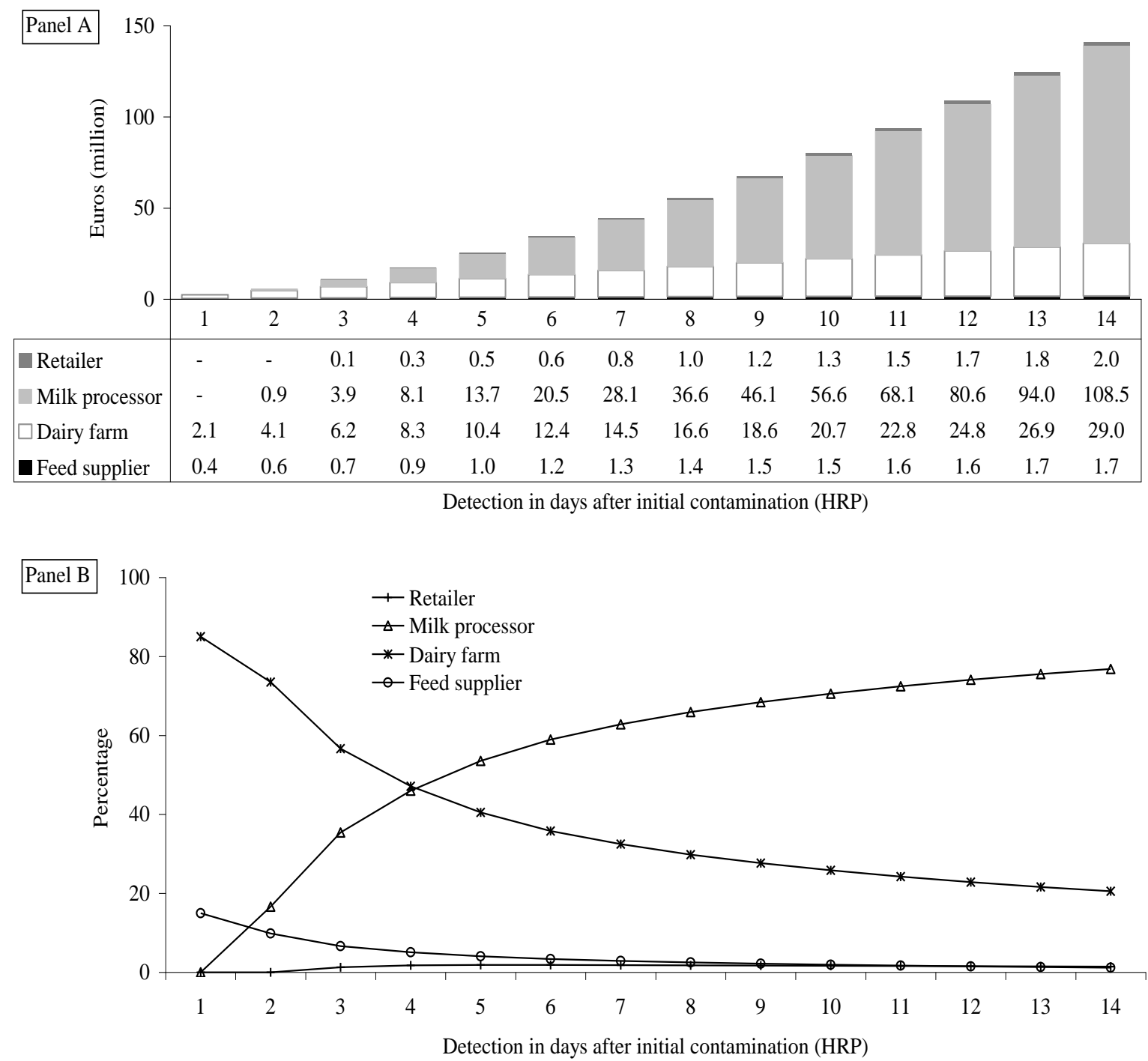

Figure 2. Absolute (A) and relative (B) contribution of each stage of the dairy chain to the total financial impact of a possible dioxin incident detected on different days after the incident started (HRP).

Total financial impact and control measures. The absolute contribution of all control measures to the total financial impact increases with the HRP (Fig. 3A). Measures related to the destruction of contaminated products $(D T)$ are the most salient contributors to the total financial impact, from $€ 1.6$ million on day 1 to $€ 121.0$ million on day 14 . To a lesser extent, the activities associated with sampling and testing ( $S T$ ) and with the recall of suspected or contaminated products ( $R C$ ) follow, contributing from $€ 0.6$ million on day 1 to $€ 16.5$ million 
on day 14. Together, these three measures represent, on average, more than $92.0 \%$ of the total financial impact. The rest of the measures contribute less.

The relative contribution of all control measure to the total financial impact decreases with an increasing HRP, except for the recall and the destruction measures (Fig. 3B). In terms of the absolute contribution, the most influential measure is $D T$, with a continuous increase from day $1(66.2 \%)$ to day $14(85.7 \%)$. The contribution of $R C$ increases from $1.9 \%$ on day 3 to $5.6 \%$ on day 14 , whereas the contribution of sampling and testing ( $S T$ ) decreases with time from $25.6 \%$ to $6.0 \%$. The other measures have minor contributions, always less than $5.0 \%$ during the entire HRP. 
Financial impact of a dioxin incident
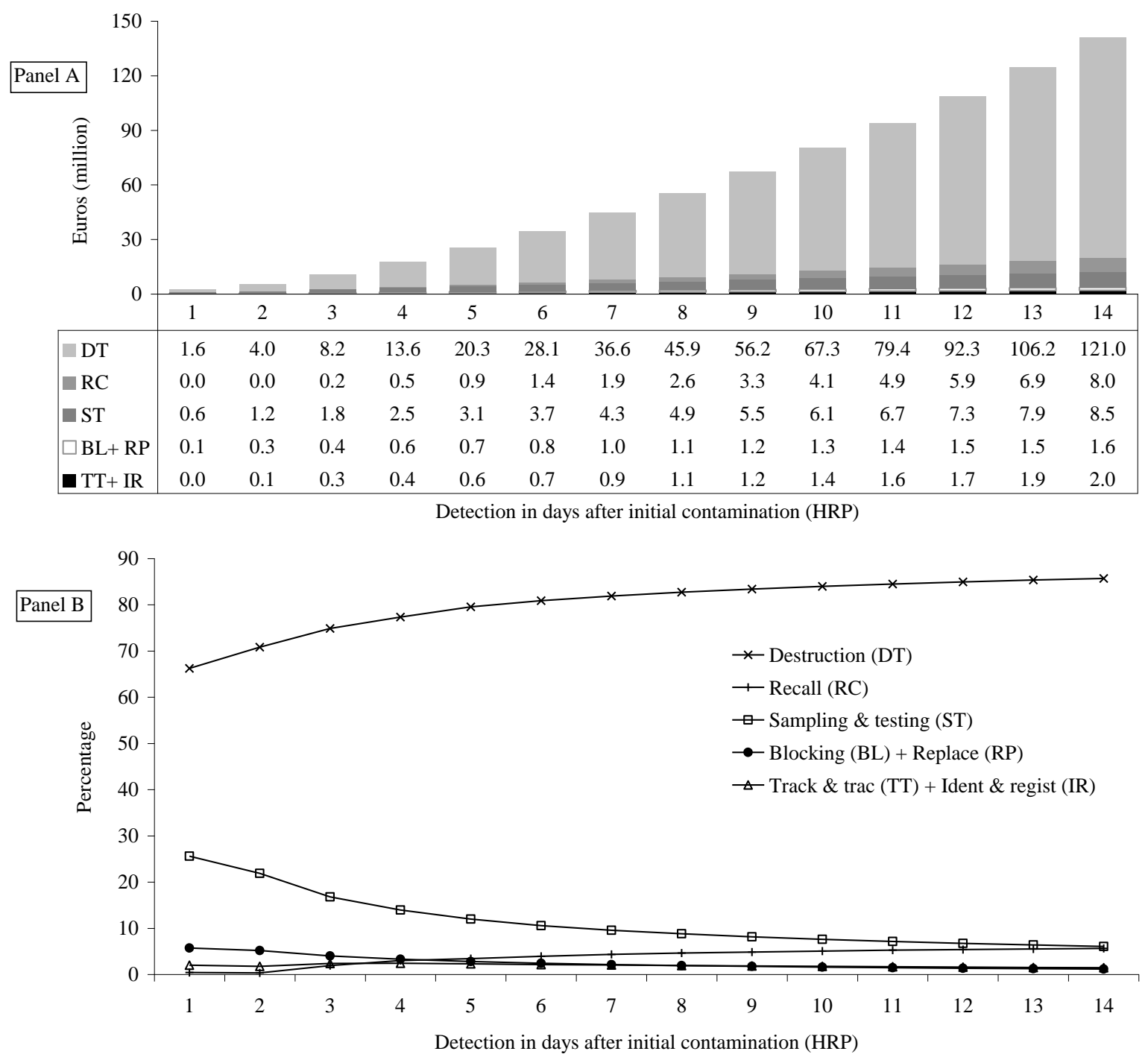

Figure 3. Absolute (A) and relative (B) contribution of each group of control measures to the total financial impact of a dioxin incident in the dairy chain detected on different days after the incident started (HRP).

The major costs of the control measures $D T, R C$ and $S T$ are at the dairy farm and milk processor stages (Table 5), where more than $90.0 \%$ of the total impact relates to the destruction of contaminated products and livestock ( $D T$ ). The relative contribution of the dairy farm stage decreases from $86.3 \%$ on day 1 to $16.1 \%$ on day 14 , whereas the contribution of the milk processor increases from $22.3 \%$ on day 2 to $83.2 \%$ on day 14 . The $R C$ is mainly contributed by the milk processor stage, from $72.1 \%$ on day 3 to $90.2 \%$ on day 14 , and to a 
lesser extent by the retailer stage, whose contribution decreases from $14.5 \%$ on day 4 to $8.4 \%$ on day 14 . The dairy farm stage mainly contributes to the total impact due to $S T$ activities, with a constant contribution of about $96.0 \%$ during each day of the HRP.

Table 5. Distribution of net costs of three important measures used to control the impact of a dioxin incident over the dairy chain stages

\begin{tabular}{|c|c|c|c|c|c|c|c|c|c|c|c|c|c|c|c|}
\hline \multirow[b]{2}{*}{$\begin{array}{l}\text { Control } \\
\text { measure }\end{array}$} & \multirow[b]{2}{*}{ Stage } & \multicolumn{14}{|c|}{$\%$ contribution to the financial impact after initial contamination } \\
\hline & & Day 1 & Day 2 & Day 3 & Day 4 & Day 5 & Day 6 & Day 7 & Day 8 & Day 9 & Day 10 & Day 11 & Day 12 & Day 13 & Day 14 \\
\hline \multirow[t]{5}{*}{$\mathrm{DT}^{a}$} & Feed supplier & 13.7 & 8.0 & 5.0 & 3.6 & 2.8 & 2.2 & 1.9 & 1.6 & 1.4 & 1.2 & 1.1 & 0.9 & 0.8 & 0.7 \\
\hline & Dairy farm & 86.3 & 69.7 & 50.8 & 41.0 & 34.2 & 29.7 & 26.6 & 24.2 & 22.3 & 20.7 & 19.3 & 18.1 & 17.0 & 16.1 \\
\hline & Milk processor & & 22.3 & 44.2 & 55.4 & 63.0 & 68.0 & 71.5 & 74.2 & 76.3 & 78.1 & 79.7 & 81.0 & 82.2 & 83.2 \\
\hline & Retailer & & & & & & & & & & & & & & \\
\hline & Entire chain & 100 & 100 & 100 & 100 & 100 & 100 & 100 & 100 & 100 & 100 & 100 & 100 & 100 & 100 \\
\hline \multirow[t]{5}{*}{$\mathrm{RC}^{b}$} & Feed supplier & 100 & 100 & 13.4 & 7.0 & 5.3 & 3.9 & 3.2 & 2.7 & 2.4 & 2.1 & 1.9 & 1.7 & 1.5 & 1.4 \\
\hline & Dairy farm & & & & & & & & & & & & & & \\
\hline & Milk processor & & & 72.1 & 76.1 & 77.8 & 81.1 & 83.1 & 84.7 & 86.0 & 87.1 & 88.1 & 88.9 & 89.6 & 90.2 \\
\hline & Retailer & & & 14.5 & 16.8 & 16.9 & 15.0 & 13.7 & 12.5 & 11.6 & 10.8 & 10.1 & 9.5 & 8.9 & 8.4 \\
\hline & Entire chain & 100 & 100 & 100 & 100 & 100 & 100 & 100 & 100 & 100 & 100 & 100 & 100 & 100 & 100 \\
\hline \multirow[t]{5}{*}{$\mathrm{ST}^{c}$} & Feed supplier & 3.8 & 1.9 & 1.3 & 1.0 & 0.8 & 0.7 & 0.6 & 0.5 & 0.4 & 0.4 & 0.4 & 0.3 & 0.3 & 0.3 \\
\hline & Dairy farm & 96.2 & 97.3 & 97.7 & 97.9 & 98.0 & 98.1 & 98.1 & 98.1 & 98.2 & 98.2 & 98.2 & 98.2 & 98.3 & 98.3 \\
\hline & Milk processor & & 0.8 & 1.0 & 1.2 & 1.2 & 1.3 & 1.3 & 1.4 & 1.4 & 1.4 & 1.4 & 1.4 & 1.4 & 1.4 \\
\hline & Retailer & & & & & & & & & & & & & & \\
\hline & Entire chain & 100 & 100 & 100 & 100 & 100 & 100 & 100 & 100 & 100 & 100 & 100 & 100 & 100 & 100 \\
\hline
\end{tabular}

Sensitivity analysis. The most influential inputs for the total financial impact of a dioxin incident on the dairy chain are the blocking time of a farm followed by the daily amount of milk produced at the average dairy farm, the daily amount of milk processed at an average milk processor, the sale price of milk for consumption from the milk processor, and the destruction costs of high-risk materials (Fig. 4). The total effect of these factors on the total financial impact is less than $8.0 \%$. The relative importance of the farm blocking time and the daily amount of milk produced at the farm decreases with an increase of the HRP (from about $6 \%$ to about $1.5 \%$ ). The opposite effect was seen for the amount of milk processed per day and the sale price of milk at the milk processor stage. The effects of these factors increase with time from about 2.0 and $1.5 \%$ to more than 7.0 and $6.0 \%$, respectively (Fig. 4). The 
Financial impact of a dioxin incident

effect of the destruction cost of high-risk materials increases from about $2.0 \%$ on day 3 to almost $3.0 \%$ on day 14 . Input values with less than a $1.0 \%$ effect on the total financial impact are not shown. Figure 4 shows the results of the sensitivity analysis only when increasing (by $10 \%$ ) each individual input value because these results are quite similar to those when decreasing (by 10\%) each individual input value. Consequently, the values for the decreased inputs are not shown.

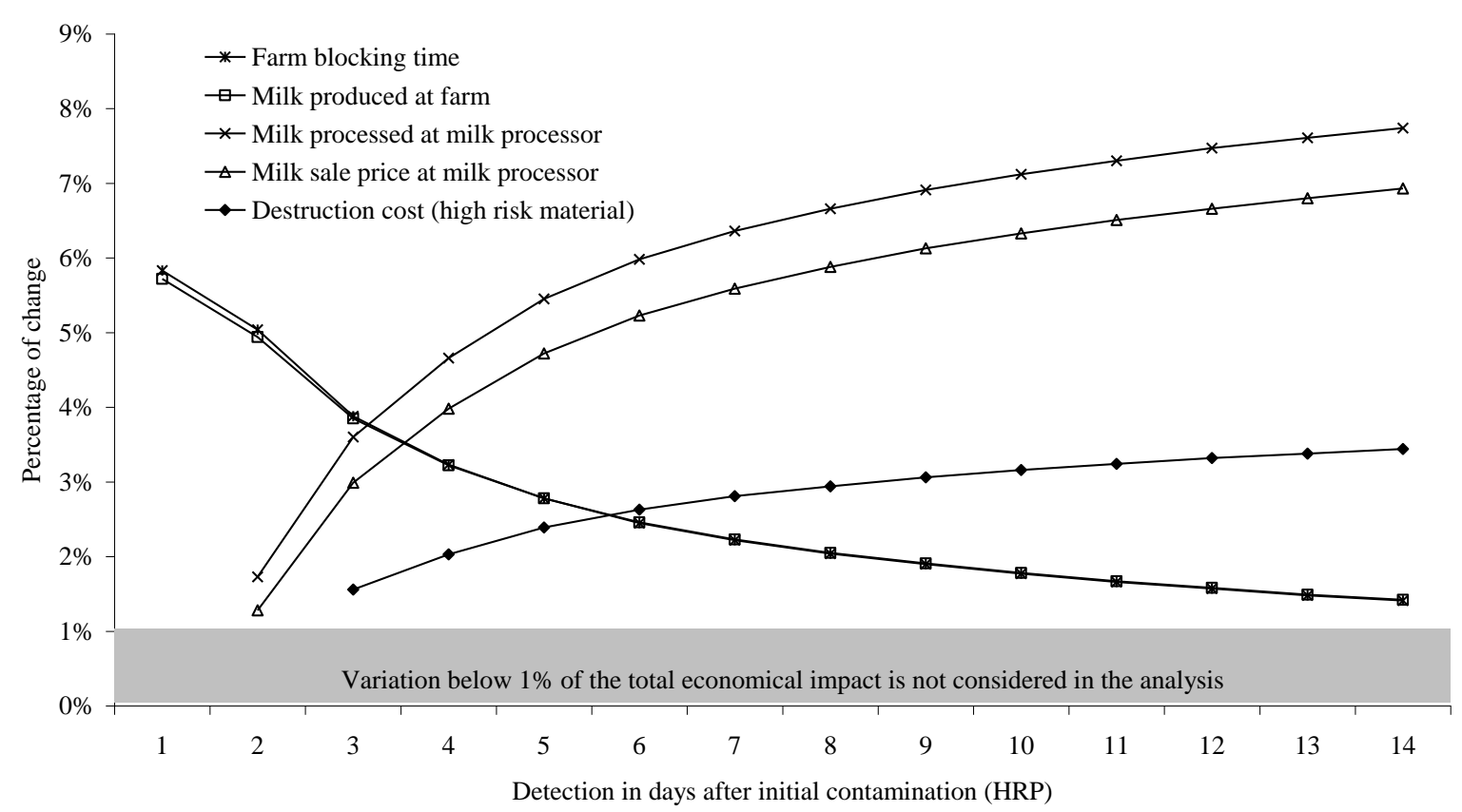

Figure 4. Relative change in total financial impact of a dioxin incident in the dairy chain when increasing the contribution of the most influential inputs by $10 \%$ at each day of the HRP.

\subsection{Discussion}

The MiDCIM is the first published model to quantify the financial impact of a dioxin incident in a dairy chain and each of its stages and to allow study of the determinants of the impact. The modeled chain includes a fixed distribution network of possible contaminated products consisting of one feed supplier production plant and a maximum of 714 dairy farms, 26 milk processing sites, and 2,664 retailers. This network plays an important role when calculating the financial impact. The number of agri-food business involved in a dioxin 
incident and the times at which they are involved differ among incidents. Consequently, the linear rate of accretion and the absolute values of the financial impact will vary depending on the network introduced in the model. For example, if the supply of feed or milk were limited to one city or area (local chain) in The Netherlands, the impact would be lower than if the supply of feed or milk were delivered at nationally. The choice of the network in the current study was based on official statistics and expert advice of the Dutch dairy sector; it is considered to represent the real Dutch dairy network as closely as possible.

The MiDCIM is deterministic and, therefore, does not include the variation or uncertainties around the estimation of the net costs. A stochastic model might be more accurate but only if the necessary information were available, which was not the case in the present study. Nevertheless, the deterministic approach using inputs from reliable data sources applied in this study provide valid information on the financial impact of a dioxin incident on a dairy product supply chain. A deterministic model is easier to explain and to transmit to professionals with different backgrounds, such as risk managers and policy makers in the private and public sectors (Dijkhuizen and Morris, 1997).

The total financial impact of a dioxin crisis increases with an increasing HRP. Intuitively, this is as expected, given the fact that the financial impact increases with time. A longer HRP suggests that a higher amount of businesses will be involved, with the resultant higher financial impact of a dioxin contamination incident in milk. No other published studies have assessed the relationship between the HRP and the financial consequences of a food safety incident. However, comparable results are available for the relationship between the HRP and the size of an animal disease outbreak. The HRP is very important when calculating the size of an outbreak because it provides the time framework during which the contamination is spread freely without being detected (Horst et al., 1998). In the case of a classical swine fever outbreak, the length of the HRP is an important indicator for the possible size of the outbreak 
Financial impact of a dioxin incident

(Mangen et al., 2003). A longer HRP could imply an increased impact of an incident, in terms of both the number of business affected and the size of the financial impact. The total financial impact of a dioxin contamination event could reach a limit depending on the source of the contamination. If the contamination were due to a batch of feed ingredients, the total impact could decrease to zero once the last batch of contaminated food related to that feed ingredient is consumed. This hypothesis is supported by a study of Velthuis et al. (2009), in which a batch of milk for consumption was completely consumed $160 \mathrm{~h}$ after being processed. Consequently, the total direct recall costs of milk, as part of the total financial impact, will be zero. However, if the feed production process were the origin of the contamination, the total impact could remain at maximum values after the HRP, provided the contamination is detected. In the Irish pork-dioxin incident of 2008, in which the origin of the dioxin-contamination was the inappropriate use of a drier motorized with "dirty" fuel in the feed production process (Alldrick, 2010). Maximum values of the total impact were persistent until the incident was detected.

In the MiDCIM, the costs associated with the milk and then the dairy farmers contribute most to the total financial impact, whereas the costs associated with the feed supplier and retailer contribute the least. This finding is in agreement with the results obtained by Buzby and Chandran (2003), who calculated the economic impact of the Belgian dioxin crisis of 1999. During this crisis, the most affected stages of the chain were the processors and farmers and, to a lesser extent, the retailers and the feed businesses. This result was due to the limited amount of contaminated feed relative to the total amount of feed produced and to the number of contaminated farms and processors affected by the initial feed contamination event. In this research, the results for the milk processor were as expected because a "zero risk" scenario was assumed, which means that although the contamination might have been detected in only a small part of the milk processed (i.e., one storage silo), we assumed that the entire amount 
of the milk processed that day was contaminated. Consequently, all processed milk would need to be recalled and destroyed. This assumption could be relaxed if the milk processor wanted to determine whether the level of dioxins could be reduced below the European Commission maximum residual level for dioxins (EC, 2001, 2006) because of the effect of dilution. Thus, the total financial impact would be reduced. The use of the zero risk assumption in this study is supported by the fact that there is no information available on the underlying decision making process. In this study, we assumed that all produced milk was converted into milk for consumption. The model does not include the contributions to the total financial impact made by other dairy products with high monetary value and potentially high dioxin contamination, i.e., products with a high percentage of fat, such as cheese. Therefore, the total dioxin impact could be underestimated when using the assumption of all milk being used for consumption but could be overestimated when using the assumption that ignores the dilution effect.

As a consequence of the milk for consumption assumption, the total financial impact at the dairy farm stage could be lower than that at the milk processor stage. However, in the current study, the total impact at the dairy farm stage is relatively high compared with that of the other chain stages, possibly because of the longer period of time that a farm is blocked and/or restricted from selling milk until the dioxin levels fall below the European Commission maximum residual level. With this assumption, the contaminated livestock is not destroyed and, consequently, the farm blocking time is longer, as occurred in the Dutch dioxin incident of 2004. Reducing the blocking time by sacrificing the livestock could result in a reduced financial impact in the short term, but probably not in the long term because of such factors as loss of the investment in the genetic improvements made to the livestock herd.

In the MiDCIM, only one feed production site is considered, but even with a single site of origin the contamination may spread over a wide area with resulting catastrophic financial 
Financial impact of a dioxin incident

consequences for the entire food chain. However, in The Netherlands only 100 feed producing sites deliver feed to almost 30,000 farms, which then sell their products to more than 80 processing plants (Meuwissen et al., 2009).

Recall activities in all stages of the chain, and specifically at the milk processor, have a major effect on the total financial impact on a dioxin incident. However, the total impact obtained in the MiDCIM includes only the direct costs related to recall measures and does not take into account intangible costs such as the damage to long term relationships among producers, processors, traders, and consumers and indirect costs such as reduction of product prices and loss of sales, liability claims and costs associated with consumer illness (Velthuis et al., 2009). Therefore, the contribution of the recall measures to the total impact will be higher than that calculated with this model.

This model also does not take into account indirect costs related to control measures applied when controlling a crisis, such as the environmental cost of the incineration of dioxincontaminated products. Because The Netherlands maintains strict control of emission and pollutants produced by such incineration procedures, it is assumed that the environmental cost is included in the incineration cost. However, this could not be the general case when applying the MiDCIM in other country.

Although the cost per sample for testing for dioxin is high, its influence on the impact value is not significant. This finding indicates the importance of an intensive monitoring surveillance program, mainly in the first chain stages, as a preventive measure for early dioxin detection to reduce HRP and minimize the total impact. Reducing the HRP by increasing monitoring could be worthwhile as demonstrated by the reduction of the financial impact when the contamination is detected on day 1 instead of day 14. An accurate monitoring surveillance program could prevent an incident from becoming a crisis. Consequently, it reduces the risk of unilateral barriers to Dutch agricultural products that can be imposed by 
export markets in other countries, as happened in 1999 (Buzby and Chandran, 2003). Although intensifying the surveillance system is likely to increase the costs for monitoring and inspection, this cost increase should be balanced against the expected decrease in the HRP and the likelihood of a dioxin incident occurring.

An important addition to this study would be an assessment of the possible financial of a dioxin incident on Dutch exports, given that dioxin is highly concentrated in animal fat and that Dutch dairy and meat products are aggressively marketed to other countries. Cheese and pork products represented more than $50 \%$ of the total export value of all Dutch dairy exports in 2008 and 2009 (PZ, 2008; PVE, 2010). At the same time, this addition could diversify the model for application to other products involving more complex production processes.

This study offers a pragmatic tool for industry and governmental institutions, which are always looking for better strategies to guarantee food safety. The model allows application of real data to quantify the financial impact of a milk dioxin contamination event in a dairy chain in another country or region. Consequently, valuable and understandable outcomes are obtained that can allow managers to quantify the size of a dioxin incident, to identify the main food chain stages affected, and to identify possible critical points for preventing and mitigating the risk when dioxin incidents occur. 
Financial impact of a dioxin incident

\section{References}

Agricultural Economics Research Institute (LEI). 2010. LEI's Farm Accountancy Data Network, BINternet. Available at: http://www.lei.wur.nl/UK/statistics/Binternet/ Accessed 12 July 2010.

Agricultural Economics Research Institute (LEI) and Centraal Bureau voor de Statistiek (CBS). 2009. Land- en tuinbouwcijfers 2009. Rapport 2009-069. LEI (Agricultural Economics Research Institute), Wageningen University and Research Center, The Hague, The Netherlands.

Alldrick, A. J. 2010. 2008: the year of melamine and dioxin. What lessons can we learn? Agro Food Ind. Hi-Tech. 21:6-8.

Animal Sciences Group (ASG), A. J. J. Bosma, A. G. Evers, W. Harlaar, I. Vermeij, and I. Vink. 2008. Kwantitatieve informatie veehouderij 2008-2009 (KWIN). Wageningen UR Livestock Research, Lelystad, The Netherlands.

Baars, A. J., M. I. Bakker, R. A. Baumann, P. E. Boon, J. I. Freijer, L. A. P. Hoogenboom, R. Hoogerbrugge, J. D. v. Klaveren, A. K. D. Liem, W. A. Traag, and J. d. Vries. 2004. Dioxins, dioxin like PCBs and non-dioxin-like PCBs in foodstuffs: occurrence and dietary intake in The Netherlands. Toxicol. Lett. 151:51-61.

Behnisch, P. A. 2005. Dioxins and dioxin-like PCBs - the show goes on in Europe. In The European food \& drink review, analysis and control. Food analysis, packaging, ingredients, processing. Andreas Lange Publishing, Jalon, Spain. 1:13-17.

Bernard, A., F. Broeckaert, G. De Poorter, A. De Cock, C. Hermans, C. Saegerman, and G. Houins. 2002. The Belgian PCB/dioxin incident: Analysis of the food chain contamination and health risk evaluation. Environ. Res. 88(1):1-18. 
Bernard, A., C. Hermans, F. Broeckaert, G. De Poorter, A. De Cock, and G. Houins. 1999. Food contamination by PCBs and dioxins. Nature 401(6750):231-232.

Buzby, J. C., and R. Chandran. 2003. The Belgian Dioxin Crisis and its effects on Agricultural Production and Exports, p125-139. In J.C. Buzby (ed.), International Trade and Food Safety: Economic Theory and Case Studies. Agricultural Economic Report No. 828. Economic Research Service. USDA.

Centraal Bureau voor de Statistiek (CBS). 2010. STATLINE. Available at: http://statline.cbs.nl/StatWeb/?LA=en Accessed: 15 July 2010.

De Meulenaer, B. 2006. Chemical hazards. p. 145-208. In P.A. Luning, Devlieghere, F., Verhé, R. (ed.), Safety in the agri-food chain. Wageningen Academic Publishers, Wageningen, The Netherlands.

De Mul, A., M. I. Bakker, M. J. Zeilmaker, W. A. Traag, S. P. J. van Leeuwen, R. L. A. P. Hoogenboom, P. E. Boon, and J. D. van Klaveren. 2008. Dietary exposure to dioxins and dioxin-like PCBs in The Netherlands anno 2004. Regul. Toxicol. Pharmacol. 51(3):278-287.

Dijkhuizen, A. A., and R. S. Morris. 1997. Animal health economics. Sidney: University of Sidney, Postgraduate Foundation in Veterinary Science. University of Sydney, Sydney, Australia.

European Commission (EC). 2000. Report of experts participating in Task 3.2.5 "Assessment of dietary intake of dioxins and related PCBs by the population of EU Member States". In Reports on Tasks for Scientific Cooperation. European Commission, Health and Consumer Protection Directorate-General, Brussels. 
Financial impact of a dioxin incident

European Commission (EC). 2001. Council Regulation (EC) No 2375/2001 of 29 November 2001 amending Commission Regulation (EC) No 466/2001 setting maximum levels for certain contaminants in foodstuffs. Off. J. Eur.Comm. L321:1-5.

European Commission (EC). 2002. Regulation (EC) No 178/2002 of the European Parliament and of the Council of 28 January2002 laying down the general principles and requirements of food law, establishing the European Food SafetyAuthority and laying down procedures in matters of food safety. Off. J. Eur.Comm. L31:1-24.

European Commission (EC). 2006. Commission regulation (EC) No 199/2006 of 3 February 2006 amending Regulation (EC) No 466/2001 setting maximum levels for certain contaminants in foodstuffs as regards dioxins and dioxin-like PCBs. Off. J. Eur. Comm. L32:34-38.

European Feed Manufacturers Federation (FEFAC). 2008. Feed \& food, statistical yearbook 2008. European Feed Manufacturers Federation. Brussels.

Hayward, D. G., D. Nortrup, A. Gardner, and M. Clower. 1999. Elevated TCDD in chicken eggs and farm-raised catfish fed a diet with ball clay from a southern United States mine. Environ. Res. 81:248256.

Hogenboom, L. A. P. 10 December 2009. Personal Communication

Hoogenboom, L. A. P. 2009. Dioxins, polychlorinated biphenyls and brominated flame retardants. p. 383-405. In I. Shaw (ed.), Endocrine disrupting chemicals in food. Woodhead Publishing Ltd. Oxford.

Hoogenboom, R., T. Bovee, L. Portier, G. Bor, G. Van Der Weg, C. Onstenk, and W. Traag. 2004. The German bakery waste incident; Use of a combined approach of screening and confirmation for dioxins in feed and food. Talanta. 63(5):1249-1253. 
Hoogenboom, R., M. Zeilmaker, J. van Eijkeren, K. Kan, M. Mengelers, D. Luykx, and W. Traag. 2010. Kaolinic clay derived PCDD/Fs in the feed chain from a sorting process for potatoes. Chemosphere. 78(2):99-105.

Horst, H. S., A. A. Dijkhuizen, R. B. M. Huirne, and P. W. De Leeuw. 1998. Introduction of contagious animal diseases into The Netherlands: elicitation of expert opinions. Livest. Prod. Sci. 53:253-264.

Huwe, J. K., and D. J. Smith. 2005. Laboratory and on-farm studies on the bioaccumulation and elimination of dioxins from a contaminated mineral supplement fed to dairy cows. J. of Agric. Food Chem. 53(6):2362-2370.

Kim, M., S.-W. Choi, J. Y. Park, D.-G. Kim, Y.-H. Bong, J. H. Jang, S. O. Song, G. S. Chung, and P. Guerrero. 2009. Dioxin contamination of Chilean pork from zinc oxide in feed. Organohalogen Compd. 71:179-182.

Lok, C. and D. Powel. 2000. The Belgium Dioxin Crisis of the Summer of 1999: A Case Study in Crisis Communication and Management. Technical Report 13. Department of Food Science, University of Guelph, Guelph, Ontario, Canada.

Malisch, R. 2000. Increase of the PCDD/F-contamination of milk, butter and meat samples by use of contaminated citrus pulp. Chemosphere. 40(9-11):1041-1053.

Mangen, M. J. J., M. Nielen, and A. M. Burrell. 2003. Simulated epidemiological and economic effects of measures to reduce piglet supply during a classical swine fever epidemic in the Netherlands. Rev. Sci. Tech. Off. Int. Epizoot. 22:811-822. 
Financial impact of a dioxin incident

Meuwissen, M. P. M., A. L. A. Van Andel, M. A. P. M. Van Asseldonk, and R. B. M. Huirne. 2009. Eliciting processing industry damage from feed crises. Br. Food J. 111(8):878-892.

Meuwissen, M. P. M., M. A. P. M. Van Asseldonk, and R. B. M. Huirne. 2008. Liability risks in agri food supply chains: the case of wet feed. Presented at the 12th Eurpean Association of Agricultural Economics Congress. Gent, Belgium, 26 to 29 August 2008.

Palisade-Coorporation (PC). 2010. TopRank. In 5.5 (ed.) Palisade Corporation, Newfield, NY.

Productschappen Vee, Vlees en Eiren (PVE). 2010. Livestock, meat and eggs in the Netherlands 2010. Productschappen Vee, Vlees en Eieren, Zoetermeer, The Netherlands.

Productschap Zuivel (PZ). 2008. Statistisch jaaroverzicht 2008. Productschap Zuivel, Zoetermeer, The Netherlands.

Tlustos, C. 2009a. The dioxin contamination incident in Ireland 2008. Organohalogen Compd. $71: 1172-1176$.

Tlustos, C. 2009b. The dioxin crisis in Ireland 2008 - challenges in risk management and risk communication. Organohalogen Compd. 71:1169-1171.

TNT Post (TNT). 2010. Available at: http://www.tntpost.nl/zakelijk/ Accessed 10 July 2010.

Traag, W. A., M. J. B. Mengelers, and R. Malisch. 1999. Studies on the uptake and carry over of polychlorinated debenzodioxins and dibenzofurans from contaminated citrus pulp pellets to cows milk. Organohalogen Compd. 42:201-204. 
Valeeva, N. I., M. Meuwissen, A. O. Lansink, and R. Huirne. 2006. Cost implications of improving food safety in the Dutch dairy chain. Eur. Rev. Agric. Econ. 33:511-541.

Velthuis, A. G. J., M. P. M. Meuwissen, and R. B. M. Huirne. 2009. Distribution of direct recall costs along the milk chain. Agribusiness. 25(4):466-479.

Velthuis, A. G. J., M. W. Reij, K. Baritakis, M. Dang, and C. P. A. van Wagenberg. 2010. Recall costs balanced against spoilage control in Dutch custard. J. of Dairy Sci. 93:2779-2791.

World Health Organization (WHO). 2007. Dioxins and their effects on human health. Fact sheet 225. World Health Organization, Geneva, Switzerland. 


\section{Chapter 3}

\section{Optimizing bulk milk dioxin monitoring based on costs and effectiveness}

V. H. Lascano Alcoser, A. G. J. Velthuis, H. J. van der Fels-Klerx, L. A. P. Hoogenboom, A. G. J. M. Oude Lansink

Published in Journal of Dairy Science, $96: 4125-4141$ DOI http://dx.doi.org/ 10.3168/jds.2012-5898 


\section{Abstract}

Dioxins are environmental pollutants, potentially present in milk products, which have negative consequences for human health and for the firms and farms involved in the dairy chain. Dioxin monitoring in feed and food has been implemented to detect their presence and estimate their levels in food chains. However, the costs and effectiveness of such programs have not been evaluated. In this study, the costs and effectiveness of bulk milk dioxin monitoring in milk trucks were estimated to optimize the sampling and pooling monitoring strategies aimed at least 1 contaminated dairy farm out of 20,000 at a target dioxin concentration level. Incidents of different proportions in terms of number of contaminated farms, and concentrations were simulated. A combined testing strategy, consisting of screening and confirmatory methods was assumed as well as testing of pooled samples. Two optimization models were built using linear programming. The first model aimed to minimize monitoring costs subject to a minimum required effectiveness of finding an incident, whereas the second model aimed to maximize the effectiveness for a given monitoring budget. Our results show that a high level of effectiveness is possible, but at high costs. Given specific assumptions, monitoring with $95 \%$ effectiveness to detect an incident of 1 contaminated farm at a dioxin concentration of $2 \mathrm{pg}$ TEQ/g of fat [European Commission's (EC) action level] costs $€ 2.6$ million per month. At the same level of effectiveness, a $73 \%$ cost reduction is possible when aiming to detect an incident where 2 farms are contaminated at a dioxin concentration of $3 \mathrm{pg} \mathrm{TEQ} / \mathrm{g}$ of fat (EC maximum level). With a fixed budget of $€ 40,000$ per month, the probability of detecting an incident with a single contaminated farm at a dioxin concentration equal to the EC action level is $4.4 \%$. This probability almost doubled $(8.0 \%)$ when aiming to detect the same incident but with a dioxin concentration equal to the EC maximum level. This study shows that the effectiveness of finding an incident depends not only on the ratio at which, for testing, collected truck samples are mixed into a pooled sample 
(aiming at detecting certain concentration), but also the number of collected trucks samples. In conclusion, the optimal cost-effective monitoring depends on the number of contaminated farms and the concentration aimed at detection. The models and study results offer quantitative support to risk managers of food industries and food safety authorities. 
Bulk milk dioxin monitoring

\subsection{Introduction}

Polychlorinated dibenzo-p-dioxins and polychlorinated dibenzofurans are known as dioxins. Polychlorinated biphenyls with dioxin-like properties are known as dioxin-like PCB (dl-PCB). Dioxins and dl-PCB are persistent organic pollutants (WHO, 2007) that belong to the 12 more prominent environmental contaminants as classified by the Stockholm Convention on Persistent Organic Pollutants (WHO, 2007; UNEP, 2009). Dioxins and dlPCB are a potential threat to human health because of their toxicity at very low levels, their stability in the environment (WHO, 2007), and their bio-accumulation and bio-magnification along food chains (Huwe, 2002; Schmid et al., 2002). If elevated levels are detected in food, dioxins may lead to extensive financial losses for food and feed businesses due to mitigation strategies and reduced sales (Velthuis et al., 2009; Lascano Alcoser et al., 2011).

In the EU, the intake of dioxins and dl-PCB by the consumers may still exceed the exposure limit of $14 \mathrm{pg}$ toxic equivalents (TEQ)/kg of BW per week (De Mul et al., 2008). Prior studies have shown that foods of animal origin, mainly those containing fat, are the main contributors of dioxins in the human diet (Huwe, 2002). Studies have also shown that the main source of dioxins in food is contaminated feed (Bchert et al., 2001; Huwe, 2002) and feed ingredients (Huwe and Smith, 2005). In this regard, and due to the occurrence of several dioxin-food safety incidents in the last part of the 1990s (Malisch, 2000; Bernard et al., 2002), the EU established legislation for dioxins and dl-PCBs in food and feed (EC, 2000; SCF, 2001). This legislation includes a strategy to reduce exposure levels over time (EC, 2001a) and defines maximum levels for these contaminants in food and feed products (EC, 2001b, c, 2006c). As part of this strategy, feed and food monitoring is conducted across the EU with the aim of diminishing exposure levels in the population (EC, 2001a, 2006a; EFSA, 2010).

Routine monitoring is a way to determine background levels and trends of dioxins in food and feed products (EC, 2001a) and to detect contaminated food and new sources in agri- 
food chains (EC, 2002, 2004; Heres et al., 2010; Hoogenboom et al., 2010). In spite of these apparent benefits, it is costly and complex to establish a dioxin monitoring plan (Büchert et al., 2001). One of the major difficulties is the lack of inexpensive and simple tests for real-time detection of dioxins (Kan and Meijer, 2007). This restricts the number of samples that can be analyzed (Huwe, 2002) and thereby reduces the capacity of monitoring to detect possible incidents. An improvement was the introduction of bioassays as CALUX (Hiyoshi Corp., Shiga, Japan), but even these tests still run at relatively high costs and require several days.

Milk is one of the main contributors of dioxins and dl-PCB to the total exposure in the European population (EFSA, 2010). Consequently, milk dioxin incidents may have a potential salient effect to human health. Additionally, the dairy chains in different countries have been one of the food chains repeatedly involved in dioxin incidents (e.g., Belgian crisis in 1999, Dutch incident in 2004), with salient potential financial effect to the involved farms and firms along the chain (Lascano Alcoser et al., 2011). In this study, the cost and effectiveness of bulk milk dioxin monitoring at milk trucks were estimated with the objective of optimizing the sampling and pooling monitoring strategies aiming at detecting a dioxin incident. This study elicits valuable information to risk managers about the relation between the financial resources spent on monitoring dioxins and the capacity of this system to detect a contamination.

\subsection{Materials and Methods}

Two optimization models were built using linear programming (Dijkhuizen and Morris, 1997). The first model (MC) aimed to minimize the monitoring costs subject to a minimum required effectiveness, whereas the second model (ME) aimed to maximize the effectiveness of monitoring for a given budget for monitoring. The models evaluated a bulk milk dioxin monitoring plan in milk trucks covering 20,000 dairy farms located in an area of 
Bulk milk dioxin monitoring

$40,000 \mathrm{~km}^{2}$. Milk trucks, which transport milk from the dairy farms to the milk processing plants, were randomly selected at each sampling time. Within this framework, a dioxin incident is assumed to last for at least $1 \mathrm{mo}$, which is realistic considering the turnover of feed and the slow elimination of these compounds in dairy cows (Hoogenboom et al., 2010). The models were applied to 8 preselected contamination scenarios representing dioxin incidents of different sizes to be detected (called detectable incidents). The size of a detectable incident was determined by the combination of the number of expected contaminated farms (1 or 10$)$ and the target dioxin concentration $(2,3,10$ or $20 \mathrm{pg} \mathrm{TEQ} / \mathrm{g}$ of fat) in the tank milk of contaminated farms (Table 1).

Table 1. Description of the contamination scenarios

\begin{tabular}{|c|c|c|}
\hline \multirow[b]{2}{*}{$\begin{array}{l}\text { Scenario } \\
\text { code }\end{array}$} & \multicolumn{2}{|c|}{ Size of detectable incident } \\
\hline & $\begin{array}{l}\text { No. of expected contaminated } \\
\text { farms (F) }\end{array}$ & $\begin{array}{c}\text { Target concentration } \\
\text { (i.e., dioxin concentration at farms) }{ }^{1}(\mathrm{C})\end{array}$ \\
\hline $\mathrm{F} 1-\mathrm{C} 2$ & 1 & $2 \mathrm{pg}$ TEQ/g fat ${ }^{2}$ \\
\hline $\mathrm{F} 1-\mathrm{C} 3$ & 1 & $3 \mathrm{pg}$ TEQ/g fat ${ }^{3}$ \\
\hline F1-C10 & 1 & $10 \mathrm{pg}$ TEQ/g fat \\
\hline $\mathrm{F} 1-\mathrm{C} 20$ & 1 & $20 \mathrm{pg}$ TEQ/g fat \\
\hline $\mathrm{F} 10-\mathrm{C} 2$ & 10 & $2 \mathrm{pg}$ TEQ/g fat ${ }^{2}$ \\
\hline F10-C3 & 10 & $3 \mathrm{pg}$ TEQ/g fat ${ }^{3}$ \\
\hline $\mathrm{F} 10-\mathrm{C} 10$ & 10 & $10 \mathrm{pg}$ TEQ/g fat \\
\hline $\mathrm{F} 10-\mathrm{C} 20$ & 10 & $20 \mathrm{pg}$ TEQ/g fat \\
\hline
\end{tabular}

TEQ = toxic equivalents.

${ }^{2}$ European Commission action level for dioxins.

${ }^{3}$ European Commission maximum level for dioxins.

The bulk milk dioxin monitoring aimed to detect at least one of the contaminated farms with a concentration $\left(c_{c f}\right)$ equal or higher than the action level for dioxins. The action level $\left(c_{A L}\right)$ was defined as the concentration of dioxins at which authorities and food business operators can decide to identify the source of the contamination (EC, 2001c). The European Commission (EC) action level for dioxins in raw milk at dairy farms equaled $2 \mathrm{pg}$ World Health Organization TEQ/g of fat (EC, 2006a). To simplify the model, and because no legal EC action level exists for the sum of dioxins and dl-PCB, only dioxins were assumed to be the cause of the incident (not dl-PCB). 
The assumed sampling and pooling procedures are presented in Figure 1.

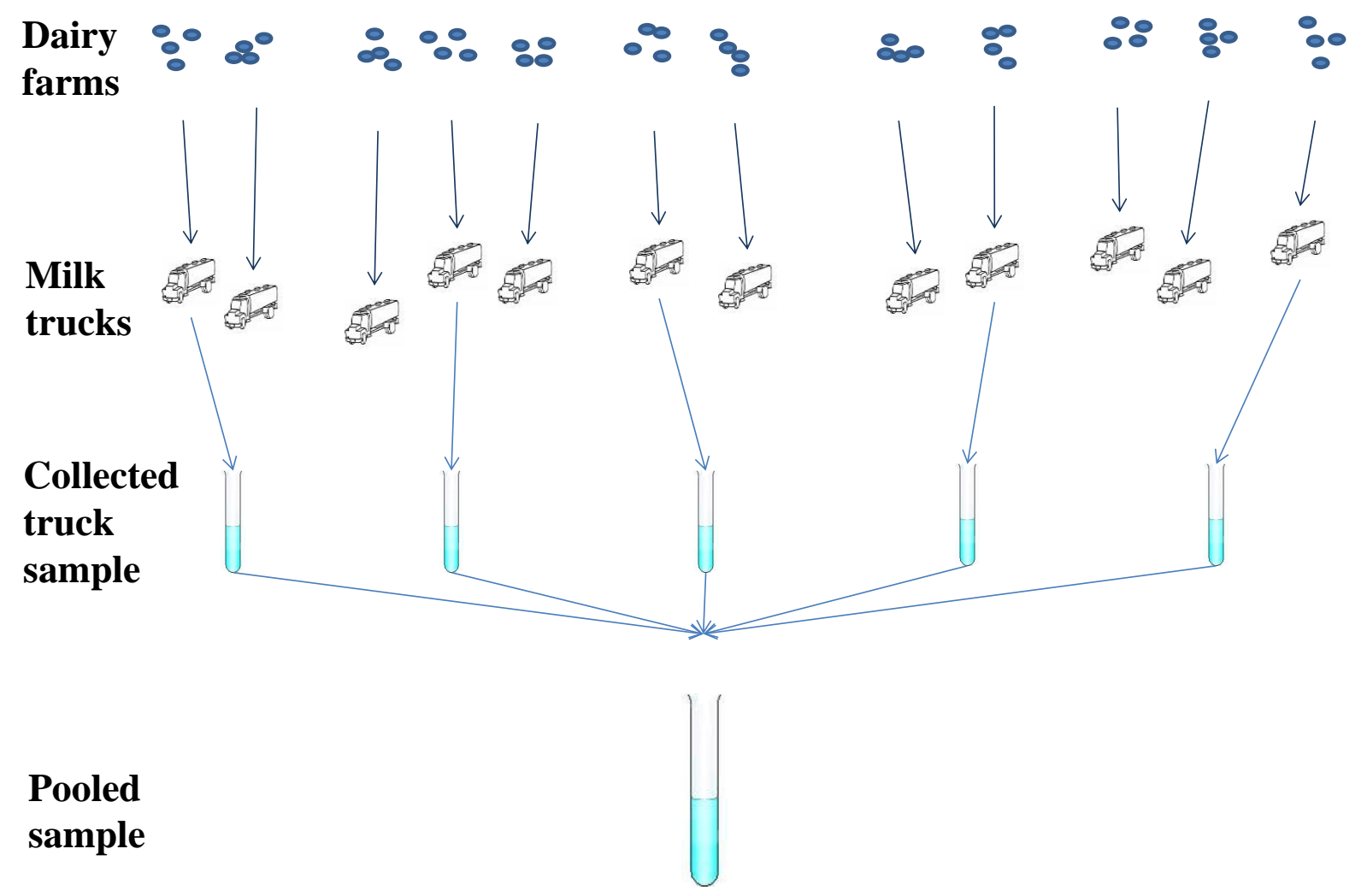

Figure 1. Example of a sampling scheme where milk trucks containing milk from 4 dairy farms are sampled; these samples are then mixed intro a pooled sample. Color version available in the online PDF.

In this regard, milk trucks collect milk from several different farms. Randomly, milk trucks are sampled by a worker of the dairy company or the truck driver just before the milk is pumped into the silos of the milk processing plants. The collected truck samples are transported to a laboratory where they are mixed into pooled samples. These pooled samples are tested for dioxins. Collected truck samples are stored at the laboratory for further analysis in case an incident is detected after testing the pooled samples. Each pooled sample is tested using a screening method, such as the Calux bioassay (EC, 2006b), to determine the possible presence of dioxins above the target level for a single farm's tank milk. Any pooled sample with an estimated concentration of dioxins equal or above a certain decision limit is considered suspected. This decision limit represents the highest concentration of dioxins above the background level below which a sample is considered not to be contaminated 
Bulk milk dioxin monitoring

(tested negative for dioxins). The decision limit is estimated considering the variability of the test results (explained in detail later). The background level is the measured concentration of dioxins in milk samples due to the ubiquitous condition of dioxins as environmental pollutant. In this study, it is assumed that noncontaminated milk samples contain a dioxin concentration equal to the assumed background level for each type of sample. Suspected pooled samples are analyzed with the high-resolution gas chromatography/high-resolution mass spectrometry (HRGC/HRMS) to verify the presence and concentration of dioxins above the decision limit for HRGC/HRMS, which is the only official confirmatory method (EC, 2006b). In case a pooled sample is confirmed to be positive for dioxins, all truck samples originally mixed into the contaminated pooled sample are tested individually using the screening method and, if suspected, the confirmatory method. Once a contaminated truck sample is identified, all farms from which the milk was collected by the truck are sampled again and tested with the screening method, and with the confirmatory method if suspected. In this way, the contaminated farm(s) and potentially the possible source of the contamination can be determined (Figure 2). Testing samples with only the screening method could lead to falsepositive contaminations; therefore, a confirmation is required. As the confirmatory method is more expensive than the screening method, the confirmatory method is only used to test the suspected contaminated samples. 


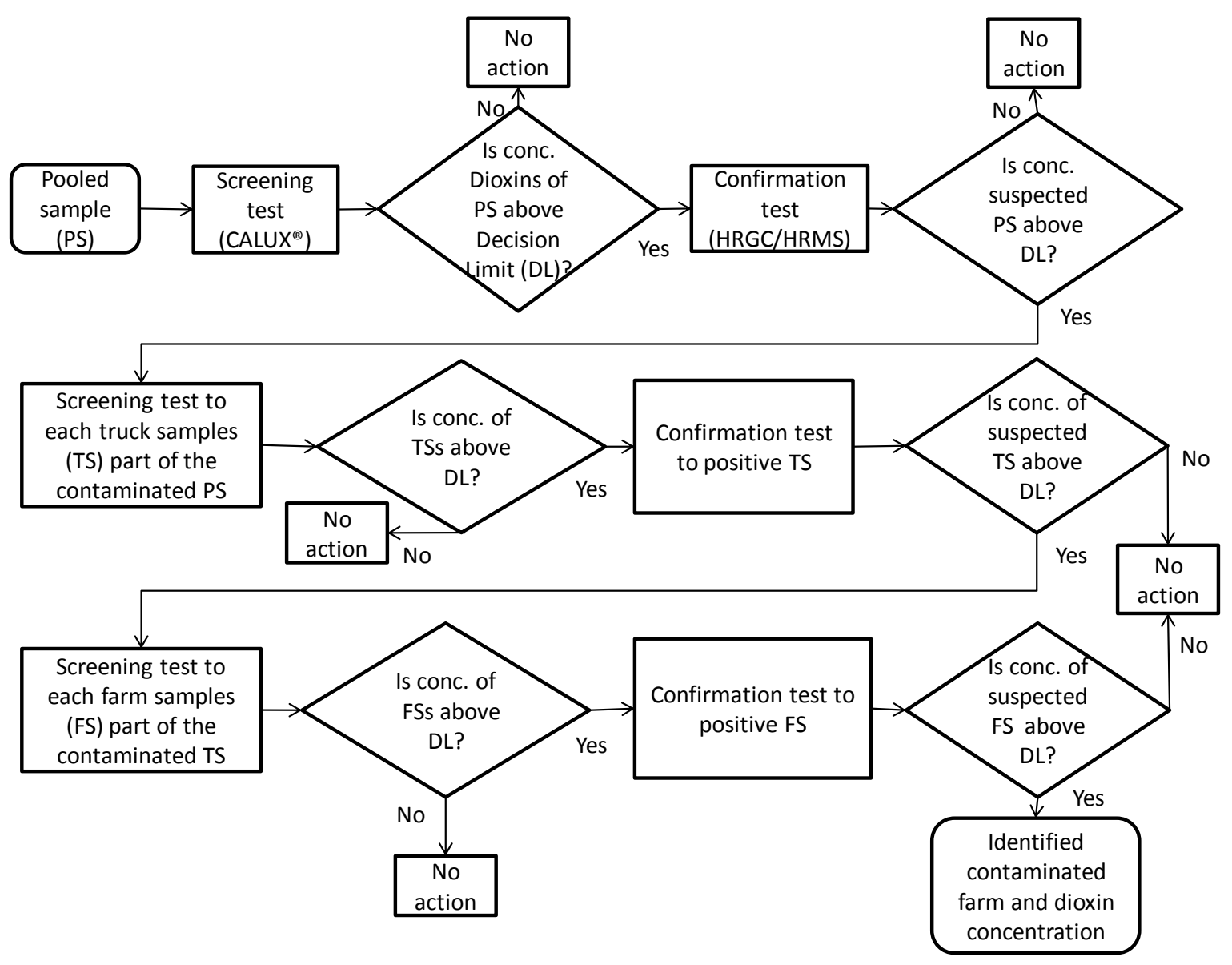

Figure 2. Decision process for testing dioxin in pooled samples, truck samples and farm samples with a screening tests, such as Calux (Hiyoshi Corp., Shiga, Japan), and confirmatory test high-resolution gas chromatography/high-resolution mass spectrometry (HRGC/HRMS). Decision limit (DL) will vary for each step, depending on whether farm, truck, or pooled samples are tested.

\section{Optimization Models}

Two optimization models were built with the aim of optimizing the sampling and pooling strategies of milk dioxin monitoring in milk trucks. Each optimization model consisted of an objective function, a set of constraints, and the optimized variables. The objective of the optimization models was either to minimize the monitoring costs $\left[T M C\left(n s_{t}, n s_{\text {truck-mix }}\right)\right] \quad$ or to maximize the effectiveness function [Prob $\left.D_{c f}\left(n s_{t}, n s_{\text {truck-mix }}\right)\right]$ when applying the MC or the ME model, respectively. The minimum required effectiveness $(E)$ and the available budget for monitoring $(B)$ were the main constraints of the MC and ME model, respectively. The optimized variables were the 
Bulk milk dioxin monitoring

number of milk trucks to be sampled, named collected truck samples $\left(n s_{t}\right)$ and the ratio at which, for testing and aiming to detect certain concentration, collected truck samples are mixed into a pooled sample, named truck samples mixed $\left(n s_{\text {truck-mix }}\right)$. Both variables were included in the cost function as well as the effectiveness function, which are explained in detail later. The cost and effectiveness functions were created in Microsoft Excel 2010 (Redmond, WA). Additionally, the optimization models were simulated using the Solver command from Frontline Systems, Inc. (Frontline Systems Inc., 2011), part of the What If Tools of Microsoft Excel 2010.

The MC model is written as follows:

Minimize: $\quad T M C\left(n s_{t}, n s_{\text {truck-mix }}\right)$

Subject to: $\quad \operatorname{Prob} D_{c f}\left(n s_{t}, n s_{\text {truck-mix }}\right) \geq E$

$$
\begin{aligned}
& 0 \leq n s_{t} \leq N s_{t} \\
& 1 \leq n s_{\text {truck-mix }} \leq N s_{\text {truck-mix }}
\end{aligned}
$$

where $N s_{t}$ is the maximum number of collected truck samples that can be taken per month; and $N s_{\text {truck-mix }}$ is the maximum number of truck samples that can be mixed into one pooled sample. The minimal $E$ were assumed to be $95.0 \%$, which can be adjusted by the food safety decision makers.

The ME model is written as follows:

Maximize: $\quad \operatorname{Prob} D_{c f}\left(n s_{t}, n s_{t r u c k-m i x}\right)$

Subject to: $\quad \operatorname{TMC}\left(n s_{t}, n s_{\text {truck-mix }}\right) \leq B$

$$
\begin{aligned}
& 0 \leq n s_{t} \leq N s_{t} \\
& 1 \leq n s_{\text {truck-mix }} \leq N s_{\text {truck-mix }}
\end{aligned}
$$

The monitoring budget $(€ 40,000)$ was selected given the results obtained when running the MC model so as to obtain comparable results when discussing the outcomes of both models. Note that the monitoring budget did not include additional costs for determining 
the source of the contamination once a positive pooled sample is detected (so called incident costs). A detailed description of the incident costs is given in the next section.

\section{Costs function of the Milk Dioxin Monitoring}

The $T M C$ includes monitoring costs $(M C)$ and incident costs $(I C)$ :

$T M C=M C+I C$

where $M C$ includes all activities performed to measure the concentration of dioxins in pooled samples, which equals the first row of Figure 2. Monitoring costs are the sum of sampling $(M S C)$ and testing $(M T C)$ costs, calculated by

$M C=M S C+M T C$

Sampling costs at monitoring are given by

$M S C=(l c+m c+t c s+s c) \cdot n s_{t}$

where $l c$ is the labor cost for personnel who take the samples; $m c$ is the materials cost for all equipment and tools used to take samples; tcs is the cost of transporting the samples to the laboratory; and $s c$ is the cost of storing the samples to allow further analysis.

The sum of testing costs (MTC) are given by

$$
\begin{aligned}
M T C= & \left(\left(\text { test }_{\text {scree }}+l c_{\text {test }}\right) \cdot \frac{n s_{t}}{n s_{\text {truck-mix }}}\right)+ \\
& \left(\left(\text { test }_{\text {conf }}+l c_{\text {test }}\right) \cdot \% p s_{\text {scree }} \cdot \frac{n s_{t}}{n s_{\text {truck-mix }}}\right)
\end{aligned}
$$

where test $t_{\text {scree }}$ and test $t_{\text {conf }}$ are the costs of the screening and confirmation methods, respectively; $l c_{\text {test }}$ is the sum of the labor costs for registering and evaluating the test results (i.e., $l c_{\text {test }}=l c_{\text {test-reg }}+l c_{\text {test-eva }}$ ); and $\% p s_{\text {scree }}$ is the proportion of the total number of pooled samples that are tested positive by the screening test. 
Bulk milk dioxin monitoring

Incident costs $(I C)$ includes costs related to tracing the source and concentration of dioxins at the level of truck samples and the farm samples that correspond to the second and third row of Figure 2, respectively:

$I C=I S C+I T C$

where ISC is the cost of sampling milk from the farms that are suspected to be the source of the incident (after testing individual truck samples); and ITC is sum of the costs individually testing each truck sample contained in the contaminated pooled sample, and each farm sample from those farms that are suspected to be the source of the incident.

The cost of sampling milk from suspect farms (ISC) is given by Equation 5 where $n s_{t}$ is the number of farm samples that should be collected from farms suspected to be contaminated $\left(n s_{f}\right)$. That is given by

$n s_{f}=n s_{\text {truck-c }} \cdot n s_{\text {farm-mix }}$

where $n s_{\text {truck }-c}$ is the number of truck samples that has a higher dioxin concentration than the decision limit; and $\mathrm{ns}_{\text {farm-mix }}$ is the number of farms served by 1 milk truck (fixed at 4 ).

The sum of the cost of individually testing each truck sample (ITC) is given by

$$
\begin{array}{r}
I T C=\left(\left(\text { test }_{\text {scree }}+l c_{\text {test }}\right) \cdot n s_{\text {truck-pool }}\right)+\left(\left(\text { test }_{\text {conf }}+l c_{\text {test }}\right) \cdot n s_{\text {truck-suspec }}\right) \\
+\left(\left(\text { test }_{\text {scree }}+l c_{\text {test }}\right) \cdot n s_{f}\right)+\left(\left(\text { test }_{\text {conf }}+l c_{\text {test }}\right) \cdot n s_{\text {farm-conf }}\right)
\end{array}
$$

where $n s_{\text {truck-pool }}$ is the number of collected truck samples mixed into the positive pooled sample which varies with the simulated $n s_{\text {truck-mix }} ; n s_{\text {truck-suspec }}$ is the number of collected truck samples mixed into the positive pooled sample identified from the simulated $n s_{\text {truck-mix }}$ and having an estimated dioxin concentration higher than the decision limit; and $n s_{\text {farm-conf }}$ is the number of farm samples that have a higher dioxin concentration than the decision limit. It is assumed that only 1 pooled sample, and subsequently, 1 collected truck 
Chapter 3

sample and 1 farm sample are tested positive. All inputs variables for monitoring cost function are given in Table 2. 
Table 2. Input variables of monitoring cost function

\begin{tabular}{|c|c|c|c|c|}
\hline Description & Variable & $€ /$ Unit & Unit & Explanation \\
\hline Labor cost & $l c$ & 12.25 & Truck sample & Take milk samples at milk truck; Time/sample: $15 \mathrm{~min}$; salary: $€ 49 / \mathrm{hr}^{1}$ \\
\hline Materials cost & $m c$ & 0.50 & Truck sample & Material for sampling \\
\hline Storage cost & $s c$ & 0.10 & Truck sample & Storage of samples in lab after testing \\
\hline Screening test cost & test $_{\text {scree }}$ & 100.00 & Pooled sample & Screening test (Calux, Hiyoshi Corp., Shiga, Japan) $)^{3}$ \\
\hline Labor cost for registering the test results & $l c_{\text {test-reg }}$ & 2.58 & Pooled sample & Registration of data in database; time/sample: $5 \mathrm{~min}$; salary: $€ 31 / \mathrm{hr}^{1}$ \\
\hline Labor cost for evaluating the test results & $l c_{\text {test-eva }}$ & 15.75 & Pooled sample & Evaluation of test results; time/sample: $15 \mathrm{~min}$; salary: $€ 63 / \mathrm{hr}^{4}$ \\
\hline Proportion of pooled samples tested positive & $\% p s_{\text {scree }}$ & 11.50 & Percent & Proportion of suspected samples in screening test ${ }^{3}$ \\
\hline No. of suspected truck samples in contaminated pooled & $n s_{\text {truck-suspec }}$ & 1 & Truck sample & $\begin{array}{l}\text { No. of positive truck samples in the positive pooled sample. Fixed } \\
\text { value assumed. }\end{array}$ \\
\hline
\end{tabular}

\footnotetext{
${ }^{1}$ Tariffs, Dutch Gov., LNV, 2011, medium tariff.

${ }^{2}$ Postal service NL.

${ }^{3}$ R. Hoogenboom (Wageningen University, Wageningen, The Netherlands, personal communication). HRGC/HRMS= high-resolution gas chromatography/high-resolution mass spectrometry.

${ }^{4}$ Tariffs, Dutch Gov., LNV, 2011, high tariff.
} 


\section{Effectiveness function of Milk Dioxin Monitoring}

The effectiveness of bulk milk dioxin monitoring from milk trucks is defined in this study as the probability of detecting at least one contaminated farm (Prob $\left.D_{c f}\right)$ per month at a target concentration (e.g., 1 of 10 contaminated farms out of 20,000 with a dioxin concentration of $2 \mathrm{pg}$ TEQ/g of fat).

The $\operatorname{Prob}\left(D_{c f}\right)$ follows a binomial distribution

$\operatorname{Prob}\left(D_{c f}\right)=1-\operatorname{Prob}\left(N D_{c f}\right)$

where $\operatorname{Prob}\left(N D_{c f}\right)$ is the probability of not detecting a contaminated farm (i.e., the number of detections equals zero; $x=0)$ :

$$
\begin{aligned}
\operatorname{Prob}\left(N D_{c f}\right)= & \left(\begin{array}{c}
n s_{t} \\
x
\end{array}\right) \cdot\left[\operatorname{Prob}\left(D_{c t}\right) \cdot \operatorname{Prob}\left(\operatorname{tpos}_{c t}\right)\right]^{x} \\
\cdot & \left\{1-\left[\operatorname{Prob}\left(D_{c t}\right) \cdot \operatorname{Prob}\left(\operatorname{tpos}_{c t)}\right)\right]\right\}^{n s_{t}-x}
\end{aligned}
$$

where $\operatorname{Prob}\left(D_{c t}\right)$ is the probability of sampling at least 1 contaminated milk truck; and $\operatorname{Prob}\left(\operatorname{tpos}_{c t}\right)$ is the probability that a true contaminated truck sample is tested positive.

The $\operatorname{Prob}\left(D_{c t}\right)$ is the number of contaminated trucks in the defined period $t$ (one month of $30.4 \mathrm{~d} ; n_{c t} t$ ) divided by the total number of trucks collecting milk in that period $\left(N_{t_{-} t}\right):$

$\operatorname{Prob}\left(D_{c t}\right)=\frac{n_{c t \_t}}{N_{t_{-} t}}$

where $n_{c t_{-} t}$ equals the number of contaminated farms $\left(n_{c f_{-} t}\right)$ in period $t$ multiplied by the number of days in $t$ divided by the number of days between 2 subsequent deliveries $\left(f_{m d}\right)$ :

$n_{c t_{-} t}=n_{c f_{-} t} \cdot \frac{t}{f_{m d}}$

The total number of trucks collecting milk in period $\mathrm{t}\left(N_{t_{t}}\right)$ equals the maximum number of truck samples that can be collected per month $(N s)$, which is given by: 
Bulk milk dioxin monitoring

$N_{t_{-} t}=\frac{N_{d f} \cdot t}{f_{m d} \cdot n_{\text {farm-mix }}}$

where $N_{d f}$ is the total number of dairy farms delivering milk to the dairy processors.

The $\operatorname{Prob}\left(\operatorname{tpos}_{c t}\right)$ is the probability that the concentration of the tested pooled sample is higher than the decision limit $\left(c_{c p}>c_{D L}\right)$ given that milk from at least 1 farm tank has a higher concentration of dioxins than the action level $\left(c_{c f}>c_{A L}\right)$. This probability equals the sensitivity of the analytical methods (test $t_{\text {sensitivity }}$ ) which is assumed to be equal for both the screening and confirmation test.

The concentration of dioxins in the contaminated pooled sample $\left(c_{c p}\right)$ depends on the dilution of the initial dioxin concentration due to the mixing of milk from different dairy farms by the truck collector and when preparing a pooled sample. In t6his study, it is assumed that 1 of the 4 farms collected in 1 truck is contaminated. In practice, milk from more than 1 farm contained in the truck sample could be contaminated.

The first dilution effect depends on the proportion of milk delivered by the contaminated farm relative to the total milk transported by the truck collector and the $c_{c f}$. Thus, the dioxin concentration of the contaminated truck sample $\left(c_{c t}\right)$ is given by

$$
c_{c t}=\left(\frac{\sum_{i}\left(c_{n c f i} \cdot \% f a t \cdot q m i l k_{n c f i}\right)+c_{c f} \cdot \% f a t \cdot q m i l k_{c f}}{\% f a t \cdot Q m i l k_{c t}}\right)
$$

where $c_{n c f i}$ is the concentration of dioxins at a non-contaminated farm (i);qmilk $k_{n c f i}$ is the amount of milk delivered by the non-contaminated farm $(i)$; $\%$ fat is the proportion of fat in the milk (given that dioxins are present in the milk fat portion), $\mathrm{qmilk}_{\mathrm{cf}}$ is the amount of milk delivered by the contaminated farm, and qmilk $_{c t}$ is the total amount of milk transported by the contaminated milk truck. For simplification, it is assumed that all farms deliver the same amount of milk with the same proportion of fat and that the milk truck is full. Equation (15) can then be simplified as follows, 
$c_{c t}=\frac{\left(\sum_{i}\left(c_{n c f i}\right)+c_{c f}\right)}{n_{f a r m-m i x}}$

The second dilution effect varies with the proportion of the contaminated collected truck sample mixed into a pooled sample. The dioxin concentration of the contaminated pooled sample $\left(c_{c p}\right)$ is quantified as follows

$c_{c p}=\frac{c_{c t}+\left(c_{n c t} \cdot n s_{\text {truck-nc }}\right)}{\left(n s_{\text {truck-nc }}+n s_{\text {truck-c }}\right)}$

where $c_{n c t}$ is the average dioxin concentration of the non-contaminated collected truck samples (assumed to be equal to the background level for truck samples), $n s_{\text {truck-nc }}$ are the number of noncontaminated truck samples combined into a pooled sample. Assuming that only 1 collected truck sample is expected to be contaminated (ns truck-c $=1)$, equation (16) is rearranged as follows:

$c_{c p}=\frac{c_{c t}+\left(c_{n c t} \cdot n s_{\text {truck-nc }}\right)}{\left(n s_{\text {truck-nc }}+1\right)}$

Given that the probability of a contaminated pooled sample testing positive depends on $c_{c p}>c_{D L}$, the following holds,

$\frac{c_{c t}+\left(c_{n c t} \cdot n s_{\text {truck-nc }}\right)}{\left(n s_{t r u c k-n c}+1\right)}>c_{D L}$

Consequently, to allow detection, a maximum number of non-contaminated collected truck samples $\left(N s_{\text {truck-nc }}\right)$ combined into a pooled sample exists. Thus, rearranging equation 19 gives

$N s_{\text {truck }-n c}<\frac{c_{c t}-c_{D L}}{c_{D L}-c_{n c t}}$

where $c_{D L}$ is the dioxin concentration at the decision limit for pooled samples, which is set as follows:

$c_{D L}=c_{n c p}+\left(c_{n c p} \cdot p v_{n c p}\right)$ 
Bulk milk dioxin monitoring

where $c_{n c p}$ is the dioxin concentration of noncontaminated pooled samples (background level for pooled samples); and $p v_{n c p}$ is the assumed percentage of possible positive deviation of the background level from its mean value with respect to the variability in concentration of collected truck samples. Assuming 1 positive collected truck sample in a pooled sample, $N s_{\text {truck-mix }}$ is given by

$N s_{\text {truck-mix }}=N s_{\text {truck-nc }}+1$

All input variables for the monitoring effectiveness function are given in Table 3. 
Table 3. Input variables of monitoring effectiveness function

\begin{tabular}{|c|c|c|c|c|}
\hline Description & Variable & Value & Unit & Explanation \\
\hline No. of contaminated farms at period $t$ & $n_{c f_{-} t}$ & $1.0-10.0$ & Dairy farm & Range of values assumed to run the optimization models \\
\hline Dioxin monitoring period & $t$ & 30.4 & Day & $\begin{array}{l}\text { No. of days per month assuming } 365 \mathrm{~d} / \text { year and } 12 \mathrm{mo} / \\
\text { year }\end{array}$ \\
\hline No. of dairy farms & $N_{d f}$ & 20,000 & Dairy farm & No. of dairy farms delivering milk to milk processors \\
\hline No. of farms collected by one milk truck & $n_{\text {farm-mix }}$ & 4.0 & Farm & Assuming a truck working at full capacity $(20,0001)$ \\
\hline Sensitivity of analytical methods & test $_{\text {sensitivity }}$ & 98.0 & Percent & Expert opinion ${ }^{2}$ \\
\hline Dioxin concentration of contaminated farm & $c_{c f}$ & $2.0-20.0$ & $\mathrm{pg} \mathrm{TEQ} / \mathrm{g}$ of fat & Range of values assumed to run the optimization models \\
\hline $\begin{array}{l}\text { Milk collected per each noncontaminated farm per } \\
\text { delivery }\end{array}$ & $q_{m i l k}$ ncfi & 5,000 & 1 & $\begin{array}{l}\text { Assumed value when } 4 \text { farms are collected by the same } \\
\text { truck and it is always full }\end{array}$ \\
\hline Milk collected per a contaminated farm per delivery & qmilk $_{c f}$ & 5,000 & 1 & $\begin{array}{l}\text { Assumed value when } 4 \text { farms are collected by the same } \\
\text { truck and it is always full }\end{array}$ \\
\hline $\begin{array}{l}\text { Positive variation of the concentration from the } \\
\text { background level }\end{array}$ & $p v_{n c p}$ & 50.0 & Percent & Expert opinion $^{2,3}$ \\
\hline
\end{tabular}

${ }^{\mathrm{I}} \mathrm{TEQ}=$ toxic equivalents.

${ }^{2}$ R. Hoogenboom (Wageningen University, Wageningen, The Netherlands, personal communication).

${ }^{2}$ W. Traag (Wageningen University, Wageningen, The Netherlands, personal communication). 
Bulk milk dioxin monitoring

\subsection{Results}

Dioxin monitoring aimed to detect at least 1 contaminated dairy farm out of 20,000, at a certain target dioxin concentration in incidents with different contamination scenarios. These scenarios varied depending on the size of the detectable incident. It was assumed that milk samples were collected from milk trucks randomly selected at each sampling time. These truck samples may be combined into pooled samples to increase the number of farms tested. The pooled samples were subsequently tested by a screening method and if exceeding the decision limit, by the confirmatory method. Prices of the tests were set at $€ 100$ and $€ 350$, based on high efficiency of the screening method due to the large sample volumes. The costs and effectiveness of the monitoring plan were minimized (given a minimum required effectiveness) or maximized (given a certain maximum budget) when applying the MC or the ME model, respectively. The optimized variables were the number of milk trucks to be sampled (collected truck samples) and the ratio at which, for testing and aiming to detect certain concentration, collected truck samples are mixed into a pooled sample (truck sample mixed).

\section{MC optimization results for $95 \%$ Effectiveness level}

The MC optimization results for a minimal effectiveness of $95 \%$ and for the 8 contamination scenarios are shown in Table 4. The optimal number of collected truck samples and the number of truck samples mixed varies with the number of expected contaminated farms and the concentration of dioxins at farm level, respectively. The bigger the detectable incident was, the lower the monitoring costs required to detect the contamination.

A 10-fold increase in the number of contaminated farms reduces the number of collected truck samples required to detect the contamination from 15,283 to 1,527 samples (Table 4). This decrease in the number of collected truck samples leads to a $90 \%$ reduction in the 
sampling costs at monitoring. However, the marginal reduction decreases with each additional expected contaminated farm (Figure 3). A reduction of $80 \%$ in the sampling costs is obtained when the number of expected contaminated farms increases from 1 to 5.

Table 4. Optimal number of 8 contamination scenarios

\begin{tabular}{lcccc}
\hline Scenario & $\begin{array}{c}\text { No. of collected } \\
\text { truck samples } \\
\text { per month }\end{array}$ & $\begin{array}{c}\text { No. of truck samples } \\
\text { mixed into a } \\
\text { pooled sample }\end{array}$ & $\begin{array}{c}\text { No. of pooled } \\
\text { samples tested per } \\
\text { month }\end{array}$ & $\begin{array}{c}\text { Monitoring costs } \\
\text { per month } \\
(€ \text { thousand })\end{array}$ \\
\hline F1-C2 & 15,283 & 1 & 15,283 & 2,667 \\
F1-C3 & 15,283 & 2 & 7,642 & 1,439 \\
F1-C10 & 15,283 & 9 & 1,698 & 484 \\
F1-C20 & 15,283 & 19 & 804 & 340 \\
F10-C2 & 1,527 & 1 & 1,527 & 266 \\
F10-C3 & 1,527 & 2 & 764 & 143 \\
F10-C10 & 1,527 & 9 & 169 & 48 \\
F10-C20 & 1,527 & 19 & 80 & 34 \\
\hline
\end{tabular}

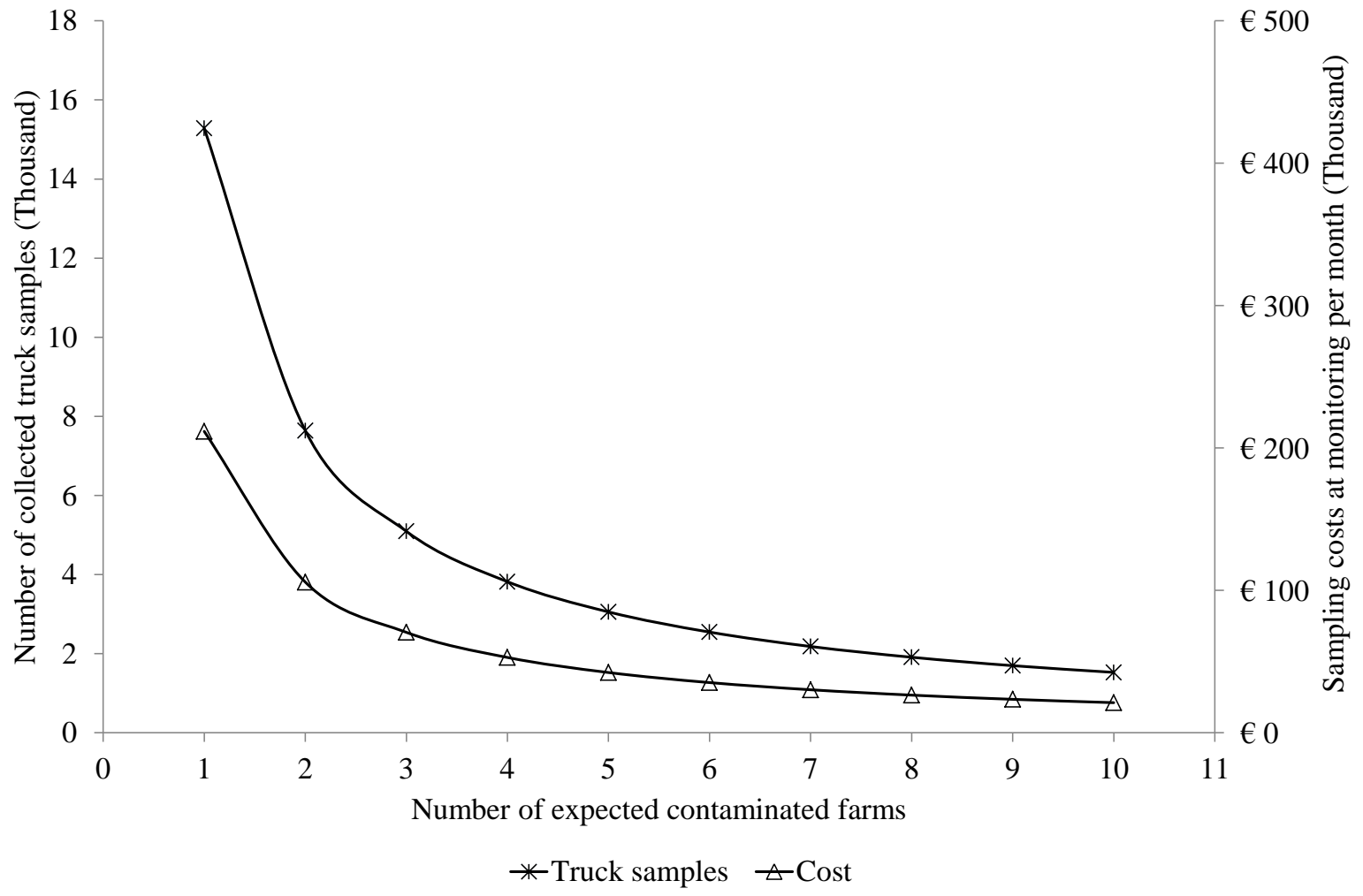

Figure 3. Effect of increasing the number of expected contaminated farms on the number of collected truck samples and the sampling monitoring costs. 
Bulk milk dioxin monitoring

An increase in the target concentration of dioxins at the contaminated farm(s) enables mixing of more truck samples into a pooled sample. The higher the mixing ratio, the smaller the number of pooled samples tested, and consequently, the lower the testing cost per collected truck sample (Table 4 and Figure 4). The optimal number of truck samples mixed into a pooled sample increases linearly from 1 to 19 at a constant rate of 1 truck sample for each additional unit of dioxin concentration (Figure 4). However, the marginal reduction in the testing costs per collected truck sample decreases for each additional unit of the target concentration. For example, the testing costs per collected truck sample decreases by $€ 80$ when the target concentration was increased from 2 to $3 \mathrm{pg} T E Q / g$ of fat, and by $€ 0.50$ when the target concentration was increased from 19 to $20 \mathrm{pg}$ TEQ/g of fat. The largest reduction of testing costs given by an increasing number of truck samples mixed into a pooled sample is observed when the target concentration increases from 2 to $6 \mathrm{pg} T E Q / g$ of fat (Figure 4). Note that at the target dioxin concentration of $2 \mathrm{pg} T E Q / \mathrm{g}$ of fat, the collected truck samples need to be tested individually because pooling would dilute the concentration of dioxins below the decision limit. 


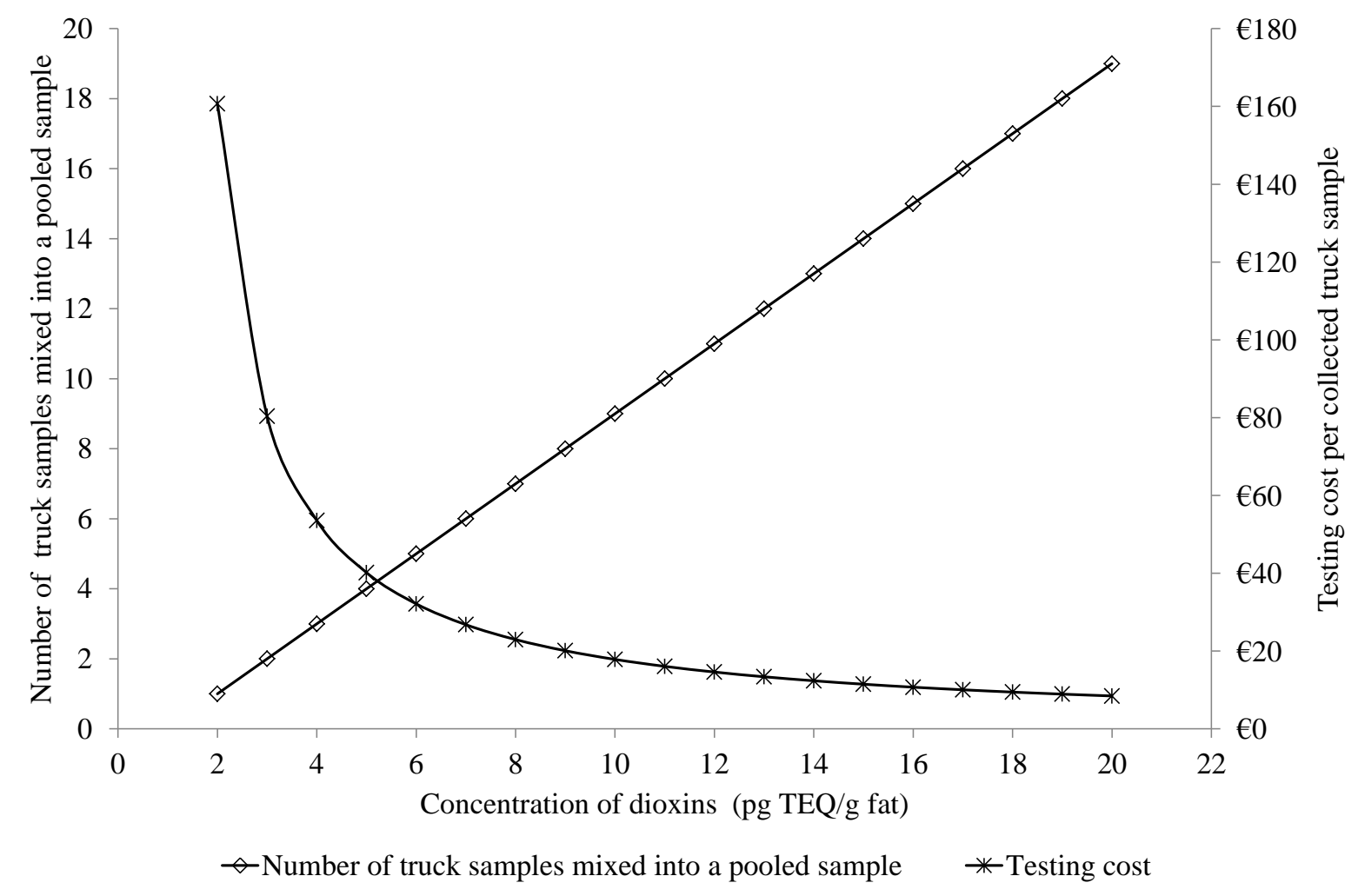

Figure 4. Effect of increasing the target concentration of dioxins on the optimal number of truck samples mixed into a pooled sample and the testing cost per collected truck sample. $\mathrm{TEQ}=$ toxic equivalents.

When increasing the number of contaminated farms and the target dioxin concentration simultaneously (i.e. a bigger detectable incident), the results show that the monitoring costs decrease markedly (Table 5). Monitoring costs differ widely between scenarios. They vary from $€ 2.6$ million when aiming to detect at least 1 contaminated farm at action level (2 pg $\mathrm{TEQ} / \mathrm{g}$ of fat; reference scenario) to $€ 34,063$ when aiming to detect at least 1 of 10 contaminated farms at $20 \mathrm{pg}$ TEQ/g of fat (Table 5). This represents a reduction in monitoring costs of approximately $98 \%$. However, a significant cost reduction of $73 \%$ can already be obtained when aiming to detect at least 1 of 2 contaminated farms at the maximum level ( $3 \mathrm{pg}$ TEQ/g of fat). 
Table 5. Reduction of the monitoring costs at $95 \%$ effectiveness when increasing the size of the detectable incident with respect to the reference scenario [ 1 contaminated farm at 2 pg toxic equivalents (TEQ)/g of fat]

\begin{tabular}{|c|c|c|c|c|c|c|c|c|c|c|c|c|c|c|c|c|c|c|c|c|}
\hline \multirow{3}{*}{$\begin{array}{l}\text { Conc. of } \\
\text { dioxins }{ }^{1}\end{array}$} & \multicolumn{20}{|c|}{ No. of contaminated farms } \\
\hline & \multicolumn{2}{|c|}{1} & \multicolumn{2}{|c|}{2} & \multicolumn{2}{|c|}{3} & \multicolumn{2}{|c|}{4} & \multicolumn{2}{|c|}{5} & \multicolumn{2}{|c|}{6} & \multicolumn{2}{|c|}{7} & \multicolumn{2}{|c|}{8} & \multicolumn{2}{|c|}{9} & \multicolumn{2}{|c|}{10} \\
\hline & $\operatorname{Cost}^{2}$ & Redc. $^{3}$ & $\operatorname{Cost}^{2}$ & Redc. $^{3}$ & $\operatorname{Cost}^{2}$ & Redc. $^{3}$ & $\operatorname{Cost}^{2}$ & Redc. $^{3}$ & $\operatorname{Cost}^{2}$ & Redc. $^{3}$ & $\operatorname{Cost}^{2}$ & Redc. $^{3}$ & $\operatorname{Cost}^{2}$ & Redc. $^{3}$ & $\operatorname{Cost}^{2}$ & Redc. $^{3}$ & $\operatorname{Cost}^{2}$ & Redc. $^{3}$ & $\operatorname{Cost}^{2}$ & Redc. $^{3}$ \\
\hline 2 & 2,667 & 0.0 & 1,334 & 50.0 & 889 & 66.7 & 667 & 75.0 & 533 & 80.0 & 444 & 83.3 & 381 & 85.7 & 333 & 87.5 & 296 & 88.9 & 267 & 90.0 \\
\hline 3 & 1,440 & 46.0 & 720 & 73.0 & 480 & 82.0 & 360 & 86.5 & 288 & 89.2 & 240 & 91.0 & 206 & 92.3 & 180 & 93.3 & 160 & 94.0 & 144 & 94.6 \\
\hline 4 & 1,030 & 61.4 & 515 & 80.7 & 343 & 87.1 & 258 & 90.3 & 206 & 92.3 & 172 & 93.6 & 147 & 94.5 & 129 & 95.2 & 114 & 95.7 & 103 & 96.1 \\
\hline 5 & 826 & 69.0 & 413 & 84.5 & 275 & 89.7 & 206 & 92.3 & 165 & 93.8 & 138 & 94.8 & 118 & 95.6 & 103 & 96.1 & 92 & 96.6 & 82 & 96.9 \\
\hline 6 & 703 & 73.7 & 351 & 86.8 & 234 & 91.2 & 176 & 93.4 & 141 & 94.7 & 117 & 95.6 & 100 & 96.2 & 88 & 96.7 & 78 & 97.1 & 70 & 97.4 \\
\hline 7 & 621 & 76.7 & 310 & 88.4 & 207 & 92.2 & 155 & 94.2 & 124 & 95.3 & 103 & 96.1 & 89 & 96.7 & 78 & 97.1 & 69 & 97.4 & 62 & 97.7 \\
\hline 8 & 562 & 78.9 & 281 & 89.5 & 187 & 93.0 & 141 & 94.7 & 112 & 95.8 & 94 & 96.5 & 80 & 97.0 & 70 & 97.4 & 62 & 97.7 & 56 & 97.9 \\
\hline 9 & 519 & 80.6 & 259 & 90.3 & 173 & 93.5 & 130 & 95.1 & 104 & 96.1 & 86 & 96.8 & 74 & 97.2 & 65 & 97.6 & 58 & 97.8 & 52 & 98.1 \\
\hline 10 & 485 & 81.8 & 242 & 90.9 & 162 & 93.9 & 121 & 95.5 & 97 & 96.4 & 81 & 97.0 & 69 & 97.4 & 61 & 97.7 & 54 & 98.0 & 48 & 98.2 \\
\hline 11 & 457 & 82.9 & 229 & 91.4 & 152 & 94.3 & 114 & 95.7 & 91 & 96.6 & 76 & 97.1 & 65 & 97.6 & 57 & 97.9 & 51 & 98.1 & 46 & 98.3 \\
\hline 12 & 435 & 83.7 & 217 & 91.8 & 145 & 94.6 & 109 & 95.9 & 87 & 96.7 & 72 & 97.3 & 62 & 97.7 & 54 & 98.0 & 48 & 98.2 & 43 & 98.4 \\
\hline 13 & 416 & 84.4 & 208 & 92.2 & 139 & 94.8 & 104 & 96.1 & 83 & 96.9 & 69 & 97.4 & 59 & 97.8 & 52 & 98.0 & 46 & 98.3 & 42 & 98.4 \\
\hline 14 & 401 & 85.0 & 200 & 92.5 & 134 & 95.0 & 100 & 96.2 & 80 & 97.0 & 67 & 97.5 & 57 & 97.9 & 50 & 98.1 & 44 & 98.3 & 40 & 98.5 \\
\hline 15 & 387 & 85.5 & 194 & 92.7 & 129 & 95.2 & 97 & 96.4 & 77 & 97.1 & 64 & 97.6 & 55 & 97.9 & 48 & 98.2 & 43 & 98.4 & 39 & 98.6 \\
\hline 16 & 375 & 85.9 & 188 & 93.0 & 125 & 95.3 & 94 & 96.5 & 75 & 97.2 & 63 & 97.7 & 54 & 98.0 & 47 & 98.2 & 42 & 98.4 & 38 & 98.6 \\
\hline 17 & 365 & 86.3 & 183 & 93.2 & 122 & 95.4 & 91 & 96.6 & 73 & 97.3 & 61 & 97.7 & 52 & 98.0 & 46 & 98.3 & 41 & 98.5 & 36 & 98.6 \\
\hline 18 & 356 & 86.6 & 178 & 93.3 & 119 & 95.6 & 89 & 96.7 & 71 & 97.3 & 59 & 97.8 & 51 & 98.1 & 45 & 98.3 & 40 & 98.5 & 36 & 98.7 \\
\hline 19 & 348 & 87.0 & 174 & 93.5 & 116 & 95.7 & 87 & 96.7 & 70 & 97.4 & 58 & 97.8 & 50 & 98.1 & 44 & 98.4 & 39 & 98.6 & 35 & 98.7 \\
\hline 20 & 341 & 87.2 & 170 & 93.6 & 114 & 95.7 & 85 & 96.8 & 68 & 97.4 & 57 & 97.9 & 49 & 98.2 & 43 & 98.4 & 38 & 98.6 & 34 & 98.7 \\
\hline
\end{tabular}

\footnotetext{
${ }^{1}$ Concentration of dioxins (pg TEQ/g of fat).

${ }^{2}$ Monitoring costs $(€$, in thousands).
}

${ }^{3}$ Reduction (\%) 


\section{The effect on the Monitoring Costs when varying the required Effectiveness level}

Figure 5 shows the increase in monitoring costs seen as the required effectiveness level increased. As seen in Figure 5, for all effectiveness levels, monitoring costs are higher for incidents with a lower number of expected contaminated farms (F1-C2, F1-C10) than for incidents with higher number of expected contaminated farms (F10-C2, F10-C10). Monitoring costs vary among scenarios with different targeted detectable incidents. The costeffective curve moves upwards and become steeper when aiming to identify smaller detectable incidents. This implies that the cost of increasing the effectiveness at the same proportion and from the same initial level is higher as the size of the incident became smaller. The cost of increasing the effectiveness level from 80 to $85 \%$ varies from $€ 256,200$ at the smallest detectable incident to $€ 4,600$ when aiming to detect at least 1 of 10 contaminated farms at $10 \mathrm{pg} \mathrm{TEQ} / \mathrm{g}$ of fat.

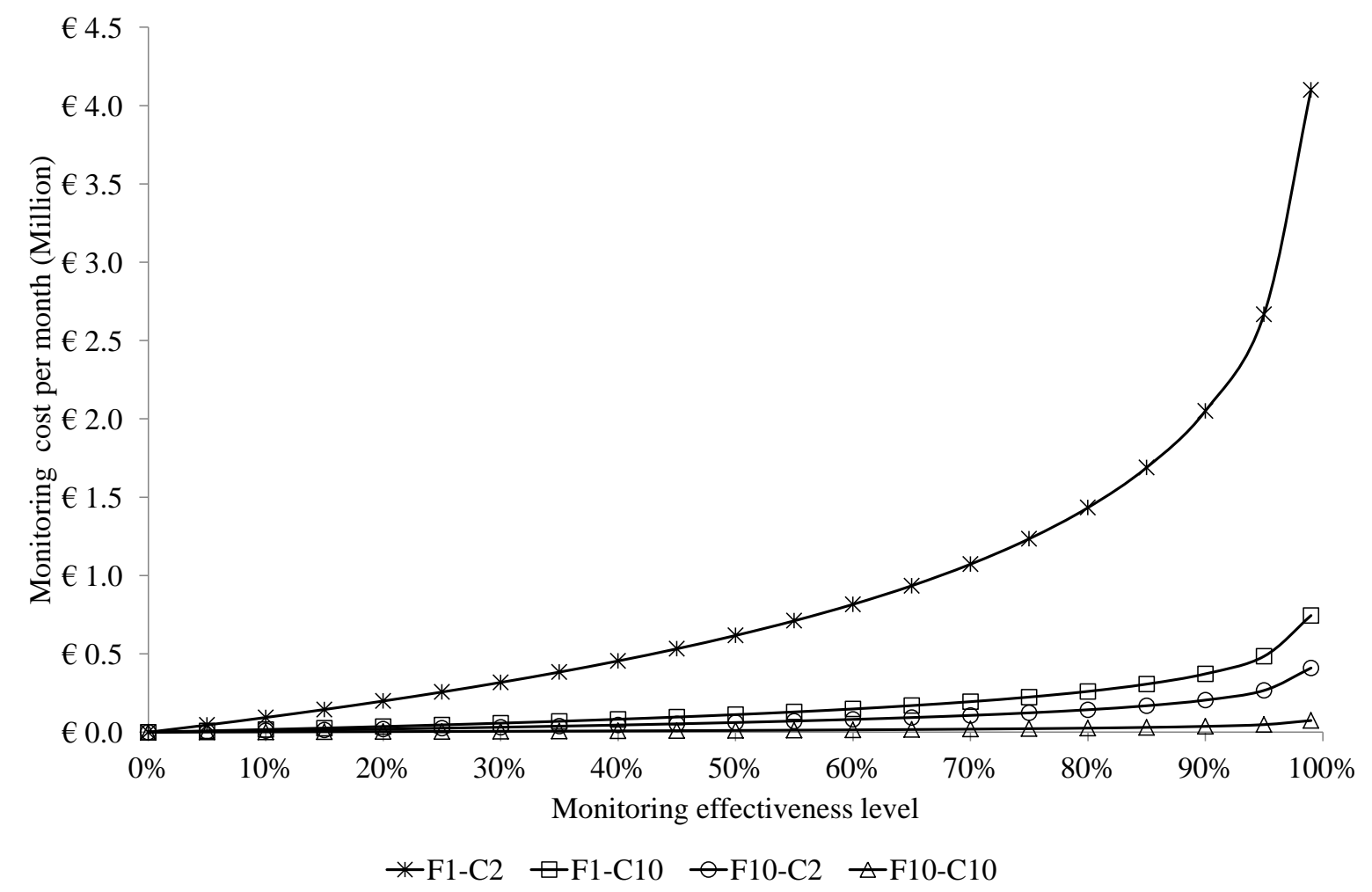

Figure 5. Effect of varying the level of monitoring effectiveness on the monitoring costs applied to 4 contamination scenarios. 
Bulk milk dioxin monitoring

\section{ME optimization results for a fixed monthly Monitoring Budget}

The results of the ME optimization model, for a fixed monthly monitoring budget of $€ 40,000$ for the 8 scenarios are presented in Table 6 . At any budget, the bigger the detectable incident, the higher the effectiveness obtained. The optimal number of collected truck samples and the optimal number of collected truck samples mixed into a pooled sample are limited by the monitoring budget and the target dioxin concentration at the contaminated farm(s) tank milk.

An increase in the target dioxin concentration increased the number of collected truck samples that could be combined into a pooled sample, and thus the number of pooled samples that must be tested decreased (Table 6, C2 versus C3, C10 and C20). If fewer pooled samples are tested, the actual testing costs can be reduced and, therefore, the remaining budget can be allocated for sampling more milk trucks. The bigger the number of collected truck samples, the higher the effectiveness that can be obtained for the same budget. When focusing on a target concentration equivalent to the action level ( $2 \mathrm{pg} \mathrm{TEQ} / \mathrm{g}$ of fat) at just one farm, the maximum effectiveness obtained is $4.4 \%$. The effectiveness level almost doubles (8.0\%) after increasing the target dioxin concentration from the action to the maximum level ( $3 \mathrm{pg} \mathrm{TEQ} / \mathrm{g}$ of fat). At the second scenario, 2 collected truck samples can be pooled and therefore, fewer pooled samples must be tested, allowing sampling of more collected truck samples and increasing the probability of detecting the contamination. Effectiveness increases to $36.2 \%$ and $56.5 \%$ when looking for a contamination that affects 10 farms at the action and maximum levels, respectively. 
Table 6. Optimal number of samples for 8 contamination scenarios

\begin{tabular}{lcccc}
\hline Scenario & $\begin{array}{c}\text { No. of collected } \\
\text { truck samples } \\
\text { per month }\end{array}$ & $\begin{array}{c}\text { No. of truck samples } \\
\text { mixed into a } \\
\text { pooled sample }\end{array}$ & $\begin{array}{c}\text { No. of pooled } \\
\text { samples tested } \\
\text { per month }\end{array}$ & $\begin{array}{c}\text { Monitoring } \\
\text { effectiveness (\%) }\end{array}$ \\
\hline F1-C2 & 229 & 1 & 229 & 4.4 \\
F1-C3 & 425 & 2 & 212 & 8.0 \\
F1-C10 & 1,262 & 9 & 140 & 21.9 \\
F1-C20 & 1,793 & 19 & 94 & 29.6 \\
F10-C2 & 229 & 1 & 229 & 36.2 \\
F10-C3 & 425 & 2 & 212 & 56.5 \\
F10-C10 & 1,262 & 9 & 140 & 91.6 \\
F10-C20 & 1,793 & 19 & 94 & 97.0 \\
\hline
\end{tabular}

An increase in the number of expected contaminated farms has no effect on the number of collected truck samples or the mixing ratio at which truck samples are combined into a pooled sample (Table 6, F1 vs. F10). However, the effectiveness level increases with a higher number of contaminated farms. Increasing the number of expected contaminated farms from 1 to 10 combined with the lowest dioxin concentration ( $2 \mathrm{pg} \mathrm{TEQ} / \mathrm{g}$ of fat), increases the effectiveness from 4.4 to $36.2 \%$. A higher range of effectiveness is observed (from 29.6 to $97.0 \%$ ) in scenarios where the number of contaminated farms was increased and combined with the highest dioxin concentration (20 pg TEQ/g of fat).

For each additional contaminated farm, the cost-effectiveness curve moves upwards and become steeper, increasing the probability of detecting the contamination (Figure 6). However, the shape of the curve becomes much less steep for any concentration higher than $10 \mathrm{pg} \mathrm{TEQ} / \mathrm{g}$ of fat. This implies that the marginal increase in the effectiveness for each additional contaminated farm is lower for scenarios with target concentrations above $10 \mathrm{pg}$ TEQ/g of fat than for those scenarios below this concentration (Figure 6). 
Bulk milk dioxin monitoring

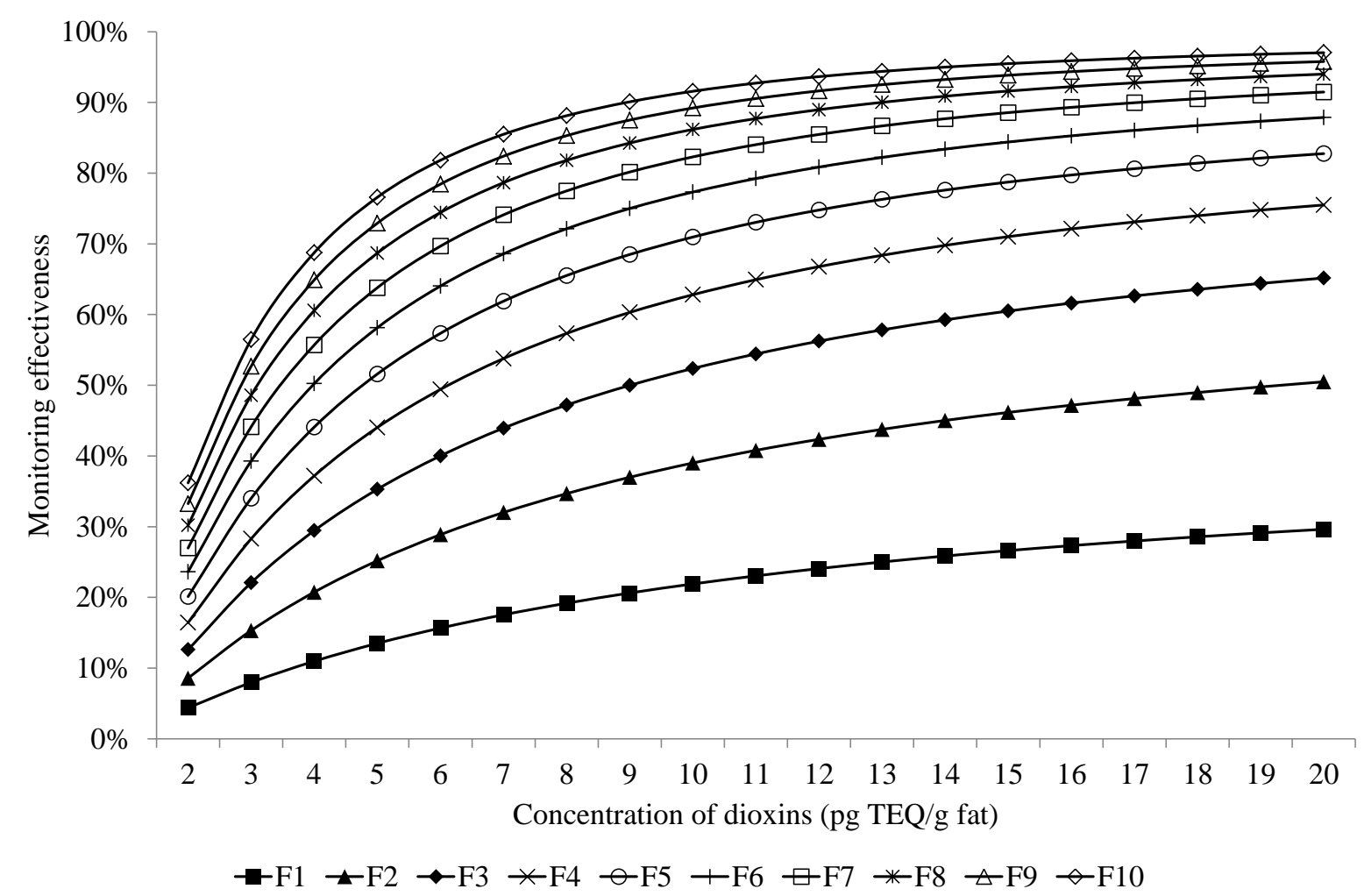

Figure 6. Maximum obtained effectiveness level for a monthly monitoring budget of $€ 40,000$ when increasing the expected number of contaminated farms (F1-F10) and the initial dioxin concentration at the farm level [ 2-20 pg toxic equivalents (TEQ)/g of fat].

\section{The effect on the Effectiveness level when varying the Monitoring Budget}

Our results show that with a higher available budget, a higher effectiveness level is obtained for all scenarios (Figure 7). However, when the monitoring budget is increased from $€ 10,000$ to $€ 50,000$, a steeper increase in effectiveness is obtained at scenarios with bigger detectable incidents (i.e., F10-C10). In such scenarios, the marginal increase in effectiveness for each additional euro invested in monitoring is bigger than for those scenarios representing small detectable incidents (i.e., F1-C2). Consequently, detecting at least one contaminated farm with a high level of effectiveness (90\%) and within detectable incidents of bigger proportions (F10-C10) is possible with relatively low monitoring budgets $(€ 50,000)$. 


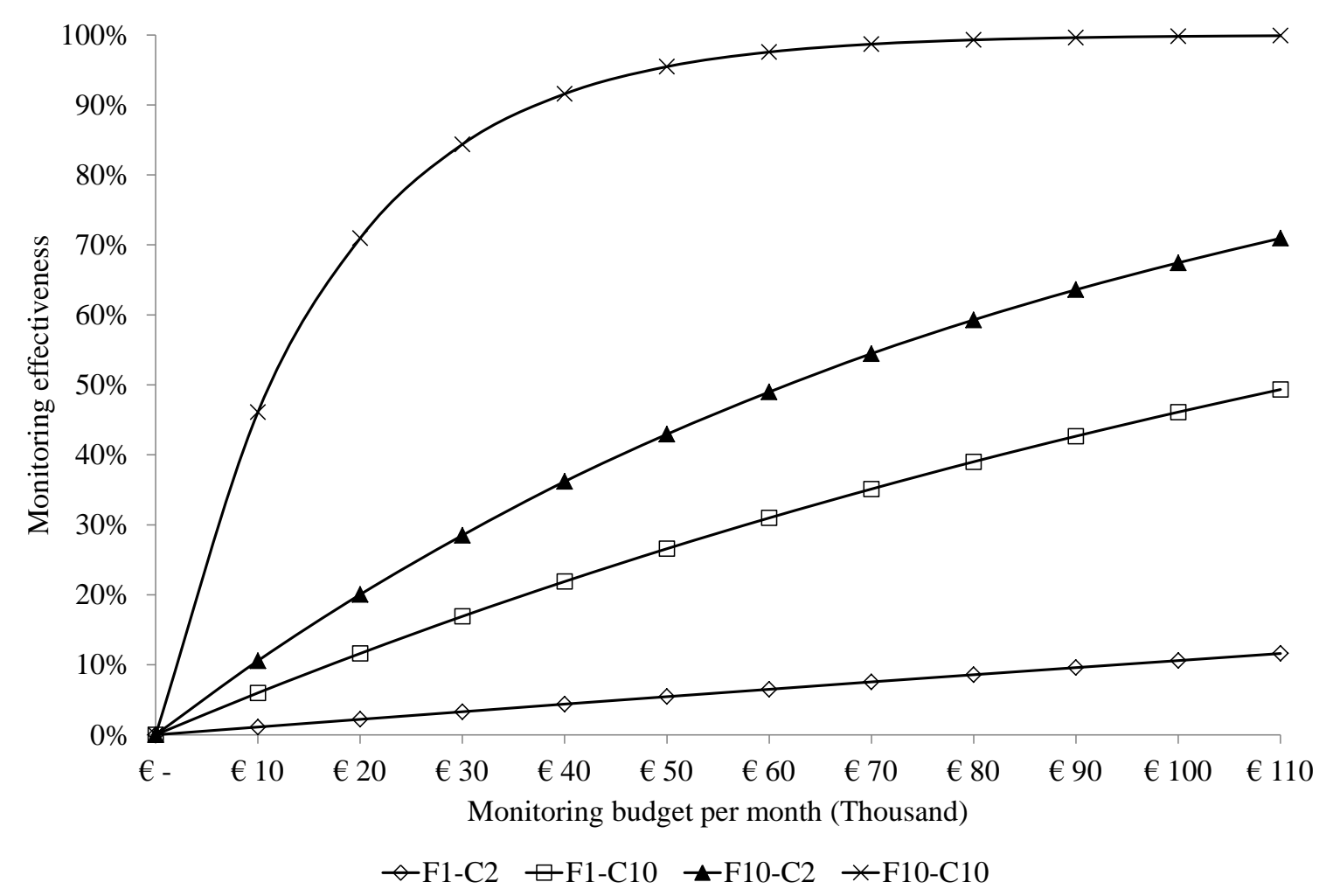

Figure 7. Levels of effectiveness for different monitoring budgets applied in 4 contamination scenarios.

\subsection{Discussion}

A linear programming methodology was used to build the MC and ME optimization models. Linear programming is a salient decision analysis method that undertakes resource allocation problems (Rushton, 2009) and ensures an optimal plan (Dijkhuizen and Morris, 1997). This methodology has been applied in previous studies to determine the optimal surveillance strategy when maximizing the efficacy of import phytosanitary inspection (Surkov et al., 2008; Surkov et al., 2009) and to determine the optimal strategy to improve food safety at farm level in the Dutch dairy chain (Valeeva and Huirne, 2008).

The contextual scenario in which the dioxin monitoring and the contamination scenarios are described was built based on available information from the Dutch dairy chain. However, this study does not aim to be linked to the context of the dairy chain of a specific 
Bulk milk dioxin monitoring

country, but to focus on presenting the methodology used to optimize dioxin monitoring in bulk milk within the context of a hypothetical dairy chain.

The losses of dairy farms or dairy processors related to mitigations strategies emplaced after an incident has been detected, such as the cost of destroying contaminated milk, are out of the scope of this study. The costs related to the impact of implementing mitigations strategies are direct financial costs (Lascano Alcoser et al., 2011) not related to the monitoring costs defined in this study.

By the MC and ME optimization models, this study established a relation between the costs of monitoring dioxins and the capacity of monitoring to detect an incident. These models can determine either the minimum amount of resources for monitoring needed to detect an incident with certain probability of detection (effectiveness), or the effectiveness from a given amount of resources. Establishing socially optimal levels of monitoring within the context of maximization of social welfare requires a more extensive analysis, including costs and benefits to government, industry and consumers. The results of this study alone cannot be seen as an independent determinant of the socially optimal level of monitoring.

This study considers the EC maximum level of dioxins in milk ( $3 \mathrm{pg} \mathrm{TEQ} / \mathrm{g}$ of fat) and concentrations above this limit as hazard levels to public health. Milk contaminated with dioxin concentrations at or above maximum level is not allowed to be placed on the market (EC, 2006b). Dioxin concentrations tested below the maximum level and at or above the EC action level (2 pg TEQ/g of fat) are considered warning signals of a potential incident. Therefore, they trigger further investigation to determine the source of the abnormal dioxin levels (EC, 2006a).

Detecting a dioxin incident with a high level of effectiveness is possible, but at high costs. Monitoring costs and effectiveness are strongly determined by the size of the incident that the monitoring is aiming to detect. The results of this study point to a large reduction in 
monitoring costs at the same level of effectiveness when aiming to find slightly larger detectable incidents than those in the reference scenario. For example, at the same level of effectiveness (95\%), a $73 \%$ reduction in monitoring costs was reached when aiming to detect 1 of 2 contaminated farms at the maximum level instead of 1 at the action level. This implies that dioxin monitoring aiming at detecting at least 1 contaminated farm among somewhat larger detectable incidents can be implemented at much lower costs without reducing the monitoring effectiveness level. Furthermore, our results show that low monitoring budgets are only highly effective when aiming to detect large incidents.

The decision to implement a specific dioxin monitoring plan given a certain budget or to reach a desired effectiveness level should be based on the level of risk accepted by the decision makers. Taking zero risk (zero tolerance), which means aiming to detect 1 contaminated farm at a bulk milk concentration equal to the action level, results in extremely high monitoring costs ( $€ 2.6$ million per month at the $95 \%$ effectiveness level). This study showed that taking a higher risk for not detecting the smallest detectable incident significantly reduces the monitoring costs. However, the question remains as to how much risk is acceptable. In this regard, historical information with respect to the size of dioxin incidents could be used to identify the minimum acceptable risk. For example, when the Dutch milk dioxin incident occurred in 2004, only 1 contaminated farm was identified with a dioxin concentration of $20 \mathrm{pg} \mathrm{TEQ} / \mathrm{g}$ of fat (Hoogenboom et al., 2010). When applying the MC model, dioxin monitoring aimed at detecting an incident at this concentration with $95 \%$ effectiveness could be done with less than $10 \%$ of the monitoring costs required to detect an incident with a concentration equal to the action level. Moreover, most of the dioxin incidents frequently involve more than 1 contaminated farm, such as the 1998 dioxin incident in Germany in which milk from 2 dairy farms had an average dioxin concentration of $3 \mathrm{pg}$ TEQ/g of fat (Malisch, 2000). In this case, the monitoring costs required to detect at least 1 of 
Bulk milk dioxin monitoring

the 2 contaminated farms with a $95 \%$ effectiveness would be one-fourth of the cost required to detect this incident at the smallest target concentration considered in this research. In this regard, looking at the maximum level instead of the action level seems justifiable but aiming at much higher levels seems more difficult to defend, as extremely high levels, such as $10 \mathrm{pg}$ $\mathrm{TEQ} / \mathrm{g}$ of fat or higher, are rarely observed. It can also be argued that incidents consisting of a single farm with concentrations around the maximum level may not be relevant, as this implies an extremely local source, the elimination of which may not contribute much to background levels.

In this study, the same decision limit was applied for both testing methods, Calux and HRGC/HRMS. In practice this could be different, because both methods could show different variations on the test results and different decision limits might be applied for each method. This would increase the accuracy of the results showed in this study. However, further research evaluating each of the methods should be carried out to determine better estimators of the decision limits for each method.

Pooling samples brings the possibility of getting false-positive results, thus, declaring certain a nonexistent incident. This is given that the same dioxin concentration at the positive pooled sample can be obtained by combining individual samples with different dioxin concentrations, none of them necessarily above the action level considered in this study. However, false-positives results are not a concern to the objective of the monitoring, which is to detect an incident (given that it is certain) with a required effectiveness.

The average sampling cost per collected truck sample considered in this study is independent of the number of collected truck samples. Therefore, the relation between sampling costs and the number of collected samples is linear. However, as the capacity of the fixed factors associated to the sampling activity is reached, it is expected that the average cost per collected truck sample rises. For example, suppose that the capacity of the storage space 
to keep the collected truck samples is reached, then renting an extra storage space would be required and, thus, the average cost per collected truck sample would increase. Consequently, the total monitoring costs could have been underestimated as costs might increase when the number of collected truck samples increased. However, this assumption has a small effect on the results because the contribution of sampling costs is small compared with the contribution of tests costs.

In this study, it was assumed that milk trucks were sampled randomly at each sampling time. This implies that milk from the same dairy farm might be sampled more than once per month. Therefore, the results of this study might vary if a different type of sampling procedure is applied (e.g., one where it can be assured that each farm is only tested once per month). This could be considered in further studies.

The pooling strategy of milk samples is highly important when the aim is to reduce the monitoring costs or increase the effectiveness of monitoring. However, the results of this research show that the possible cost advantage of mixing more truck or farm samples into a pooled sample is feasible to a limited extent. In fact, the maximum number of truck or farm samples that can be pooled depends on the target concentration aimed at detecting. Any pooling strategy mixing a bigger number of samples than the mentioned limit would dilute the concentration below the decision limit, compromising the possible detection of an incident. This is also the case when monitoring dioxins at other control points where a large number of trucks or farms are combined, such as at the silos at the entry of the milk processors. Additionally, if a contamination were detected at this control point, the incident costs aiming to identify the contaminated farm are expected to increase strongly. This is true given that a sample taken from a silo at the milk company could consist of milk from a large number of farms. 
Bulk milk dioxin monitoring

Further research should evaluate the cost and effectiveness of other monitoring strategies at other sampling points along the dairy chain. One of these strategies could be to monitor the feed or feed ingredients at the feed producer. Monitoring dioxins at this stage of the chain would be logical, given the importance of feed as one of the main sources of food dioxin contaminations (Büchert et al., 2001; Huwe, 2002). Additionally, monitoring at this stage of the chain could avoid the contamination of milk and the contamination of other agrifood chains. However, compliance of feed products to legal dioxin levels does not guarantee that dioxin levels in food products are not exceeded (van Raamsdonk et al., 2009). Minimum standard levels of dioxins in feed are required such that dioxin levels in food are not exceeded.

\subsection{Conclusions}

This study developed decision-making tools for risk managers of food industries and food safety authorities, to evaluate the costs and effectiveness of dioxin monitoring in bulk milk. The models developed can be used to determine the minimum amount of resources required to accomplish a certain level of effectiveness or to calculate the achieved level of effectiveness at a certain monitoring budget. To the knowledge of the authors no such models in the domain of food safety have ever been published. The optimal cost-effective dioxin monitoring depends on the monitoring goal, which at the same time, depends on the level of risk (tolerance) that decision makers are willing to take. Taking zero risk (zero tolerance) results in extremely high monitoring costs; however, such incidents, caused by a local source of dioxins, may not contribute to the background level and may not be relevant. This study does not include costs and benefits of monitoring to government, industry and consumers. Consequently, based only on the results of this study, it is not possible to determine optimal levels of dioxin monitoring that maximize social welfare. In all, the probability of detecting 
an incident largely depends on the number of truck samples collected. Thus, the sampling strategy can be improved by optimizing the number of collected truck samples, thereby ensuring an effective detection of an incident. 
Bulk milk dioxin monitoring

\section{References}

Bernard, A., F. Broeckaert, G. De Poorter, A. De Cock, C. Hermans, C. Saegerman, and G. Houins. 2002. The Belgian PCB/dioxin incident: Analysis of the food chain contamination and health risk evaluation. Environ. Res. 88(1):1-18.

Büchert, A., T. Cederberg, P. Dyke, H. Fiedler, P. Fürst, A. Hanberg, J. Hosseinpour, O. Hutzinger, J. G. Kuenen, R. Malisch, L. L. Needham, K. Olie, O. Papke, J. Rivera Aranda, G. Thanner, G. Umlauf, T. Vartiainen, and C. van Holst. 2001. Dioxin contamination in food. Bayreuth, Germany, from September 28 to October 1, 2000. Environ. Sci. Poll. Res. 8(2):84-88.

De Mul, A., M. I. Bakker, M. J. Zeilmaker, W. A. Traag, S. P. J. van Leeuwen, R. L. A. P. Hoogenboom, P. E. Boon, and J. D. van Klaveren. 2008. Dietary exposure to dioxins and dioxin-like PCBs in The Netherlands anno 2004. Regul. Toxicol. Pharmacol. 51(3):278-287.

Dijkhuizen, A. A., and R. S. Morris. 1997. Animal health economics. Sidney: University of Sidney, Postgraduate Foundation in Veterinary Science. University of Sydney, Sydney, Australia.

European Commission (EC). 2000. Report of experts participating in Task 3.2.5 "Assessment of dietary intake of dioxins and related PCBs by the population of EU Member States". In Reports on Tasks for Scientific Cooperation. European Commission, Health and Consumer Protection Directorate-General, Brussels.

European Commission (EC). 2001a. Communication from the Commission to the Council, the European Parliament and the Economic and Social Committe. Community Strategy for Dioxins, Furans and Polychlorinated Biphenyls. COM(2001) 593 final. Off. J. Eur. Comm. C322:2-18. 
European Commission (EC). 2001b. Council Directive 2001/102/EC of 27 November 2001 amending Directive 1999/29/EC on the undesirable substances and products in animal nutrition. Off. J. Eur. Comm. L6:45-49.

European Commission (EC). 2001c. Council Regulation (EC) No 2375/2001 of 29 November 2001 amending Commission Regulation (EC) No 466/2001 setting maximum levels for certain contaminants in foodstuffs. Off. J. Eur. Comm. L 321:1-5.

European Commission (EC). 2002. Commission Recommendation 2002/201/EC of 4 March 2002 on the reduction of the presence of dioxins, furans and PCBs in feedingstuffs and foodstuffs. Off. J. Eur. Comm. L 67:69-73.

European Commission (EC). 2004. Commission Recommendation 2004/704/EC of 11 October 2004 on the monitoring of background levels of dioxins and dioxin-like PCBs in feedingstuffs. Off. J. Eur. Comm. L 321:38-44.

European Commission (EC). 2006a. Commission Recommendation 2006/88/EC of 6 February 2006 on the reduction of the presence of dioxins, furans and PCBs in feedingstuffs and foodstuffs. Off. J. Eur. Comm. L42:26-28.

European Commission (EC). 2006b. Commission regulation (EC) No 1883/2006 of 19 December 2006 laying down methods of sampling and analysis for the official control of levels of dioxins and dioxin-like PCBs in certain foodstuffs. Off. J. Eur. Comm. L364:32.

European Commission (EC). 2006c. Commission Regulation (EC) No. 1881/2006 of 19 December 2006 setting maximum levels for certain contaminants in foodstuffs. Off. J. Eur. Comm. L364:5-24. 
Bulk milk dioxin monitoring

European Food Safety Authority (EFSA). 2010. Results of the monitoring of dioxin level in food and feed. EFSA J. 8(3):1385.

Frontline Systems Inc. 2011. Solver. Frontline Systems Inc., Incline Village, NV.

Heres, L., R. Hoogenboom, R. Herbes, W. Traag, and B. Urlings. 2010. Tracing and analytical results of the dioxin contamination incident in 2008 originating from the Republic of Ireland. Food Addit. Contam. Part A-Chem. 27(12):1733-1744.

Hoogenboom, R., M. Zeilmaker, J. van Eijkeren, K. Kan, M. Mengelers, D. Luykx, and W. Traag. 2010. Kaolinic clay derived PCDD/Fs in the feed chain from a sorting process for potatoes. Chemosphere. 78(2):99-105.

Huwe, J. K. 2002. Dioxins in food: A modern agricultural perspective. J. Agric. Food Chem. 50(7):1739-1750.

Huwe, J. K., and D. J. Smith. 2005. Laboratory and on-farm studies on the bioaccumulation and elimination of dioxins from a contaminated mineral supplement fed to dairy cows. J. of Agric. Food Chem. 53(6):2362-2370.

Kan, C. A. and G. A. L. Meijer. 2007. The risk of contamination of food with toxic substances present in animal feed. Anim. Feed Sci. Technol. 133(1-2):84-108.

Lascano Alcoser, V. H., A. G. J. Velthuis, L. A. P. Hoogenboom, and H. J. van der Fels-Klerx. 2011. Financial impact of a dioxin incident in the Dutch dairy chain. J. Food Prot. 74(6):967-979.

Malisch, R. 2000. Increase of the PCDD/F-contamination of milk, butter and meat samples by use of contaminated citrus pulp. Chemosphere. 40(9-11):1041-1053. 
Rushton, J. 2009. The Economics of Animal Health and Production. Foreward by P. Ellis with contributions from A. James, A. Shaw, D. Leonard, C. Tisdell, J. Otte, A. Stott, H. Rojas, P. Bonnet, C. Devendra, L. Redmond, H. Beck, U. Pica-Ciamarra, M. Lesnoff, V. Ahuja and M. Upton. CABI Publishing, Wallingford, UK.

Scientific Committee on Food (SCF). 2001. Opinion of the Scientific Committee on Food on the risk assessment of dioxins and dioxin-like PCBs in food. Scientific Committee on Food report CS/CNTM/DIOXIN/20 final. Accessed Apri. 2012. http://ec.europa.eu/food/fs/sc/scf/out90_en.pdf

Schmid, P., E. Gujer, S. Degen, M. Zennegg, A. Kuchen, and C. Wuthrich. 2002. Levels of polychlorinated dibenzo-p-dioxins and dibenzofurans in food of animal origin. The Swiss dioxin monitoring program. J. Agric. Food Chem. 50(25):7482-7487.

Surkov, I. V., A. G. J. M. Oude Lansink, and W. van der Werf. 2009. The optimal amount and allocation of sampling effort for plant health inspection. Eur. Rev. Agric. Econ. 36(3):295-320.

Surkov, I. V., A. G. J. M. Oude Lansink, O. van Kooten, and W. van der Werf. 2008. A model of optimal import phytosanitary inspection under capacity constraint. Agric. Econ. 38(3):363-373.

United Nations Environment Program (UNEP). 2009. Stockholm Convention on persisten organic pollutants (POPs) as amended in 2009. Text and Anexes. United Nations Environment Program. Accessed June, 2012. http://chm.pops.int/Convention/ConventionText/tabid/2232/Default.aspx

Valeeva, N. I. and R. B. M. Huirne. 2008. Strategies to improve food safety in the dairy chain: A casestudy from The Netherlands. Opportunities and Challenges for Smallholder Ruminant Systems in Latin America. Universidad Autonoma Estado Mexico, Toluca, Mexico. 
Bulk milk dioxin monitoring

van Raamsdonk, L. W. D., J. C. H. van Eijkeren, G. A. L. Meijer, M. Rennen, M. J. Zeilmaker, L. A. P. Hoogenboom, and M. Mengelers. 2009. Compliance of feed limits, does not mean compliance of food limits. Biotech. Agron. Soc. 13:51-57.

Velthuis, A. G. J., M. P. M. Meuwissen, and R. B. M. Huirne. 2009. Distribution of direct recall costs along the milk chain. Agribusiness. 25(4):466-479.

World Health Organization (WHO). 2007. Dioxins and their effects on human health. Fact sheet 225. World Health Organization, Geneva, Switzerland. 


\section{Chapter 4}

\section{Cost-effective allocation of resources for monitoring dioxins along the pork production chain}

V. H. Lascano Alcoser, M. C. M. Mourits, H. J. van der Fels-Klerx, L. Heres, A. G. J. Velthuis, L. A. P. Hoogenboom, A. G. J. M. Oude Lansink 
Monitoring dioxins along the pork chain

\section{Abstract}

The pork chain has been seriously affected by dioxin incidents in recent decades. Hence, monitoring dioxins is crucial for detecting contaminations in the pork chain. This study aims to develop a decision support tool (optimization model) to determine cost-effective monitoring schemes for detecting and tracing a dioxin contamination over multiple control points along the pork production chain. The optimization model considers four control points (i.e. at the supplier of fatty feed ingredients, the feed mill, the slaughterhouse and the fat melting facility) and a weekly monitoring period. It was applied to several hypothetical contamination scenarios involving contaminated animal fatty feed ingredients. The costeffective allocation of resources for detecting and tracing the dioxin contamination from an integrated chain approach (i.e. considering all control points) focuses on monitoring at the feed mill, followed by the supplier of fatty feed ingredients and - to a lesser extent - by the slaughterhouse. The number of contaminated feed mills, the frequency of dioxin contaminations, the required level of effectiveness, and the cost of screening are main factors driving the total monitoring costs. Sharing the responsibility of monitoring dioxins within control points along the chain largely reduces the total monitoring costs. In each of the evaluated scenarios, the total costs of monitoring dioxins at individual control points are larger than the costs resulting from an optimal allocation of resources among all control points integrated in one overarching chain monitoring scheme. These results elicit the economic benefits of a chain approach to monitoring dioxins over an approach where each chain actor independently monitors dioxins. The developed model can be used by decision makers in the feed and food industry for determining optimal schemes for monitoring dioxins in the pork chain focusing on preventing specific contaminations. 


\subsection{Introduction}

Polychlorinated dibenzo-p-dioxins and dibenzofurans (PCDD/Fs), from here on termed 'dioxins', are ubiquitous environmental pollutants found in human tissues even in cases where neither occupational nor accidental exposure has been reported (Rose et al., 2009). Dioxins are toxic at low levels, with proven effects as endocrine disruptors in animals and humans (Hoogenboom, 2009). They bio-accumulate and bio-magnify along the food chain (Schmid et al., 2002). From all possible human exposure pathways, food ingestion is the major route (Rose et al., 2009) with food products of animal origin as the main contributors (Büchert et al., 2001; Huwe, 2002). Feed ingredients and/or additives used in compound feed for livestock production have been a main cause of such food dioxin incidents in the past decade (Abalos, et al., 2008; Bernard et al., 2002; Heres et al., 2010; Hoogenboom et al., 2004; Hoogenboom, et al., 2004; Huwe and Smith, 2005; Kim et al., 2009; Kim et al., 2011; Llerena et al., 2003; Malisch, 2000; Sapkota et al., 2007). The pork production chain has been one of the food sectors seriously affected by compound feed contaminated with dioxins (Bernard et al., 2002; Heres et al., 2010; Hoogenboom et al., 2004; Kim et al., 2009). Such incidents may result into large financial implications due to recalls and trade disruptions, as was e.g., the case with the Belgian incident of 1999 (Buzby and Chandran, 2003; Lascano Alcoser, et all., 2011), the Irish incident of 2008 (Heres et al., 2010; Tlustos, 2009a, 2009b) and the Chilean incident in 2008 (Kim et al., 2009; Kim et al., 2011). Public and private efforts have taken place to manage dioxin contaminations in feed and food aiming to prevent the occurrence of future incidents. The European Commission (EC) has set maximum levels for the presence of dioxins in feed and food (EC, 2006a, 2011a, 2011b, 2012), enforced the adoption of feed and food safety assurance systems (i.e. Hazard Analysis and Critical Control Points (HACCP) and Good Manufacturing Practice (GMP)) (Domenech et al., 2008; EC, 2004, 2005; Heres et al., 2010), which resulted into the implementation of monitoring 
Monitoring dioxins along the pork chain

schemes. Regular monitoring in the food chain is crucial for detecting accidental or intentional food contaminations (Zach et al., 2012), to verify the well-functioning of the safety management systems (Ropkins and Beck, 2002; Domenech et al., 2008), to identify sources of dioxin contaminations, and to determine weak control points along the food chain (Heres et al., 2010). However, the intensity of monitoring is limited as the required analytical methods for detecting dioxins are costly and time consuming (Ropkins and Beck, 2002; Zach et al., 2012). So far, the challenge to maximize monitoring performance while accounting for resource constraints has received little attention. Quantitative decision support systems that aid in the allocation of resources to the various controls points along the food chain are desired. Lascano-Alcoser et al., (2013) developed an optimization model that statistically determines the optimal sample size necessary to detect a dioxin contamination in bulk milk and a method to quantitatively measure the performance of the monitoring scheme. This study was, however, restricted to a single control point along the chain. Studies to evaluate a costeffective intensity of monitoring food safety hazards along the food chain are seriously lacking. The present study aims to develop a decision support tool to determine cost-effective schemes for monitoring dioxins over multiple control points along the pork production chain aiming at detecting and tracing a dioxin contamination to its origin.

\subsection{Materials and Methods}

For the aim of this study, it is important to distinguish between a dioxin contamination and a dioxin incident. A dioxin contamination in the pork chain is defined as the presence of dioxins (without considering any referential concentration) in a raw material or processed product at any control point along the pork chain. The detection of a dioxin contamination results in a dioxin incident when the concentration of dioxins in the raw material or processed 
product, at any control point of a food production chain, is higher than a certain threshold concentration (i.e. maximum limit).

A model was constructed to optimize resource allocations for monitoring dioxins across a hypothetical pork production chain. To simplify the model, only dioxins were considered, excluding dl-PCBs. This section starts by describing the pork chain assumed, the control points for monitoring dioxins and the simulated course of the contamination through the chain. It is followed by a description of the actor related activities to monitor dioxins, a description of the optimization model, and the evaluated contamination scenarios.

\section{Simulation of a dioxin contamination along the pork chain}

Based on statistical data from the year 2011, obtained from the European Feed Manufacturers' Federation (FEFAC), the Agricultural Economics Institute of Wageningen University (LEI) and the Product Boards for Livestock, Meat and Eggs (PVE) in The Netherlands, a hypothetical pork production chain for fattening pigs was designed. This chain represents a western European pork supply chain consisting of five production stages and therefore, five distinct actors: the supplier of fatty feed ingredients, the manufacturer of compound feed for fattening pigs (feed mill), the pig fattening farm, the slaughterhouse, and the pork fat melting processor (see Fig. 1). From the five production stages described, four logical control points for monitoring dioxins are considered. These are located: (1) at the suppliers of fatty feed ingredients to monitor containers with animal fatty feed ingredient before delivery to feed mills, (2) at the feed mills for monitoring batches of manufactured pig feed, (3) at the slaughterhouses for monitoring full carcasses, and (4) at the fat melting facilities for monitoring batches of pure pork fat (Fig. 1). 


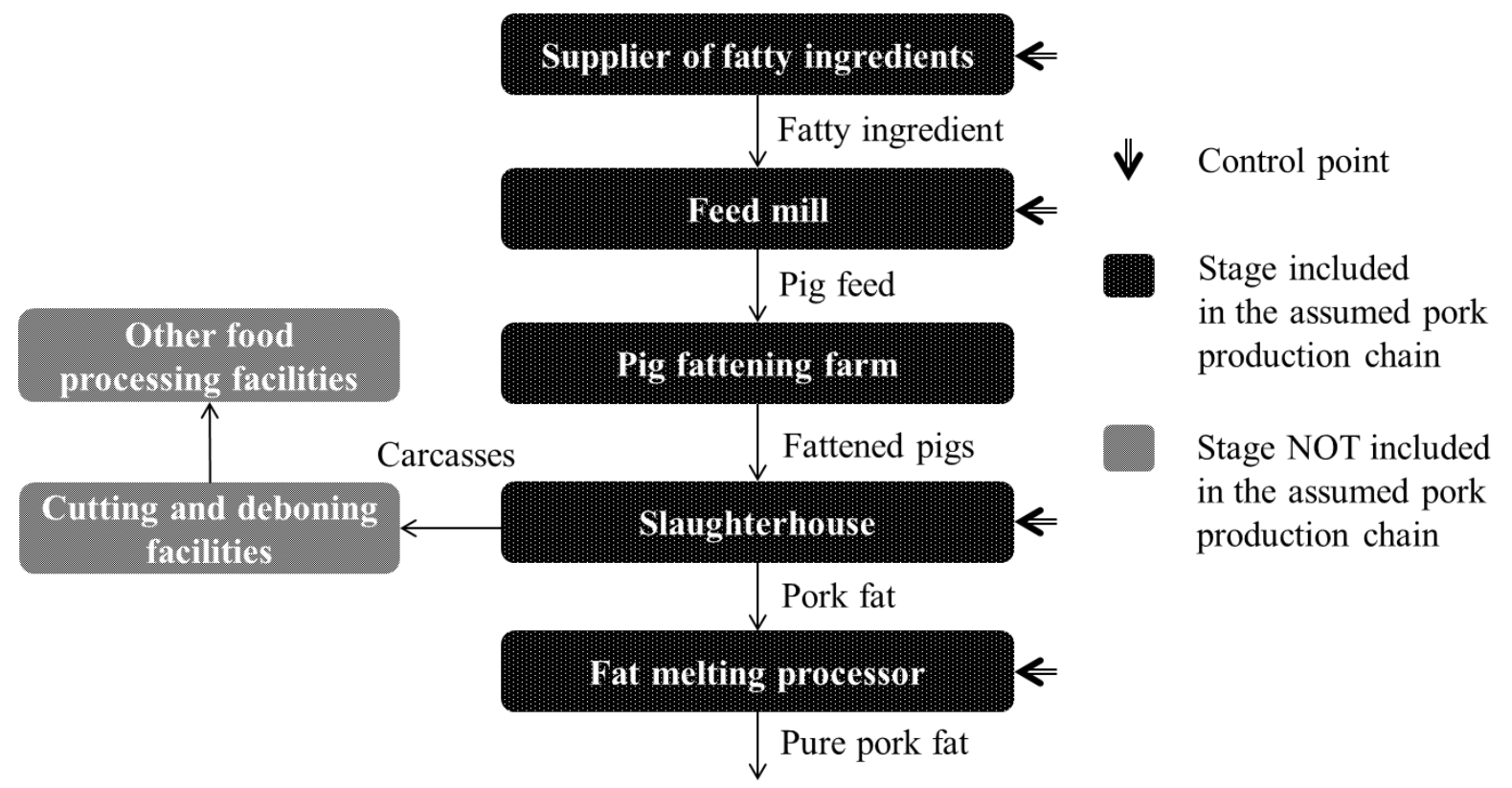

Figure 1. Description of the assumed pork chain and the dioxin control points.

To simplify the complexity of the real pork production chain, average values of input variables are used to parameterize the production chain. Moreover, all production facilities (including farms) within each stage of the chain are assumed to have the same production capacity (size). The dioxin contamination is followed throughout the production chain from the suppliers of fatty feed ingredients to the fat melting processor. At each control point, the fraction of contaminated material and its concentration of dioxins are estimated. On a weekly basis, a certain number of containers with animal fatty feed ingredients are dispatched by suppliers of fatty feed ingredients to feed mills. A predefined number of those containers is assumed to be contaminated with a specific dioxin concentration, and dispatched to feed mills specialized in producing feed for fattening pigs. At these feed mills, animal fatty ingredients are stored into a silo filled to its maximum capacity before its content is used in the feed production line. In this silo, contaminated animal fatty ingredient can be mixed with noncontaminated material, since feed mills may receive fatty feed ingredients from many suppliers. Thus, a dilution of the initial concentration in the contaminated animal fatty 
ingredient is expected. The amount of contaminated pig feed produced in a week at each feed mill is estimated based on the size of the storage silo and measured in batches of pig feed. A batch size equals the size of the daily production of pig feed. Each feed mill has a fixed network of pig farms to which it dispatches part of the contaminated daily batch of feed produced. Each farm receives a load of pig feed once a week. Pigs were assumed to be fully housed indoors, and completely fed with delivered feeds. Pig farms dispatch pigs to slaughterhouse every two weeks. However, for determining the optimal resource allocation, only those pigs delivered to the slaughterhouse immediately after the week of exposure are considered. This assumption is based on two factors: 1) the monitoring period is settled for one week, since it is assumed that contaminated animal fatty ingredients are delivered only for one week (exposure period) and 2) the highest concentration of dioxins in pigs is obtained at the end of the exposure period (Hoogenboom et al., 2004). Pigs delivered in subsequent weeks after the exposure period are not considered in the study. The concentration of dioxins in those animals is expected to decrease because they would no longer consume contaminated feed. Lower concentration of dioxins in those animals can limit the chance of detecting the contamination. Each slaughterhouse has a fixed network of pig farms from which it receives fattened pigs. An average number of contaminated pigs is assumed to be slaughtered per day by each slaughterhouse. From the slaughtering process, pork fat and carcasses are obtained. Pork fat received at the fat melting facility is processed into batches of pure pork fat. A batch size of pure pork fat processed in the fat melting facility is assumed to be equal to one-dayslaughter production. It is assumed that the fat melting facility receives the same amount of contaminated pork fat every day during a week. All input variables describing the pork supply chain and the course of the dioxin contamination are shown in Table 1. The formulas to estimate the fraction of contaminated material and the concentration of dioxins in samples collected at each control point are depicted in Table 2. 
Table 1

Input variables defining the spread of a dioxin contamination along the pork chain and used to compute the fraction of contaminated material and the concentration of dioxins at every control point

\begin{tabular}{|c|c|c|c|c|}
\hline Variable & Description & Unit & Value & Reference \\
\hline$N_{\text {ccont }}$ & Number of contaminated containers with animal fatty ingredients & containers & 30 & Input variable for contamination scenario \\
\hline$N_{\text {cont }}$ & Number of containers of animal fatty ingredients received per week & container/week & 272 & $\begin{array}{l}\text { Calculated from annual production of compound feed in the } \\
\text { Netherlands. Source: FEFAC (2013) }\end{array}$ \\
\hline$N_{c f m}$ & Number of contaminated feed mills & Facility & 10 & Input variable for contamination scenario \\
\hline$N_{f m}$ & Number of feed mills specialized on producing feed for fattening pigs & Facility & 29 & Calculated from data obtained from FEFAC (2013) \\
\hline$N_{\text {farm }}$ & Number of pig fattening farms & Farm & 2,120 & LEI (2013) \\
\hline$N_{\text {pig-deliv }}$ & $\begin{array}{l}\text { Number of pigs dispatched from a fattening farm to a slaughterhouse per } \\
\text { delivery }\end{array}$ & pig/farm/delivery & 215 & Calculated from data obtained in LEI (2013) \\
\hline$R_{f-s l}$ & Frequency of delivery of pigs from farms to slaughterhouses per month & number/month & 2 & Personal Communication: Lourens Heres, VION \\
\hline$N_{s l}$ & Number of slaughterhouses & Facility & 13 & PVE (2013) \\
\hline$W_{p-s l}$ & Weekly number of pigs slaughtered per facility & pig/facility & 20,844 & $\begin{array}{l}\text { Calculated from the annual number of pigs slaughtered in the } \\
\text { Netherlands in 2011. Source: PVE (2013) }\end{array}$ \\
\hline$A_{c f a t-i n g}$ & $\begin{array}{l}\text { Additional concentration of dioxins in contaminated animal fatty feed } \\
\text { ingredients }\end{array}$ & ng TEQ/kg fat ${ }^{\mathrm{a}}$ & 70 & Input variable for contamination scenario \\
\hline$P_{p f}$ & $\begin{array}{l}\text { Proportion of animal fatty ingredient delivered to feed mills specialized in } \\
\text { producing feed for fattening pigs }\end{array}$ & $\%$ & 26 & $\begin{array}{l}\text { Calculated from the annual production (2011) of pig feed and } \\
\text { compound feed in the Netherlands. Source: FEFAC (2013) }\end{array}$ \\
\hline$S_{\text {cont }}$ & Capacity of container with fatty feed ingredients & $\mathrm{t}$ & 30 & Stärk, Boyd, \& Mousing (2002) \\
\hline$S_{\text {silo }}$ & Capacity of storage silo for animal fatty feed ingredients at feed mill & $\mathrm{t}$ & 73 & $\begin{array}{l}\text { Calculated from the amount of pig feed produced per week and per } \\
\text { feed mill. Source: FEFAC, }(2013)\end{array}$ \\
\hline$F_{p f e e d}$ & Fat content of pig feed & $\%$ & 3 & Stärk et al. (2002) \\
\hline$I_{\text {ffpig }}$ & Intake of feed for pigs at the last week of fattening period & $\mathrm{kg} /$ week & 19.6 & Hoogenboom et al. (2007) \\
\hline Bio & Bioavailability of dioxins from feed & $\%$ & 60 & Calculated from Hoogenboom et al., (2004) \\
\hline$G_{\text {carc }}$ & Weight of carcass & $\mathrm{kg}$ & 77.1 & Stärk et al. (2002) \\
\hline$F_{\text {carc }}$ & Fat content of carcass & $\%$ & 25 & Stärk et al. (2002) \\
\hline$G_{\text {fcarc-sl }}$ & Weight of fat trimmed off during slaughter & $\mathrm{kg}$ & 2.5 & Stärk et al. (2002) \\
\hline$L_{s l}$ & Labor days per week at slaughterhouse & day/week & 6 & Personal Communication: Lourens Heres, VION \\
\hline$A_{\text {fpf }}$ & Amount of fat per pig delivered to fat melting facility & t/pig & 0.0026 & Personal Communication: Lourens Heres, VION \\
\hline$B L_{f a t-i n g}$ & Background concentration of dioxins in animal fatty feed ingredients & ng TEQ/kg fat ${ }^{\mathrm{a}}$ & 0.2 & $\begin{array}{l}\text { LOQ for dioxins in animal fatty feed ingredients given by the } \\
\text { confirmatory method }^{\mathrm{b}}\end{array}$ \\
\hline$B L_{\text {pig-feed }}$ & Background concentration of dioxins in pig feed & ng TEQ/kg feed ${ }^{\mathrm{a}}$ & 0.17 & LOQ for dioxins in pig feed given by the confirmatory method ${ }^{b}$ \\
\hline$B L_{\text {carc }}$ & Background concentration of dioxins in pig carcass & ng TEQ/kg fat ${ }^{a}$ & 0.2 & LOQ for dioxins in pig carcass given by the confirmatory method ${ }^{b}$ \\
\hline$B L_{\text {pork-fat }}$ & Background concentration of dioxins in pork fat & ng TEQ $/ \mathrm{kg}$ fat $^{\mathrm{a}}$ & 0.2 & LOQ for dioxins in pork fat given by the confirmatory method ${ }^{\mathrm{b}}$ \\
\hline
\end{tabular}

${ }^{\mathrm{b}}$ LOQ $=$ Limit of Quantification 
Table 2

Calculations to estimate the fraction of contaminated material and the concentration of dioxins at each control point along the pork chain

\begin{tabular}{|c|c|c|c|}
\hline Variable & Description & Unit & Calculation \\
\hline$F R_{\text {ccont }}$ & Fraction of contaminated containers with animal fatty ingredients & $\%$ & $N_{\text {ccont }} \div N_{\text {cont }}$ \\
\hline$F R_{c b-f m}$ & Fraction of contaminated batches of pig feed & $\%$ & $N_{c f m} \div N_{f m}$ \\
\hline$F R_{c c-s l}$ & Fraction of contaminated carcasses & $\%$ & $\left(\frac{N_{c f m} \cdot\left(\frac{N_{f a r m}}{N_{f m}}\right) \cdot\left(N_{\text {pig-deliv }}\right)}{R_{f-s l}}\right) \div\left(N_{s l} \cdot W_{p-s l}\right)$ \\
\hline$F R_{c b-f f}$ & Fraction of contaminated batches of pure pork fat & $\%$ & 100 \\
\hline$c c_{\text {fat-ing }}$ & $\begin{array}{l}\text { Concentration of dioxins in contaminated samples of animal fatty } \\
\text { feed ingredient }\end{array}$ & ng TEQ/kg fat ${ }^{\mathrm{a}}$ & $A_{c f a t-i n g}+B L_{\text {fat-ing }}$ \\
\hline$A_{c f e e d}$ & $\begin{array}{l}\text { Increase in concentration of dioxins in pig feed due to the } \\
\text { simulated contamination }\end{array}$ & ng TEQ/kg feed ${ }^{\mathrm{a}}$ & $\left(N_{\text {ccont }} \cdot P_{p f} \cdot S_{\text {cont }} \div N_{c f m} \cdot A_{c f a t-i n g} \div S_{\text {silo }} \cdot F_{\text {pfeed }}\right)$ \\
\hline$c c_{\text {feed }}$ & Concentration of dioxins in contaminated samples of pig feed & ng TEQ/kg feed ${ }^{\mathrm{a}}$ & $A_{\text {cfeed }}+B L_{\text {pig-feed }}$ \\
\hline$A_{\text {ccarc }}$ & $\begin{array}{l}\text { Increase in concentration of dioxins in pig carcass due to the } \\
\text { simulated contamination }\end{array}$ & ng TEQ/kg fat ${ }^{\mathrm{a}}$ & $\left(\left(A_{c f e e d} \cdot I_{f f p i g} \cdot B i o\right) \div\left(\left(G_{\text {carc }} \cdot F_{\text {carc }}\right)+G_{\text {fcarc }-s l}\right)\right)$ \\
\hline$c c_{\text {carc }}$ & Concentration of dioxins in contaminated samples of pig carcass & ng TEQ/kg fat ${ }^{\mathrm{a}}$ & $A_{\text {ccarc }}+B L_{\text {carc }}$ \\
\hline$B_{p f a t}$ & $\begin{array}{l}\text { Daily amount of pig fat processed in the fat melting facility (batch } \\
\text { pork fat) }\end{array}$ & t/day & $W_{p-s l} \cdot N_{s l} \div L_{s l} \cdot A_{f p f}$ \\
\hline$A_{c f a t}$ & $\begin{array}{l}\text { Increase in concentration of dioxins in pork fat due to the } \\
\text { simulated contamination }\end{array}$ & ng TEQ/kg fat ${ }^{\mathrm{a}}$ & $\left.A_{\text {ccarc }} \cdot A_{f p f} \cdot\left(\frac{N_{c f m} \cdot\left(\frac{N_{f a r m}}{N_{f m}}\right) \cdot\left(N_{\text {pig-deliv }}\right)}{R_{f-s l} \cdot L_{s l}}\right)\right) \div B_{\text {pfat }}$ \\
\hline$c c_{\text {fat }}$ & Concentration of dioxins in contaminated samples of pork fat & ng TEQ/kg fat ${ }^{\mathrm{a}}$ & $A_{c f a t}+B L_{\text {pork-fat }}$ \\
\hline
\end{tabular}

${ }^{\mathrm{a}} \mathrm{TEQ}=$ Toxic Equivalent 
Monitoring dioxins along the pork chain

\section{Actor related monitoring activities}

Monitoring activities consist of detection and tracing; detection activities are performed continuously and tracing activities are only applied upon detection of a contamination. For the purpose of detection, specific products are randomly sampled and collected samples are combined into pooled samples at each control point. As far as possible, samples are pooled and subsequently tested with a screening method (i.e. DR CALUX ${ }^{\circledR}$ ), which - when exceeding the decision limit- are tested with a confirmatory method (i.e. GC/HRMS). This combination of both methods is assumed to be applied in order to diminish the testing costs for detection. The screening method is only capable of giving an indication of the concentration of dioxins in the samples, but it is less expensive than the confirmatory method. Moreover, the screening method works well, even at low contamination levels (Heres et al., 2010) and very few to inexistent false negatives results are obtained (Hoogenboom et al., 2004; Hoogenboom et al., 2007).

The combined testing strategy used in detection of a potential contamination is also applied in tracing the source. Tracing starts at the control point where a contamination has been detected. At this point, samples used to prepare the positive pooled sample(s) are tested individually to identify positive individual samples, which are then related to specific batches of contaminated products. Based on the results of testing suspected batches of products and given the information on the distribution network, positive samples can be linked to a batch of products in the previous stage of the chain, which are subsequently, sampled and tested. The tracing process to identify contaminated batches of products along the chain is replicated at each stage of the chain. The tracing ends when the contaminated fatty ingredient is identified. 


\section{Optimization model for monitoring dioxins in the pork supply chain}

In general, the optimization model is settled for $I$ control points located along the pork chain. The optimal allocation of resources across each of the $I$ control points is subjected to a minimum required probability of detecting and tracing a dioxin contamination within the overall chain $(A)$. For each control point, the amount of resources and the probability of detecting and tracing a dioxin contamination are defined as the cost $\left(M C_{i}\right)$ and the effectiveness $\left(M E_{i}\right)$ of monitoring, respectively. The $M C_{i}$ and $M E_{i}$ are a function of the number of samples collected $\left(n s_{i}\right)$ and the number of samples mixed into one pooled sample $\left(q_{i}\right)$ for every control point $i$. The total monitoring cost $(T M C)$ is estimated as the sum of all individual $M C_{i}$ while the probability of detecting and tracing a dioxin contamination within the overall chain $(T M E)$ results from the product of all individual $M E_{i}$.

The optimization model is written as follows:

Minimize: $\quad T M C=\sum_{i}^{I} M C_{i}\left(n s_{i}, q_{i}\right) \quad i=1,2,3, \ldots, I$

Subject to: $\quad T M E=\left(1-\left(\prod_{i}^{I}\left(1-M E_{i}\left(n s_{i}, q_{i}\right)\right)\right)\right) \geq A \quad i=1,2,3, \ldots, I$

$$
\begin{aligned}
& l n s_{i} \leq n s_{i} \leq \text { uns }_{i} \\
& 1 \leq q_{i} \leq u q_{i} \\
& n s_{i} \geq 0 \text { and integer } \\
& q_{i} \geq 1 \text { and integer }
\end{aligned}
$$

where $u n s_{i}$ and $l n s_{i}$ are the maximum and minimum $n s_{i}$ that can be collected at each control point $i$, respectively, and $u q_{i}$ is the maximum number of samples that can be combined into one pooled sample at each control point $i$.

$T M C$ is given by the sum of $M C_{i}$ for every control point $i$ at a given monitoring period (i.e. a week in this specific case). At each control point $i$, the $M C_{i}$ is given by the costs of 
Monitoring dioxins along the pork chain

detection $\left(D T_{i}\right)$ and the costs of tracing $\left(T R_{i}\right)$. Detection costs account for the costs of sampling and testing activities aiming at detecting a contamination. Tracing costs account for the costs of sampling and testing activities to identify the initial source of the contamination. Thus, tracing costs account only for the control point(s) where the contamination has been detected (i.e. dioxin concentration above the decision limit, which is specific for each control point). Sampling costs for detection $\left(D T s c_{i}\right)$ consist of costs for labor $\left(l c_{i}\right)$ (i.e. personnel who take the samples), materials to collect samples $\left(m c_{i}\right)$, transport of samples to the laboratory $\left(t c_{i}\right)$ and temporal storage of samples for further tracing in case a contamination is detected $\left(s c_{i}\right)$. Sampling costs for tracing $\left(T R s c_{i}\right)$ are composed of the same cost items as in DTsc $c_{i}$. Testing costs for detection $\left(D T t c_{i}\right)$ and for tracing $\left(T R t c_{i}\right)$ under the combined testing strategy, are composed of the costs of screening (scr) and confirmatory (cof) dioxin testing methods and the labor costs for registering and evaluating the results of the test $\left(l c t_{i}\right)$. The TRtc $_{i}$ is considered a variable cost in this study since it depends on the number of samples combined into the positive pooled samples detected $\left(q_{i}\right)$. Tracing activities (i.e. sampling costs $\left(T R s c_{j}\right)$ and testing costs $\left.\left(T R t c_{j}\right)\right)$ to elicit the initial source of the contamination are considered fixed costs in this study. They are estimated for each control point, based on the assumed minimum number of samples that must be collected and tested to elicit the origin of the contamination $\left(n s_{j}\right)$, in the control point $i$ where the contamination is detected and in prior stages of the chain towards the origin of the contamination. The input variables and the formulas used to estimate the TMC and TME are shown in Tables 3 and 4, respectively. 
Table 3

Inputs variables to estimate the costs effectiveness of monitoring schemes

\begin{tabular}{|c|c|c|c|c|}
\hline Variable & Description & Unit & Value & Explanation \\
\hline$l c_{i}$ & Labor costs for personnel who take the samples & $€ /$ sample & 12.2 & Time/sample: 15 min. Salary: $€ 49 / \mathrm{hr}^{\mathrm{I}}$ \\
\hline$m c_{i}$ & Materials cost for equipment and tools used to take samples & $€ /$ sample & 0.5 & Own estimation \\
\hline$t c_{i}$ & Cost of transporting the samples to the laboratory & $€ /$ sample & 1 & Assuming $€ 10 / 10$ samples at weight of $2 \mathrm{~kg}^{2}$ \\
\hline$S c_{i}$ & Cost of storing the samples for further testing & $€ /$ sample & 0.1 & Own estimation \\
\hline scr & Cost of screening test & $€ /$ sample & 100 & Cost of CALUX® $\circledR^{3}$ \\
\hline $\operatorname{cof}$ & Cost of confirmatory test & $€ /$ sample & 350 & Cost of $\mathrm{GC} / \mathrm{MS}^{3}$ \\
\hline$l c t_{i}$ & Labor costs for registering and evaluating the test results & $€ /$ sample & 21 & Time/sample: $20 \mathrm{~min}$. Salary: $€ 63 / \mathrm{hr}^{4}$ \\
\hline$\% p s c r_{i}$ & Proportion of positive pooled samples at the screening test & $\%$ & 10 & Expert Opinion $^{3}$ \\
\hline$n s p_{i}$ & $\begin{array}{l}\text { Number of contaminated pooled samples detected at control } \\
\text { point } i\end{array}$ & pooled sample & 1 & $\begin{array}{l}\text { For simplification, } n s p_{i} \text { equals one for those control points considered } \\
\text { in the output of the optimization model }\end{array}$ \\
\hline Test $_{\text {sens }}$ & Combined sensitivity of screening and confirmatory methods & $\%$ & 98 & Expert Opinion ${ }^{3}$ \\
\hline$c c_{i}$ & Concentration of dioxins in contaminated samples & ng TEQ/g fat ${ }^{5}$ & & Estimated for each control point $i$ (Table 6) \\
\hline$p v B L_{i}$ & Deviation of the background level from its mean value & $\%$ & 50 & Expert Opinion $^{3}$ \\
\hline$A$ & Required monitoring effectiveness & $\%$ & 95 & Input variable for contamination scenario \\
\hline$R_{\text {inc }}$ & Frequency of occurrence of a dioxin contamination per year & number & 3 & Input variable for contamination scenario \\
\hline$n s_{j-f m}$ & $\begin{array}{l}\text { Number of samples to be collected and tested to trace the } \\
\text { contamination to its origin if the contamination is detected in } \\
\text { the control point at the feed mill }\end{array}$ & number & 12 & $\begin{array}{l}\text { Given } 1 \text { pig feed sample from the contaminated feed mill, } 10 \text { samples of } \\
\text { fatty ingredients from the contaminated feed mill and } 1 \text { sample of the } \\
\text { suspected container of the animal fatty ingredients }\end{array}$ \\
\hline$n s_{j-s l}$ & $\begin{array}{l}\text { Number of samples to be collected and tested to trace the } \\
\text { contamination to its origin if the contamination is detected in } \\
\text { the control point at the slaughterhouse }\end{array}$ & number & 26 & $\begin{array}{l}\text { Given } 8 \text { pig-fat samples from the contaminated farm, } 6 \text { samples of pig } \\
\text { feed and suspected feed supplements from the contaminated farm and } \\
n s_{j-f m}\end{array}$ \\
\hline$n s_{j-f f}$ & $\begin{array}{l}\text { Number of samples to be collected and tested to trace the } \\
\text { contamination to its origin if the contamination is detected in } \\
\text { the control point at the fat melting processor }\end{array}$ & number & 203 & $\begin{array}{l}\text { Given } 1 \text { pig-fat sample from each one of the } 177 \text { suspected farms and } \\
n s_{j-s l} \text {. Given the structure of the pork chain, one positive pork fat } \\
\text { sample represents the one batch of pork fat processed at the fat melting } \\
\text { processor which is directly related to } 177 \text { farms }\end{array}$ \\
\hline
\end{tabular}

\footnotetext{
Tariffs, Dutch Gov, LNV, 2009, medium tariff

${ }^{2}$ Postal service NL, 2010

${ }^{3}$ Hoogenboom (personal communication)

${ }^{4}$ Tariffs, Dutch Gov., LNV, 2009, high tariff

${ }^{5} \mathrm{TEQ}=$ Toxic Equivalen
} 
Table 4

Formulas to estimate monitoring costs and monitoring effectiveness

Variable Description Unit

Calculation

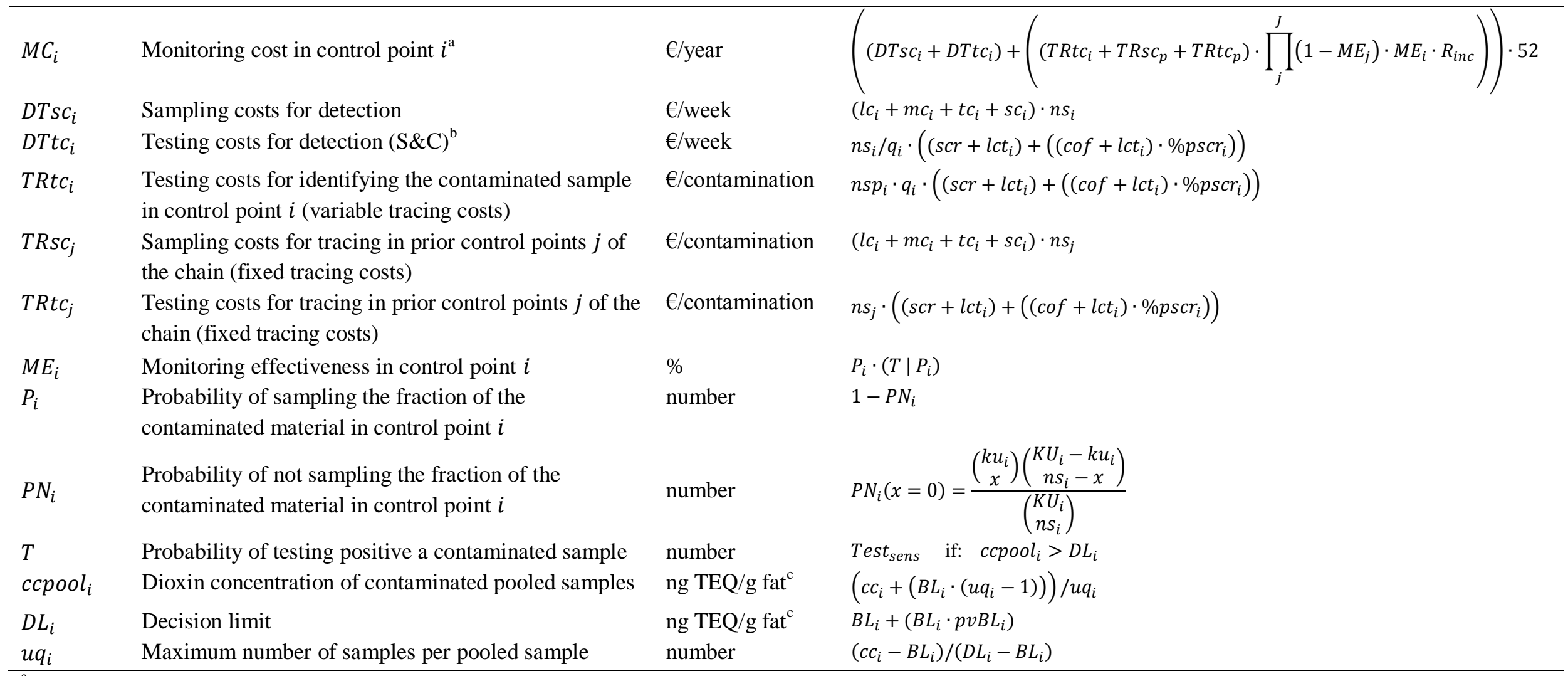

${ }^{\mathrm{a}} M E_{j}$ is the monitoring effectiveness of the control point $j$ that are part of the control points along the pork chain but not necessarily part of the optimal solution.

${ }^{\mathrm{b}}$ Screening and confirmatory methods as testing strategy in detection and tracing procedures. For alternatives testing strategies $(\mathrm{CiT}$ or $\mathrm{C})$ in which only confirmatory method is used for testing, the formula for estimating the testing cost per unit $\left(\left(s c r+l c t_{i}\right)+\left(\left(c o f+l c t_{i}\right) \cdot \% p s c r_{i}\right)\right)$ is modified to include only the cost of the confirmatory method $\left(c o f+l c t_{i}\right)$.

${ }^{\mathrm{c}} \mathrm{TEQ}=$ Toxic Equivalent 
The Total Monitoring Effectiveness $(T M E)$ is defined as the probability of detecting and tracing a dioxin contamination from at least one of the control points $i$ located in the pork chain (Table 4). The TME is given by the product of the probabilities of detecting at least one positive pooled sample at each control point $i\left(M E_{i}\right)$. The $M E_{i}$ is given by the probability of sampling the contaminated batch(es) of products at each control point $i\left(P_{i}\right)$, and the probability that the contaminated sample picked is tested positive by the analytical methods applied $(T)$. The $P_{i}$ is a continuous variable estimated as one minus the probability of not picking any sample from the contaminated batches $\left(P N_{i}\right)$ at each control point $i$. The $P N_{i}$ was estimated using a hyper geometric distribution with the number of contaminated batches $\left(k u_{i}\right)$ and the total number of batches that can be sampled during the assumed monitoring period $\left(K U_{i}\right)$ as inputs. $T$ is reflecting the sensitivity of the analytical methods applied for testing of dioxins $\left(\right.$ test $\left._{\text {sens }}\right) . T$ equals $98 \%$ if the dioxin concentration of the contaminated pooled sample $\left(\right.$ ccpool $\left._{i}\right)$ is higher than the decision limit $\left(D L_{i}\right)$ at each monitoring point $i$ (i.e. $c c p o o l_{i}>D L_{i}$ ). The ccpool $_{i}$ is estimated given the dioxin concentration of the contaminated samples $\left(c c_{i}\right)$ contained in the contaminated pooled sample, the maximum number of samples that can be combined into a pooled sample $\left(u q_{i}\right)$, and the dioxin concentration of the not contaminated samples which equals the background dioxin concentration $\left(B L_{i}\right)$. The background dioxin concentration is the pre-existent concentration of dioxins in sampled products due to anthropogenic or natural sources. It is specific for the type of product sampled at each control point $i$. Consequently, the $c c_{i}$ at each control point $i$ is the result of summing the concentration of dioxins due to the additional contamination at samples collected at each control point $i$ and its corresponding $B L_{i}$. The $D L_{i}$ is thus defined as the maximum concentration of dioxins below which tested pooled samples are still considered negative for dioxins. The $D L_{i}$ is estimated from the $B L_{i}$ and a maximum expected positive percentage of deviation of the $B L_{i}\left(p v B L_{i}\right)$. In the case of animal fatty feed ingredients, fat 
Monitoring dioxins along the pork chain

from carcass and pork fat from pigs, the $D L_{i}$ is set at $0.3 \mathrm{ng} \mathrm{TEQ} / \mathrm{kg}$ fat and for pig feed at $0.26 \mathrm{ng}$ TEQ/kg feed. In the European Union (EU), the European Commission has regulated product limits by defining the Maximum Level (ML: the maximum concentration at which feed and food products can be traded) and the Action Level (AL: the dioxin concentration at which action needs to be taken to eliminate the source of the contamination (EC, 2001a,b). The $D L_{i}$ defined in this study are lower than the current ML and AL, since pooled samples are considered.

For every control point $i$, the maximum number of samples that can be combined into a pooled sample $\left(u q_{i}\right)$ is estimated assuming that the dioxin concentration of a contaminated pooled sample $\left(\right.$ ccpool $\left._{i}\right)$ was due to the dioxin concentration of just one contaminated sample. This assumption underestimates $u q_{i}$ because in a random pooling process, many contaminated samples might be pooled into a contaminated pooled sample. However, it limits the dilution of the dioxin concentration in the contaminated pooled sample to the lower limit, enabling to test positive any contaminated pooled sample, in which $\operatorname{ccpool}_{i}>D L_{i}$.

\section{Contamination scenarios}

Based on the indicated settings of Tables 1-4, the base contamination scenario for monitoring dioxins along the pork chain is defined. Twelve additional contamination scenarios are defined by altering the setting of one of the six main input variables, i.e. 1) number of contaminated containers of animal fatty feed ingredients per contamination, 2) concentration of dioxins at contaminated containers, 3) number of contaminated feed mills per contamination, 4) frequency of dioxin contaminations per year, 5) required effectiveness of monitoring and 6) cost of the screening test (Table 5). These input variables were selected as they showed to have the highest influence on total monitoring costs when optimizing the allocation of resources considering an integrated chain approach. These influences were 
determined by a univariate sensitivity analysis in which the individual input values were changed by $30 \%$. The scenario settings of the input values were selected to exemplify extreme but credible scenarios in order to obtain an ample range of inputs for the optimization model and, therefore, an evaluation of an extensive range of possible monitoring schemes.

Besides these 12 contamination scenarios, two additional scenarios were defined based on the use of two alternative testing strategies for detection and tracing (Table 5).

Each contamination scenario was optimized following two approaches. The first approach assumes that each control point (at corresponding stages of the chain) carries out its own independent monitoring procedure. Thus, the optimization model was directed to determine the optimal monitoring scheme for each separate control point aiming at detecting the dioxin contamination. The second approach, the chain approach, considers all control points along the chain integrated in a single monitoring plan (assuming, for example, a central food safety authority controlling the monitoring procedure in all control points along the chain). Table 6 presents -for each of the contamination scenarios and control points- the resulting fraction of contaminated material and corresponding concentration of dioxins. In the case of pig feed, fat from carcass and pork fat the background dioxin concentrations are taken into account and added to the concentration resulting from the contaminated animal fatty ingredient. The background dioxin concentrations are set at the Limit of Quantification (LOQ) of the confirmatory method. The information in Table 6 is used as input for the optimization model. 
Table 5

Description of the contamination scenarios

\begin{tabular}{|c|c|c|c|c|c|c|c|}
\hline Scenario & $\begin{array}{l}\text { Number of } \\
\text { contaminated } \\
\text { containers of animal } \\
\text { fatty feed ingredients } \\
\text { per contamination } \\
(\#)\end{array}$ & $\begin{array}{l}\text { Additional concentration } \\
\text { of dioxins in } \\
\text { contaminated animal fatty } \\
\text { feed ingredient } \\
\text { (ng TEQ/ kg fat) }\end{array}$ & $\begin{array}{l}\text { Number of } \\
\text { contaminated } \\
\text { feed mills per } \\
\text { contamination } \\
\text { (\#) }\end{array}$ & $\begin{array}{l}\text { Frequency of } \\
\text { dioxin } \\
\text { contaminations } \\
\text { per year } \\
\text { (\#/year) }\end{array}$ & $\begin{array}{l}\text { Required } \\
\text { level of } \\
\text { effectiveness } \\
(\%)\end{array}$ & 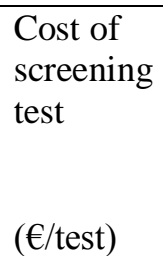 & $\begin{array}{l}\text { Testing } \\
\text { Strategy }\end{array}$ \\
\hline Base & 30 & 70 & 10 & 3 & 95 & 100 & $S \& C$ \\
\hline s1 & 10 & 70 & 10 & 3 & 95 & 100 & $S \& C$ \\
\hline s2 & 50 & 70 & 10 & 3 & 95 & 100 & $\mathrm{~S} \& \mathrm{C}$ \\
\hline s3 & 30 & 50 & 10 & 3 & 95 & 100 & $\mathrm{~S} \& \mathrm{C}$ \\
\hline s4 & 30 & 100 & 10 & 3 & 95 & 100 & $\mathrm{~S} \& \mathrm{C}$ \\
\hline s5 & 30 & 70 & 5 & 3 & 95 & 100 & $S \& C$ \\
\hline s6 & 30 & 70 & 20 & 3 & 95 & 100 & $\mathrm{~S} \& \mathrm{C}$ \\
\hline s7 & 30 & 70 & 10 & 1 & 95 & 100 & $S \& C$ \\
\hline s8 & 30 & 70 & 10 & 6 & 95 & 100 & $\mathrm{~S} \& \mathrm{C}$ \\
\hline s9 & 30 & 70 & 10 & 3 & 93 & 100 & $\mathrm{~S} \& \mathrm{C}$ \\
\hline s10 & 30 & 70 & 10 & 3 & 97 & 100 & $\mathrm{~S} \& \mathrm{C}$ \\
\hline s11 & 30 & 70 & 10 & 3 & 95 & 90 & $\mathrm{~S} \& \mathrm{C}$ \\
\hline s12 & 30 & 70 & 10 & 3 & 95 & 110 & $\mathrm{~S} \& \mathrm{C}$ \\
\hline s13 & 30 & 70 & 10 & 3 & 95 & 100 & $\mathrm{CiT}$ \\
\hline s14 & 30 & 70 & 10 & 3 & 95 & 100 & $\mathrm{C}$ \\
\hline
\end{tabular}

Note: S\&C = screening and confirmatory methods (combined strategy) is the default testing strategy for detection and tracing the contamination, CiT = Combined method is applied at detection and only the confirmatory method is applied for tracing the contamination, $\mathrm{C}=$ only the confirmatory method is applied for detecting and tracing the contamination. 


\subsection{Results}

\section{Concentration of dioxins in the contaminated material at each control point}

The simulated course of a contamination along the chain is demonstrated by the estimated dioxin concentrations within the base contamination scenario (Table 6). In this scenario, the volume of the contaminated animal fat is 30 containers of 30 tons or 900 ton in total, of which only $26 \%$ is used for producing pig feed during one week. This amounts to 234 tons which are distributed equally to 10 feed producers, where the animal fatty feed ingredient is initially stored in silos of 73 tons, which also contain 50 tons of clean fat. As a result, the initial concentration of $70 \mathrm{ng} \mathrm{TEQ} / \mathrm{kg}$ fat is reduced to $22.5 \mathrm{ng} \mathrm{TEQ} / \mathrm{kg}$. This animal fatty feed ingredient is subsequently used to produce pig feed at a concentration of $3 \%$. This further reduces the contamination level to $0.67 \mathrm{ng} \mathrm{TEQ} / \mathrm{kg}$ feed, on top of the background concentration of $0.17 \mathrm{ng} \mathrm{TEQ} / \mathrm{kg}$ feed. With the total amount of 730 tons of animal fatty feed ingredient, 24,333 tons of pig feed is produced, of which $28 \%$ is exported to external markets and $72 \%$ delivered to the customers of the 10 feed producers, being 731 farms for fattening pigs. The feed is consumed within one week, resulting in an average uptake of $19.6 \mathrm{~kg}$ feed, containing 13.2 ng TEQ dioxins. About $60 \%$ of the dioxins end up in their body fat, equaling $7.9 \mathrm{ng}$ TEQ per $21.8 \mathrm{~kg}$ fat, or $0.36 \mathrm{ng} \mathrm{TEQ} / \mathrm{kg}$ fat. On top of this, there are other sources of dioxins (causing a background of $0.2 \mathrm{ng} \mathrm{TEQ} / \mathrm{kg}$ fat), resulting in a total level of $0.56 \mathrm{ng}$ $\mathrm{TEQ} / \mathrm{kg}$ fat. At the fat melting processor, the fat from the contaminated pigs ( $34 \mathrm{t} / \mathrm{day}$ ) will be mixed with fat of clean pigs with a background level of $0.2 \mathrm{ng} \mathrm{TEQ} / \mathrm{kg}$ fat, resulting in a reduction of the contamination level to $0.31 \mathrm{ng} \mathrm{TEQ} / \mathrm{kg}$ fat. 


\section{Table 6}

Fraction of contaminated material, expected dioxin concentration at contaminated samples for each contamination scenario Fraction of contaminated material Concentration of dioxins in contaminated samples $\left(\boldsymbol{c} \boldsymbol{c}_{\boldsymbol{i}}\right)^{+}$ $(\%)$ (ng TEQ/kg)

\begin{tabular}{|c|c|c|c|c|c|c|c|c|}
\hline Scenario & SI & FM & SL & FF & SI & FM & SL & $\mathbf{F F}$ \\
\hline Base & 11 & 34 & 29 & 100 & 70.20 & 0.84 & 0.56 & 0.31 \\
\hline s1 & 4 & 34 & 29 & 100 & 70.20 & 0.39 & 0.32 & $0.24^{*}$ \\
\hline s2 & 18 & 34 & 29 & 100 & 70.20 & 1.29 & 0.80 & 0.38 \\
\hline s3 & 11 & 34 & 29 & 100 & 50.20 & 0.65 & 0.46 & $0.28^{*}$ \\
\hline s4 & 11 & 34 & 29 & 100 & 100.20 & 1.13 & 0.72 & 0.35 \\
\hline s5 & 11 & 17 & 15 & 100 & 70.20 & 1.51 & 0.93 & 0.31 \\
\hline s6 & 11 & 69 & 58 & 100 & 70.20 & 0.51 & 0.38 & 0.31 \\
\hline s7 & 11 & 34 & 29 & 100 & 70.20 & 0.84 & 0.56 & 0.31 \\
\hline s8 & 11 & 34 & 29 & 100 & 70.20 & 0.84 & 0.56 & 0.31 \\
\hline s9 & 11 & 34 & 29 & 100 & 70.20 & 0.84 & 0.56 & 0.31 \\
\hline s10 & 11 & 34 & 29 & 100 & 70.20 & 0.84 & 0.56 & 0.31 \\
\hline s11 & 11 & 34 & 29 & 100 & 70.20 & 0.84 & 0.56 & 0.31 \\
\hline s12 & 11 & 34 & 29 & 100 & 70.20 & 0.84 & 0.56 & 0.31 \\
\hline s13 & 11 & 34 & 29 & 100 & 70.20 & 0.84 & 0.56 & 0.31 \\
\hline s14 & 11 & 34 & 29 & 100 & 70.20 & 0.84 & 0.56 & 0.31 \\
\hline
\end{tabular}

Note: SI : Supplier of Fatty Feed Ingredients, FM : Feed mill, SL: Slaughterhouse, FF: Fat Melting Processor. ${ }^{+}:$The decision limits $\left(D L_{i}\right)$ for each type of sample are: 0.3 ng $\mathrm{TEQ} / \mathrm{kg}$ fat in animal fatty ingredients, $0.26 \mathrm{ng} \mathrm{TEQ} / \mathrm{kg}$ feed in pig feed, $0.3 \mathrm{ng} \mathrm{TEQ} / \mathrm{kg}$ fat in carcass, $0.3 \mathrm{ng} \mathrm{TEQ} / \mathrm{kg}$ fat in pork fat. ": The expected concentration of dioxins is below the decision limit settled for this control point, therefore, this contamination scenario cannot be detected in the control point at the fat melting processor. 


\section{Optimizing the allocation of resources for monitoring dioxins}

For each of the selected scenarios, results for optimizing the resource allocation to detect and trace the dioxin contamination with an effectiveness level of $95 \%$ at each separate control point are shown in Table 7. Table 8 presents the optimal resource allocations when an integrated chain approach is considered. The comparison of Tables 7 and 8 shows the economic benefits of monitoring dioxins on an integrated chain approach as compared to each chain actor monitoring dioxins independently. At each scenario, the total monitoring costs for an independent optimal monitoring scheme (Table 7) at each control point are larger (e.g. $€ 239.9$ thousand per year for the base scenario) than the total monitoring costs from an integrated chain approach (Table 8) (e.g. €30.3 thousand per year for the base scenario). For all scenarios in both the individual and the integrated chain approach, the optimal costeffective solution for detecting and tracing the dioxin contamination is to monitor dioxins at the feed mill. The most costly control point for monitoring dioxins is at the fat melting processor. This is mainly due to the elevated costs for tracing the contamination to its origin.

As can be seen in Table 7, in nearly all scenarios, it is possible to detect the contamination at each individual control point, but the number of samples that must be collected and related detection costs vary widely between the control points. In the base scenario, for instance, many samples $(n=29)$ are required for detecting the contamination at the supplier of fatty feed ingredients, while a single sample is sufficient for detecting the contamination at the fat melting processor. The number of samples needed for detecting the contamination is influenced by the fraction of contaminated material and the required level of effectiveness for detecting the contamination. The detection costs go in line with the number of samples that must be collected, but also rely on the number of pooled samples that must be tested. In all scenarios tracing costs are smallest when the contamination is traced from the feed mill (most cost-effective solution), and highest when the contamination has to be traced 
Monitoring dioxins along the pork chain

from the fat melting processor. The variable component of the tracing costs relies upon the number of samples combined into the pooled sample (pooling rate) that must be tested individually after a pooled sample has been found to be contaminated/positive for dioxins. The larger the pooling rate, the higher is the contribution of the variable component to the total tracing costs. The selection of an alternative testing strategy (s13 and s14) has a direct impact on the total monitoring costs. Note that the contamination cannot be detected at the fat melting facility when the number of contaminated containers reduces (s1) or a lower initial dioxin concentration at the containers $(\mathrm{s} 3)$ is considered, because the expected concentration of dioxins in the collected fat samples is below its decision limit. As a result, for these two scenarios, total monitoring costs for the entire chain cannot be compared to the total monitoring costs of the other scenarios. 
Table 7

Results for optimizing the allocation of resources for monitoring dioxins in the pork chain for each separate control point

\begin{tabular}{|c|c|c|c|c|c|c|c|c|c|c|c|c|c|c|c|c|c|}
\hline \multirow[b]{3}{*}{ Scenario } & \multirow{2}{*}{\multicolumn{4}{|c|}{$\begin{array}{l}\text { Number of samples } \\
\text { collected } \\
\text { (\#/week) }\end{array}$}} & \multirow{2}{*}{\multicolumn{4}{|c|}{$\begin{array}{l}\text { Detection Costs } \\
(€ \text { thousand/year) }\end{array}$}} & \multirow{2}{*}{\multicolumn{4}{|c|}{$\begin{array}{l}\text { Tracing Costs } \\
\text { (€ thousand/year) }\end{array}$}} & \multicolumn{5}{|c|}{ Total Monitoring Costs } \\
\hline & & & & & & & & & & & & & (€ thou & nd/year & & & \\
\hline & SI & FM & SL & $\mathrm{FF}$ & SI & FM & SL & $\mathrm{FF}$ & SI & FM & SL & $\mathrm{FF}$ & SI & FM & SL & $\mathrm{FF}$ & Chain \\
\hline Base & 29 & 9 & 11 & 1 & 29.1 & 22.9 & 40.8 & 8.9 & 13.1 & 8.2 & 14.2 & 102.6 & 42.2 & 31.1 & 55.0 & 111.6 & 239.9 \\
\hline s1 & 79 & 9 & 11 & - & 65.1 & 80.5 & 98.4 & - & 35.6 & 5.9 & 12.8 & - & 100.7 & 86.4 & 111.2 & - & $>298.3$ \\
\hline $\mathrm{s} 2$ & 17 & 9 & 11 & 1 & 20.5 & 14.7 & 24.4 & 8.9 & 7.7 & 10.0 & 15.6 & 102.6 & 28.1 & 24.7 & 39.9 & 111.6 & 204.4 \\
\hline s3 & 29 & 9 & 11 & - & 29.1 & 22.9 & 98.4 & - & 13.1 & 8.2 & 12.8 & - & 42.2 & 31.1 & 111.2 & - & $>184.6$ \\
\hline s4 & 29 & 9 & 11 & 1 & 29.1 & 14.7 & 32.6 & 8.9 & 13.1 & 10.0 & 14.7 & 102.6 & 42.2 & 24.7 & 47.2 & 111.6 & 225.8 \\
\hline s5 & 29 & 18 & 23 & 1 & 29.1 & 29.4 & 49.4 & 8.9 & 13.1 & 10.0 & 15.5 & 102.6 & 42.2 & 39.4 & 64.9 & 111.6 & 258.1 \\
\hline s6 & 29 & 3 & 5 & 1 & 29.1 & 10.4 & 44.7 & 8.9 & 13.1 & 7.2 & 13.0 & 102.6 & 42.2 & 17.6 & 57.7 & 111.6 & 229.1 \\
\hline s7 & 29 & 9 & 11 & 1 & 29.1 & 22.9 & 40.8 & 8.9 & 4.4 & 2.7 & 4.7 & 34.2 & 33.5 & 25.7 & 45.5 & 43.1 & 147.8 \\
\hline s8 & 29 & 9 & 11 & 1 & 29.1 & 22.9 & 40.8 & 8.9 & 26.2 & 16.4 & 28.4 & 205.2 & 55.3 & 39.4 & 69.2 & 214.2 & 378.1 \\
\hline s9 & 25 & 7 & 9 & 1 & 26.2 & 13.3 & 31.1 & 8.9 & 11.1 & 8.9 & 13.9 & 102.6 & 37.3 & 22.1 & 45.0 & 111.6 & 216.0 \\
\hline $\mathrm{s} 10$ & 37 & 11 & 14 & 1 & 34.9 & 24.4 & 51.2 & 8.9 & 17.0 & 8.8 & 14.4 & 102.6 & 51.9 & 33.1 & 65.6 & 111.6 & 262.2 \\
\hline s11 & 29 & 9 & 11 & 1 & 28.6 & 21.9 & 38.7 & 8.4 & 12.3 & 7.7 & 13.4 & 96.7 & 40.9 & 29.6 & 52.1 & 105.1 & 227.7 \\
\hline $\mathrm{s} 12$ & 29 & 9 & 11 & 1 & 29.6 & 24.0 & 42.9 & 9.5 & 13.9 & 8.7 & 14.7 & 108.5 & 43.6 & 32.7 & 57.6 & 118.0 & 251.9 \\
\hline s13 & 29 & 9 & 11 & 1 & 29.1 & 22.9 & 40.8 & 8.9 & 30.8 & 18.7 & 31.9 & 229.7 & 59.9 & 41.6 & 72.7 & 238.6 & 412.8 \\
\hline s14 & 29 & 9 & 11 & 1 & 40.2 & 45.1 & 85.1 & 20.0 & 30.8 & 18.7 & 31.9 & 229.7 & 70.9 & 63.7 & 117.0 & 249.7 & 501.4 \\
\hline
\end{tabular}

Note: SI : Supplier of Fatty Feed Ingredients, FM : Feed mill, SL: Slaughterhouse, FF: Fat Melting Processor, - : No costs reported since this control point is not included in the optimization model for this scenario, > : The total monitoring costs for the entire chain is expected to be higher than the value reported since the results for the optimization at the fat melting processor is not reported. 
Table 8

Results for optimizing the allocation of resources for monitoring dioxins in the pork chain in an integrated chain approach (i.e. including all control points)

\begin{tabular}{|c|c|c|c|c|c|c|c|c|c|c|c|c|c|c|c|c|c|c|c|}
\hline \multirow[b]{3}{*}{ Scenario } & \multirow{2}{*}{\multicolumn{3}{|c|}{$\begin{array}{l}\text { Number of } \\
\text { Samples } \\
\text { Collected } \\
\text { (\#/week) }\end{array}$}} & \multicolumn{4}{|c|}{ Detection costs } & \multicolumn{4}{|c|}{ Tracing costs } & \multicolumn{4}{|c|}{ Total Monitoring Costs } & \multicolumn{4}{|c|}{$\begin{array}{l}\text { Total Monitoring } \\
\text { Effectiveness }\end{array}$} \\
\hline & & & & \multicolumn{4}{|c|}{ (€ thousand/year) } & \multicolumn{4}{|c|}{ (€ thousand/year) } & \multicolumn{4}{|c|}{ (€ thousand/year) } & \multicolumn{4}{|c|}{$(\%)$} \\
\hline & SI & FM & SL & SI & FM & SL & Total & SI & FM & SL & Total & SI & FM & SL & Chain & SI & FM & SL & Chain \\
\hline Base & 3 & 7 & & 10.4 & 13.3 & - & 23.6 & 0.4 & 6.3 & - & 6.7 & 10.8 & 19.6 & - & 30.3 & 29 & 93 & - & 95 \\
\hline s1 & - & 7 & 1 & - & 62.6 & 8.9 & 71.5 & - & 5.8 & 0.3 & 6.0 & - & 68.4 & 9.2 & 77.6 & - & 93 & 28 & 95 \\
\hline s2 & - & 9 & - & - & 14.7 & - & 14.7 & - & 10.0 & - & 10.0 & - & 24.7 & - & 24.7 & - & 96 & - & 96 \\
\hline s3 & - & 9 & - & - & 22.9 & - & 22.9 & - & 8.2 & - & 8.2 & - & 31.1 & - & 31.1 & - & 96 & - & 96 \\
\hline s4 & - & 9 & - & - & 14.7 & - & 14.7 & - & 10.0 & - & 10.0 & - & 24.7 & - & 24.7 & - & 96 & - & 96 \\
\hline s5 & 9 & 11 & - & 14.7 & 16.1 & - & 30.8 & 2.7 & 3.5 & - & 6.3 & 17.4 & 19.7 & - & 37.1 & 64 & 87 & - & 95 \\
\hline s6 & - & 3 & - & - & 10.4 & - & 10.4 & - & 7.2 & - & 7.2 & - & 17.6 & - & 17.6 & - & 95 & - & 95 \\
\hline s7 & - & 6 & 2 & - & 12.5 & 9.7 & 22.2 & - & 2.7 & 0.2 & 2.9 & - & 15.3 & 9.9 & 25.2 & - & 91 & 49 & 95 \\
\hline s8 & 6 & 6 & - & 12.5 & 12.5 & - & 25.1 & 2.8 & 8.2 & - & 11.1 & 15.4 & 20.8 & - & 36.1 & 50 & 91 & - & 95 \\
\hline s9 & - & 7 & - & - & 13.3 & - & 13.3 & - & 8.9 & - & 8.9 & - & 22.1 & - & 22.1 & - & 93 & - & 93 \\
\hline s 10 & 8 & 7 & - & 14.0 & 13.3 & - & 27.2 & 2.3 & 3.5 & - & 5.8 & 16.3 & 16.8 & - & 33.1 & 60 & 93 & - & 97 \\
\hline s11 & 3 & 7 & - & 9.9 & 12.7 & - & 22.6 & 0.4 & 5.9 & - & 6.3 & 10.2 & 18.7 & - & 28.9 & 29 & 93 & - & 95 \\
\hline $\mathrm{s} 12$ & 3 & 7 & - & 10.9 & 13.8 & - & 24.7 & 0.4 & 6.7 & - & 7.1 & 11.3 & 20.4 & - & 31.8 & 29 & 93 & - & 95 \\
\hline s 13 & 6 & 6 & - & 12.5 & 12.5 & - & 25.1 & 3.3 & 9.4 & - & 12.7 & 15.9 & 21.9 & - & 37.8 & 50 & 91 & - & 95 \\
\hline s14 & 6 & 6 & - & 23.6 & 23.6 & - & 47.2 & 3.3 & 9.4 & - & 12.7 & 26.9 & 33.0 & - & 59.9 & 50 & 91 & - & 95 \\
\hline
\end{tabular}

Note: SI = Supplier of Fatty Feed Ingredients, FM = Feed mill, SL= Slaughterhouse, FF= Fat Melting Processor.

The control point at the fat melting processor is not included in Table 8 because they are not part of optimal solution in any contamination scenario 
To detect and trace the dioxin contamination with $95 \%$ of effectiveness dioxins should be monitored at the supplier of fatty feed ingredients and the fee mill (Table 8). A decrease in the number of contaminate containers (s1) shifts the combined optimal solution from the supplier of fatty feed ingredients to the slaughterhouse. It is more cost-effective to monitor dioxins at the slaughterhouse in combination with the feed mill, since less pork carcass (with respect to the number of containers) should be sampled for detecting the contamination. An increase in the number of contaminated containers (s2) and the concentration of dioxins at the contaminated containers (s3 and s4) suggest that monitoring dioxins must be done exclusively at the feed mill. For these three scenarios the same number of samples is required to be collected at the feed mill (e.g. 9 samples). Differences in detection and tracing costs are due to the variation in the pooling rate due to the expected concentration of dioxins in the feed samples. If less feed mills are involved in the contamination (s5), a combined solution is obtained, in which -as compared to the base scenario- a higher number of samples must be collected at the supplier of fatty feed ingredients and at the feed mill. A decrease in the number of contaminated feed mills, increases the number of samples to be collected at the feed mill because the fraction of contaminated material decreases. The expected number of contaminations per year influences the inclusion of control points in the optimal monitoring scheme. A decrease in the expected number of contamination per year (s7), shift the combined optimal solution -with respect to the base scenario- from the supplier of fatty feed ingredients to the slaughterhouse. To monitor dioxins exclusively at the feed mill is not an optimal solution when varying the expected number of contaminations per year since the same effectiveness with lower costs can be achieved by integrating other control points in the monitoring scheme. Aiming for detecting the contamination with a lower level of effectiveness (s9) shifts the optimal control point for monitoring dioxins exclusively to the feed mill, and the total monitoring costs reduces with $27 \%$ as compared to the costs at the 
Monitoring dioxins along the pork chain

base scenario. If a higher level of effectiveness is aimed for (s10), a higher number of samples must be collected at the supplier of fatty feed ingredients than at the feed mill. An additional sample collected at the feed mill increases the effectiveness but at a higher cost than the same increase in effectiveness achieved by collecting more samples at the supplier of fatty feed ingredients. The change in the screening costs (s11 and s12) affects directly the detection and tracing costs without modifying the optimal scheme for detecting the contamination as in the base scenario. The testing costs for eliciting faster the initial source of the contamination (s13) increases the total monitoring costs by $25 \%$ as compared to the costs at the base scenario. Reducing the time for detecting and tracing the contamination to its source (s14) by applying only the confirmatory method as testing strategy increases the total monitoring costs by $98 \%$ as compared to the total monitoring cost at the base scenario.

\subsection{Discussion}

This study presents a decision support tool to allocate in a cost-effective way the resources for monitoring dioxins at several control points along a hypothetical pork chain. The input data used to estimate the concentration of dioxins in fat of pork carcass has been obtained from studies analyzing the carry-over of dioxin in pigs fed with contaminated feed (Hoogenboom et al., 2004; Hoogenboom et al., 2007). Only dioxins are considered as the source of the contamination to simplify the model, although the inclusion of dl-PCBs would have resulted in more realistic contamination scenarios. However, the general insights in the optimal allocation of resources to monitor dioxins as obtained in this research will not be altered by including dl-PCBs as an additional contamination source. The pigs considered in this study are assumed to be fully housed indoors and fed with the delivered compound feed. Therefore, the results of this study cannot be fully extended to pigs reared outdoors, in which the concentration of dioxins in pork fat, meat and liver due to soil ingestion is expected to be 
higher than in pigs reared indoors (Rose et al., 2012). However, the spread of a dioxin contamination in pigs due to environmental sources such as soil ingestion is limited by geographical conditions. Consequently, it would be very unlikely that ingestion of dioxin contaminated soil would lead to widespread contamination of pigs comparable to contaminations caused by compound feeds.

The course of a dioxin contamination within the chain was simulated in a deterministic way. In reality, such input variables and their interactions occur randomly; thus, a stochastic approach should be more suitable to simulate the flow of the dioxin contamination along the pork chain. In fact, by using a stochastic approach the full distribution including all possible contamination scenarios can be elicited. However, information describing the probability distributions of such inputs is rather inexistent or very limited. Moreover, when using a stochastic approach, it will not be possible to get clear insights into the main factors affecting the spread of a contamination, given the simultaneous variation of the inputs and their interactions. In this case, the deterministic approach was considered more useful for describing the driving factors that affect the flow of the dioxin contamination along the pork chain. Moreover, it allows for building contamination scenarios that can show the spread and the possible extent of a dioxin contamination throughout the chain. So far, the deterministic approach has offered sufficient inputs for the optimization model to determine cost-effective monitoring schemes for detecting and tracing contaminations above a certain decision limit.

In this study, the costs of tracing the contamination from the fat melting processor are nine and six times higher than the costs of tracing the contamination from the feed mill and the slaughterhouse, respectively. As a consequence of the high tracing cost, the control point at the fat melting processor is not a cost-effective solution for monitoring dioxins in any of the evaluated scenarios, even though it has the lowest costs of detecting the contamination. The size of the tracing costs is mainly caused by the large number of pig farms that must be 
Monitoring dioxins along the pork chain

sampled and tested when a contaminated fat sample is detected at the fat melting processor. Samples from suspected farms are assumed to be tested individually given the limited information regarding the spread of the contamination and the unknown concentration of dioxins in the samples from suspected farms. Assuming that the contamination is exclusively caused by compound feed, the tracing procedure from the fat melting processor can be focused directly at feed mills instead of pig farms. Given the limited information, the number of samples required to trace the contamination can be lowered from 177 farm-samples to 29 feed mill-samples. Consequently, the tracing costs per contamination at the fat melting processor will be reduced from $€ 34.9$ to $€ 7.1$ thousand, respectively. These tracing costs are, however, still larger than the costs of tracing the contamination from any other control point. Therefore, monitoring dioxins at the fat melting processor is still not considered by the optimization model in any optimal monitoring schemes. With additional information on, for instance, the geographical distribution of the suspected farms or the relation of suspected farms to a specific feed supplier, a risk based sampling and pooling can be applied to trace the contamination and to reduce even more the tracing costs.

In this study, the same testing costs per sample unit are applied at all control points. In practice, however, the testing costs at each control point can vary depending on, for example, the number of samples that are tested at each point. If more samples from the slaughterhouse are tested than from the other control points, the testing cost per sample unit can be lowered and this can concentrate the allocation of resources into this specific control point. In fact, decreasing the cost of the screening test at the slaughterhouse by $10 \%$ shifts the optimal monitoring scheme in the base scenario from controlling at the supplier of fatty ingredients to controlling at the slaughterhouse. However, a unique cost of the screening test for all control points is more practical when optimizing the allocation of resources in an integrated chain approach. 
By considering the costs of tracing the contamination to its initial source, this study has shown that the cost-effective allocation of resources for monitoring dioxins focuses on the earlier stages of the chain (i.e. feed mill and supplier of fatty feed ingredients). The financial consequences of a dioxin contamination on the actors of the pork chain and the costs of tracking all contaminated material are not considered in the optimization model. It is expected that including these factors into the optimization model will even more strongly point to allocation of resources to the first stages of the chain.

Modelling results elicit relevant information regarding the economic benefits of monitoring dioxins in an integrated chain approach rather than in an independent chain actor approach. Moreover, the results indicated the importance of monitoring dioxins at the feed mill. For all evaluated contamination scenarios, monitoring dioxins at the feed mill has the highest contribution to the total effectiveness of the optimal monitoring schemes. This contribution is on average higher than $90 \%$. This implies that if the minimum required total effectiveness under the integrated chain approach is reduced form $95 \%$ to $90 \%$, monitoring dioxins exclusively at the feed mill will become the optimal monitoring scheme for all contamination scenarios. The importance of monitoring dioxins at the feed mill is also reflected by the small differences in total monitoring costs when the optimization model is applied separately at the feed mill instead of in the integrated chain approach. For example, the cost of detecting the base contamination scenario separately at the feed mill is just $2.6 \%$ higher than the corresponding cost obtained under the integrated chain approach. Additionally, by monitoring dioxins in feed samples at the feed mill, it is possible to detect contaminations that are not only caused by fatty feed ingredients but also by other kind of ingredients. In fact, compound feed by itself can be considered a pooled sample (since it is resulting from the combination of many kinds of ingredients), in which dioxin contaminations 
Monitoring dioxins along the pork chain

can be effectively detected, thus preventing the spread of contaminations in further stages of the food chain.

A dioxin contamination caused by a very elevated concentration of dioxins in animal fatty feed ingredients (i.e. 93 times above the AL and 70 times above the ML, for feed ingredients) are hardly reflected in the concentration of dioxins in pig-carcass and pork fat estimated in the base scenario depicted in this study. In fact, the concentration of dioxins in pig carcass and pork fat are below the ML (1 ng TEQ/kg fat) for this kind of food products. This is mainly caused by the short contamination period considered in the study (one week) and thus, the short exposure time of pigs to contaminated feed. If the contamination lasts longer, (as it is the case of salient dioxin contaminations, such as the Irish incident in 2008) higher levels of dioxins will be found in pigs slaughtered in subsequent weeks than in pigs delivered to slaughterhouses just after one week of exposure. Considering the same input values used to simulate the base scenario, it is expected that pigs delivered after three weeks of exposure show higher concentrations of dioxins than the AL (0.75 ng TEQ/kg fat). However, to acknowledge the occurrence of a dioxin contamination and start the tracing procedure only when the concentration of dioxins is above the AL (as it is underlined in the European regulation) would avoid the possible early detection of a contamination at the slaughterhouse or at the fat melting processor. Consequently, this study shows that to detect dioxin contaminations effectively and early along the pork chain, risk managers in feed and food industry should apply lower decision limits than the AL or ML for dioxins stated in the EU legislation.

The model described in this study is flexible and can be used for optimizing the resource allocation for monitoring other chemical contaminants along animal production chains and to include specific chain characteristics. Optimizing the resource allocation for monitoring biological hazards would require a further extension of the model with functional 
relationships for characteristics of micro-organisms, like growth, mortality and survival rates under specific conditions (e.g. time and temperature) within the chain. Studies such as those carried out by Ferrier and Buzby (2013) in which these relations are considered can be used as a baseline for creating an application of this model for monitoring biological hazards.

The results obtained in this study elicit information for decision makers at the food and feed industry regarding the economic importance of sharing the responsibility and costs of monitoring dioxins among different actors (stages) along the chain. Combining efforts for monitoring dioxins can optimize the use of the resources by focusing at specific control points where contaminations have a higher probability of being detected and can be traced at lower costs. Additionally, from the output of the model it is possible to determine the amount of resources that is required to detect and trace a specific dioxin contamination within the chain. Consequently, decision makers can focus the efforts to ensure the detection of specific types of contaminations, given the amount of resources available for this activity.

\subsection{Conclusions}

Isolated efforts by pork chain actors for detecting and tracing a dioxin contamination, to its origin can be effective but not economically efficient. The results of this study show the large economic benefits of a chain approach for monitoring dioxins compared to an approach where each chain actor individually monitors for dioxins. This indicates the relevance of sharing the responsibility and the costs of monitoring dioxins along the chain among the different chain actors.

This study shows that monitoring dioxins at the control point located at the feed mill is crucial to reduce the cost and increase the effectiveness of detecting and tracing a dioxin contamination in the pork chain. Moreover, the tool developed in this study is useful to underpin decision making for determining monitoring schemes that allocate resources in 
Monitoring dioxins along the pork chain

control points with low cost and high probability of detecting and tracing a dioxin contamination. This tool increases the awareness of decision makers about the optimal monitoring schemes that should be applied to detect specific types of contaminations and the amount of financial resources that must be invested to achieve that goal. 


\section{References}

Abalos, M., Parera, J., Abad, E., \& Rivera, J. 2008. PCDD/Fs and DL-PCBs in feeding fats obtained as co-products or by-products derived from the food chain. Chemosphere. 71(6):1115-1126.

Agricultural Economics Research Institute, LEI. 2013, December 20. LEI's farm accountancy data network, BINternet. Retrieved from http://www.wageningenur.nl/en/Expertise-Services/ResearchInstitutes/lei/Statistics/Binternet-1.htm

Bernard, A., F. Broeckaert, G. De Poorter, A. De Cock, C. Hermans, C. Saegerman, and G. Houins. 2002. The Belgian PCB/dioxin incident: Analysis of the food chain contamination and health risk evaluation. Environ. Res. 88(1):1-18.

Büchert, A., T. Cederberg, P. Dyke, H. Fiedler, P. Fürst, A. Hanberg, J. Hosseinpour, O. Hutzinger, J. G. Kuenen, R. Malisch, L. L. Needham, K. Olie, O. Papke, J. Rivera Aranda, G. Thanner, G. Umlauf, T. Vartiainen, and C. van Holst. 2001. Dioxin contamination in food. Bayreuth, Germany, from September 28 to October 1, 2000. Environ. Sci. Poll. Res. 8(2):84-88.

Buzby, J. C., and R. Chandran. 2003. The Belgian Dioxin Crisis and its effects on Agricultural Production and Exports, p125-139. In J.C. Buzby (ed.), International Trade and Food Safety: Economic Theory and Case Studies. Agricultural Economic Report No. 828. Economic Research Service. USDA.

Domenech, E., I. Escriche, and S. Martorell. 2008. Assessing the effectiveness of critical control points to guarantee food safety. Food Control. 19(6):557-565.

European Commission (EC). 2004. Commission Regulation (EC) No 852/2004 of the European Parliament and of the Council of 29 April 2004 on the hygiene of foodstuffs. Off. J. Eur. Comm. L139/1. 
Monitoring dioxins along the pork chain

European Commission (EC). 2005. Commission Regulation (EC) No 183/2005 of the European Parliament and of the Council of 12 January 2005 laying down requrements for feed hygiene. Off. J. Eur. Comm. L35:1-22.

European Commission (EC). 2006. Commission Directive 2006/13/EC of 3 February 2006 amending Annexes I and II to Directive 2002/32/EC of the European Parliament and of the Council on undesirable substances in animal feed as regards dioxins and dioxin-like PCBs. Off. J. Eur. Comm. L32:42-53.

European Commission (EC). 2011a. Commission Regulation (EC) No 1259/2011 of 2 December 2011 amending Regulation (EC) No 1881/2006 as regards maximum levels for dioxins, dioxins-like PCBs and non dioxin-like PCBs in foodstuffs. Off. J. Eur. Comm. L320:18-23.

European Commission (EC). 2011b. Commission Recommendation of 23 August 2011 on the reduction of the presence of dioxins, furans and PCBs in feed and food (2011/516/EU). Off. J. Eur. Comm. L218:23-25.

European Commission (EC). 2012. Commission Regulation (EU) No 277/2012 of 28 March 2012 amending Annexes I and II to Directive 2002/32/EC of the European Parliament and of the Council as regards maximum levels and action thresholds for dioxins and polychlorinated biphenyls. Off. J. Eur. Comm. L91:1-7.

European Feed Manufacturers Federation (FEFAC). 2013, December 20. 2011 Feed and Food Statistical Yearbook. Retrieved from http://www.fefac.eu/files/42596.pdf

Ferrier, P. M., and Buzby, J. C. 2013. The Economic Efficiency of Sampling Size: The Case of Beef Trim. Risk Anal. 33(3):368-384. 
Heres, L., R. Hoogenboom, R. Herbes, W. Traag, and B. Urlings. 2010. Tracing and analytical results of the dioxin contamination incident in 2008 originating from the Republic of Ireland. Food Addit. Contam. Part A-Chem. 27(12):1733-1744.

Hoogenboom, L. A. P. 2009. Dioxins, polychlorinated biphenyls and brominated flame retardants. p. 383-405. In I. Shaw (ed.), Endocrine disrupting chemicals in food. Woodhead Publishing Ltd. Oxford.

Hoogenboom, R., T. Bovee, L. Portier, G. Bor, G. Van Der Weg, C. Onstenk, and W. Traag. 2004. The German bakery waste incident; Use of a combined approach of screening and confirmation for dioxins in feed and food. Talanta. 63(5):1249-1253.

Hoogenboom, L. A. P., C. A. Kan, T. F. H. Bovee, G. van der Weg, C. Onsten, and W. A. Traag. 2004. Residues of dioxins and PCBs in fat of growing pigs and broilers fed contaminated feed. Chemosphere. 57(1):35-42.

Hoogenboom, L. A. P., J. C. H. Van Eijkeren, M. J. Zeilmaker, M. J. B. Mengelers, R. Herbes, J. Immerzeel, and W. A. Traag. 2007. A novel source for dioxins present in recycled fat from gelatin production. Chemosphere. 68(5):814-823.

Huwe, J. K. 2002. Dioxins in food: A modern agricultural perspective. J. Agric. Food Chem. 50(7):1739-1750.

Huwe, J. K., and D. J. Smith. 2005. Laboratory and on-farm studies on the bioaccumulation and elimination of dioxins from a contaminated mineral supplement fed to dairy cows. J. Agric. Food Chem. 53(6):2362-2370. 
Monitoring dioxins along the pork chain

Kim, M., S.-W. Choi, J. Y. Park, D.-G. Kim, Y.-H. Bong, J. H. Jang, S. O. Song, G. S. Chung, and P. Guerrero. 2009. Dioxin contamination of Chilean pork from zinc oxide in feed. Organohalogen Compd. 71:179-182.

Kim, M., D. G. Kim, S. W. Choi, P. Guerrero, J. Norambuena, and G. S. Chung. 2011. Formation of polychlorinated dibenzo-p-dioxins/dibenzofurans (PCDD/Fs) from a refinery process for zinc oxide used in feed additives: A source of dioxin contamination in Chilean pork. Chemosphere 82(9):1225229.

Lascano Alcoser, V. H., Velthuis, A. G. J., Hoogenboom, L. A. P., \& van der Fels-Klerx, H. J. 2011. Financial impact of a dioxin incident in the Dutch dairy chain. J. Food Prot. 74(6):967-979.

Lascano Alcoser, V. H., Velthuis, A. G. J., van der Fels-Klerx, H. J., Hoogenboom, L. A. P., \& Oude Lansink A. G. J. M. 2013. Optimizing bulk milk dioxin monitoring based on costs and effectiveness. J. Dairy Sci. 96(7):4125-4141.

Llerena, J. J., E. Abad, J. Caixach, and J. Rivera. 2003. An episode of dioxin contamination in feedingstuff: the choline chloride case. Chemosphere. 53(6):679-683.

Malisch, R. 2000. Increase of the PCDD/F-contamination of milk, butter and meat samples by use of contaminated citrus pulp. Chemosphere. 40(9-11):1041-1053.

Productschappen Vee, Vlees en Eieren (PVE). 2013, December 20. 2012. Livestock, meat and eggs in The Netherlands. Retrieved from:

http://www.pve.nl/wdocs/dbedrijfsnet/up1/ZsxvvlzIqgB_432682PVEpromoENG_LR_definitef.pdf

Ropkins, K., and A. J. Beck. 2002. Application of hazard analysis critical control points (HACCP) to organic chemical contaminants in food. Crit. Rev. Food Sci. Nutr. 42(2):123-149. 
Rose, M., B. Thomson, A. M. Jensen, L. Giorgi, and C. Schulz. 2009. Food monitoring and control for environmental contaminants. Qual. Assur. Saf. Crop. 1(3):160-169.

Rose, M., A. Fernandez, C. Foxall, and A. Dowding.2012. Transfer and uptake of polychlorinated dibenzo-p-dioxins and furans (PCDD/Fs) and polychlorinated biphenyls (PCBs) into meat and organs of indoor and outdoor reared pigs. Food Addit. Contam. Part A. 29(3):431-448.

Sapkota, A. R., Lefferts, L. Y., McKenzie, S., \& Walker, P. 2007. What do we feed to food production animals? A review of animal feed ingredients and their potential impacts on human health. Environ. Health Perspect. 115(5):663-670.

Schmid, P., E. Gujer, S. Degen, M. Zennegg, A. Kuchen, and C. Wuthrich. 2002. Levels of polychlorinated dibenzo-p-dioxins and dibenzofurans in food of animal origin. The Swiss dioxin monitoring program. J. Agric. Food Chem. 50(25):7482-7487.

Stärk, K. D. C., H. B. Boyd and J. Mousing. 2002. Risk assessment following the hypothetical import of dioxin-contaminated feed for pigs - An example of quantitative decision-support under emergency conditions. Food Control, 13(1):1-11.

Tlustos, C. 2009a. The dioxin contamination incident in Ireland 2008. Organohalogen Compd. 71:1172-1176.

Tlustos, C. 2009b. The dioxin crisis in Ireland 2008 - challenges in risk management and risk communication. Organohalogen Compd. 71:1169-1171.

Zach, L., M. E. Doyle, V. Bier, and C. Czuprynski. 2012. Systems and governance in food import safety: A U.S. perspective. Food Control, 27(1):153-162. 


\title{
Chapter 5
}

\section{Cost-effective strategies for monitoring dioxins at the feed mill}

\author{
V. H. Lascano Alcoser, H. J. van der Fels-Klerx,
} M. C. M. Mourits, A. G. J. M. Oude Lansink 
Monitoring dioxins at the feed mill

\section{Abstract}

The aim of this study was to determine cost-effective strategies for monitoring dioxins in feed ingredients or compound feeds in order to prevent elevated levels of dioxins in charges of compound feed entering the poultry production chain. For this purpose, the feed production process at a poultry feed mill was modelled based on the characteristics of the Dutch feed industry. The developed model consists of three modules to simulate: 1) the annual influx of individual vessels or trucks with feed ingredients in the feed production process, resulting in the number of unique charges of compound feed, 2) the concentration of dioxins in compound feed resulting from the individual contribution of each feed ingredient considered in the feed formulation, and 3) the cost-effectiveness of monitoring strategies directed to individual ingredients as well as produced compound feed. The effectiveness of a monitoring strategy is defined as the proportion of contaminated compound feed charges that is prevented from entering the poultry production chain in comparison to a situation without any monitoring in place. Monitoring dioxins in wheat and corn can be considered as the cost-effective solution for monitoring dioxins in ingredients compared to the other evaluated monitoring strategies. This strategy results in a high average level of effectiveness $(96.2 \%)$ at lower total costs (20\% less) compare to the costs of monitoring dioxins in charges of compound feed. Monitoring dioxins in those ingredients with a high inclusion rate generates a high effectiveness and a more cost-efficient use of monitoring resources compared to monitoring those ingredients with a low inclusion rate. Moreover, ingredients with above ML dioxins levels, but a low inclusion rate cannot be detected by monitoring dioxins in compound feed. This is caused by the dilution of the dioxin concentration of feed ingredients in compound feed. As no extreme dioxin levels, but background levels of dioxins are considered in feed ingredients, results of this study are useful to quality assurance managers at the feed industry and policy makers. 


\subsection{Introduction}

Since the end of the 1990 's, dioxin incidents in food of animal origin have been mainly caused by the use of dioxin-contaminated feed in livestock production (Büchert et al., 2001, EC, 2000). Dioxin-contaminated feed is featured as feed containing elevated levels of these chemical pollutants, caused by the use of feed ingredients with increased concentration of dioxins in the manufacturing process (Adamse et al., 2015). Since feed is considered a salient source of food dioxin contaminations, feed producers play a key role in tackling potential contaminations and prevent further spreading of these pollutants in the food chain (Meuwissen et al., 2009).

Dioxin-monitoring reports show that feed and food products of animal origin have higher levels of dioxins than products of plant origin (Abalos et al., 2008, EFSA, 2010). However, feed dioxin incidents of the last 25 years show that sources of dioxin contaminations are not exclusively caused by feed ingredients of animal origin. In fact, elevated levels of dioxins have been found in feed ingredients of plant origin such as coconut oil (van Asselt, 2011), corn (Hoogenboom et al., 2015), and feed additives and mineral ingredients such as choline chloride (Llerena et al., 2003) or zinc oxide (Kim et al., 2011). The sources of these contaminations included accidental mixes of PCB oils or industrial fatty acids as in the Belgian crisis in 1999 (Bernard et al., 1999) and the German incident in 2010 (Fürst, 2011, Rieger et al., 2016). Feed ingredients can also be contaminated during intermediate steps in the manufacturing process, for example through improper drying procedures involving fuels containing PCB-oil or wood treated with PCP as in the Irish incident in 2008 (Heres et al., 2010, Tlustos et al., 2012). The use of natural contaminated materials for producing feed ingredients are also a source of dioxin contaminations, like the use of kaolinic clay for sorting potatoes in the food industry (Hoogenboom et al., 2010). 
Monitoring dioxins at the feed mill

Incidents involving fat and oily feed ingredients have received special attention from the European Commission due to the nature of the contaminations, particularly since the German incident in 2010 (Fürst, 2011). In this regard, DG SANCO produced a working document proposing that, in most cases, every batch of by-products of fats and oils intended to be used in the feed industry must be analytically tested for the presence of dioxins (van Asselt, 2011). However, based on RASFF dioxin notifications from 1999 to 2011, only 30\% of the reported dioxin feed and food contaminations was caused by contaminated fat or oil (van Asselt, 2011). This implies that $70 \%$ of the detected feed contaminations were due to other ingredients. The RASFF notifications show the wide variety of feed ingredients that can be contaminated. This variety poses a big challenge to the feed industry and national government agencies when allocating -the often limited- resources for monitoring dioxins in feed ingredients. Designing cost-effective monitoring schemes is therefore needed to optimally allocate monitoring resources along the chain. Studies on cost-effective dioxin monitoring have been carried out for bulk milk and the pork chain (Lascano-Alcoser et al., 2014, Lascano-Alcoser et al., 2013). To date, studies on designing cost-effective strategies for monitoring dioxins, focusing exclusively on the feed industry have not been performed. This stage of the food chain is of utmost importance in tackling any dioxin incident early in the food supply chain. This is because food dioxin contaminations often originate from dioxincontaminated feed materials. Moreover, by adequate monitoring dioxins in the feed industry, the financial losses of dioxins contaminations in consecutive stages of the milk chain can be avoided (Lascano Alcoser et al., 2011). The aim of this study was to determine cost-effective strategies for monitoring dioxins in feed ingredients or compound feed in order to prevent elevated levels of dioxins in charges of compound feed entering the food supply chain. 


\subsection{Materials and Methods}

A model is used to evaluate the cost-effectiveness of monitoring dioxins in feed ingredients or compound feed at a feed mill. For this purpose, the feed production process of a Dutch poultry feed mill was mimicked. The developed model consists of three modules to simulate 1) the annual influx of individual vessels or trucks with feed ingredients in the feed production process, resulting in the number of unique charges of compound feed, 2) the concentration of dioxins in compound feed resulting from the individual contribution of each feed ingredient considered in the feed formulation, and 3) the cost-effectiveness of monitoring strategies directed to individual ingredients as well as produced compound feed. The flow of information between modules is depicted in Figure 1.

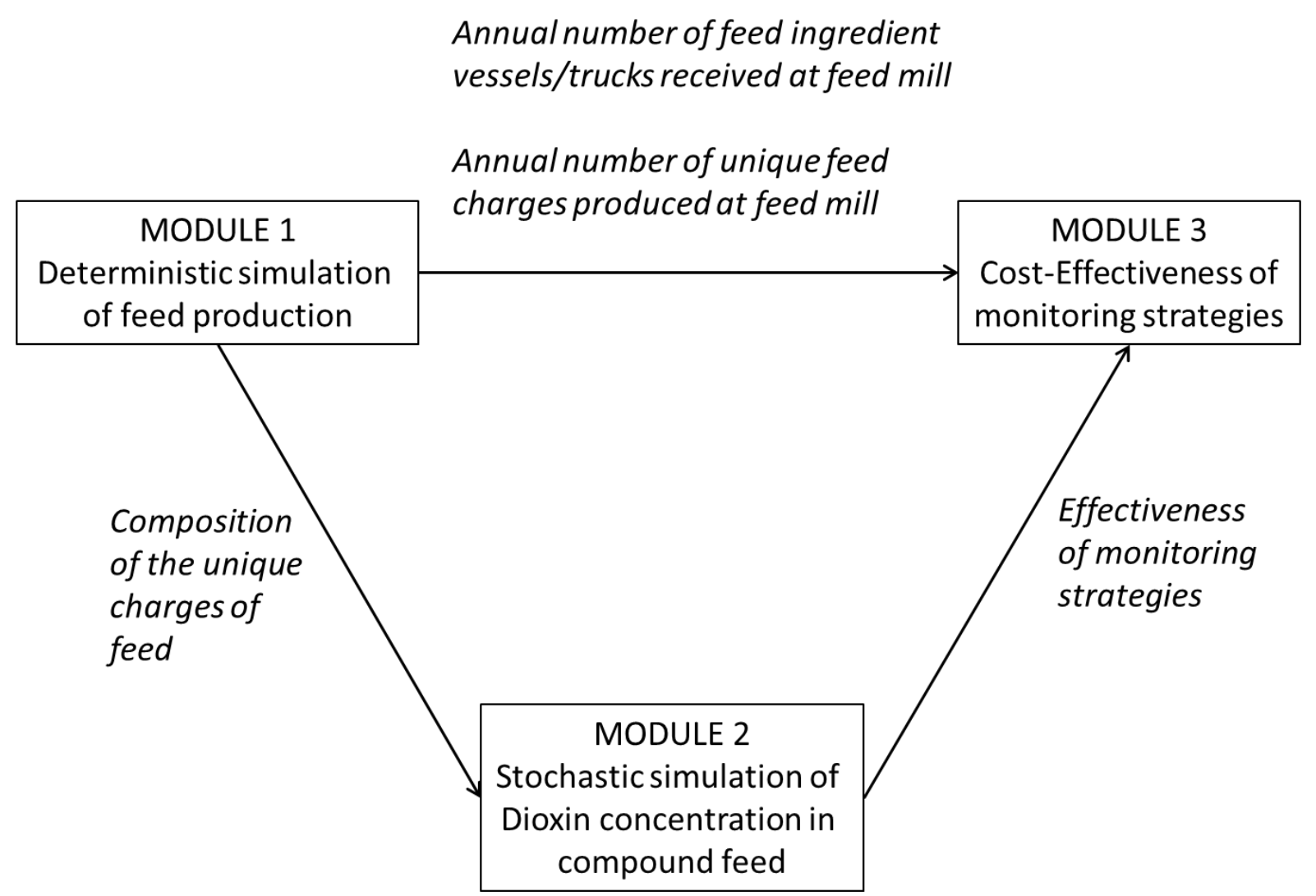

Figure 1. Flow of information between Modules. 
Monitoring dioxins at the feed mill

\section{Feed production at the feed mill: case description}

The case study considers a customized feed mill producing compound feed for broiler and laying hens. The evaluated feed production process is depicted in Figure 1. Data on feed production, ingredients and volumes are based on the characteristics of the Dutch feed industry. For the production of the two types of compound feed, the feed mill uses ten feed ingredients (Table 1), i.e., wheat, corn, soymeal, rapeseed, sunflower, animal fat (Ani. Fat), vegetable oil (Veg. Oil), lime, vitamins \& minerals (Vit. \& Min.), and amino acids synthetics (AA.) during the course of one year which has 312 production days. Feed ingredients are transported to the feed mill in vessels of $2000 \mathrm{t}$ or $1000 \mathrm{t}$ or in trucks of $30 \mathrm{t}$. An empty clean silo is used for storing every new vessel/truck of ingredient received at the feed mill. Every day, 540t of each of the two compound feeds are produced at the feed mill in a single continuous production line. The production of feed is organized in batches. The size of a batch is given by the size of the mixer, which is assumed to be 6t. Based on the size of the mixer and the formulation of the compound feed at the production site, specific quantities of each ingredient are collected from the storage silos. Subsequently, they are transported and loaded into the mixer, in which they are combined to produce the compound feed. For this study, a unique charge of compound feed is defined as a group of batches of a compound feed that shares an identical origin with respect to the shipments of ingredients that were used in the manufacturing of the particular compound feed batch. Every time the type of compound feed at the production line is shifted or a new vessel/truck of any ingredient (considered in the feed formulation) is uploaded in the feed production line, a new unique charge of compound feed is created. By identifying these unique charges of feed, it is possible to avoid double testing for dioxins at feed-batches that are identical in its composition; thus, optimizing the use of monitoring resources. 


\section{Sampling and testing procedures}

A sample is collected from a feed ingredient when it arrives at the feed mill (Figure 2). The number of incremental samples that is collected depends on the size of the vessel/truck in which the ingredient is transported. It is assumed that a vessel of $2000 t$ or $1000 t$ is physically divided into compartments of 500t. As indicated in the Commission Regulation (EU) No $589 / 2014$, for every sublot with a volume of 500t, 5 incremental samples are collected and mixed into an aggregate sample for analytical dioxin testing. Thus, from every vessel of $2000 \mathrm{t}$ and 1000t, 4 and 2 aggregate samples, respectively, are individually tested for dioxins. From each truck (of 30t), 3 incremental samples are collected and combined into an aggregate sample, which is tested for dioxins. It is assumed that the results of analytically testing dioxins in feed ingredients are known before ingredients are arrayed to the feed production line. The ingredient is only used for feed production when the result of the test indicates that it complies with the EC maximum limit for dioxins.

When monitoring compound feed, a sample of every unique charge of compound feed is collected at the moment of transporting the compound feed from the mixer to a temporary storage silo, and this sample is individually tested for the presence of dioxins. The sensitivity of the confirmatory analytical method to test the dioxin concentrations above the decision limit in ingredients as well as in compound feed (EC, 2014) is assumed to be $100 \%$. 


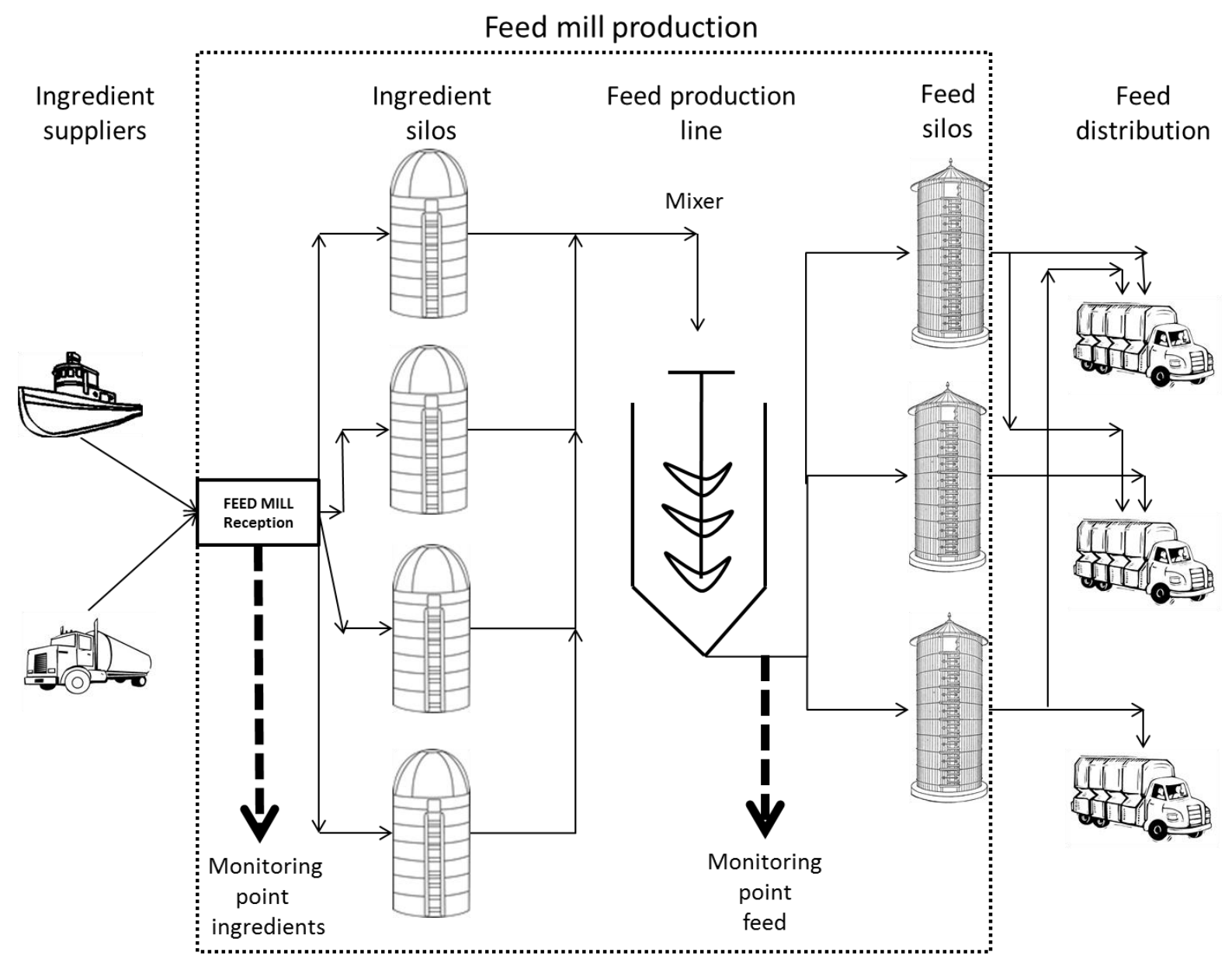

Figure 2. Feed production scheme including sampling points for monitoring dioxins

\section{Module 1: Simulation of feed production}

A deterministic model is developed to determine the number of vessels of feed ingredients and unique charges of compound feeds that are received and manufactured, respectively, during one year. The output is subsequently used as input of the models to estimate the dioxin concentration in the unique charges of compound feed (module 2) and to calculate the costs of monitoring schemes (module 3) (Figure 1).

The number of vessels/trucks per type of ingredient received at the feed mill in a year $\left(n v_{i}\right)$ is estimated as follows:

$n v_{i}=\frac{\sum_{j}^{J}\left(q d_{j} \cdot w d \cdot f_{i j}\right)}{s v_{i}}$ 
where $q d_{j}$ is the quantity produced per day for each compound feed $j$ (540t of each feed), wd is the number of production days at the feed mill in a year (312 days), $f_{i j}$ is the proportion of the ingredient $i$ used for producing compound feed $j$, and $s v_{i}$ is the vessel/truck size for ingredient $i$. The formulation for each compound feed and the shipment size of each ingredient are shown in Table 1.

In this study, a constant daily order in feed production is assumed where broiler compound feed is always produced first, followed by layer compound feed. At the starting point of the simulation, all silos of ingredients are assumed to be empty. The model a priori knows the amount of ingredients used in every batch of compound feed produced. This allows to identify the moment when a storage silo of an ingredient is empty and a new shipment of that ingredient is used in the feed production line. The model assumes simultaneous replacements of vessels/trucks of ingredients and also discriminates the batches by the type of compound feed produced at the feed production line. If at the same batch, several vessels/trucks of ingredients are replaced together with a shift in the type of compound feed, the model identifies only one change and, therefore, only one new unique charge of feed is reckoned.

The number of unique charges of feed produced per year $\left(U C F_{j}\right)$ is calculated as follows:

$U C F_{j}=\sum_{k}^{K} z_{k j}$

where $z_{k j}$ is a binary variable that takes a value of 1 or 0 for every batch $k$ of feed $j$. It takes the value of 1 when a new shipment of ingredient is uploaded in the feed production line and/or a shift in the production line for producing compound feed $j$ occurs; otherwise it takes a value of 0 . 
Monitoring dioxins at the feed mill

Table 1. Characteristics of feed ingredients and compounds feeds including (where relevant) inclusion rate in compound feeds, size of vessels/trucks/charges, number of samples collected and tested per vessel/truck/charge, and price

\begin{tabular}{|c|c|c|c|c|c|c|}
\hline Ingredient & Formula & $\left(f_{i j}\right)$ & $\begin{array}{c}\text { Vessel } \\
\text { or truck } \\
\text { size } \\
\left(s v_{i}\right) \\
\mathrm{t}\end{array}$ & $\begin{array}{c}\text { Number of } \\
\text { samples } \\
\text { collected per } \\
\text { vessel/trucks } 2 \\
(x)\end{array}$ & $\begin{array}{c}\text { Number of } \\
\text { tested samples } \\
\text { per } \\
\text { vessel/truck }{ }^{2} \\
\quad(x a)\end{array}$ & $\begin{array}{c}\text { Price of } \\
\text { ingredient } \\
\left(p_{i}\right) \\
€ / \mathrm{t}\end{array}$ \\
\hline & Broiler & Layer & & & & \\
\hline Wheat & 39.1 & 30.3 & 2000 & 20 & 4 & 172 \\
\hline Corn & 20 & 37.5 & 2000 & 20 & 4 & 175 \\
\hline Soymeal & 26.6 & 10.4 & 2000 & 20 & 4 & 356 \\
\hline Rapeseed & 1.7 & 2.1 & 30 & 3 & 1 & 218 \\
\hline Sunflower & 3.2 & 9.6 & 1000 & 10 & 2 & 205 \\
\hline Ani. Fat & 2.5 & 0.5 & 30 & 3 & 1 & 710 \\
\hline Veg. Oil & 3.7 & 2 & 30 & 3 & 1 & 699 \\
\hline Lime & 1.1 & 5.5 & 30 & 3 & 1 & 158 \\
\hline Vit.\&Min. & 1.1 & 1.5 & 30 & 3 & 1 & 508 \\
\hline AA & 1 & 0.8 & 30 & 3 & 1 & 1887 \\
\hline $\begin{array}{l}\text { Compound } \\
\text { feed }\end{array}$ & & & $\begin{array}{c}\text { Vessel } \\
\text { or truck } \\
\text { size } \\
\left(s v_{j}\right) \\
\mathrm{t}\end{array}$ & $\begin{array}{c}\text { Number of } \\
\text { samples } \\
\text { collected per } \\
\text { vessel/trucks }{ }^{2} \\
(x)\end{array}$ & $\begin{array}{c}\text { Number of } \\
\text { tested samples } \\
\text { per } \\
\text { vessel/truck }{ }^{2} \\
\quad(x a)\end{array}$ & $\begin{array}{c}\text { Price of } \\
\text { ingredient } \\
\left(p_{j}\right) \\
€ / \mathrm{t}\end{array}$ \\
\hline Broiler & & & 168.5 & 1 & 1 & 260 \\
\hline Layer & & & 157.8 & 1 & 1 & 210 \\
\hline
\end{tabular}

${ }^{1}$ Source: NUSCIENCE April 2017

${ }^{2}$ Commission Regulation (EU) No 589/2014

\section{Module 2: Simulation of dioxin concentration}

Determination of the number of contaminated charges of compound feed

A stochastic simulation model (module 2, Figure 1) is developed to simulate the number of contaminated vessels/trucks of feed ingredients entering the feed mill as well as the number of resulting contaminated unique charges of compound feed. The simulation model was run with 10,000 iterations, accounting for variation in the dioxin concentration per shipment of ingredient. Each iteration is reflecting the sequence of concentrations per vessel/truck of ingredient supplied to the feed mill and per charge of compound feed produced during a production year. 
The variation in dioxin concentration is described by a probability distribution that is estimated from data of EFSA (2010) on dioxin levels in feed ingredients in Europe. Unfortunately, the data are not available for each of the 10 feed ingredients specifically. Therefore, the categorization of feed ingredients by EFSA is used, and similar distributions are assumed for different ingredients within the same category. The log normal distribution is used to model the distributions of all groups of feed ingredients since this distribution shows the smallest difference of the Root Mean Square Error compared to the other fitted probability distributions. The EFSA data used and the fitted probability distributions categories for each ingredient are shown in Table 2.

Every time a new vessel/truck of ingredient is replaced in the production sequence, a dioxin concentration is drawn from the probability distribution of dioxin concentrations assigned to that ingredient. The dioxin concentration of the unique charge of compound feed is subsequently determined by weighing the dioxin concentrations of each ingredient according to their inclusion rate in the compound feed (Table 1). 
Monitoring dioxins at the feed mill

Table 2. Probability distributions for each feed ingredient based on the category considered in EFSA report, 2010 regarding the results of the monitoring of dioxin levels in food and feed. The unit of measure for concentrations of dioxins is pg $\mathrm{TEQWHO}_{05} / \mathrm{g}$

\begin{tabular}{lll}
\hline \multicolumn{1}{c}{ Feed ingredients } & \multicolumn{1}{c}{ Category of ingredients } & \multicolumn{1}{c}{ Probability distributions } \\
\hline Wheat & Feed ingredients of vegetable origin & $\operatorname{LogNormal}^{1}(0.1818,0.2251)$ \\
Soymeal & Feed ingredients of vegetable origin & $\operatorname{LogNormal}^{1}(0.1818,0.2251)$ \\
Rapeseed & Feed ingredients of vegetable origin & $\operatorname{LogNormal}^{1}(0.1818,0.2251)$ \\
Sunflower & Feed ingredients of vegetable origin & $\operatorname{LogNormal}^{1}(0.1818,0.2251)$ \\
Ani. Fat & Feed ingredients of vegetable origin & $\operatorname{LogNormal}^{1}(0.1818,0.2251)$ \\
Veg. Oil & Animal fat including milk fat and egg fat & $\operatorname{LogNormal}{ }^{1}(0.3815,0.3054)$ \\
Lime & Vegetable oils and their by-products & $\operatorname{LogNormal}(0.2386,0.0888)$ \\
Vit. \& Min. & Feed materials of mineral origin & $\operatorname{LogNormal}{ }^{1}(0.1258,0.1132)$ \\
Amin. Synth. & Pre-mixtures & $\operatorname{LogNormal}^{1}(0.1157,0.1395)$ \\
\hline
\end{tabular}

${ }^{\mathrm{T}}$ LogNormal probability distribution (mean, std. dev.)

The model estimates the dioxin concentration in compound feed $j\left(C F_{j r}\right)$ at every charge $r$ as follows:

$C F_{j r}=\sum_{i}^{I}\left(c i_{i r} \cdot f_{i j}\right)$

where $c i_{i r}$ is a dioxin concentration of ingredient $i$ at charge $r$ that is obtained from a draw from the probability distribution for dioxin concentrations assigned to ingredient $i$ and $f_{i j}$ is the proportion of ingredient $i$ used in the production of feed $j$ (Table 1).

The number of contaminated vessels of ingredients $\left(C V I_{i}\right)$ is estimated as follows:

$C V I_{i}=\sum_{r}^{R} t i_{i r} \quad t i_{\text {ir }}=1$ when $c i_{\text {ir }} \geq T C_{i}$

where $t i_{\text {ir }}$ is a binary variable that takes a value of either 1 or 0 for ingredient $i$ at each charge $r$. It takes the value 1 , when the concentration of dioxins $c i_{i r}$ is larger or equal to the threshold concentration of dioxins $\left(T C_{i}\right)$ for the ingredient $i$, and 0 otherwise.

The number of contaminated unique charges of compound feed $\left(C C F_{j}\right)$ is calculated in a similar way: 
$C C F_{j}=\sum_{r}^{R} t i_{j r} \quad t i_{j r}=1$ when $C F_{j r} \geq T C_{j}$

where $t i_{j r}$ is a binary variable that takes a value of either 1 or 0 at each charge $r$. It takes the value 1 when the concentration of dioxins $C F_{j r}$ is larger or equal to the threshold concentration of dioxins $T C_{j}$ for the compound feed $j$, and 0 otherwise.

In this study, the threshold concentrations (TC) equals the maximum limits (ML) as set by the European Commission Regulation No. 774/2012 (EC, 2012b) for the presence of dioxins in the various feed ingredients and compound feeds (see Table 3).

Table 3. Threshold concentrations for feed ingredients and compound feed

\begin{tabular}{cc}
\hline Feed ingredients & $\begin{array}{c}\text { EC-Maximum Limit } \\
\text { (ng WHO-PCDD/F-TEQ/kg) }{ }^{1}\end{array}$ \\
\hline Wheat & 0.75 \\
Corn & 0.75 \\
Soymeal & 0.75 \\
Rapeseed & 0.75 \\
Sunflower & 0.75 \\
Ani. Fat & 1.5 \\
Veg. Oil & 0.75 \\
Lime & 1 \\
Vit. \& Min. & 1 \\
Amin. Synth. & 1 \\
\hline Compound feed & EC-Maximum Limit \\
& (ng WHO-PCDD/F-TEQ/kg) ${ }^{1}$ \\
\hline Broiler & 0.75 \\
Layer & 0.75 \\
\hline
\end{tabular}

Commission Regulation (EU) No 744/2012

\section{Module 3: Cost effectiveness analysis of monitoring strategies}

\section{Selection of monitoring strategies}

Besides strategies based on the monitoring of individual ingredients or compound feed, monitoring strategies consisting of combinations of ingredients are evaluated. Selected combinations include ingredients with the largest inclusion rate in the compound feed, resulting in the following strategies: 
Monitoring dioxins at the feed mill

1. Wheat + Corn $(w+C)$

2. Wheat + Soymeal $(W+S y)$

3. Wheat + Corn + Soymeal $(w+C+S y)$

4. Wheat + Corn + Rapeseed $(\mathrm{W}+\mathrm{C}+\mathrm{R})$

5. Wheat + Corn + Sunflower $(\mathrm{W}+\mathrm{C}+\mathrm{Sf})$

Costs of monitoring dioxins in feed ingredients and compound feed

The monitoring costs $(M C)$ are accounted per year and estimated as follow:

$M C=\sum_{i}^{I} s c_{i}+t c_{i}+i c_{i}+\sum_{j}^{J} s c_{j}+t c_{j}+i c_{j}$

where $s c$ is the cost of collecting one sample of either a shipment of feed ingredients $i$ or a unique charge of compound feed $j, t c$ is the cost of testing one sample of feed ingredients or compound feed, ic is the indirect cost that includes the losses of downgrading and selling contaminated ingredients to other industry.

Sampling cost $(s c)$ are given by:

$s c=(l c+m c+t r c+s t c) \cdot n \cdot x$

where $l c$ represents the costs for labor (i.e. personnel who take the samples), $m c$ the costs of the materials to collect samples, $\operatorname{trc}$ the costs of transporting the samples to the laboratory, stc the costs for temporal storing samples for further tracing in case a contamination is detected, $n$ the number of vessels/trucks of ingredients or charges of feed monitored, and $x$ the number of samples collected from each vessel/truck of ingredients or charge of feed.

Testing costs $(t c)$ are estimated by:

$t c=x a \cdot(\operatorname{cof}+l c t)$

where cof is the cost of the confirmatory dioxin testing method and lct stands for the labor costs for registering and evaluating the results of the test. 
The input variables for estimating the monitoring costs are shown in Table 4.

Besides direct costs resulting from sampling and testing, indirect costs are considered in the case the dioxin concentration in vessels of feed ingredients or charges of compound feed is above the ML. Indirect costs (ic) are defined as the financial losses due to replacement of contaminated ingredients or compound feeds. In this study, indirect costs are estimated by:

$i c=\left(\sum_{i=1}^{I} e i_{i} \cdot s v_{i} \cdot p_{i}+\sum_{j=1}^{J} e i_{j} \cdot s v_{j} \cdot p_{j}\right)$

where, $e i_{i}$ and $e i_{j}$ are the number of contaminated vessels/trucks of feed ingredients $i$ and contaminated charges of compound feed $j$, respectively (see Table 5); $s v_{i}$ and $s v_{j}$ are the amount of ingredient $i$ and compound feed $j$ per vessels/truck or charge, respectively (see Table 1$) ; p_{i}$ and $p_{j}$ are the price per ton of feed ingredients $i$ and compound feed $j$, respectively (see Table 1). 
Monitoring dioxins at the feed mill

Table 4. Input variables to estimate the costs of monitoring

\begin{tabular}{|c|c|c|c|c|}
\hline Variable & Description & Unit & Value & Explanation \\
\hline$l c$ & $\begin{array}{l}\text { Labor costs for personnel who take the } \\
\text { samples }\end{array}$ & $€ /$ sample & 12.2 & $\begin{array}{l}\text { Time/sample: } 15 \\
\text { min. Salary: } € 49 / \mathrm{hr}^{1}\end{array}$ \\
\hline$m c$ & $\begin{array}{l}\text { Materials cost for equipment and tools } \\
\text { used to take samples }\end{array}$ & $€ /$ sample & 0.5 & Own estimation \\
\hline $\operatorname{trc}$ & $\begin{array}{l}\text { Cost of transporting the samples to the } \\
\text { laboratory }\end{array}$ & $€ /$ sample & 1 & $\begin{array}{l}\text { Assuming } € 10 / 10 \\
\text { samples at weight of } \\
2 \mathrm{~kg}^{2}\end{array}$ \\
\hline stc & $\begin{array}{l}\text { Cost of storing the samples for further } \\
\text { testing }\end{array}$ & $€ /$ sample & 0.1 & Own estimation \\
\hline $\operatorname{cof}$ & Cost of confirmatory test & $€ /$ sample & 350 & $\begin{array}{l}\text { Costs of } \\
\text { confirmatory method } \\
(\mathrm{GC} / \mathrm{MS})^{3}\end{array}$ \\
\hline$l c t$ & $\begin{array}{l}\text { Labor costs for registering and } \\
\text { evaluating the test results }\end{array}$ & $€ /$ sample & 21 & $\begin{array}{l}\text { Time/sample: } 20 \\
\text { min. Salary: } € 63 / \mathrm{hr}^{4}\end{array}$ \\
\hline$n$ & $\begin{array}{l}\text { Number of vessels/trucks of ingredients } \\
\text { or unique charges of feed monitored, } \\
\text { and }\end{array}$ & Number & & See Table 5 \\
\hline$x$ & $\begin{array}{l}\text { Number of samples collected from each } \\
\text { vessel/truck of ingredients }\end{array}$ & Number & & See Table 1 \\
\hline$x a$ & $\begin{array}{l}\text { Number of aggregates samples tested } \\
\text { from each vessel/truck of ingredients }\end{array}$ & Number & & See Table 1 \\
\hline
\end{tabular}

${ }^{\mathrm{T}}$ Tariffs, Dutch Gov., LNV, 2009, medium tariff

${ }^{2}$ Postal service NL, 2010

${ }^{3}$ Hoogenboom (personal communication)

${ }^{4}$ Tariffs, Dutch Gov., LNV, 2009, high tariff.

\section{Effectiveness of the monitoring strategy}

In this study, the effectiveness of a monitoring strategy is defined as the proportion of dioxin contaminated compound feed charges that are prevented from entering the poultry production chain in comparison to a situation without any monitoring in place. It is assumed that -when a unique vessel/truck of an ingredient or a unique charge of a compound feed is included in the monitoring scheme- all vessels of that ingredient or all unique charges of that compound feed (received and produced in a year, respectively) are sampled and tested for the presence of dioxins. Given a test sensitivity of $100 \%$ the effectiveness of monitoring at compound feed is considered to be $100 \%$. The effectiveness of the monitoring strategies 
based on the sampling of ingredients $\left(E M S_{z}\right)$ is an outcome of Module 2 (Simulation of dioxin concentration). It is given by:

$E M S_{z}=\frac{C C F_{j}-C C F_{j z}}{C C F_{j}}$

where $C C F_{j z}$ is the number of charges of compound feed $j$ in a production year that is still contaminated after excluding the dioxin contribution directly related to the ingredients sampled in monitoring strategy $z$.

$C C F_{j z}$ is given by:

$C C F_{j z}=\sum_{r}^{R} t i_{j z r} \quad t i_{j r z}=1$ when $C F_{j z r} \geq T C_{j}$

where $t i_{j z r}$ is a binary variable that takes a value of either 1 or 0 at each charge of compound feed $r$. It takes the value 1 when the concentration of dioxins $C F_{j z r}$ is larger or equal to the threshold concentration of dioxins $T C_{j}$ for the compound feed $j$, and 0 otherwise.

The dioxin concentration in compound feed $j\left(C F_{j z r}\right)$ in every charge $r$, excluding the ingredients considered in the monitoring strategy $\mathrm{z}$ is estimated as follows:

$C F_{j z r}=\sum_{i}^{I}\left(c i_{i r} \cdot f_{i j}\right)-\sum_{i z}^{I z}\left(c i_{i z r} \cdot f_{i j}\right)$

where $c i_{i z r}$ is a dioxin concentration of ingredient $i$ included in the monitoring strategy $z$ at charge $r$ that is obtained from a draw from the probability distribution for dioxin concentrations assigned to ingredient $i$. 
Monitoring dioxins at the feed mill

\subsection{Results}

Module 1 results in the total number of vessels/trucks of feed ingredients received, and the total number of unique charges of compound feed produced per year by the compound feed mill (Table 5). The number of contaminated vessels/trucks of feed ingredients and the number of contaminated feed charges are outcomes of Module 2 (Table 6). The size of the vessels/trucks and the inclusion rate of the ingredient in compound feed have an impact on the number of vessels/trucks received per year. On average, 5.4 times more trucks are received per year than the number of vessels. The number of unique charges of compound feed is almost equal for both compound feeds (broiler and layer). This is expected since both feeds are produced in the same daily volume. However, the total number of vessels and trucks supplying the feed mill is $68 \%$ smaller than the total number of unique charges for both compound feeds (1,481 vessels and trucks versus 2,069 unique charges of compound feed).

On average $1.0 \%$ of the total number of vessels and trucks supplying the feed mill have a dioxin concentration above the ML of the related ingredients. Of these contaminated shipments, $37 \%$ originates from the large number of vessels supplying rapeseed. Given the relatively high number of contaminated vessels, rapeseed could be considered as a source of risk of dioxin contamination in compound feed. Other ingredients to consider in this respect are wheat, corn, animal fat and amino acids, since these ingredients result in comparable numbers of contaminated vessels or trucks as indicated by the mean as well as the P90 interval. In general, the distributions of the number of contaminated vessels, trucks and charges are positively skewed. The average number of contaminated compound feed charges equals 18.7 charges a year, while the median corresponds to 0 charges a year. 
Table 5. Annual number of vessels/trucks of ingredients received and annual number of vessels/trucks of feed ingredients that have a dioxin concentration above their respective MLs

\begin{tabular}{lccccc}
\multicolumn{1}{c}{ Ingredient } & $\begin{array}{c}\text { Number of } \\
\text { vessels/trucks of } \\
\text { feed ingredients } \\
\text { received per year }\end{array}$ & \multicolumn{4}{c}{$\begin{array}{c}\text { Number of contaminated vessels/trucks of feed ingredients } \\
\text { per year }\end{array}$} \\
\cline { 3 - 6 } & $(n)$ & Mean $\left(e i_{i}\right)$ & Median & P5 & P95 \\
Wheat & 59 & 1.51 & 1 & 0 & \\
Corn & 49 & 1.24 & 1 & 0 & 3 \\
Soymeal & 32 & 0.82 & 1 & 0 & 2 \\
Rapeseed & 215 & 5.43 & 5 & 2 & 9 \\
Sunflower & 22 & 0.55 & 0 & 0 & 2 \\
Ani. Fat & 167 & 1.8 & 2 & 0 & 4 \\
Veg. Oil & 321 & 0.12 & 0 & 0 & 1 \\
Lime & 367 & 0.38 & 0 & 0 & 2 \\
Vit\&Min & 146 & 0.42 & 0 & 0 & 2 \\
AA & 103 & 2.53 & 2 & 0 & 5
\end{tabular}

\begin{tabular}{lccccc}
\hline Compound Feed & $\begin{array}{c}\text { Number of } \\
\text { charges of } \\
\text { produced per year }\end{array}$ & \multicolumn{4}{c}{ Number of contaminated charges of feed produced per year } \\
\cline { 3 - 6 } & $(n)$ & Mean $\left(e i_{j}\right)$ & Median & P5 & P95 \\
\hline Broiler & 1000 & 9.71 & 0 & 0 & 44 \\
Layer & 1069 & 9.02 & 0 & 0 & 44 \\
\hline
\end{tabular}

Ani. Fat= Animal Fat, Veg. Oil= Vegetable Oil, Vit/Min= Vitamins \& Minerals, AA= Amino acids Synthetic

Monitoring all vessels/trucks of feed ingredients to prevent any contaminated compound feed charge is more expensive than monitoring dioxins in all compound feed charges. Annual costs for sampling and testing ingredient samples are 3\% higher than those costs for compound feed sampling and testing (€714 thousand versus $€ 693$ thousand). The indirect costs resulting from the monitoring of ingredients are $83 \%$ larger than in the case of monitoring compound feed ( $€ 1,888$ thousand versus $€ 724$ thousand) (Table 6$)$.

The highest direct costs of monitoring feed ingredients relate to vegetable oil (€133 thousand) and lime ( $€ 116$ thousand), followed by wheat (€92 thousand). This situation is of interest because, respectively, 6.7 and 4 times more samples are collected and tested per wheat vessel than per truck of vegetable oil or lime. Moreover, the sampling costs of the three ingredients are almost the same. The difference in direct cost is given by the large number of 
Monitoring dioxins at the feed mill

trucks of vegetable oil or lime compared to the number of wheat vessels that increases the testing costs. Consequently, it is more expensive to monitor vegetable oil or lime than wheat.

The highest indirect costs relate to the first three ingredients (wheat, corn and soymeal). This is explained by the size of the vessel, in which these ingredients are delivered to the feed mill. Although the numbers of contaminated vessels of wheat, corn and soymeal are smaller than the number of contaminated trucks of rapeseed, a vessel (2000t) is 66 times larger than a truck (30t). Consequently, the amount of contaminated wheat is by far larger than the amount of contaminated rapeseed. This situation is also observed when comparing the indirect costs of dioxin contaminations in wheat to the indirect costs of dioxin contaminations in compound feeds. The average number of contaminated charges of compound feed is 6.2 times larger than the number of contaminated vessels of wheat. However, the amount of compound feed per charge is 11.8 times smaller than the amount of contaminated wheat per vessel. 
Table 6. Monitoring costs for each feed ingredient, combinations of feed ingredients and compound feeds

\begin{tabular}{|c|c|c|c|c|c|}
\hline \multirow[b]{2}{*}{ Feed ingredient } & \multicolumn{5}{|c|}{ Monitoring costs (thousand $€ /$ year) } \\
\hline & Sampling & Testing & Total Direct Cost & Indirect Cost & Total Cost \\
\hline Wheat & 16.3 & 75.7 & 92.1 & 522.0 & 614.1 \\
\hline Corn & 13.5 & 62.9 & 76.4 & 434.2 & 510.7 \\
\hline Soymeal & 8.8 & 41.0 & 49.9 & 590.8 & 640.7 \\
\hline Rapeseed & 8.9 & 69.0 & 77.9 & 35.5 & 113.4 \\
\hline Sunflower & 3.0 & 14.1 & 17.1 & 113.2 & 130.4 \\
\hline Ani. Fat & 6.9 & 53.6 & 60.5 & 38.6 & 99.1 \\
\hline Veg. Oil & 13.3 & 103.0 & 116.3 & 2.6 & 118.9 \\
\hline Lime & 15.2 & 117.8 & 133.0 & 1.8 & 134.8 \\
\hline Vit\&Min & 6.0 & 46.8 & 52.9 & 6.4 & 59.3 \\
\hline AA & 4.2 & 33.0 & 37.3 & 143.3 & 180.7 \\
\hline All ingredients & & & 713.91 & $1,888.4$ & $2,602.7$ \\
\hline $\begin{array}{c}\text { Monitoring } \\
\text { Strategy }\end{array}$ & Sampling & Testing & Total Direct cost & Indirect Cost & Total Cost \\
\hline $\mathrm{W}+\mathrm{C}$ & 29.9 & 138.6 & 168.5 & 956.3 & $1,124.9$ \\
\hline $\mathrm{W}+\mathrm{Sy}$ & 25.2 & 116.8 & 142.0 & $1,112.8$ & $1,254.9$ \\
\hline $\mathrm{W}+\mathrm{C}+\mathrm{Sy}$ & 38.7 & 179.7 & 218.5 & $1,547.1$ & $1,765.6$ \\
\hline $\mathrm{W}+\mathrm{C}+\mathrm{R}$ & 38.8 & 207.6 & 246.5 & 991.8 & $1,238.4$ \\
\hline $\mathrm{W}+\mathrm{C}+\mathrm{Sf}$ & 32.9 & 152.8 & 185.7 & $1,069.5$ & $1,255.3$ \\
\hline $\mathrm{W}+\mathrm{C}+\mathrm{R}+\mathrm{S}$ & 41.9 & 221.8 & 263.7 & $1,105.1$ & $1,368.8$ \\
\hline Compound Feed & Sampling & Testing & Total Direct Cost & Indirect Cost & Total Cost \\
\hline Broiler & 13.8 & 321.0 & 334.8 & 425.3 & 760.1 \\
\hline Layer & 14.8 & 343.1 & 357.9 & 298.8 & 656.7 \\
\hline Both compound fee & & & 692.8 & 724.1 & $1,416.9$ \\
\hline
\end{tabular}

Ani. Fat= Animal Fat; Veg. Oil= Vegetable Oil; Vit/Min= Vitamins \& Minerals; AA= Amino acids Synthetics; $\mathrm{W}+\mathrm{C}=$ Wheat $\&$ Corn; $\mathrm{W}+\mathrm{Sy}=$ Wheat $\&$ Soymeal; $\mathrm{W}+\mathrm{C}+\mathrm{Sy}=$ Wheat $\&$ Corn $\&$ Soymeal; $\mathrm{W}+\mathrm{C}+\mathrm{R}=$ Wheat $\&$ Corn \& Rapeseed; $\mathrm{W}+\mathrm{C}+\mathrm{Sf}=$ Wheat $\&$ Corn $\&$ Sunflower

For cost-effective prevention of a dioxin contamination above the ML in compound feed, not all feed ingredients need to be monitored. Combined results of Tables 6 and 7 show that a high level of cost-effectiveness can be achieved by following a strategy of monitoring either by single feed ingredients or a combination of ingredients. Considering individual ingredients, the highest level of cost-effectiveness with respect to both compound feeds is obtained by monitoring wheat (total costs $€ 614$; average overall effectiveness $73.8 \%$ ). The average level of effectiveness differs per compound feed as monitoring in wheat prevents $88.5 \%$ of the contaminated broiler feed charges and $65 \%$ of the contaminated layer feed charges. Monitoring corn also has a high level of effectiveness but only with respect to layer 
Monitoring dioxins at the feed mill

feed (79.2\%), and not with respect to broiler feed (36.1\%). However the costs of monitoring dioxins in corn (€511 thousand) is only $20 \%$ less than the costs of monitoring dioxins in wheat with a much lower overall level of effectiveness for both compound feeds (57.6\%). Soymeal is the ingredient that ranks third in terms of effectiveness. However, the costs of monitoring dioxins in soymeal (€641 thousand) are higher than the costs of monitoring dioxins in wheat. Therefore, the highest effectiveness for both compound feeds can be obtained by monitoring dioxins in wheat. The level of effectiveness when monitoring dioxins in the remaining ingredients is on average lower than $15 \%$ for both compound feeds.

By using a combination of ingredients as monitoring strategy, it is possible to achieve a higher level of effectiveness for both compound feeds than with individual ingredients but costs are also higher. The best strategy results from combining monitoring for dioxins in wheat, corn and soymeal. Following this strategy, an average $99.9 \%$ effectiveness is achieved for both compound feeds with a confidence interval of 100\% (P5=100\% and P95=100\%). This result shows that there is almost certainty on preventing a dioxin contamination in compound feed by monitoring dioxins in the combination of these three ingredients. However, the monitoring costs for this strategy ( $€ 1.7$ million) are larger than the costs of monitoring both compound feeds ( $€ 1.4$ million). The second best strategy is to monitor dioxins in wheat and corn, with an average effectiveness of $96.2 \%$ for both feeds, as well as for broiler $(94.4 \%)$ and layer $(99.7 \%)$. The confidence interval of this strategy for both compound feeds ranges between $95.5 \%$ at P5 and $100 \%$ at P95, which implies no certainty but a very high probability of preventing a contamination in both compound feeds. By using this strategy, the costs of monitoring are $35 \%$ and $20 \%$ less than the costs of monitoring for dioxins separately in wheat, corn and soymeal or both compound feeds, respectively. Monitoring dioxins in wheat and corn can be considered as the cost-effective solution for 
monitoring dioxins in ingredients since it shows a high level of effectiveness at the lowest costs compared to the other evaluated monitoring strategies.

In this study, it is assumed that the entire vessel of ingredient is contaminated, although four independent aggregate samples are tested from each vessel. In reality, each compartment of a vessel is physically separated, and a contamination above ML levels of dioxins may occur in only one of the compartments. Therefore, only one quarter of the vessel would be dismissed by the feed mill and thus, the indirect cost would be reduced to $25 \%$ of the costs estimated in this study. The overall conclusions from this study would, however, not change. Monitoring dioxins in feed ingredients aiming at preventing the contamination in compound feed is relatively more cost-effective than monitoring dioxins in compound feed. 
Monitoring dioxins at the feed mill

Table 7. Effectiveness (in percentage) of monitoring individual feed ingredients and combinations of ingredients, considering the Maximum Limit for the presence of dioxins in compound feed as threshold

\begin{tabular}{|c|c|c|c|c|c|c|c|c|c|c|c|c|}
\hline \multirow{2}{*}{ Ingredient } & \multicolumn{4}{|c|}{ Broiler feed } & \multicolumn{4}{|c|}{ Layer feed } & \multicolumn{4}{|c|}{ Both feeds } \\
\hline & Mean & Med. & P5 & P95 & Mean & Med. & P5 & P95 & Mean & Med. & P5 & P95 \\
\hline Wheat & 88.5 & 100 & 0 & 100 & 65 & 100 & 0 & 100 & 73.8 & 100 & 0 & 100 \\
\hline Corn & 36.1 & 0 & 0 & 100 & 79.2 & 100 & 0 & 100 & 57.6 & 65 & 0 & 100 \\
\hline Soymeal & 45.2 & 28.3 & 0 & 100 & 17.7 & 0 & 0 & 100 & 35.4 & 11.1 & 0 & 100 \\
\hline Rapeseed & 4.5 & 0 & 0 & 30.8 & 5 & 0 & 0 & 33.3 & 4.8 & 0 & 0 & 27.8 \\
\hline Sunflower & 6.9 & 0 & 0 & 55.6 & 16.3 & 0 & 0 & 100 & 11.5 & 0 & 0 & 90.9 \\
\hline Ani. Fat & 10.7 & 0 & 0 & 100 & 2.6 & 0 & 0 & 13.3 & 7.6 & 0 & 0 & 56 \\
\hline Veg Oil & 10.1 & 0 & 0 & 87.5 & 5.7 & 0 & 0 & 42.9 & 8.5 & 0 & 0 & 61.4 \\
\hline Lime & 2.1 & 0 & 0 & 12.5 & 8.5 & 0 & 0 & 81 & 4.9 & 0 & 0 & 27.1 \\
\hline Vit/Min & 2.1 & 0 & 0 & 11.4 & 2.4 & 0 & 0 & 12 & 2.4 & 0 & 0 & 11.1 \\
\hline $\mathrm{AA}$ & 3 & 0 & 0 & 18 & 2.7 & 0 & 0 & 12.5 & 3 & 0 & 0 & 15.8 \\
\hline \multirow{2}{*}{$\begin{array}{c}\text { Monitoring } \\
\text { strategy }\end{array}$} & \multicolumn{4}{|c|}{ Broiler feed } & \multicolumn{4}{|c|}{ Layer feed } & \multicolumn{4}{|c|}{ Both feeds } \\
\hline & Mean & Med. & P5 & P95 & Mean & Med. & P5 & P95 & Mean & Med. & P5 & P95 \\
\hline $\mathrm{W}+\mathrm{C}$ & 94.4 & 100 & 33.7 & 100 & 99.7 & 100 & 100 & 100 & 96.2 & 100 & 95.5 & 100 \\
\hline $\mathrm{W}+\mathrm{SY}$ & 97.2 & 100 & 100 & 100 & 69.1 & 100 & 0 & 100 & 81.3 & 100 & 0 & 100 \\
\hline $\mathrm{W}+\mathrm{C}+\mathrm{Sy}$ & 100 & 100 & 100 & 100 & 99.9 & 100 & 100 & 100 & 99.9 & 100 & 100 & 100 \\
\hline $\mathrm{W}+\mathrm{C}+\mathrm{R}$ & 94.5 & 100 & 34 & 100 & 99.7 & 100 & 100 & 100 & 96.3 & 100 & 100 & 100 \\
\hline $\mathrm{W}+\mathrm{C}+\mathrm{Sf}$ & 94.6 & 100 & 34 & 100 & 99.8 & 100 & 100 & 100 & 96.3 & 100 & 100 & 100 \\
\hline
\end{tabular}

Med.= Median; Ani. Fat= Animal Fat; Veg. Oil= Vegetable Oil; Vit/Min= Vitamins \& Minerals; AA= Amino acids Synthetics; $\mathrm{W}+\mathrm{C}=$ Wheat \& Corn; $\mathrm{W}+\mathrm{Sy}=$ Wheat \& Soymeal; W+C+Sy= Wheat \& Corn \& Soymeal; $\mathrm{W}+\mathrm{C}+\mathrm{R}=$ Wheat $\&$ Corn \& Rapeseed; $\mathrm{W}+\mathrm{C}+\mathrm{Sf}=$ Wheat \& Corn \& Sunflower 


\subsection{Discussion}

Monitoring dioxins at feed mills is highly demanding for financial resources. The results of this study show that even monitoring dioxins in all charges of just one feed ingredient requires a high amount of resources with a relatively small probability of preventing contaminated charges of compound feeds. This study also shows that dioxin monitoring efforts should be put into a combination of ingredients rather than at a single feed ingredient. Monitoring dioxins in a combination of wheat, corn and soymeal proves to be as effective as monitoring in compound feeds. However, the total costs of monitoring in these three ingredients are $24 \%$ higher than the total costs of monitoring both compound feeds. Monitoring dioxins in a combination of wheat and corn is cost-effective since it results into a high level of effectiveness $(96.2 \%)$ at lower total costs (20\% less) compared to monitoring dioxins in both compound feeds. It is important to state that monitoring costs in feed ingredients are highly influenced by the indirect costs. This study applies the worst-case scenario where the entire vessel is assumed to be contaminated. In reality, indirect costs can be substantially smaller (by $75 \%$ ) because four independent aggregate samples corresponding to four compartments of the vessel are tested. This reduction in indirect cost strengthens our findings that monitoring feed ingredients is a more cost-effective approach than monitoring dioxins in compound feeds. Moreover, once a dioxin contamination is detected in compound feed it is impossible to avoid the direct and indirect financial impact given the control and tracing measures that must be applied. Although, financial impact due to recall activities and losses due to brand damages or insurance liabilities are not considered in this study, it is expected that such costs enhance the cost-effectiveness of monitoring dioxins in feed ingredients. In addition, by monitoring dioxins in the compound feed, it is possible that a contaminated feed ingredient remains undetected even though the concentration of dioxins in the contaminated ingredient vessel is above the ML. This is caused by the dilution of the 
Monitoring dioxins at the feed mill

dioxin-concentration of feed ingredients in compound feeds, which is determined by the inclusion rate of the feed ingredient in the compound feed. The same dilution effect in dioxin monitoring is seen in the milk production chain, when dioxins are monitored in milk trucks (Lascano-Alcoser et al., 2013).

The inclusion rate of each feed ingredient used in the formulations of compound feeds plays a major role in the final concentration of dioxins in the compound feeds. Monitoring dioxins in those ingredients with a high inclusion rate generates a high effectiveness and a more cost-efficient use of monitoring resources compared to monitoring those ingredients with a lower inclusion rate. Fatty ingredients have been the subject of a great scrutiny under the current European Regulations regarding strategies for monitoring of dioxins at feed ingredients (EC, 2012a). In fact, after the German dioxin incident in 2010 (Fürst, 2011, Rieger et al., 2016), DG SANCO proposed that all vessels of fatty ingredients must be tested for dioxins before they are used in feed production (van Asselt, 2011). This proposal was to a large extent the consequence of the involvement of fatty ingredients in the historical feeddioxin-incidents in Europe (Bernard et al., 1999, Hoogenboom et al., 2015). However, given the assumed inclusion rate of fatty ingredients in compound feeds and the data available for fitting the probability distributions for dioxin concentrations in feed ingredients as used in this study, fatty ingredients did not have a large effect on the dioxin concentration in the compound feeds. Ingredients such as wheat, corn and soymeal are more important determinants of the final dioxins concentrations in compound feeds. It is important to note that this study did not use data of extreme dioxin concentrations in ingredients, such as related to a certain dioxin incident or crisis to establish the probability distributions of dioxin concentrations at ingredients. The main reason of this omission is the fact that such data are not available. Dioxins concentrations reported by EFSA and used in this study relate to background levels of dioxins in ingredients. Moreover, extremely elevated concentrations of 
dioxins occur in ingredients with a much lower frequency than background levels for all ingredients. Therefore, this study allows us to determine the sources of dioxin contaminations in feed focusing on feed ingredients that are not contaminated with extreme dioxin levels, but with elevated concentrations that occur at a higher frequency.

Data on the feed ingredients as reported by EFSA were the only data available for this study, and some ingredients needed to be grouped. If better information would become available for the feed ingredients in the future, then this will increase the accuracy of the results presented in this study. However, this information is not expected to change the main conclusions of this study.

The results obtained in this study provide additional information to quality assurance managers in the feed industry and policy makers. It shows that large amounts of resources are needed to ensure that dioxin concentrations in feed industry do not exceed pre-defined thresholds. Furthermore, it shows the relative importance of dioxin contamination in feed ingredients used in compound feed production. Based on studies in which historical dioxin incidents and crises in the food chain are analyzed (Hoogenboom et al., 2015, Malisch and Kotz, 2014), the use of contaminated feed ingredients and compound feed in livestock production is considered the main cause of the food-dioxin-contaminations. Feed mills are, therefore, considered the core stage of the food chain at which monitoring schemes should be implemented to effectively prevent further spread of dioxin contaminations from feed further in the food chain. A recent study shows that from the four different stages of food (pork) production considered, the feed mill is the most cost-effective stage to allocate resources for monitoring and tracing dioxin contaminations along the livestock production chain (LascanoAlcoser et al., 2014). In line with that study, the current study shows that monitoring dioxins at the entry point of compound feed production (i.e., feed ingredients) is more cost-effective than monitoring dioxins in compound feeds. By focusing monitoring efforts at the entry 
Monitoring dioxins at the feed mill

points of the contamination (i.e., feed ingredients), as it is enforced by the current EU entrytesting regulation for some feed ingredients, the financial damage due to contaminated compound feed is avoided as well as the further dissemination of the pollutants along the food chain.

\subsection{Conclusions}

This study aimed to determine cost-effective strategies for monitoring dioxins in feed ingredients or compound feeds, in order to prevent dioxin contaminations in compound feed entering the poultry production chain. Results showed that monitoring dioxins in a combination of wheat and corn results into a high level of effectiveness at lower costs compared to monitoring compound feeds. Furthermore, based on the EFSA data on the (background) presence of dioxins in feed ingredients, more attention should be paid to those ingredients that have a large inclusion rate in the compound feed. Animal fat, wheat and corn supplies resulted in comparable numbers of contaminated trucks and vessels entering the feed mill in a year. However, due to the relative high inclusion rate of wheat and corn the numbers of contaminated charges of feed caused by wheat and corn were much higher than the once caused by animal fat. Monitoring dioxins in those feed ingredients that are used in high proportion in the compound feed production is more cost-effective than monitoring ingredients with a lower inclusion rate. As no extreme dioxin levels, but background levels of dioxins are considered in feed ingredients, results of this study are useful to quality assurance managers at the feed industry and policy makers. 


\section{References}

Abalos, M., J. Parera, E. Abad, and J. Rivera. 2008. PCDD/Fs and DL-PCBs in feeding fats obtained as co-products or by-products derived from the food chain. Chemosphere. 71(6):1115-1126.

Adamse, P., H. J. Van der Fels-Klerx, S. Schoss, J. de Jong, and R. Hoogenboom. 2015. Concentrations of dioxins and dioxin-like PCBs in feed materials in the Netherlands, 2001-11 Food Addit. Contam. Part A Chem. Anal. Control. Expo. Risk Assess. 32(8):1301-1311.

Bernard, A., C. Hermans, F. Broeckaert, G. De Poorter, A. De Cock, and G. Houins. 1999. Food contamination by PCBs and dioxins. Nature. 401(6750):231-232.

Büchert, A., T. Cederberg, P. Dyke, H. Fiedler, P. Fürst, A. Hanberg, J. Hosseinpour, O. Hutzinger, J. G. Kuenen, R. Malisch, L. L. Needham, K. Olie, O. Papke, J. Rivera Aranda, G. Thanner, G. Umlauf, T. Vartiainen, and C. van Holst. 2001. Dioxin contamination in food. Bayreuth, Germany, from September 28 to October 1, 2000. Environ. Sci. Poll. Res. 8(2):84-88.

EC (European Commission). 2000. Opinion of the SCAN on the dioxin contamination of feedingstuffs and their contribution to the contamination of food of animal origin. Health and Consumer Protection Directorate-General,. Available from: https://ec.europa.eu/food/sites/food/files/safety/docs/animalfeed-undes-sub-out55_en.pdf.

EC (European Commission). 2012a. Commission Regulation (EU) No 225/2012 of 15 March 2012 amending Annex II to Regulation (EC) No 183/2005 of the European Parliament and of the Council as regards the approval of establishments placing on the market, for feed use, products derived from vegetable oils and blended fats and as regards the specific requirements for production, storage, transport and dioxin testing of oils, fats and products derived thereof. Off. J. Eur. Comm. L77:1-5. 
Monitoring dioxins at the feed mill

EC (European Commission). 2012b. Commission Regulation (EU) No 744/2012 of 16 August 2012 amending Annexes I and II to Directive 2002/32/EC of the European Parliament and of the Council as regards maximum levels for arsenic, fluorine, lead, mercury, endosulfan, dioxins, Ambrosia spp., diclazuril and lasalocid A sodium and action thresholds for dioxins. Off. J. Eur. Comm. L219:5-12.

European Food Safety Authority (EFSA). 2010. Results of the monitoring of dioxin level in food and feed. EFSA J. 8(3):1385.

Fürst, P. 2011. Dioxins in feed and food again - real or perceived risk? Eur. J. Lipid Sci. Technol. 113(4):401-402.

Heres, L., R. Hoogenboom, R. Herbes, W. Traag, and B. Urlings. 2010. Tracing and analytical results of the dioxin contamination incident in 2008 originating from the Republic of Ireland. Food Addit. \& Contam. Part A-Chem. 27(12):1733-1744.

Hoogenboom, R., W. Traag, A. Fernandes, and M. Rose. 2015. European developments following incidents with dioxins and PCBs in the food and feed chain. Food Control. 50:670-683.

Hoogenboom, R., M. Zeilmaker, J. van Eijkeren, K. Kan, M. Mengelers, D. Luykx, and W. Traag. 2010. Kaolinic clay derived PCDD/Fs in the feed chain from a sorting process for potatoes. Chemosphere. 78(2):99-105.

Kim, M., D. G. Kim, S. W. Choi, P. Guerrero, J. Norambuena, and G. S. Chung. 2011. Formation of polychlorinated dibenzo-p-dioxins/dibenzofurans $(\mathrm{PCDD} / \mathrm{Fs})$ from a refinery process for zinc oxide used in feed additives: A source of dioxin contamination in Chilean pork. Chemosphere 82(9):12251229. 
Lascano-Alcoser, V. H., M. C. M. Mourits, H. J. van der Fels-Klerx, L. Heres, A. G. J. Velthuis, L. A. P. Hoogenboom, and A. G. J. M. Oude Lansink. 2014. Cost-effective allocation of resources for monitoring dioxins along the pork production chain. Food Res. Int. 62:618-627.

Lascano-Alcoser, V. H., A. G. J. Velthuis, H. J. van der Fels-Klerx, L. A. P. Hoogenboom, and A. Lansink. 2013. Optimizing bulk milk dioxin monitoring based on costs and effectiveness. J. Dairy Sci. 96(7):4125-4141.

Lascano Alcoser, V. H., A. G. J. Velthuis, L. A. P. Hoogenboom, and H. J. van der Fels-Klerx. 2011. Financial impact of a dioxin incident in the Dutch dairy chain. J. Food Prot. 74(6):967-979.

Llerena, J. J., E. Abad, J. Caixach, and J. Rivera. 2003. An episode of dioxin contamination in feedingstuff: the choline chloride case. Chemosphere. 53(6):679-683.

Malisch, R. and A. Kotz. 2014. Dioxins and PCBs in feed and food - Review from European perspective. Sci. Total Environ. 491-492(0):2-10.

Meuwissen, M. P. M., A. L. A. Van Andel, M. A. P. M. Van Asseldonk, and R. B. M. Huirne. 2009. Eliciting processing industry damage from feed crises. Br. Food J. 111(8):878-892.

Rieger, J., C. Kuhlgatz, and S. Anders. 2016. Food scandals, media attention and habit persistence among desensitised meat consumers. Food Policy. 64:82-92.

Tlustos, C., M. Sheridan, D. O'Sullivan, W. Anderson, and A. Flynn. 2012. The dioxin contamination incident in Ireland, 2008: analytical results and congener patterns. Food Addit. Contam. Part A Chem. Anal. Control. Expo. Risk Assess. 29(1):128-138. 
Monitoring dioxins at the feed mill

van Asselt, E. D., and a. P. Sterrenburg. 2011. Dioxin monitoring in fats and oils for the feed industry.

Report 2011.004. RIKILT - Institute of Food Safety, Wageningen University and Research Center, Wageningen, The Netherlands. 


\section{Chapter 6}

General discussion 
General discussion

\subsection{Introduction}

Monitoring dioxins in feed and food products has been widely promoted and required by national and international government agencies as well as through the introduction of private certification systems and quality assurance programs in feed and food industries. There is, however, a lack of knowledge on assessing economic aspects inherent to dioxin monitoring in food chains. To fill in this knowledge gap, this dissertation aims to analyze the cost-effectiveness of monitoring schemes for dioxins along the food chain. This main goal is broken down in four specific objectives addressed in the four previous Chapters of this thesis. Chapter 2 assesses the financial impact of dioxin incidents in the food chain considering direct losses. Chapter 3 aims to determine cost-effectiveness of monitoring dioxins in a specific product at a single control point along the food chain. Chapter 4 elicits the most costeffective allocation of resources for monitoring dioxins at different stages of the food chain. Chapter 5 describes the cost-effective allocation of resources at one stage of the food chain considering incoming ingredients and final products.

This Chapter first provides a synthesis of the results obtained in the previous Chapters (section 6.2). The synthesis is followed by a critical discussion of methodological issues (section 6.3) regarding data availability and modelling approaches used to analyze the data. Implications of the findings for policy makers as well as for food safety managers in agri-food business are discussed in section 6.4. In section 6.5, topics for further research that go in line with this thesis are presented. Section 6.6 presents the main conclusions of this dissertation.

\subsection{Synthesis of Results}

\subsubsection{Economic value of monitoring}

Establishing schemes for monitoring dioxins levels in feed and food products is an activity highly demanding for financial resources. However, the question is how much 
financial resources are sufficient to fund cost-effective schemes for monitoring dioxins along the food chain? Estimating the financial room for monitoring or the economic value of monitoring is the first step in this thesis in analyzing cost-effectiveness of dioxin monitoring schemes. In this thesis, the economic value of monitoring is assumed to be equivalent to or lower than the financial losses caused by the presence of dioxins in the dairy supply chain. Results of this dissertation show that there is scope for further increasing the resources available for monitoring because the direct financial losses of a dioxin incident exceed - in most of the evaluated contamination scenarios - the costs of establishing monitoring strategies aiming at a high level of effectiveness. This dissertation starts by quantifying the direct financial losses in the Dutch dairy supply chain caused by the "hypothetical" use of dioxincontaminated compound feed on dairy farms (Chapter 2). Results of this Chapter allow for deriving the economic value of establishing dioxin monitoring schemes along the dairy supply chain, considering the accretion of direct losses depending on the time (in days) when a dioxin incident is detected. Estimated direct financial losses in the dairy supply chain range from $€ 2.5$ to $€ 141$ million per dioxin incident, from day 1 to day 14 of the High Risk Period (HRP), respectively. Considering that, based on expert opinion, the most likely frequency of a feed crisis in The Netherlands (caused in most of the cases by dioxins) is one event every 5 years (van Asseldonk et al., 2011), the annual economic value of monitoring dioxins in the Dutch dairy chain is $20 \%$ of the direct financial losses estimated in Chapter 2. Hence, the economic value of monitoring would range between $€ 41.7$ thousand and $€ 2.4$ million per month (€500.4 thousand and $€ 28.8$ million per year).This wide range suggests a lower and upper value for the financial room for designing cost-effective dioxin monitoring schemes along the dairy chain. Given an incident is detected late (i.e., day 14 of HRP), the upper value of the financial room for monitoring is estimated at $€ 2.4$ million per month. This amount of resources is more than $90 \%$ of the costs ( $€ 2.6$ million) needed for a monitoring scheme able to 


\section{General discussion}

identify, with $95 \%$ effectiveness, the lowest contamination level evaluated in Chapter 3 (detecting a contamination resulting from a single dairy farm at a level of $2 \mathrm{pg}$ TEQ/g fat). However, such a low contamination level (one dairy farm with $2 \mathrm{pg} T E Q / g$ fat) might be caused by an extremely local source of dioxins with a limited capacity of increasing the dioxin level in milk relative to the background level. Thus, investing such large amount of resources for detecting this low contamination level may not be a priority for public sector food safety agencies. Every other contamination level - evaluated in Chapter 3 - including more contaminated farms and/or higher dioxin concentrations, result into lower monitoring costs needed to detect the contamination. The lower estimated economic value of monitoring (i.e., at day 1 of the HRP) is sufficient to finance a monitoring scheme to identify, with $95 \%$ effectiveness, a contamination of (at least one out of) 10 dairy farms contaminated with $20 \mathrm{pg}$ TEQ/g fat. As reported in literature, food dioxin incidents can be detected weeks or even months after the beginning of the contamination (Hoogenboom et al., 2010, Lok and Powel, 2000, Malisch, 2000). In such cases, elevated financial losses can be expected in the range as those calculated for day 14 of the HRP. Hence, an ample economic value of monitoring would be available for establishing ambitious dioxin-monitoring schemes along the dairy chain. Moreover, food dioxin incidents caused by contaminated feed often result into a large number of farms and food processors that get contaminated (Malisch, 2000, Meuwissen et al., 2008), which reduces the required resources to implement dioxin monitoring schemes capable of identifying food dioxin incidents. Economic research in US horticultural food chains has shown that the costs paid by producers due to foodborne illness outbreaks are far greater than the costs invested on preventing such events (Ribera et al., 2012). A similar conclusion is presented by (Golan et al., 2000, Reijnders, 2004), showing the economic benefits of enhancing food safety related to the presence of microbiological hazards in meat and poultry products, surpass by far its costs. Implementing good manufacturing practices is another 
measure to enhance food safety. In certain dioxins incidents, applying proper drying processes in specific feed ingredients would have increased its production cost but avoided large financial damages caused by its contamination (Heres et al., 2010, Tlustos, 2009). It is important to emphasize that indirect financial losses such as economic disruptions on national and international trade, brand image damages or stock prices shocks are not considered in Chapter 2 and, hence, are not reflected in the economic value of monitoring. Indirect financial losses are expected to be much larger than direct financial losses, explaining managers' preferences to immediately trigger control measures like a recall of products in case of a contamination (Teratanavat et al., 2005, Tlustos, 2009, Velthuis et al., 2009). As such, the occurrence of indirect costs increases the economic value of monitoring even more.

\subsubsection{Dilution of dioxin concentration in aggregate samples}

This dissertation showed the effect of dilution of the dioxin concentration in testing aggregate samples (hereafter, named dilution effect), and its relation with the cost and effectiveness of monitoring for dioxin contaminations in the food chain. Aggregate samples can be obtained by pooling milk truck samples (Chapter 3), by sampling pork fat storage silos (Chapter 4), and by sampling compound feed (Chapter 5). In this dissertation, two causes of dilution are analyzed. The first cause is tackled in Chapter 3 and 4 where the dilution is given by the number of individual samples combined into an aggregate sample and by the number of individual sources of pork fat mixed into a fat storage silo, respectively. The second cause of dilution is considered in Chapter 5 where the dilution is given by the proportion (inclusion rate) of feed materials combined into a compound feed.

Testing aggregate samples rather than individual samples is a valid strategy to reduce monitoring costs. However, due to the dilution effect in combining samples, batches of pork fat or feed ingredients, elevated concentrations of dioxins of individual samples, single 


\section{General discussion}

batches or individual feed ingredients can be overlooked, thus, reducing the effectiveness of monitoring aimed to detect contaminations. The larger the number of individual samples combined into an aggregate sample (as in Chapter 3), or the larger the number of batches of pork fat mixed into a silo at the fat melting facility (as in Chapter 4), the higher the dilution effect and the lower might be the chance that a single contaminated sample or batch is detected. Chapter 3 presents a quantitative tool to manage the dilution effect in aggregate milk truck samples, by considering in the calculation, a target dioxin concentration for detection in individual dairy farms samples. Results of Chapter 3 show the maximum number of milk truck samples that can be pooled into an aggregate sample in order to minimize monitoring costs while at the same time requiring a minimum level of effectiveness. Chapter 4 elicits the effect of combining sources of pork fat on the tracing costs and, thus, on the cost-effective allocation of resources, when elevated levels of dioxins are detected in a pork fat silo sample collected at the fat melting facility. Although the detection cost of the incident at this stage is the lowest relative to the other control points considered, tracing costs are so high that this stage is not a cost-effective solution for monitoring dioxins at any contamination scenario analyzed. High tracing costs are caused by the large number of pig farms that are represented in the fat melting sample and, hence, must be tested individually to trace back the contamination. A similar situation is expected when dioxins are monitored in milk storage silos at milk processors or in compound feed at feed mills. Results of Chapter 5 show that levels of dioxins in compound feed depends on the dioxin concentration and inclusion rate of every ingredient in the compound feed. An elevated concentration in compound feed can occur given the cumulative effect of adding the dioxin concentrations of the other ingredients. However, this result is valid only when feed ingredients with a ML higher than the ML for compound feed are mixed into the compound feed. Thus, an ingredient with a concentration slightly above the ingredient's ML might not cause an elevated concentration of dioxins in the 
compound feed (above feed's ML) if it has small inclusion rate relative to the other ingredients. On the other hand, an ingredient with a dioxin concentration slightly below the ingredient's ML but with a large inclusion rate might be the main contributor to an elevated concentration (above ML) in compound feed. A similar result is shown by (van der Fels-Klerx et al., 2017) where the use of a highly contaminated feed ingredients in the compound feed for a particular animal category do not always lead to a high level of the contaminant in the animal derived food product.

\subsubsection{Monitoring in earlier versus later stages of the chain}

The results of this dissertation demonstrate that it is cost-effective to focus monitoring resources in earlier rather than later stages of the food chain, when a dioxin contamination originates from a source early in the chain. Results obtained in every Chapter offer quantitative evidence on the cost-effectiveness of establishing monitoring schemes in the feed industry stage of the food chain. The benefits are the avoided direct financial impact and tracing costs for the entire food chain in case of a dioxin-contamination is detected at the feed industry. Previous literature also showed the large economic impact that the use of contaminated feed cause in further stages of the food chain (Buzby and Chandran, 2003, Meuwissen et al., 2009, Thomson et al., 2012). There is a clear recognition of the importance of monitoring dioxins in the feed industry as a measure of preventing further spread of a contamination (Sapkota et al., 2007, van der Fels-Klerx et al., 2017). EU Regulations have been imposed to ensure monitoring activities at EU borders in those feed ingredients that are considered of high risk for dioxin contamination (EC, 2009, 2011). However, none of these studies estimated quantitatively the cost-effectiveness of monitoring dioxins in the feed industry and compared these with other monitoring points along the food chain. Therefore, results of this thesis contribute to the current state of knowledge on monitoring strategies for dioxins in the food chain. The financial resources dedicated to detect a contamination in 


\section{General discussion}

livestock farms, food processors or retailers can be less than the resources required to detect a contamination in a feed mill. However, the costs for tracing the contamination to its origin and the financial losses as a consequence of a contamination (e.g., recall costs) are much higher when a contamination is detected in later stages of the food chain (livestock farms, food processors) as compared to detection of the contamination at the feed production stage. Results of Chapter 2 show that the direct financial losses for dairy farms and milk processors substantially increase with time when a dioxin incident occurs. Although the financial losses for feed mills also increase, this increment occurs at a lower rate and it is much smaller than the losses in further stages of the chain. Moreover, results of Chapter 4 show that monitoring dioxins at the feed mill requires less financial resources than monitoring dioxins at any other stage of the pork chain and for all contamination scenarios depicted in this Chapter.

\subsubsection{Integrated scheme for monitoring dioxins along the food chain}

Intensifying monitoring efforts at feed mills to tackle a dioxin contamination in the food chain increases the cost-effectiveness of monitoring dioxins for the whole food chain, as shown in Chapter 4. This result should motivate agri-food businesses along the food chain to join efforts in an integrated dioxin-monitoring scheme aiming at sharing not only the benefits, but also the associated costs. Individual monitoring at every single stage of the food chain or within feed/food business is the traditional strategy to monitoring dioxins in feed and food products. Such monitoring schemes have to some extent been improved in the last decade and some of them have proven to be efficient to identify and trace contaminated food products (Heres et al., 2010). However, to date, conjoint dioxin monitoring schemes among food chain actors have not been reported. On the contrary, the feed industry has been encouraged by food processing companies to increase its product insurance liabilities to cover the damages that contaminated compound feed can cause in further stages of the food chain (Meuwissen et al., 2009). However, feed producers argue that processing decisions out of their control and taken 
in further stages of the food chain, like mixing products in large silos increase the size of incident-damages (Meuwissen et al., 2009). It should be acknowledged that intensifying dioxin monitoring at the level of the feed industry implies additional monitoring costs for feed mills. As the benefits of feed mill's monitoring efforts also accrue to further stages of the chain, it might be optimal for the downstream stages of the chain to compensate the feed mill for the additional monitoring costs. Encouraging intensive monitoring by the feed industry can be done by, for example, acknowledging a rise in the price of compound feed to compensate for the additional costs of intensifying monitoring at feed mills. Another approach can be to share monitoring results between individual companies, either at one stage or at various stages of the production chain, and/or between industry and the government. An example of sharing monitoring results is the current SecureFeed program, in which the main feed producing companies in the Netherlands share their monitoring results for various chemical contaminants, per feed ingredient, supplier and country of origin. In total, partners of the SecureFeed program are responsible for $90 \%$ of compound feed production in the Netherlands (www.securefeed.eu). By pooling monitoring results, it is possible to create riskbased monitoring schemes such to focus monitoring on contaminants, ingredients, suppliers and/or country of origin that have a higher probability to be contaminated (van der Fels-Klerx et al., 2017). In such a case, it is possible to prevent the contamination of compound feed by early scheduling dioxin-testing of chosen feed ingredients. Chapter 5 is an example of the use of shared information (in this case from an EFSA report) to build probability distributions of the concentration of dioxins in feed ingredients and proceed with a stochastic simulation to determine contaminated batches of feed. This approach allows to identify feed ingredients that more often are the cause of a contamination. It is important to remark that monitoring dioxins at different control points along the food chain cannot be replaced by monitoring dioxins exclusively at feed mills. Current European legislation as well as private quality assurance 


\section{General discussion}

systems, enforce monitoring of dioxins at different stages of the chain and at individual feed or food facilities in order to safeguard the quality of the products. Moreover, there is a small probability that dioxin contaminations can occur by causes different from feed contaminations, for instance, by outside grazing of dairy cattle. Compliance of feed products to legal limits does not ensure that dioxin legal limits in food products are not surpassed (van Raamsdonk et al., 2009). Therefore, in addition to strengthening monitoring efforts at feed mills, it is essential to ensure that monitoring schemes and resources at other stages along the food chain remain salient.

Implementing cost-effective schemes for monitoring dioxins in the food chain demands vast amount of resources. For example, Chapter 3 shows that monitoring dioxins aiming to detect with $95 \%$ effectiveness a single farm contaminated with $2 \mathrm{pg}$ TEQ/g fat requires a budget of $€ 2.6$ million/month. To keep in place such a monitoring scheme during a year, monitoring resources up to $€ 31.2$ million are required. In 2016, the Netherlands produced 14.3 million tons of milk (CBS, 2018), implying additional production costs of $€ 0.25$ cents/kg of milk.

Finally, the size of sampling and testing costs is relatively small as compared to either tracing costs or direct losses in case an incident is detected. Costs for sampling can, however, be reduced if sampling activities are not only focusing on dioxins, but also on other food/feed safety hazards (e.g., aflatoxins) following a surveillance-portfolio framework (Guo, 2015). The integration of monitoring schemes to cover more food safety hazards can result into large reductions of the overall monitoring costs.

\subsection{Methodological Issues: data collection and modelling approaches}

The limited availability of data on the structures of the food chains considered, the dioxin concentrations in feed and food products and the decision making process when a 
dioxin contamination is detected is a recurrent issue in all Chapters of this dissertation. Assumptions and methodologies chosen to achieve the objectives of each Chapter depended on available data. In Chapter 2 and Chapter 4, the course of the dioxin contaminations in the dairy and pork chain, respectively, is modelled through fixed distribution networks using a deterministic approach. In both cases, a stochastic approach would be more appropriate to model the spread of such contaminations because input variables, such as, the number of agrifood business, dioxin concentrations at feed/food products and the time at which they become contaminated vary among incidents. However, data describing the probability distributions of the required input variables are limited. This limitation obstructs the opportunity of getting insights into the variation or uncertainties around the estimated net financial impact obtained in Chapter 2 and the probability of occurrence of the contamination scenarios described in Chapter 4. Nevertheless, the deterministic approach allows us to clearly acknowledge the driving factors affecting the linear accretion rate of the financial impact on the dairy chain and the flow of the contamination in the pork chain. Access to additional data is not expected to change the core results obtained in Chapter 2 and Chapter 4, but to enhance the performance and accuracy of the models. In Chapter 5, a stochastic approach is applied to determine the final concentration of dioxins in compound feed, given probability distributions derived from dioxin levels at feed ingredients in Europe (EFSA, 2010). This approach to analyze the resulting concentration of dioxins in compound feed from feed ingredients is a step forward in creating risk profiles for every feed ingredient and include risk assessment into schemes for monitoring dioxins in the food chain. However, the approach is currently limited by the lack of data regarding the probability distributions for each feed ingredient. Dioxin levels for feed ingredients in Europe are only available for the group of feed ingredients under the feed categories designed by EFSA. 
The decision making process when a dioxin contamination is detected at any stage of the food chain has a large impact on the estimated absolute values. For example in Chapter 2, in case a contamination is detected at the milk processor, a zero risk scenario is assumed. This scenario implies that the entire amount of processed milk, related to the day of detection, is contaminated, recalled and destroyed. A different absolute net financial impact at milk processor might be obtained if contaminated milk batches are identified and separated from non-contaminated material. However, such information is not available. Chapter 2 does not take into account the indirect financial losses that are expected to be elevated and indirectly linked to the occurrence of the incident. Indirect losses are, for example, brand damages and market disruptions on supply and demand of the products involved in the dioxin-incident. There is, however, not a generally accepted method to estimate the indirect and direct financial losses due to food safety incidents and, consequently, it is difficult to compare the impacts among incidents (Thomson, Poms, and Rose, 2012). In Chapter 4, the cost of tracing a dioxin contamination from the fat melting facility to the initial contaminated feed ingredient has a large impact on the allocation of resources for monitoring dioxins at the pork chain. Tracing costs are higher due to the large number of pig fattening farms and feed suppliers that are contained in a pork fat sample collected at the fat melting facility. Different results might be expected if tracing costs at the fat melting facility are lower. Such a reduction in the tracing costs might occur if contaminated pork fat samples can be related to a smaller and geodistributed number of pig fattening farms and feed suppliers. This type of information on the network was, however, not available, hence, it was assumed that geo-dependency between farms and feed suppliers was absent. In Chapter 3, milk trucks samples are collected randomly at each sampling time. This sampling method underlines the possibility that milk from a dairy farm can be sampled more than once during the monitoring period. A more efficient use of monitoring resources is expected if other sampling method is applied, in 
which, for example, milk from every dairy farm -include in the monitoring scheme- is sampled just once during the monitoring period. Further studies are required, however, to evaluate the effect of such a sampling method on the cost-effectiveness of monitoring.

Linear programming is the core methodology used in this dissertation to assess costeffectiveness of schemes for monitoring dioxins in a single control point of the dairy chain (Chapter 3) and in several control points along the pork chain (Chapter 4). This methodology is a decision analysis tool widely used in resource allocation problems to get an optimal solution (Dijkhuizen and Morris, 1997, Rushton, 2009). In both Chapters, a linear objective function is presented. The objective function consists of a monitoring cost or a monitoring effectiveness function to be minimized or maximized, respectively, by changing decision variables and satisfying certain constrains. For example, in Chapter 3 the optimization model aims to maximize monitoring effectiveness (objective function); the models produces the number of milk truck samples that should be collected (decision variable) considering a given budget for monitoring (constraint). Linear programing has been applied previously in food safety and pests control issues. It was used to determine the optimal strategy to improve food safety at milk farms in the Dutch dairy chain (Valeeva and Huirne, 2008) and to determine the optimal strategy to improve efficacy of import phytosanitary inspections (Surkov et al., 2009, Surkov et al., 2008). However, linear programing is a rather new methodology in the field of assessing cost-effectiveness for optimizing monitoring schemes (Focker et al., 2018).

\subsection{Implications for policy makers and business}

Policy makers and food safety managers in feed and food industries face the challenge of ensuring safety standards at feed and food products (monitoring effectiveness) while preserving the competitiveness of these industries in food markets (monitoring costs). The results of this dissertation raise quantitative insights on the interaction between cost and 


\section{General discussion}

effectiveness of schemes for monitoring dioxins in feed and food products. These insights can be used by public and private feed/food safety agents to enhance safety protocols along the food chain.

Results of Chapter 2 present the size of direct financial consequences of intervention measures aimed at controlling feed/food dioxin incidents. The model depicts the allocation of losses at each stage of the chain and the spread of the contamination with time. Intermediary stages of the chain, such as farms and food processors are mainly affected by the intervention measures. As shown in section 6.2, policy makers and food safety managers can derive an economic value of monitoring in order to determine upper and lower financial room of resources that can be used for establishing or enhancing schemes for monitoring.

Results of Chapter 3 show that testing aggregate samples for monitoring dioxins is a reliable strategy to reduce monitoring cost. However, this strategy must take into account the possible dilution of the dioxin concentration in the aggregate sample aiming at ensuring the effective detection of any elevated dioxin level. Policy makers and food safety managers can use insights to determine optimal pooling strategies for testing aggregate samples that minimize the cost of monitoring without reducing the required level of effectiveness. Food safety agents have to be aware of the limits on the effectiveness of monitoring due to financial restrictions.

Results of Chapter 4 show that monitoring efforts and resources should be allocated at earlier stages of the food chain (instead of later stages) when the origin of a dioxin contamination is the compound feed. Policy makers should create incentives to enhance schemes for monitoring dioxin in earlier stages of the chain. Food safety managers at feed and food industries should look for agreements to share costs and benefits of schemes for monitoring dioxins within in an integrated chain approach. 
Results of Chapter 5 provide a new perspective to policy makers with respect to the origin of dioxin contaminations in compound feed. It shows the importance not only of the concentration of dioxins in feed ingredient but also of the inclusion rate of the ingredient used in the compound feed. Current feed safety regulations focus on monitoring feed ingredients that most often have been involved in dioxin contaminations. However, the results of this Chapter show that even if no extreme levels of dioxins are detected in an ingredient, the source of a dioxin contamination at compound feed can come from ingredients with above ingredient's ML -but not extreme- concentrations but used with a high inclusion rate in the feed.

The results of Chapter 5 can guide policy makers and food safety managers to identify the most risky ingredients and allocate monitoring resources accordingly. This is an intermediate step towards analyzing schemes for monitoring dioxins following a risk based monitoring approach. Policy makers and food safety managers should promote the collection of data of dioxin levels for each feed ingredient. In addition, qualitative data such as the country of origin of ingredient can be included in establishing a risk profile of each feed ingredient.

The results obtained in this dissertation show that establishing effective monitoring plans requires elevated financial resources. The results of this thesis enable policy makers as well as food safety managers to explore the effective bounds of prior, current and future monitoring plans emplaced to control dioxin levels in the food chain. To be able to detect all possible contaminations implies sampling every batch of raw material or final products. Moreover, it implies to limit the maximum number of samples that might be pooled before testing. The higher the number of individual samples pooled, the higher the risk that elevated levels of dioxins remain undetected in the pooled samples. 


\subsection{Outlook for further research}

This thesis used a deterministic approach to create simulation models that describe the spread of dioxin contaminations in the food chain. Optimal cost-effective schemes for monitoring dioxins in the food chain have been obtained as outputs of linear programming models. These models do not consider the variation and uncertainty of input variables (that in reality occur randomly) on the obtained contamination scenarios and optimal schemes for monitoring dioxins. Including stochastic inputs in simulation and optimization models will provide the likelihood of occurrence to the outputs of the models. This addition would allow to include risk simulations and stochastic dynamic programming in the analysis of costeffectiveness of schemes for monitoring dioxins in the food chain. However, sources of theses inputs still have to be identified and data must be collected.

In this dissertation, the direct financial impact of a dioxin incident in the dairy chain is estimated. However, total financial losses caused by a dioxin incident in the food chain also include indirect financial losses that have not been included. Further research should focus on estimating such indirect financial losses. As these indirect financial losses include, among others, market disruptions on supply and demand of affected food products, economic methodologies such as partial equilibrium models can be applied to obtain an accurate results. Having insights into the total losses including direct and indirect losses will provide better understanding of the financial room for monitoring dioxins.

As the first attempt to calculate the financial impact of feed dioxin incidents in the food chain, this dissertation focuses on the dairy chain and specifically on consumption milk as the main contaminated product. However, also poultry and pork chains have been seriously economically affected by feed dioxin contaminations in the past. A more clear idea about the magnitude of such losses would open the possibility to integrate monitoring schemes within 
food chains. In the wide spectrum of milk derived products, cheese is one of the products with a high economic value (higher than milk); moreover, cheese is exported to foreign markets worldwide. Extending the analysis of the financial losses caused by dioxin incidents in the dairy chain to cheese is key to getting a more realistic estimation of the financial consequences of dioxin incident to the dairy industry.

The food chains considered in this dissertation do not include the consumer stage. Therefore, the direct financial impact of dioxins incidents estimated in this dissertation cannot be used as a measure of the socio-economic impact to consumers. Moreover, the optimal costeffective schemes for monitoring dioxins depicted in this dissertation are no determinants of optimal levels of monitoring towards maximizing social welfare. Further research should focus on including the health and welfare impact of dioxin incidents to consumers in order to obtain additional inputs to enhancing the results obtained in this research.

The results of this research show that isolated efforts of stakeholders at each stage of the food chain are not cost-effective strategies to monitoring dioxins in the food chain. Costeffective schemes for monitoring dioxins along the food chain should focus on earlier stages of the chain. Further research should thus focus on pursuing the integration of individual monitoring schemes where cost and benefits of the integrated scheme are shared among stakeholders. Methodologies such as Principal-Agent model can be used to assess the strategies of integration.

\subsection{Main Conclusions}

The main objective of this dissertation was to analyze the cost-effectiveness of schemes for monitoring dioxins along the food chain. The main conclusions of this dissertation are the following: 
General discussion

- There is financial room for monitoring dioxins along the Dutch dairy chain (between $€ 500.4$ thousand and $€ 28.8$ million per year) suggested by the size of the direct financial losses of a dioxin incident in the dairy chain (Chapter 2).

- Monitoring bulk milk with $95 \%$ probability of detecting contamination levels as low as $2 \mathrm{pg} \mathrm{TEQ} / \mathrm{g}$ fat requires resources of approximately $€ 2.6$ million/month (Chapter 3 ).

- Testing dioxins levels in aggregate samples rather than in individual samples is a valid strategy for reducing monitoring costs. However, pooling strategies must take into account the target dioxin concentration in individual samples, in order to avoid dilution of dioxin levels and to ensure the proper detection of dioxin contamination (Chapter 3).

- Focusing monitoring efforts at feed mills to tackle a dioxin contamination in the food chain is the cost-effective solution of monitoring dioxins for the whole pork chain (Chapter 4).

- Monitoring dioxins in an integrated chain approach rather than in an independent chain actor approach has large economic benefits for the whole pork chain (Chapter 4).

- For all evaluated contamination scenarios, monitoring dioxins at the feed mill stage contributes, on average, $90 \%$ to the total effectiveness of the optimal monitoring schemes (Chapter 4).

- It is cost effective to focus dioxin monitoring efforts in earlier rather than later stages of the pork and poultry chain, when a dioxin contamination originates from a source early in the chain (Chapter 4 and 5). 
- Elevated levels of dioxins in compound feed not only depend on the concentration of dioxins in feed ingredients but also on the inclusion rate of the ingredients in the compound feed (Chapter 5). 


\section{General discussion}

\section{References}

Buzby, J. C., and R. Chandran. 2003. The Belgian Dioxin Crisis and its effects on Agricultural Production and Exports, p125-139. In J.C. Buzby (ed.), International Trade and Food Safety: Economic Theory and Case Studies. Agricultural Economic Report No. 828. Economic Research Service. USDA.

Centraal Bureau voor de Statistiek. 2018. Statline. Available at: https://opendata.cbs.nl/statline/\#/CBS/en/dataset/7425eng/table?ts=1531671543742 Accessed 14 July 2018.

Dijkhuizen, A. A., and R. S. Morris. 1997. Animal health economics. Sidney: University of Sidney, Postgraduate Foundation in Veterinary Science. University of Sydney, Sydney, Australia.

EC (European Commission). 2009. Commission Regulation (EC) No 1069/2009 of the European Parliament and of the Council of 21 October 2009 laying down health rules as regards animal byproducts and derived products not intended for human consumption and repealing Regulation (EC) No 1774/2002 (Animal by-products Regulation). Off. J. Eur. Comm. L 300.

EC (European Commission). 2011. Commission Regulation (EC) No 142/2011 of 25 February 2011 implementing Regulation (EC) No 1069/2009 of the European Parliament and of the Council laying down health rules as regards animal by-products and derived products not intended for human consumption and implementing Council Directive 97/78/EC as regards certain samples and items exempt from veterinary checks at the border under that Directive. Off. J. Eur. Comm. L54:1-254.

European Food Safety Authority (EFSA). 2010. Results of the monitoring of dioxin level in food and feed. EFSA J. 8(3):1385. 
Focker, M., H. J. van der Fels-Klerx, and A. G. J. M. Oude Lansink. 2018. Systematic Review of Methods to Determine the Cost-Effectiveness of Monitoring Plans for Chemical and Biological Hazards in the Life Sciences. Compr. Rev. Food Sci. Food Saf. 17(3):633-645.

Golan, E. H., S. J. Vogel, P. D. Frenzen, and K. L. Ralston. 2000. Tracing the costs and benefits of improvements in food safety: The case of hazard analysis and critical control point program for meat and poultry. Agricultural Economics Report 34023, USDA, Econ. Res. Ser. U.S.

Guo, X. 2015. Economic optimization of surveillance in livestock production chains. $\mathrm{PhD}$ thesis, Wageningen University, Wageningen, NL:182.

Heres, L., R. Hoogenboom, R. Herbes, W. Traag, and B. Urlings. 2010. Tracing and analytical results of the dioxin contamination incident in 2008 originating from the Republic of Ireland. Food Addit. \& Contam. Part A-Chem. 27(12):1733-1744.

Hoogenboom, R., M. Zeilmaker, J. van Eijkeren, K. Kan, M. Mengelers, D. Luykx, and W. Traag. 2010. Kaolinic clay derived PCDD/Fs in the feed chain from a sorting process for potatoes. Chemosphere 78(2):99-105.

Lok, C. and D. Powel. 2000. The Belgium Dioxin Crisis of the Summer of 1999: A Case Study in Crisis Communication and Management. Technical Report 13. Department of Food Science, University of Guelph, Guelph, Ontario, Canada.

Malisch, R. 2000. Increase of the PCDD/F-contamination of milk, butter and meat samples by use of contaminated citrus pulp. Chemosphere. 40(9-11):1041-1053.

Meuwissen, M. P. M., A. L. A. Van Andel, M. A. P. M. Van Asseldonk, and R. B. M. Huirne. 2009. Eliciting processing industry damage from feed crises. Br. Food J. 111(8):878-892. 


\section{General discussion}

Meuwissen, M. P. M., M. A. P. M. Van Asseldonk, and R. B. M. Huirne. 2008. Liability risks in agrifood Supply chains: the case of wet feed. Presented at the 12th European Association of Agricultural Economics Congress. Gent, Belgium, 26-29 August 2008.

Reijnders, L. 2004. Food safety, environmental improvement and economic efficiency in The Netherlands. Br. Food J. 105(5):388-405.

Ribera, L. A., M. A. Palma, M. Paggi, R. Knutson, J. G. Masabni, and J. Anciso. 2012. Economic analysis of food safety compliance costs and foodborne illness outbreaks in the United States. Hort. Tech. 22(2):150-156.

Rushton, J. 2009. The Economics of Animal Health and Production. Foreward by P. Ellis with contributions from A. James, A. Shaw, D. Leonard, C. Tisdell, J. Otte, A. Stott, H. Rojas, P. Bonnet, C. Devendra, L. Redmond, H. Beck, U. Pica-Ciamarra, M. Lesnoff, V. Ahuja and M. Upton. CABI Publishing, Wallingford, UK.

Sapkota, A. R., L. Y. Lefferts, S. McKenzie, and P. Walker. 2007. What do we feed to foodproduction animals? A review of animal feed ingredients and their potential impacts on human health. Environ. Health Perspect. 115(5):663-670.

Surkov, I. V., A. G. J. M. Oude Lansink, O. van Kooten, and W. van der Werf. 2008. A model of optimal import phytosanitary inspection under capacity constraint. Agric. Econ. 38(3):363-373.

Surkov, I. V., A. G. J. M. Oude Lansink, and W. van der Werf. 2009. The optimal amount and allocation of sampling effort for plant health inspection. Eur. Rev. Agric. Econ. 36(3):295-320.

Teratanavat, R., V. Salin, and N. H. Hooker. 2005. Recall event timing: measures of managerial performance in U.S. meat and poultry plants. Agribusiness 21(3):351-373. 
Thomson, B., R. Poms, and M. Rose. 2012. Incidents and impacts of unwanted chemicals in food and feeds. Qual. Assur. Saf. Crop. 4(2):77-92.

Tlustos, C. 2009. The dioxin crisis in Ireland 2008 - challenges in risk management and risk communication. Organohalogen Compd. 71:1169-1171.

Valeeva, N. I. and R. B. M. Huirne. 2008. Strategies to improve food safety in the dairy chain: A casestudy from The Netherlands. Opportunities and Challenges for Smallholder Ruminant Systems in Latin America. Universidad Autonoma Estado Mexico, Toluca, Mexico.

van Asseldonk, M., M. Meuwissen, and R. Huirne. 2011. A risk analysis of compound feed contamination. Pages 169-181 in Animal Feed: Types, Nutrition and Safety.

van der Fels-Klerx, H. J., P. Adamse, J. de Jong, R. Hoogenboom, M. de Nijs, and P. Bikker. 2017. A model for risk-based monitoring of contaminants in feed ingredients. Food Control 72:211-218.

van Raamsdonk, L. W. D., J. C. H. van Eijkeren, G. A. L. Meijer, M. Rennen, M. J. Zeilmaker, L. A. P. Hoogenboom, and M. Mengelers. 2009. Compliance of feed limits, does not mean compliance of food limits. Biotech. Agron. Soc. 13:51-57.

Velthuis, A. G. J., M. P. M. Meuwissen, and R. B. M. Huirne. 2009. Distribution of direct recall costs along the milk chain. Agribusiness. 25(4):466-479. 


\section{Summary}

Dioxins are important chemical pollutants due to their high toxicity to human health even at very low concentrations. From all possible human exposure pathways, food ingestion is the major route with food products of animal origin as the main contributors. Feed ingredients and/or additives used in compound feed for livestock production have been a main cause of various food dioxin incidents in recent decades. These incidents resulted into large financial implications due to recalls and trade disruptions.

Monitoring dioxins in feed and food products is deemed crucial when aiming at reducing human dioxin exposure with time as well as when preventing and diminishing the salient financial impact of dioxin incidents in agribusiness along the food chain. However, economic aspects embedded in the practical assessment and implementation of dioxin monitoring schemes along the food chain have not yet been analyzed in the scientific literature. Hence this dissertation aims to analyze the cost-effectiveness of schemes for monitoring dioxins along the food chain by 1) assessing the financial impact of a dioxin incident in the food chain, 2) determining the cost-effectiveness of monitoring dioxins at a single control point along the food chain 3) determining the cost-effective allocation of resources for monitoring dioxins at different stages of the food chain, and 4) determining the cost-effective allocation of resources at one stage of the food chain considering incoming ingredients and final products.

Chapter 2 aimed to quantify the financial consequences of a milk-dioxin crisis on the stages of the dairy chain involved. Results obtained based on the assumption of the worst-case scenario in which the entire daily production of each business unit from feed supplier to milk processor is contaminated, show that the financial impact of a dioxin incident would be $€ 141.2$ million. The stages of the chain that contributed most to the total net costs are the milk processor $(76.9 \%)$ and the dairy farm $(20.5 \%)$. In case the moment of detection was reduced 
from 2 weeks to 3 days after initial contamination, the estimated total financial impact decreased to $€ 10.9$ million. This result emphasizes the importance of an early detection of the contamination in decreasing the number of food businesses involved and lowering the total financial impact value.

Chapter 3 assessed the costs and effectiveness of bulk milk dioxin monitoring in milk trucks to optimize the sampling and pooling monitoring strategies aimed at detecting at least one contaminated farm out of 20,000 at a target dioxin concentration level. Two optimization models were built using linear programming. The first model aimed to minimize monitoring costs subject to a minimum required effectiveness of finding an incident, whereas the second model aimed to maximize the effectiveness for a given monitoring budget. Incidents with different numbers of contaminated farms and concentrations were simulated. The results show that monitoring with $95 \%$ probability of detecting one contaminated farm with $2 \mathrm{pg}$ TEQ/g fat costs $€ 2.6$ million per month. At the same level of effectiveness, a $73 \%$ cost reduction is possible when aiming to detect an incident where 2 farms are contaminated at a dioxin concentration of $3 \mathrm{pg}$ of toxic equivalents/g of fat (EC maximum level). With a fixed budget of $€ 40,000$ per month, the probability of detecting an incident with a single contaminated farm at a dioxin concentration equal to the $\mathrm{EC}$ action level is $4.4 \%$. This probability almost doubled $(8.0 \%)$ when aiming to detect the same incident but with a dioxin concentration equal to the EC maximum level.

In Chapter 4 a decision support tool (optimization model) is developed to determine cost-effective monitoring schemes for detecting and tracing a dioxin contamination over four control points (i.e. at the supplier of fatty feed ingredients, the feed mill, the slaughterhouse and the fat melting facility) along the pork chain. The cost-effective allocation of resources for detecting and tracing the dioxin contamination from an integrated chain approach (i.e. considering all control points) focuses on monitoring at the feed mill, followed by the supplier 
of fatty feed ingredients and - to a lesser extent - by the slaughterhouse. The number of contaminated feed mills, the frequency of dioxin contaminations, the required level of effectiveness, and the cost of screening are main factors driving the total monitoring costs. Sharing the responsibility of monitoring dioxins within control points along the chain largely reduces the total monitoring costs. In each of the evaluated scenarios, the total costs of monitoring dioxins at individual control points are larger than the costs resulting from an optimal allocation of resources among all control points integrated in one overarching chain monitoring scheme. These results elicit the economic benefits of a chain approach to monitoring dioxins over an approach where each chain actor independently monitors dioxins.

Chapter 5 determined cost-effective strategies for monitoring dioxins at the feed mill, in order to prevent dioxin contaminations in compound feed entering the poultry production chain. Results showed that monitoring dioxins in a combination of feed ingredients (i.e., Wheat and Corn) results into a high level of effectiveness of preventing elevated levels of dioxins in the compound feed $(96.2 \%)$ at lower total costs (20\% less) compared to the costs related to the $100 \%$ effective monitoring in charges of compound feed. Ingredients with dioxin concentrations above ML dioxins levels but with a low inclusion rate in the feed formulation are not detected by monitoring dioxins in compound feed as a result of the dilution effect.

Chapter 6 provides a synthesis of the results obtained in the previous chapters and discusses these findings with respect to existing literature. This chapter also presents a critical discussion of methodological issues regarding data availability and modelling approaches used to analyze the data. This is followed by a discussion about the implications of the findings for policy makers as well as for food safety managers in agri-food business, and topics for further research that go in line with this dissertation. The main conclusions of this dissertation are the following: 
- There is financial room for monitoring dioxins along the Dutch dairy chain (between $€ 500.4$ thousand and $€ 28.8$ million per year) suggested by the size of the direct financial losses of a dioxin incident in the dairy chain (Chapter 2).

- Monitoring bulk milk with $95 \%$ probability of detecting contamination levels as low as $2 \mathrm{pg} \mathrm{TEQ} / \mathrm{g}$ fat requires resources of approximately $€ 2.6$ million/month (Chapter 3 ).

- Testing dioxins levels in aggregate samples rather than in individual samples is a valid strategy for reducing monitoring costs. However, pooling strategies must take into account the target dioxin concentration in individual samples, in order to avoid dilution of dioxin levels and to ensure the proper detection of dioxin contamination (Chapter 3).

- Focusing monitoring efforts at feed mills to tackle a dioxin contamination in the food chain is the cost-effective solution of monitoring dioxins for the whole pork chain (Chapter 4).

- Monitoring dioxins in an integrated chain approach rather than in an independent chain actor approach has large economic benefits for the whole pork chain (Chapter 4).

- For all evaluated contamination scenarios, monitoring dioxins at the feed mill stage contributes, on average, $90 \%$ to the total effectiveness of the optimal monitoring schemes (Chapter 4).

- It is cost effective to focus dioxin monitoring efforts in earlier rather than later stages of the pork and poultry chain, when a dioxin contamination originates from a source early in the chain (Chapter 4 and 5). 
- Elevated levels of dioxins in compound feed not only depend on the concentration of dioxins in feed ingredients but also on the inclusion rate of the ingredients in the compound feed (Chapter 5). 


\begin{abstract}
About the Author
Víctor Hugo Lascano Alcóser was born on September 1 ${ }^{\text {st }}, 1977$ in Quito, Ecuador. In 1996, he entered the Pan-American Agricultural University "Zamorano" (Honduras) to study agriculture. After four years he got his agriculture bachelor degree with a specialization in Zootechnics. After his graduation, he worked for seven years as sales manager in an agroindustrial project at Zamorano and as an independent consultant for projects related to agricultural and rural development. In 2007, the Dutch Government granted him a NUFFIC scholarship to start at Wageningen University \& Research his master studies in Management, Economics and Consumers Studies. In 2010, he was accepted by the Business Economics Group and RIKILT at Wageningen University \& Research to start his doctoral study. He is currently working as an independent consultant in projects regarding health, nutrition and agriculture, and as an independent technical advisor concerning regulatory issues for pharmaceutical and food companies.
\end{abstract}


Víctor Hugo Lascano Alcóser

Wageningen School of Social Sciences (WASS)

Completed Training and Supervision Plan

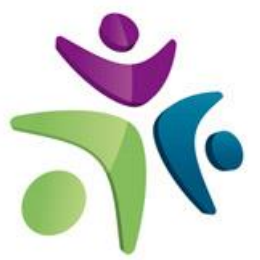

Wageningen School

of Social Sciences

\begin{tabular}{|c|c|c|c|}
\hline Name of the learning activity & Department/Institute & Year & ECTS* \\
\hline \multicolumn{4}{|l|}{ A) Project related competences } \\
\hline Organisation of Agribusiness, BEC 31306 & WUR & 2013 & 6 \\
\hline Writing PhD proposal & WUR & 2011 & 6 \\
\hline BEC PhD meetings & WUR & $2010-2014$ & 2 \\
\hline $\begin{array}{l}\text { "Economical impact of a dioxin incident in } \\
\text { the Dutch dairy chain" }\end{array}$ & $\begin{array}{l}\text { International Association of Food } \\
\text { Protection, Dublin, Ireland }\end{array}$ & 2010 & 1 \\
\hline $\begin{array}{l}\text { "Optimizing bulk milk dioxin monitoring } \\
\text { based on costs and effectiveness" }\end{array}$ & $\begin{array}{l}\text { International Association of Food } \\
\text { Protection, Rhode Island, US. }\end{array}$ & 2012 & 1 \\
\hline $\begin{array}{l}\text { "Estimating the financial consequences of } \\
\text { a dioxin crisis in the Dutch dairy chain". }\end{array}$ & $\begin{array}{l}\text { International Symposium on } \\
\text { Veterinary Epidemiology and }\end{array}$ & 2012 & 2 \\
\hline $\begin{array}{l}\text { "Assessing the costs versus the } \\
\text { effectiveness of dioxin monitoring in bulk } \\
\text { milk }\end{array}$ & $\begin{array}{l}\text { Economics, Maastricht, The } \\
\text { Netherlands }\end{array}$ & & \\
\hline \multicolumn{4}{|l|}{ B) General research related competences } \\
\hline WASS Introduction Course & WASS & 2012 & 1 \\
\hline Scientific Writing Skills & WASS & 2012 & 1 \\
\hline Food Ethics, APP20803 & WUR & 2010 & 3 \\
\hline \multicolumn{4}{|c|}{ C) Career related competences/personal development } \\
\hline $\begin{array}{l}\text { Macroeconomics and International Trade, } \\
\text { DEC21806 }\end{array}$ & WUR & 2011 & 6 \\
\hline Advanced Econometrics & WUR & 2013 & 6 \\
\hline $\begin{array}{l}\text { Teaching assistant at Lab of Food Safety } \\
\text { Economics }\end{array}$ & WUR & 2013-2014 & 1 \\
\hline Total & & & 36.0 \\
\hline
\end{tabular}

* One credit according to ECTS is on average equivalent to 28 hours of study load 
The research described in this thesis was financially supported by EC Marie Curie Award Program, by RIKILT, and by Business Economics Group, Wageningen University and Research (Wageningen, The Netherlands).

Financial support from Wageningen University for printing this thesis is gratefully acknowledged.

Cover design by: Carlos Mogrovejo and Alejandro Gálvez

Printed by: Digiforce || ProefschriftMaken 


\section{Propositions}

1. Losses related to a dioxin incident in the dairy chain indicate financial room for monitoring dioxins.

(this thesis)

2. Monitoring for dioxin contaminations in the feed industry is the cost-effective approach for detecting dioxins along the pork chain.

(this thesis)

3. Since the physical appearance of a food product is important to the consumer, agricultural practices move away from nature.

4. Biomimicry is key in the development of a sustainable global society.

5. Latin American countries will not achieve a high level of social welfare, as long as their populations base their success on individual accomplishments rather than collective achievements.

6. The rise of populist leaders is threatening basic human rights and democracy.

Propositions belonging to the thesis, entitled

Cost-effective monitoring of dioxins in agri-production chains

Víctor Hugo Lascano Alcóser

Wageningen, 14 November 2018 

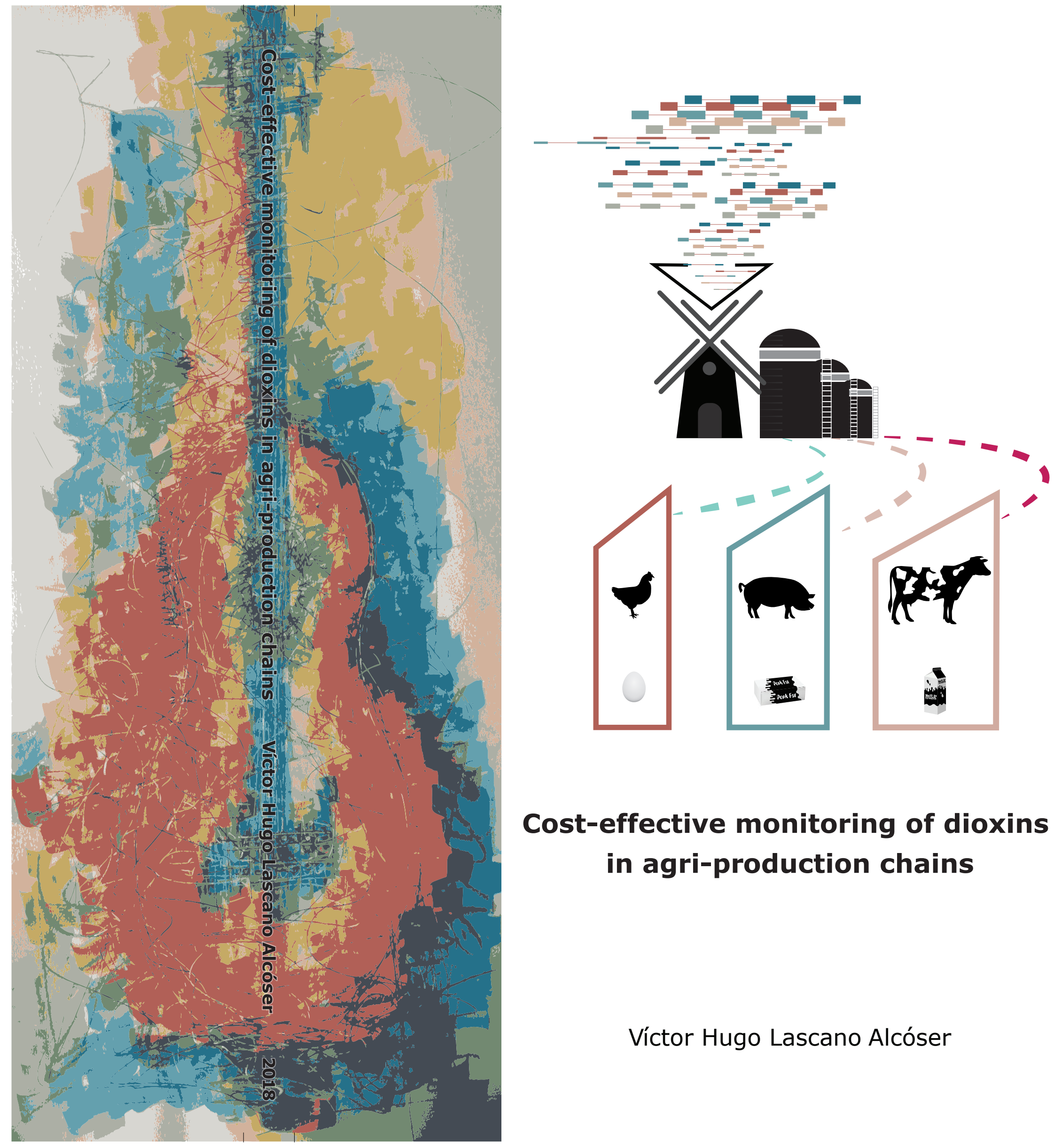

Cost-effective monitoring of dioxins in agri-production chains

Víctor Hugo Lascano Alcóser 